\author{
UNIVERSIDADE DE SÃO PAULO \\ INSTITUTO DE QUÍMICA DE SÃO CARLOS \\ PROGRAMA DE PÓS-GRADUAÇÃO EM QUÍMICA
}

Graziela Cristina Sedenho

Bioelectrochemical and bioinspired energy conversion systems: from heterogeneous and extracellular electron transfer to applications in aqueous batteries and biofuel cells

São Carlos - SP 


\section{GRAZIELA CRISTINA SEDENHO}

Bioelectrochemical and bioinspired energy conversion systems: from heterogeneous and extracellular electron transfer to applications in aqueous batteries and biofuel cells

Thesis presented to the São Carlos Institute of Chemistry (IQSC), University of São Paulo, in partial fulfillment of the requirements for the degree of Doctor of Science.

Concentration area: Physical Chemistry

Advisor: Prof. Dr. Frank Nelson Crespilho

\section{Exemplar revisado}

O exemplar original encontra-se em acervo reservado na Biblioteca do IQSC-USP

São Carlos - SP 
Autorizo a reprodução e divulgação total ou parcial deste trabalho, por qualquer meio convencional ou eletrônico para fins de estudo e pesquisa, desde que citada a fonte.

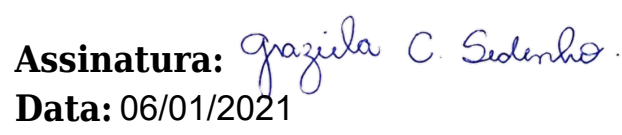

Sedenho, Graziela Cristina

Bioelectrochemical and bioinspired energy conversion systems: from heterogeneous and extracellular electron transfer to applications in aqueous batteries and biofuel cells / Graziela Cristina Sedenho. - São Carlos, 2021. $137 \mathrm{f}$.

Tese (Doutorado em Físico-Química) - Instituto de Química de São Carlos / Universidade de São Paulo, 2021.

Orientador: Prof. Dr. Frank Nelson Crespilho

1. Transformação de energia. 2. Eletrodos de carbono. 3. Imobilização enzimática. 4. Reação de redução de oxigênio. 5. Transferência extracelular de elétrons. I. Título. 


\section{ACKNOWLEDGMENTS}

- $\quad$ To my parents, Luís and Sueli, for teaching me to be strong, for always supporting and encouraging me.

- $\quad$ To my sister Ana Flávia for being always present and supporting my dreams.

- $\quad$ To my grandparents for being always present and praying for me.

- To my husband, Diego, for always understanding my renunciations and supporting me in all moments.

- To my advisor, Professor Frank N. Crespilho, for all teachings and the confidence in all these years.

- $\quad$ To my lab colleagues, Andressa Pereira, Kamila Pagnoncelli, Lucyano Macedo, João Souza, Thiago Bertaglia, Ayaz Hassan, Natália Sanches, Iago Modenez, Giovana Rossi, Isabela Mattioli, Luana Faria, Bruno Rossi and José Eduardo Clarindo, for the collaborations, friendship, and funny moments.

- To São Carlos Institute of Chemistry, USP, for the facilities and infrastructure needed to perform this work.

- To Professors Michael J. Aziz and Roy G. Gordon for receiving me in their group at Harvard John A. Paulson School of Engineering and Applied Sciences, and for all teachings.

- To Dr. Diana De Porcellinis for kindly helping me during my period at Harvard University and for the fruitfully collaboration.

- To Dr. Valdecir A. Paganin from Electrochemistry Group (São Carlos Institute of Chemistry, USP) for the technical support in the preparation of the gas diffusion layer of the bilirubin oxidase-based biocathode.

- To Professor Daniel R. Cardoso and Dr. Sinara for the technical support in the Bradford assay and SDS-Page electrophoresis.

- To São Paulo Research Foundation (FAPESP) for the financial support provided through the scholarships (process numbers: 2015/22973-6 and 2017/15714-0). 


\section{EPIGRAPH}

To raise new questions, new possibilities, to regard old problems from a new angle, requires creative imagination and marks real advance in science.

Albert Einstein

You are free to make your own choices, but you are a prisoner of the consequences. 


\begin{abstract}
If we consider that part of cellular respiration is a model of energy obtention, it is envisioned that natural bioelectrochemical systems can be mimicked for the sustainable obtaining of electricity, as in biofuel cells (BFC) and aqueous batteries. Based on that, four topics in the state-of-the-art in bioelectrochemical and bioinspired energy conversion are considered here in closely correlated chapters: the role of electrode-electrolyte interface structure in systems involving quinone derivatives and carbon-based electrodes for application in aqueous-organic redox flow batteries (Chapter I); the use of redox-active compounds incorporated into a gel for development of non-corrosive and low toxicity semi-solid aqueous battery (Chapter II); stabilization of biocatalyst, such as bilirubin oxidase (BOD), for $\mathrm{O}_{2}$ reduction to water, aiming the obtention of high-performance biocathodes (Chapter III); and the understanding of how microorganisms, such as Saccharomyces cerevisiae, convert energy from organic substrates into electrical energy, as well as, the exploitation of this process and the $\mathrm{O}_{2}$ reduction to water for the electricity generation in BFCs (Chapter IV). It was concluded that edge-like defects and oxygenated functional groups, such as $\mathrm{C}-\mathrm{O}$ and $\mathrm{C}=\mathrm{O}$, are crucial for obtaining highperformance carbon electrodes for energy conversion systems. In fact, when flexible carbon fibers-based electrodes with these properties are used in aqueous semi-solid microbatteries, with organic and organometallic redox molecules in agarose hydrogel, a capacity of $0.79 \mathrm{~mA} \mathrm{~h}$ was obtained, which is able to meet the needs of small biomedical devices. In the case of biocatalysis to reduce $\mathrm{O}_{2}$ to water, the results indicate that the incorporation of BOD into a biogel matrix in a gas diffusion electrode can generate currents of $1.52 \mathrm{~mA} \mathrm{~cm}$ and unprecedented operational stability, contributing to overcome critical issues for the practical application of BFCs. At last, a proposal for an extracellular electron transfer mechanism for Saccharomyces cerevisiae applied in microbiological BFC is shown. It was verified, for the first time, that the film of extracellular polymeric substances secreted by the yeast is able to confine flavoproteins that exchange charge with the electrode. Therefore, the results presented here cooperate to the advance in the field of bioelectrochemical and bioinspired energy conversion systems, as they contribute overcoming their critical issues and elucidating fundamental aspects in this area.
\end{abstract}

Keywords: Energy transformation. Carbon electrodes. Enzyme immobilization. Oxygen reduction reaction. Extracellular electron transfer. 


\section{RESUMO}

Se ponderarmos que parte da respiração celular é um modelo de obtenção de energia, vislumbra-se que os sistemas bioeletroquímicos naturais podem ser mimetizados para a obtenção sustentável de eletricidade, como em biocélulas a combustível (BCCs) e baterias aquosas. Baseado nisso, quatro tópicos inseridos no estado-da-arte em conversão eletroquímica de energia são considerados aqui em capítulos intimamente correlacionados: o papel da estrutura da interface eletrodo-eletrólito em sistemas envolvendo derivados de quinonas e eletrodos baseados em carbono para aplicação em baterias de fluxo redox orgânico-aquosas (Capítulo I); o uso de compostos redox incorporados em gel para desenvolvimento de bateria semi-sólida aquosa, não corrosiva e de baixa toxicidade (Capítulo II); estabilização de um biocatalisador, tal como bilirrubina oxidase (BOD), para redução de $\mathrm{O}_{2}$ a água, visando a obtenção de biocátodos de alto desempenho (Capítulo III); e o entendimento de como microorganismos, tal como Saccharomyces cerevisiae, convertem a energia contida nos substratos orgânicos em energia elétrica, bem como, a exploração desse processo e da redução de $\mathrm{O}_{2}$ a água para geração de eletricidade em BCCs. Concluiu-se que defeitos do tipo borda e grupos funcionais oxigenados, como $\mathrm{C}-\mathrm{O}$ e $\mathrm{C}=\mathrm{O}$, são cruciais para obtenção de eletrodos de carbono de alto desempenho em sistemas de conversão de energia. De fato, quando eletrodos de fibras flexíveis de carbono com estas propriedades são empregados em microbaterias aquosas semi-sólidas, com moléculas redox orgânicas e organometálicas em hidrogel de agarose, obteve-se uma capacidade de $0,79 \mathrm{~mA}$ h, capaz de atender às necessidades de pequenos dispositivos biomédicos. No caso da biocatálise para redução de $\mathrm{O}_{2}$ à água, os resultados mostram que a incorporação da BOD em matriz de biogel em eletrodo de difusão de gás pode gerar correntes de $1,52 \mathrm{~mA} \mathrm{~cm}{ }^{-2}$ e estabilidade operacional sem precedentes, contribuindo na superação de pontos críticos para a aplicação prática de BCCs. Por fim, apresenta-se uma proposta de mecanismo de transferência extracelular de elétrons da Saccharomyces cerevisiae aplicada em BCC microbiológica. Verificou-se, pela primeira vez, que o filme de substâncias poliméricas extracelulares secretado pela levedura confina flavoproteínas que trocam carga com o eletrodo. Portanto, os resultados apresentados cooperam para o avanço na área de sistemas bioeletroquímicos e bioinspirados de conversão de energia, contribuindo na superação de pontos críticos e elucidando questões fundamentais dessa área.

Palavras-chave: Transformação de energia. Eletrodos de carbono. Imobilização enzimática. Reação de redução de oxigênio. Transferência extracelular de elétrons. 


\section{LIST OF FIGURES}

\section{Introduction}

Figure 1 - Cellular respiration. (a) The first two stages: catabolism of proteins, fats, and carbohydrates. (b) The third stage: respiratory chain and ATP synthesis in the mitochondria.

\section{Chapter I}

Figure 1. CVs (third cycle) of GC, HOPG, and HEDGE in $1.0 \mathrm{~mol} \mathrm{~L}^{-1} \mathrm{H}_{2} \mathrm{SO}_{4}$ containing (a) $1.0 \mathrm{mmol} \mathrm{L}^{-1} \mathrm{CQ}$, (b) $1.0 \mathrm{mmol} \mathrm{L}^{-1} \mathrm{BQDS}$, (c) $10.0 \mathrm{mmol} \mathrm{L}^{-1} \mathrm{FQ}$, and (d) $1.0 \mathrm{mmol} \mathrm{L}^{-1} \mathrm{ARS}$. Scan rate: $50 \mathrm{mV} \mathrm{s}^{-1}$ (for FQ, CQ, and BQDS) and $5 \mathrm{mV} \mathrm{s}^{-1}$ (for ARS). Reference electrode is $\mathrm{Ag} / \mathrm{AgCl}$ in $3 \mathrm{~mol} \mathrm{~L}^{-1} \mathrm{NaCl}$.

Figure 2. Raman spectra of HOPG (a) and HEDGE (b) obtained with $633 \mathrm{~nm}$ excitation laser. SEM images of HOPG (c) and HEDGE (d). XPS survey spectra (e) of HOPG and HEDGE and their high- resolution spectra in $\mathrm{O} 1 \mathrm{~s}$ region (f), where solid red and solid black curves represent raw spectra of HOPG and HEDGE, respectively, and dotted gray lines and solid gray line represent respectively the deconvoluted peaks and the sum of the deconvoluted peaks .24

Figure 3. $\mathrm{CVs}$ recorded at $5 \mathrm{mV} \mathrm{s}^{-1}$ in $1.0 \mathrm{~mol} \mathrm{~L}^{-1} \mathrm{H}_{2} \mathrm{SO}_{4}$ on HEDGE after electroadsorption of FQ (a), CQ (b), BQDS (c), and ARS (d). Thin lines: CVs after subtraction of the capacitive current. (e) Surface excess $(\Gamma)$ of quinones on the HEDGE surface obtained from anodic peak of the first $\mathrm{CV}$; the plot shows the mean $\Gamma$ obtained from three HEDGE electrodes, and error values were obtained based on a t-distribution with $95 \%$ confidence interval.

Figure 4. Successive $\mathrm{CVs}$ recorded at $5 \mathrm{mV} \mathrm{s}^{-1}$ in $1.0 \mathrm{~mol} \mathrm{~L}^{-1} \mathrm{H}_{2} \mathrm{SO}_{4}$ on HEDGE after electroadsorption of FQ (a), CQ (b), BQDS (c), and ARS (d); the vertical arrows indicate the decrease in the anodic peak currents. Anodic peak current density over successive CVs after elecroadsorption of FQ (e), CQ (f), BQDS (g), and ARS (h). Insets show zoomed-in views of the curves.

Figure 5. Lowest energy configurations of the fully oxidized form of FQ (a), CQ (b), BQDS (c), and ARS (d) on HEDGE. The arrows indicate the sites with which the quinone-based compound interacts. Gray, white, yellow, red, and blue spheres represent carbon, hydrogen, sulfur, oxygen, and nitrogen atoms, respectively. (e) $\Delta E_{\text {ads }}$ at $300 \mathrm{~K}$ of each quinone on HEDGE

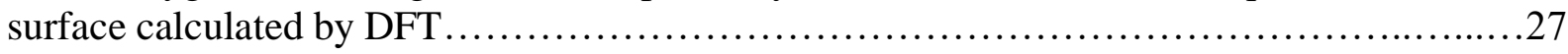

Figure 6. Surface excess vs calculated $\Delta E_{\mathrm{ads}} / \mathrm{k} T(T=300 \mathrm{~K})$ for each quinone on the HEDGE......................................................................27

Figure S1. ${ }^{1} \mathrm{H}$ NMR spectrum of $\mathrm{FQH}_{2} .1 \mathrm{H}$ NMR (500 MHz, CDCl3): $\delta 3.63$ (s, 8H), 2.27 (s,

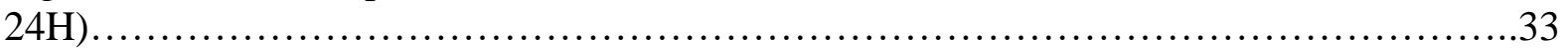

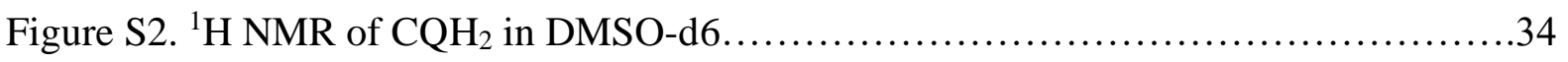

Figure S3. (a) HEDGE (geometric area $=0.559 \pm 0.017 \mathrm{~cm}^{2}$ ) and (b) HOPG (geometric area $=$ $0.291 \mathrm{~cm}^{2}$ ) electrodes. The area of both electrodes was delimited by nitrocellulose resin,

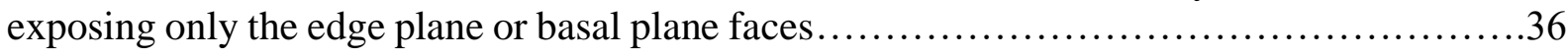

Figure S4. CVs (third cycle) of HEDGE in $1.0 \mathrm{~mol} \mathrm{~L}^{-1} \mathrm{H}_{2} \mathrm{SO}_{4}$ containing (a) $1.0 \mathrm{mmol} \mathrm{L}^{-1} \mathrm{CQ}$, (b) $1.0 \mathrm{mmol} \mathrm{L} \mathrm{m}^{-1} \mathrm{BQDS}$, (c) $10.0 \mathrm{mmol} \mathrm{L}^{-1} \mathrm{FQ}$, and (d) $1.0 \mathrm{mmol} \mathrm{L}^{-1} \mathrm{ARS}$ at different scan 
rates. Dependence of peak current density on scan rate for (e) CQ, (f) BQDS, (g) FQ and (h) ARS.

Figure S5. Raman spectrum of GC obtained with $633 \mathrm{~nm}$ excitation laser....................38

Figure S6. High-resolution spectrum of HEDGE in C 1s region

Figure S7. CVs of HOPG (a) and HEDGE (b) and difference between the anodic $\left(j_{\mathrm{a}}\right)$ and cathodic $(j \mathrm{c})$ capacitive current densities at $0.25 \mathrm{~V}$ of HOPG $(\mathrm{c})$ and HEDGE (d) plotted against scan rates fitted to linear regression enables the estimation of $C_{\mathrm{dl}}$

Figure S8. Chronoamperograms of the electro-adsorption in $1.0 \mathrm{~mol} \mathrm{~L}^{-1} \mathrm{H}_{2} \mathrm{SO}_{4}$ containing 1.0 mmol L ${ }^{-1}$ of each quinone derivative at a potential $50 \mathrm{mV}$ more positive than peak oxidation potential of each species. The backgrounds were previously subtracted.... .42

Figure S9. Adsorption quinone experimental setup. (a) Electro-adsorption in degassed $1.0 \mathrm{~mol}$ $\mathrm{L}^{-1} \mathrm{H}_{2} \mathrm{SO}_{4}$ containing $1.0 \mathrm{mmol} \mathrm{L}-1$ of quinone, for $120 \mathrm{~s}$ at a potential approximately $50 \mathrm{mV}$ more positive than peak oxidation potential of the species; (b) electrode dipping in $1.0 \mathrm{~mol} \mathrm{~L}^{-1}$ $\mathrm{H}_{2} \mathrm{SO}_{4}$; (c) electrode rinsing in $1.0 \mathrm{~mol} \mathrm{~L}^{-1} \mathrm{H}_{2} \mathrm{SO}_{4}$ for $30 \mathrm{~s}$ under magnetic stirring of $60 \mathrm{rpm}$; and (d) electrochemical measurements in clean electrolyte.

Figure S10. (a) Simulation process to generate the carbon electrode surfaces with some degree of graphitization. (b) Example of the three different degrees of graphitization using RDF. (c) radial distribution functions of graphene-like structure, HEDGE and amorphous-like structure.

Figure S11. Lowest energy configurations of the fully-oxidized form of ARS (a), BQDS (b), CQ (c) and FQ (d) on HEDGE-nO surface. The arrows indicate edge sites with which the quinone-based compound interacts; gray, white, yellow, red and blue spheres represent carbon, hydrogen, sulfur, oxygen and nitrogen atoms, respectively. (e) Calculated $\Delta E_{\text {ads }}$ of each compound on HEDGE-nO

Figure S12. Surface excess vs. calculated $\Delta E_{\text {ads }} / \mathrm{k} T(T=300 \mathrm{~K})$ for each quinone on HEDGEnO.

\section{Chapter II}

Figure 1. (a) Gels containing agarose, $\mathrm{KCl}$, and BTMAP-Vi (gel-N) and BTMAP-Fc (gel-P). (b) Scheme of the microbattery (i), photos of the gel on FCF electrode (ii and iii) and of the device (iv), and scanning electron microscopic images of FCF at different magnifications ( $\mathrm{v}$ and vi). (c) Cyclic voltammograms of BTMAP-Vi and BTMAP-Fc and background recorded on FCF microelectrodes. Conditions: $2.0 \mathrm{mM}$ of BTMAP-Vi and BTMAP-Fc in $1.0 \mathrm{M} \mathrm{KCl}, 50$ $\mathrm{mV} \mathrm{s}^{-1}, \mathrm{Ar}$ atmosphere. The expected cell potential is indicated ..........................52

Figure 2. (a) Voltage vs. time for galvanostatic discharge at $40 \mu \mathrm{A} \mathrm{cm}^{-2}$. (b) Cell voltage and power density vs. current density at $20 \%$ SOC. (c) Charge and discharge curves at $1.10 \mathrm{~V}$ and $0.30 \mathrm{~V}$, respectively. (d) Capacity and current efficiency values of 100 cycles. (e) Representative voltage and current density vs. time curves during 100 charging-discharging cycles at $40 \mathrm{~mA} \mathrm{~cm}^{-2}$. All data here were collected at room temperature, under $\mathrm{N}_{2}$ atmosphere, and using gel containing $1.0 \mathrm{M} \mathrm{KCl}$ and $0.50 \mathrm{M} \mathrm{BTMAP-Fc}$ on the positive side and gel containing 1.0 M KCl and 0.50 M BTMAP-Vi on the negative side, and Selemion DSV as anion exchange membrane. 
Figure S1. (a) Scheme of synthesis of BTMAP-Vi and (b) ${ }^{1} \mathrm{H}$ NMR spectrum of BTMAP-Vi recorded at $500 \mathrm{MHz}$, in $\mathrm{D}_{2} \mathrm{O} . \delta 9.12(\mathrm{~d}, 4 \mathrm{H}), 8.63(\mathrm{~d}, 4 \mathrm{H}), 4.87(\mathrm{t}, 4 \mathrm{H}), 3.61(\mathrm{~m}, 4 \mathrm{H}), 3.22(\mathrm{~s}$,

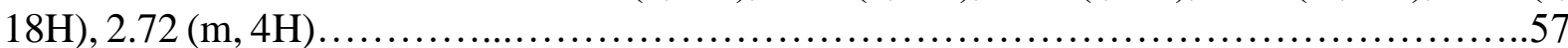

Figure S2. (a) Scheme of synthesis of BTMAP-Fc and ${ }^{1} \mathrm{H}$ NMR spectrum of BTMAP-Fc recorded at $500 \mathrm{MHz}$, in $\mathrm{D}_{2} \mathrm{O} . \delta 4.15(\mathrm{~m}, 8 \mathrm{H}), 3.27(\mathrm{~m}, 4 \mathrm{H}), 3.05(\mathrm{~s}, 18 \mathrm{H}), 2.55(\mathrm{t}, 4 \mathrm{H}), 1.94$

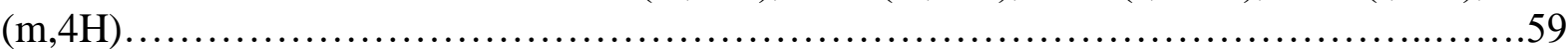

Figure S3. Measurement of cell voltage after $48 \mathrm{~h}$ of storage (no current drained)

\section{Chapter III}

Figure 1. (a) Scheme of one-pot reaction for obtaining BOD-based biogel and (b) photo and schematic representation of BOD-based biogel/C GDE. .66

Figure 2. (a) FTIR spectra of the components of the BOD-based biogel. (b) Zoom view of the spectra of GA, BOD, and BOD + GA. (c) BOD three-dimensional structure with highlighted lysine residues in blue, PDB: 2XLL. (d) Second-derivative of the spectra depicted in (b).......67

Figure 3. (a) Micro-FTIR setup with FPA detector. (b-e) Optical images of the bare-BOD film $(b, c)$ and BOD-based biogel (d, e) on gold-coated glass substrate. The red square in (e) indicates the area selected to record the spectra and used to build the chemical images. (f) FTIR spectrum of the BOD-based biogel showing the signals integrated for obtaining the chemical images. (g, h) Chemical images showing the distribution of $1543 \mathrm{~cm}^{-1}$ (amide-II) and $1233 \mathrm{~cm}^{-1}\left(\mathrm{CF}_{2}\right.$ asymmetric stretching) spectral bands of BOD and Nafion, respectively . . . . . . . . . . . . . . ....68

Figure 4. CVs at $5 \mathrm{mV} \mathrm{s}^{-1}$ in phosphate buffer $\mathrm{pH} 7.2$ at $25{ }^{\circ} \mathrm{C}$ obtained with BOD-based biogel/C on the GDL platform (blue curves) and enzyme-free electrode (gray curves) in absence of $\mathrm{O}_{2}$ (a) and in electrolyte saturated with $\mathrm{O}_{2}$ in non-gas diffusion mode (b). The arrows indicate the potential scan direction. (c) Linear voltammograms at $5 \mathrm{mV} \mathrm{s}^{-1} 1$ and (d) chronoamperogram at $0.00 \mathrm{~V}$ of BOD-based biogel/C on GC RDE in $\mathrm{O}_{2}$-saturated phosphate buffer $\mathrm{pH} 7.2$ at $25^{\circ} \mathrm{C}$, at quiescent condition (dashed lines) and under different electrode rotation rates (100, 250, 500, 750, 1000, 1500, 2000, 2500, and $3000 \mathrm{rpm}$, solid lines). Koutecky-Levich plots obtained from linear voltammograms (e) and chronoamperograms (f).

Figure 5. SEM images at different magnifications of the (a) GDL, (b) carbon nanoparticles layer on the top of GDL, and (c) BOD-based biogel on the top of carbon nanoparticles layer..........70

Figure 6. (a) Scheme of ORR on BOD-based biogel/C GDE. The blue and white spheres represent the oxygen and hydrogen atoms, respectively. The blue arrow indicates the diffusion of atmospheric dioxygen and the red arrow represents the ORR catalyzed by BOD-based biogel. (b) $\mathrm{CV}$ at $5 \mathrm{mV} \mathrm{s}^{-1}$, (c) operational stability at $-1.00 \mathrm{~mA} \mathrm{~cm}$, and (d) at open circuit potential of the BOD-based biogel/C GDE in phosphate buffer $\left(\mathrm{pH} \mathrm{7.2)}\right.$ at $25{ }^{\circ} \mathrm{C}$, under atmospheric

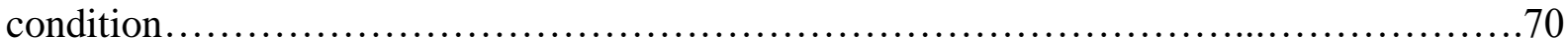

Figure S1. Homemade glass electrochemical used in the gas-diffusion experiments..........75

Figure S2. FTIR spectra of the components of BOD-based biogel....................... 76

Figure S3. FTIR spectra of (a) Nafion, GA and their mixture, and (b) Nafion, BOD and their

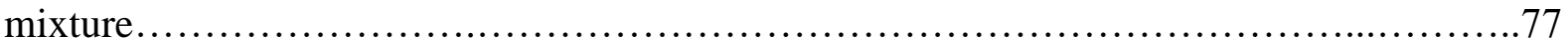

Figure S4. Optical microscopic images obtained in the reflectance mode of BOD-based biogel $(a, b)$ and bare-BOD $(c, d)$ films obtained by drop-casting on GC substrate......................78

Figure S5. CVs at $5 \mathrm{mV} \mathrm{s}^{-1}$ obtained with enzyme-free carbon electrode in phosphate buffer $\mathrm{pH}$ 7.2 at $25^{\circ} \mathrm{C}$ saturated with $\mathrm{O}_{2}$ (black curve) and with $\mathrm{Ar}$ (gray curve) ...................... 78 
Figure S6. Histogram of the carbon nanoparticle diameter

Figure S7. CV at $5 \mathrm{mV} \mathrm{s}^{-1}$ of (a) BOD-based biogel/C GDE dried at room temperature and humidity (about 60\%) and (b) dried at vacuum and room temperature. CVs were recorded in phosphate buffer $(\mathrm{pH} 7.2)$ at $25^{\circ} \mathrm{C}$, under atmospheric condition ....................... 80

Figure S8. CV at $5 \mathrm{mV} \mathrm{s}^{-1}$ of BOD-based biogel/C GDE in phosphate buffer (pH 7.2) at $25^{\circ} \mathrm{C}$,

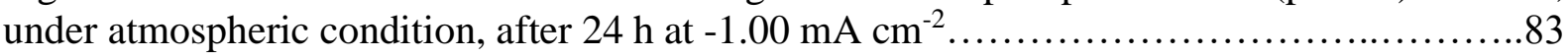

Figure S9. Operational stability at $-0.20 \mathrm{~mA} \mathrm{~cm}^{-2}$ of the BOD-based biogel/C GDE in phosphate buffer $(\mathrm{pH} 7.2)$ at $25^{\circ} \mathrm{C}$, under atmospheric condition....................................

Figure $\mathrm{S} 10$. (a) $\mathrm{CV}$ at $5 \mathrm{mV} \mathrm{s}^{-1}$ of the GDEs with regular amount of BOD-based biogel (black curve), 30\% lower (blue curve), and 50\% lower (red curve). (b) Maximum current density toward ORR of the bioelectrodes and the respective potentials. (c) Operational stability at -0.50 $\mathrm{mA} \mathrm{cm} \mathrm{cm}^{-2}$ of BOD-based biogel/C GDE with $50 \%$ lower biogel. All measurements were

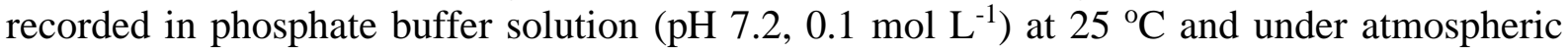
conditions.......................................................................... 84

Figure S11. (a) UV-vis spectra of BOD, Nafion and GA control solutions in phosphate buffer

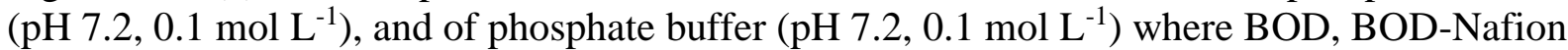
and BOD-GA and BOD-based biogel electrodes were incubated for $24 \mathrm{~h}$. (b) Zoomed UV-vis spectra shown in (a). (c) Normalized absorbance at $595 \mathrm{~nm}$. Absorbance intensities were

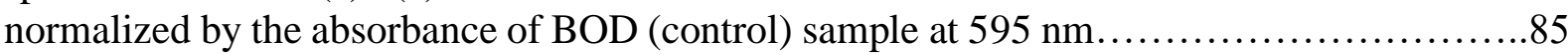

Figure S12. (a) CVs at $5 \mathrm{mV} \mathrm{s}^{-1}$ recorded with BOD/C (red) and BOD-based biogel/C (blue) GDEs. Insets show the maximum reduction current densities. (b) long-term operational stability at $-0.20 \mathrm{~mA} \mathrm{~cm}{ }^{-2}$ of BOD/C GDE. All measurements were performed in phosphate buffer $(\mathrm{pH}$ $7.2)$ at $25^{\circ} \mathrm{C}$, under atmospheric condition........................................... 86

Figure S13. (a) CVs at $5 \mathrm{mV} \mathrm{s}-1$ recorded with BOD-Nafion/C (red) and BOD-based biogel/C (blue) GDEs in phosphate buffer $(\mathrm{pH} 7.2)$ at $25^{\circ} \mathrm{C}$, under atmospheric condition. Insets show the maximum reduction current densities.

\section{Chapter IV}

Figure 1 - EET mechanisms in microorganisms.......................................................... 93

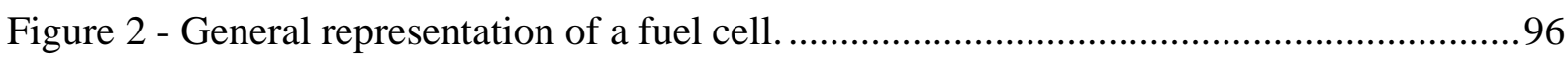

Figure 3 - Representative (a) polarization and (b) power curves of a fuel cell. .................... 101

Figure 4 - Scheme of EPS extraction Saccharomyces cerevisiae ........................................ 105

Figure 5 - Schematic representation of MFC structure.................................................... 106

Figure 6 - (a) CVs (third cycles) at $5 \mathrm{mV} \mathrm{s}^{-1}$ of FCF in degassed $0.10 \mathrm{~mol} \mathrm{~L}^{-1}$ phosphate buffer solution ( $\mathrm{pH} \mathrm{7.2)}$ at $40{ }^{\circ} \mathrm{C}$, initially containing $1.00 \mathrm{~mol} \mathrm{~L}^{-1}$ glucose, before, right after the addition of $0.05 \mathrm{~g} \mathrm{~mL}^{-1}$ yeast $(t=0 \mathrm{~h})$, and after $1 \mathrm{~h}, 2 \mathrm{~h}, 3 \mathrm{~h}, 4 \mathrm{~h}, 5 \mathrm{~h}$ of incubation in the fermentation suspension. (b) Zoomed-in view of the CVs. (c) Four successive CVs after $24 \mathrm{~h}$ of fermentation and (d) the its zoomed-in view. 108

Figure 7 - (a) Optical microscopic image of non-activated Saccharomyces cerevisiae cells on $\mathrm{CaF}_{2}$ substrate, indicating the region where the spectra were recorded (blue dot). (b) FTIR spectra recorded on yeast aggregate. Zoomed-in view of the yeast spectrum at high (c) and low (d) wavenumbers. 109 
Figure 8 - Optical microscopic images of Saccharomyces cerevisiae cells on $\mathrm{CaF}_{2}$ substrate after $1 \mathrm{~h}, 5 \mathrm{~h}$ and $24 \mathrm{~h}$ of fermentation.

Figure 9 - (a) FTIR spectra of non-activated Saccharomyces cerevisiae cells (black line) and after $1 \mathrm{~h}$ (blue line), $5 \mathrm{~h}$ (red line) and $24 \mathrm{~h}$ (green line) of fermentation. (b) Zoomed-in view of the spectra between 1500 and $900 \mathrm{~cm}^{-1}$.

Figure 10 - (a) CVs (third cycles) at $5 \mathrm{mV} \mathrm{s}^{-1}$ of fresh FCF in degassed $0.10 \mathrm{~mol} \mathrm{~L}^{-1}$ phosphate buffer solution ( $\mathrm{pH} \mathrm{7.2)}$ ), at $40^{\circ} \mathrm{C}$, containing $1.00 \mathrm{~mol} \mathrm{~L}^{-1}$ glucose (gray line), of $S c$-FCF after 24h-incubation in the fermentation suspension (black line), of fresh FCF recorded in $24 \mathrm{~h}$ fermentation solution without yeast cells (blue line). (b) The zoomed-in view. 113

Figure 11 - CV (third cycle) at $5 \mathrm{mV} \mathrm{s}^{-1}$ of $S c$-FCF, resulting of 24h-incubation in fermentation suspension, recorded in degassed $0.10 \mathrm{~mol} \mathrm{~L}^{-1}$ phosphate buffer solution $\left(\mathrm{pH} \mathrm{7.2)}\right.$, at $40{ }^{\circ} \mathrm{C}$.

Figure 12 - SEM images of FCFs at different magnifications after $1 \mathrm{~h}$ (a), $2 \mathrm{~h} \mathrm{(b),} 3 \mathrm{~h}$ (c), $4 \mathrm{~h}$ (d), $5 \mathrm{~h}$ (e), and $24 \mathrm{~h}$ (f) of incubation in Saccharomyces cerevisiae fermentation suspension.

Figure 13 - (a) CVs at $5 \mathrm{mV} \mathrm{s}^{-1}$ and $40{ }^{\circ} \mathrm{C}$ of $\mathrm{FCF}$ recorded in degassed $0.10 \mathrm{~mol} \mathrm{~L}^{-1}$ phosphate buffer solution, $\mathrm{pH} 7.2$ (gray line), of $S c$-FCF incubated for $24 \mathrm{~h}$ in fermentation suspension (black line), of fresh FCF in EPS solution. (b) DPV at $5 \mathrm{mV} \mathrm{s}^{-1}$ and $40^{\circ} \mathrm{C}$ of fresh FCF in EPS solution.

Figure 14 - (a) UV-vis spectrum, (b) its zoomed-in view between 300 and $600 \mathrm{~nm}$, and (c) fluorescence emission spectrum of EPS solution with excitation at $450 \mathrm{~nm}$. 118

Figure 15 - SDS-page electrophoresis of molecular weight standard (i) and EPS solution (ii) by staining with Coomassie blue dye. The orange arrows indicate the main separated proteins in the EPS solution 119

Figure 16 - (a) OCP monitoring and (b) steady-state polarization curve of $S c$-FCF bioanode recorded after $24 \mathrm{~h}$ of fermentation. Measurements in degassed $0.10 \mathrm{~mol} \mathrm{~L}^{-1}$ phosphate buffer solution ( $\mathrm{pH}$ 7.2) initially containing $1.00 \mathrm{~mol} \mathrm{~L}^{-1}$ glucose, at $40{ }^{\circ} \mathrm{C}$. 120

Figure 17 - Current density-time curve of $S c$-FCF bioanode at $0.00 \mathrm{~V}$ in degassed $0.10 \mathrm{~mol} \mathrm{~L}$ ${ }^{1}$ phosphate buffer solution ( $\mathrm{pH} \mathrm{7.2)}$, at $40{ }^{\circ} \mathrm{C}$, initially containing $1.00 \mathrm{~mol} \mathrm{~L}^{-1}$ glucose. .... 121

Figure 18 - Theoretical cell growth curve of a yeast colony. 122

Figure 19 - Photos of $S c-M F C$ MFC (a), the anodic (b) and cathodic (c) chambers. 123

Figure 20 - OCP monitoring of the Saccharomyces cerevisiae-based MFC. 124

Figure 21 - (a) Polarization and (b) power density curves of the MFC after $24 \mathrm{~h}$ of fermentation. 


\section{LIST OF TABLES}

\section{Introduction}

Table 1 - Standard reduction potentials of some electron carriers and systems involved in the

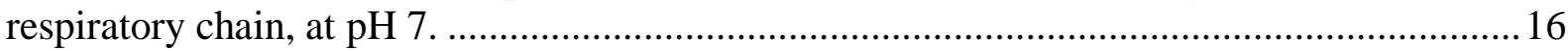

\section{Chapter II}

Table 1. Examples of low-power medical microdevices.................................54

Table S1. Composition of the BTMAP-Vi and BTMAP-Fc hydrogels......................60

\section{Chapter III}

Table S1. Vibrational modes assignment of the various functional groups of BOD-based biogel

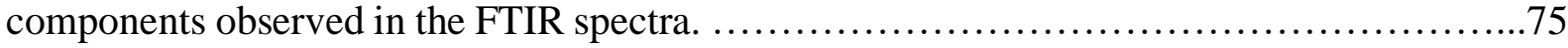

Table S2. Performance of BOD-based gas diffusion electrodes towards ORR without redox mediator .81

\section{Chapter IV}

Table 1 - Reported artificial mediatorless Sc-MFC. .98

Table 2 - Vibrational modes assignment of the non-activated Saccharomyces cerevisiae cells. 


\section{TABLE OF CONTENTS}

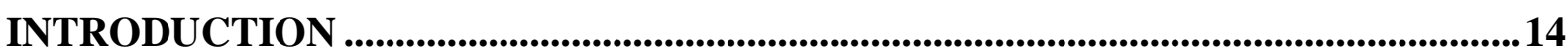

PRESENTATION OF THE CHAPTERS ...................................................................17

CHAPTER I - Effect of molecular structure of quinones and carbon electrode surfaces on

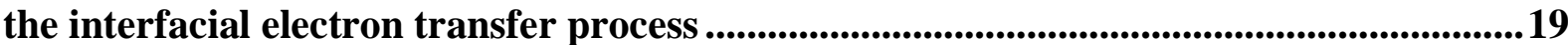

CHAPTER II - Non-corrosive, low-toxicity gel-based microbattery from organic and organometallic molecules .50

CHAPTER III - Stabilization of bilirubin oxidase in a biogel matrix for high-performance gas diffusion electrodes .63

CHAPTER IV - Extracellular electron transfer in Saccharomyces cerevisiae and energy conversion in a microbial fuel cell....................................................................................90

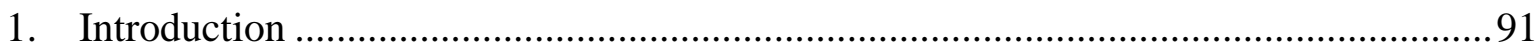

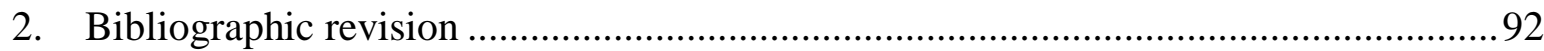

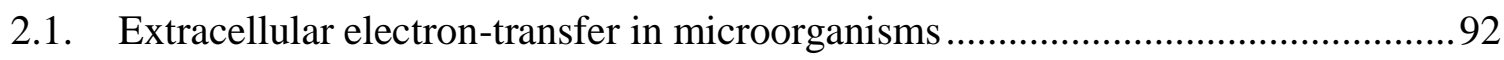

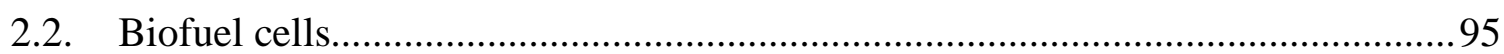

2.3. Saccharomyces cerevisiae-based microbial fuel cells ........................................97

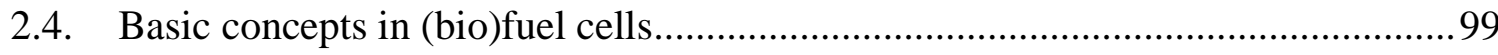

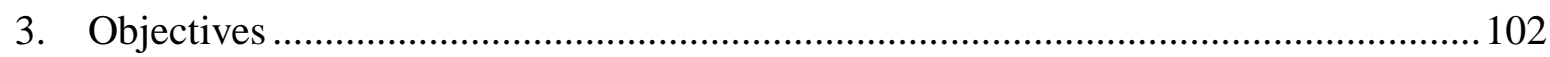

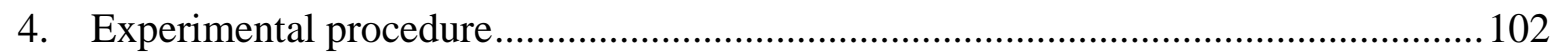

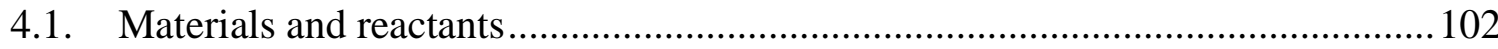

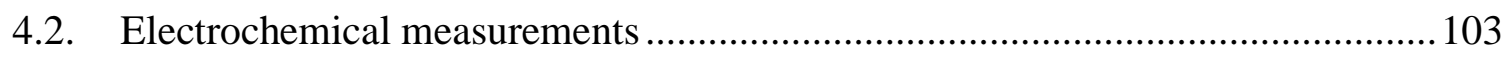

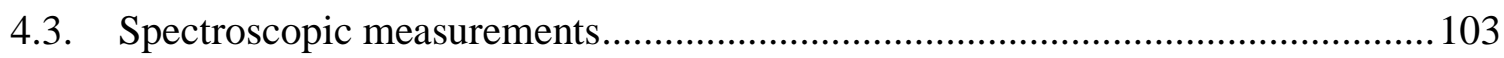

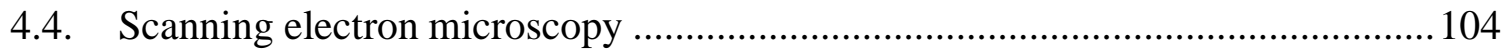

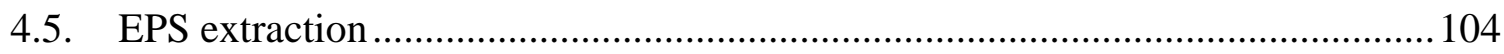

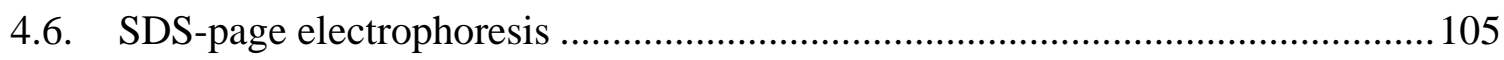

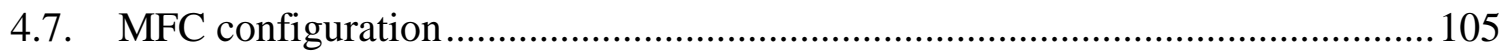

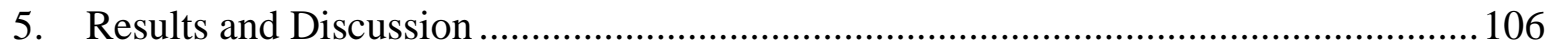

5.1. Electrochemical behavior of Saccharomyces cerevisiae on FCF electrode.......... 106

5.2. Characterization of Saccharomyces cerevisiae fermentation............................... 109

5.3. Extracellular electron transfer of Saccharomyces cerevisiae to the FCF surface 112

5.4. Saccharomyces cerevisiae EPS characterization................................................ 116

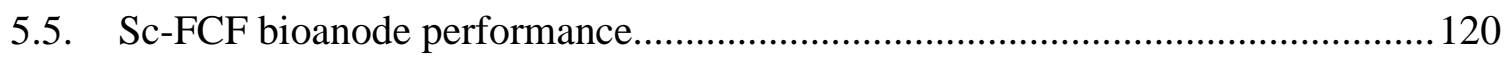

5.6. Saccharomyces cerevisiae-based MFC ............................................................... 122

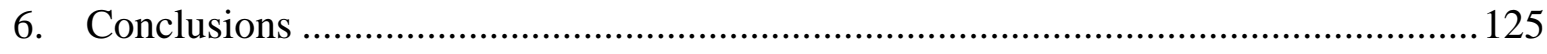

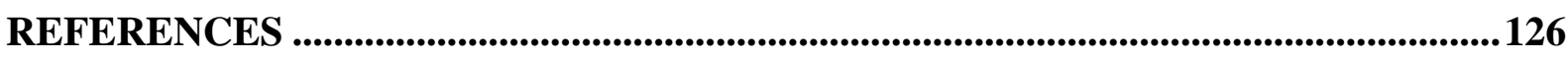

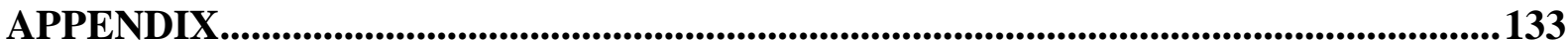

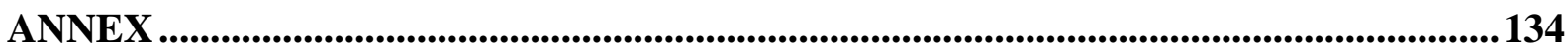




\section{INTRODUCTION}

To keep alive, all organisms need continuously of energy. Along the evolution, living cells have developed highly efficient mechanisms for obtaining energy from sunlight (in phototrophs) or fuels (in chemotrophs) to maintain their intricate and organized structure and all of the many processes that require mechanical, chemical, osmotic, and electrical work. ${ }^{1}$ Independently how the living organisms derive their energy, the metabolic energy generated in the cells is resulting from electron transfer processes, in which donor molecules, called fuels (reducing agents) release electrons, which are channeled and transferred to an acceptor molecule (oxidant agent). The free-energy $(\Delta G)$ of this entire process is partially conserved in form of ATP (adenosine triphosphate), an energy-carrying molecule found in all living organisms. Therefore, the metabolic energy obtention is intrinsically related to redox reactions, and this magnificent mechanism developed by the nature has been exploit by the human beings and worked as inspiration to develop energy conversion systems for electricity generation, such as biofuel cells (BFCs) and green batteries.

The cellular respiration in chemotrophs (Figure 1) is a great inspiration for the development of green energy conversion and storage systems. The entire process is divided into three main steps: oxidation of carbohydrates, fatty acids, and amino acids; citric acid cycle (or Krebs cycle); and respiratory chain (in aerobic organisms). Initially, the fuel is oxidized and converted into acetyl-CoA. For example, glucose, an excellent fuel, is oxidized through a series of 10 successive enzymatic reactions (glycolysis) in the cytosol converting NAD(P) ${ }^{+}, \mathrm{FAD}$, FMN respectively into $\mathrm{NAD}(\mathrm{P}) \mathrm{H}, \mathrm{FADH}_{2}, \mathrm{FMNH}_{2}$ (universal biological electron carriers) and producing pyruvate and ATP. Then, pyruvate is converted to acetyl-Coenzyme A (acetyl-CoA), also producing $\mathrm{NADH}$ and $\mathrm{CO}_{2}$. Acetyl-CoA is the starting product of citric acid cycle that occurs in the mitochondria. The citric acid cycle is a universal central catabolic pathway, where compounds from glycolysis as well as the breakdown of fats, and proteins are completely oxidized to $\mathrm{CO}_{2}$, with most of the energy of oxidation temporarily stored in the electron carriers $\mathrm{FADH}_{2}$ and NADH (Figure 1a). In the respiratory chain, the electrons from NADH and other oxidizable substrates flow through a chain of four complexes (Complexes I, II, III and IV) arranged asymmetrically in the inner mitochondrial membrane and to be finally transferred to $\mathrm{O}_{2}$ (Figure 1b). Electrons from NADH are transferred through a flavoprotein to a series of ironsulfur proteins (in Complex I) and then to ubiquinone (coenzyme Q.) Also, in Complex II, electrons from succinate pass through a flavoprotein and several Fe-S centers to $\mathrm{Q}$. Then, 
Complex III transfers the electron from reduced coenzyme Q (ubiquinol, $\mathrm{QH}_{2}$ ) to cytochrome $c$, where $\mathrm{Fe}^{3+}$ of heme prosthetic group is reduced to $\mathrm{Fe}^{2+}$. In the final step, electrons of cytochrome $c$ are transferred to $\mathrm{O}_{2}$ by the Complex IV, generating $\mathrm{H}_{2} \mathrm{O}$. In this process, protons are pumping across the inner mitochondrial membrane, and this proton gradient provides the energy (proton-motive force) for ATP synthesis, from ADP and inorganic phosphate $\left(\mathrm{P}_{\mathrm{i}}\right)$, by ATP synthase in the inner membrane. The sequence of electron transfer processes is mostly governed by the reduction potentials of the electron carriers and systems involved in the respiratory chain (see Table 1 ).

Figure 1 - Cellular respiration. (a) The first two stages: catabolism of proteins, fats, and carbohydrates. (b) The third stage: respiratory chain and ATP synthesis in the mitochondria.

a)

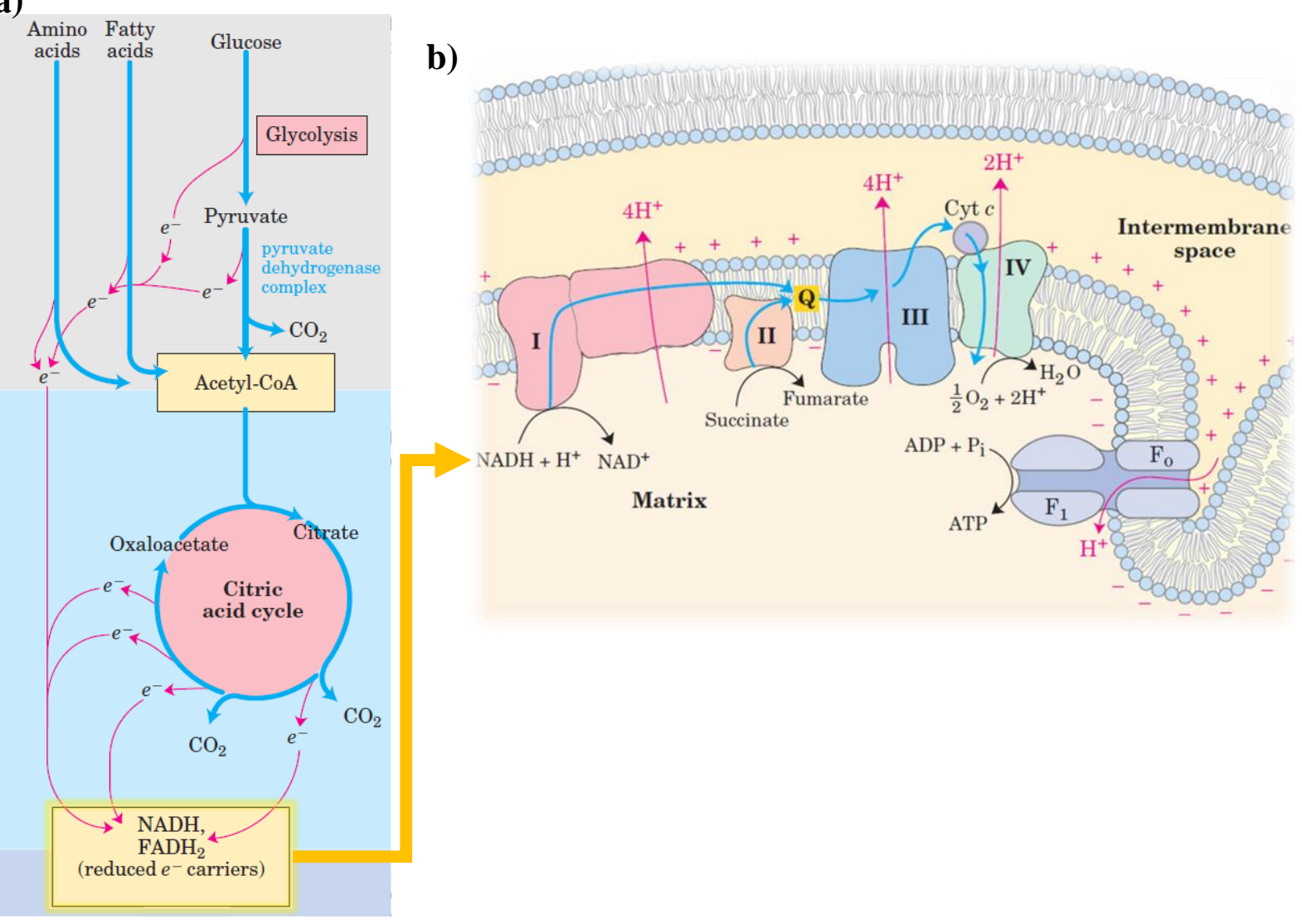

Source: Nelson and Cox (2008). ${ }^{1}$ 
Table 1 - Standard reduction potentials of some electron carriers and systems involved in the respiratory chain, at $\mathrm{pH} 7$.

\begin{tabular}{lc}
\hline Redox reaction & Standard reduction potential / V \\
\hline $2 \mathrm{H}^{+}+2 \mathrm{e}^{-} \rightarrow \mathrm{H}_{2}$ & -0.41 \\
$\mathrm{NAD}(\mathrm{P})^{+}+\mathrm{H}^{+}+2 \mathrm{e}^{-} \rightarrow \mathrm{NAD}(\mathrm{P}) \mathrm{H}$ & -0.32 \\
$\mathrm{FAD}($ free $)+2 \mathrm{H}^{+}+2 \mathrm{e}^{-} \rightarrow \mathrm{FADH}_{2}($ free) & $-0.20 *$ \\
Ubiquinone $+2 \mathrm{H}^{+}+2 \mathrm{e}^{-} \rightarrow$ ubiquinol & 0.045 \\
Cytochrome $c\left(\mathrm{Fe}^{3+}\right)+\mathrm{e}^{-} \rightarrow$ cytochrome $c\left(\mathrm{Fe}^{2+}\right)$ & 0.25 \\
$1 / 2 \mathrm{O}_{2}+2 \mathrm{H}^{+}+2 \mathrm{e}^{-} \rightarrow \mathrm{H}_{2} \mathrm{O}$ & 0.81 \\
\hline
\end{tabular}

Source: Nelson and Cox (2008). ${ }^{1}$

*varies when bound to a protein.

The development of various ecofriendly and safe batteries have been inspired by the electron carriers and molecules involved in the cellular respiration because they are sustainable and show attractive reduction potentials, such as quinone- ${ }^{2-4}$ and alloxazine ${ }^{5,6}$-based molecules. Also, the efficiency of metabolic energy conversion of microorganisms and the high catalytic activity of redox enzymes have been used to produce green electricity in BFCs ${ }^{7,8,17-23,9-16}$ and batteries. $^{24,25}$

However, the developing bioelectrochemical and bioinspired energy conversion systems with satisfactory power density output and stability and long lifetime for practical applications in the real world is not trivial. It requires many efforts on bioelectrochemistry, chemistry, physics, material science and engineering fields, to understand the biocatalytic mechanisms, biological pathways, interfacial electron transfer processes and to develop attractive electrode surfaces and cell designs. In this context, the present thesis addresses, in four chapters, crucial aspects for the development of high-performance bioelectrochemical energy conversion systems inspired in the cellular respiration. 


\section{PRESENTATION OF THE CHAPTERS}

The present thesis is divided in four main chapters, which are independently reported. All chapters are closely correlated and describe studies related to the development of bioelectrochemical and safe energy conversion systems, which are correlated to the initial research project. Chapters I and II shows research articles published during the doctorate period resulting from the studies developed in the research internship in the group of Professor Michael J. Aziz at Harvard University (USA). Chapter III and IV presents, respectively, a published research article and an original work not yet published, both developed in the group of Professor Frank N. Crespilho at IQSC-USP, in Brazil. The reproduction of the research articles in this thesis was permitted by the publishers with no charge. The permissions are shown in Annex.

Chapter I, intitled "Effect of Molecular Structure of Quinones and Carbon Electrode Surfaces on the Interfacial Electron Transfer Process", " shows a research article about how carbon-based material surfaces can influence the electrochemical kinetics of quinone derivatives in quiescent solution. Inspired by the capability of ubiquinol/ubiquinone to efficiently accept and release electrons in the respiratory chain, quinone-based molecules are being used as interesting redox-active compounds in energy systems, such as in enzymatic BFCs and in aqueous organic redox flow batteries. This chapter shows how the structure and composition of carbon-based electrodes can affect the electrochemical behavior of four different quinone derivatives. It is demonstrated that high-performance carbon-based electrodes can be obtained without catalysts for application in organic batteries, by the engineering of carbon-based surfaces with edge-like defects and oxygenated functional groups.

Chapter II, intitled "Non-corrosive, low-toxicity gel-based microbattery from organic and organometallic molecules", $\dagger$ describes the development of a safe, non-corrosive and nonflammable microbattery. For that, organic and organometallic redox-active molecules were incorporated into a natural agarose hydrogel, which works as electrolyte-supporting matrix, similarly to what happens in the respiration chain, where redox-active organic and organometallic redox molecules and complexes are embedded into the mitochondrial membrane. Based on the studies shown in Chapter I, that reveal edge-like defects and

\footnotetext{
* SEDENHO, G. C.; PORCELLINIS, D. De; JING, J.; KERR, E.; MEJIA-MENDOZA L. M., VAZQUEZMAYAGOITIA, A.; ASPURU-GUZIK, A.; GORDON, R. G.; CRESPILHO, F. N.; AZIZ, M. J. ACS Appl. Energy Mater., v. 3, p.1933-1943, 2020.

$\dagger$ CRESPILHO, F. N., SEDENHO, G. C., PORCELlinIS, D. De; KERR, E., GRANADOS-FOCIL, S.; GORDON, R. G.; Aziz, M. J. J. Mater. Chem. A, v. 7, 24784, 2019.
} 
oxygenated functional groups enhance the interfacial electron transfer kinetics of organic molecules, flexible carbon fibers with similar features were used as electrodes in the microbattery. The developed microbattery can safely meet the needs of ingestible medical microdevices as a primary battery. Additionally, it is shown that this redox gel system can be used as a secondary battery for on-chip electronics applications, potentially enabling safe and cost-effective small-scale energy storage.

Chapter III, intitled "Stabilization of bilirubin oxidase in a biogel matrix for highperformance gas diffusion electrodes $"$, presents a methodology for bilirubin oxidase (BOD) immobilization on carbon-based gas diffusion electrode for four-electron electrochemical oxygen reduction reaction used in cathodes of BFCs. In the final step of respiration chain, molecular oxygen is efficiently reduced to water in Complex IV by the electron transfer from cytochrome $c$ in the mitochondrial membrane. To mimic what happens in this step and to enable application on electrochemical energy conversion systems, bilirubin oxidase (BOD) was used as biocatalyst and it was incorporated into a gel matrix on the electrode surface. This approach provided stable electrode performance and allows the direct electron-transfer mechanism of multicopper centers buried in the enzyme. This gave to the bioelectrode an unprecedented longterm stability under continuous operation combined with satisfactory catalytic current without redox mediator. Further, the BOD-based biogel provides a suitable microenvironment for longterm enzymatic activity involving three-phase interfacial reaction. This study provided new insights into enzyme immobilization to overcome the critical short-term stability of enzymebased electrochemical devices for practical applications.

Chapter IV, intitled "Extracellular electron transfer in Saccharomyces cerevisiae and energy conversion in a microbial fuel cell", shows the elucidation of the extracellular electron transfer mechanism (EET) of Saccharomyces cerevisiae. This study showed Saccharomyces cerevisiae extracellularly transfers electrons released in the carbohydrate oxidation to flexible carbon fiber surface through a flavoprotein mostly confined in the film of extracellular polymeric substances (EPS) on the cell surface. Inspired by the cellular respiration, the energy obtention process in chemotrophs organisms, the electricity generation in a mediatorless MFC exploiting carbohydrate oxidation by the yeast in the bioanode, and the oxygen reduction to water in the BOD-based gas diffusion biocathode (shown in Chapter III) was demonstrated.

\footnotetext{
\$SEDENHO, G. C.; HASSAN, A.; MACEDO, L. J. A., CRESPILHO, F. N. J. Power Sources, v. 482, 229035, 2021.
} 


\section{CHAPTER I - Effect of molecular structure of quinones and carbon electrode surfaces on the interfacial electron transfer process}

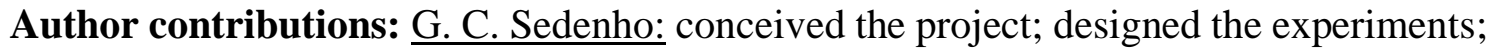
collected and analyzed the electrochemical data; characterized the carbon-based materials; wrote and revised the manuscript. D. De Porcellinis: performed the SEM measurements; revised the manuscript. Y. Jing: synthesized, purified, and characterized CQ; revised the manuscript. E. Kerr: synthesized, purified, and characterized FQ; revised the manuscript. L. M. M.Mendoza: performed the molecular dynamics simulation and DFT calculations; revised the manuscript. Á. V.-Mayagoitia: performed the molecular dynamics simulation and DFT calculations A. A.-Guzik: supervised molecular dynamics simulation and DFT calculations; revised the manuscript. R. G. Gordon: supervised synthesis, purification, and characterization of FQ and CQ; revised the manuscript. F. N. Crespilho: conceived the project; designed the

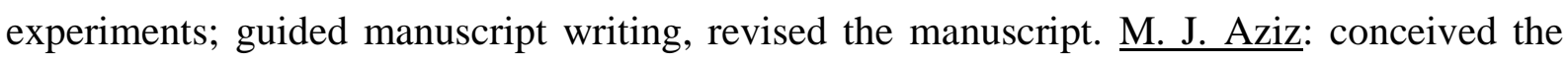
project; guided manuscript writing; revised the manuscript.

This work, published in 2020 in the ACS Applied Energy Materials, aims to show how the molecular structure of quinone derivatives and the edge-like defects, as well as, oxygenated functional groups on the carbon-based electrode surface can affect the interfacial electron transfer kinetics. Quinone derivatives are redox-active compounds very often employed in redox flow batteries and BFC. The use of this class of compounds in these electrochemical energy conversion systems is inspired by the respiratory chain, which uses the high efficiency of ubiquinol/ubiquinone to reversibly accept and release electrons.

It is very-known that the structure of carbon-based electrodes affects the electrochemical behavior of organic redox-active molecules, however, for the first time, it is shown atomistic insights and the evaluation of the adsorption energy of between different quinone derivatives and carbon-based electrode surface. This was possible due to the combination of systematic experimental studies with molecular dynamics simulation and quantum mechanics calculations. 


\title{
Effect of Molecular Structure of Quinones and Carbon Electrode Surfaces on the Interfacial Electron Transfer Process
}

\author{
Graziela C. Sedenho, Diana De Porcellinis, Yan Jing, Emily Kerr, Luis Martin Mejia-Mendoza, \\ Álvaro Vazquez-Mayagoitia, Alán Aspuru-Guzik, Roy G. Gordon, Frank N. Crespilho,* \\ and Michael J. Aziz*
}

Cite This: ACS Appl. Energy Mater. 2020, 3, 1933-1943

Read Online

ACCESS | Lلll Metrics \& More | 回 Article Recommendations | st Supporting Information

ABSTRACT: Quinones can undergo thermodynamically reversible proton-coupled electron transfer reactions and are being applied as electroactive compounds in aqueous organic batteries. However, the electrochemical reversibility of these compounds is affected not only by their molecular structure but also by the properties of a carbon-based electrode surface. This study combines experimental and theoretical approaches to understand this dependence. We study the electron transfer kinetics of two synthesized quinone derivatives and two commercially available ones with a glassy carbon, a highly ordered pyrolytic graphite, and a high-edge-density graphite electrode (HEDGE). The electrochemical reversibility is notably improved on the HEDGE, which shows a higher density of defects and presents oxygenated functional groups at its surface. The electron transfer kinetics are controlled by adsorbed species onto the HEDGE. Molecular dynamics simulation and quantum mechanics calculations suggest defects with oxygen-

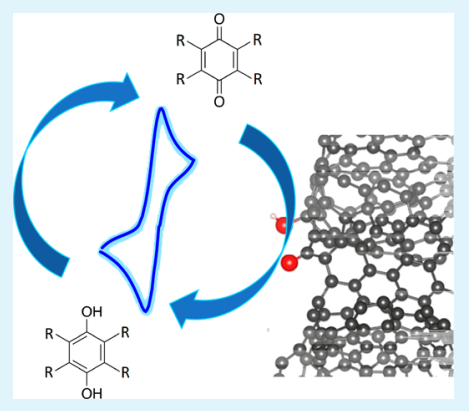
containing functional groups, such as $\mathrm{C}-\mathrm{O}$ and $\mathrm{C}=\mathrm{O}$, on HEDGE surfaces drive the interaction with the functional groups of the molecules, during physisorption from van der Waals forces. The presence of sulfonic acid side groups and a greater number of aromatic rings in the molecular structure may contribute to a higher stabilization of quinone derivatives on HEDGEs. We propose that high-performance carbon-based electrodes can be obtained without catalysts for organic batteries, by the engineering of carbonbased surfaces with edge-like defects and oxygenated functional groups.

KEYWORDS: quinones, carbon-based electrodes, graphite electrode, edge-plane-like defects, aqueous organic batteries, electrochemical reversibility, electron transfer kinetics

\section{INTRODUCTION}

The generation of electrical energy from renewable sources, particularly wind and solar, is assuming increasing importance in modern society and can contribute to the worldwide expansion of the electric power generating capacity. However, to effectively use this renewable energy, it is necessary to deal with the inherent intermittency of these natural sources. ${ }^{1}$ Methods for storing electrical energy could overcome this issue. Redox flow batteries (RFBs) have been recognized as a promising technology for large-scale energy storage. ${ }^{2}$ In a RFB system, redox-active compounds are dissolved in electrolytes and separately stored in external tanks. The electroactive species are pumped between the reservoirs and the cell, where they are reversibly oxidized and reduced on the electrodes, storing or generating electricity that flows through an external circuit. $^{2}$ The performance of RFBs depends on several chemical, physical, and engineering factors, including the choice of redox compounds, electrode materials, membrane characteristics, and cell configuration. ${ }^{1,2}$ Vanadium is the most popular electroactive species employed in commercial RFBs; however, the geographically limited supplies and high and fluctuating cost of this metal limit the widespread use of vanadium-based RFBs. ${ }^{3}$ Quinone derivatives are interesting redox-active compounds in energy systems, such as in enzymatic biofuel cells ${ }^{4-6}$ and in aqueous organic RFBs (AORFBs). ${ }^{7-10}$ Quinone based molecules have been explored as alternative electroactive compounds in aqueous organic AORFBs because they are entirely composed of Earthabundant elements and can be low cost and safe for use in residential and commercial environments. ${ }^{7-10}$

Quinone-based molecules can show thermodynamically reversible proton-coupled electron transfer reactions in acidic conditions. $^{11,12}$ However, the electrode material and its microstructure may also play a crucial role in affecting the electrochemical response and consequently the AORFB performance. Carbon-based electrodes have been widely employed in aqueous and nonaqueous RFBs because they show high electronic conductivity, high chemical and electrochemical stability, high specific surface area, and low cost. ${ }^{13} \mathrm{~A}$ variety of carbon materials have been used in RFBs, such as

Received: December 5, 2019

Accepted: January 28, 2020

Published: January 28, 2020 
Scheme 1. Chemical Structure and Redox Reactions of (a) FQ (b) CQ (c) BQDS, and (d) ARS in Strongly Acidic Condition $(\mathrm{pH} \approx 0)$

a)<smiles>CN(C)CC1=C(CN(C)C)C(=O)C(CN(C)C)=C(CN(C)C)C1=O</smiles>

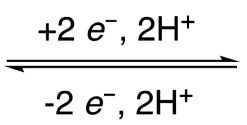<smiles>CN(C)Cc1c(O)c(CN(C)C)c(CN(C)C)c(O)c1CN(C)C</smiles>

b)<smiles>O=C1C(=O)C(CN2CCOCC2)=CC=C1CN1CCOCC1</smiles><smiles>Oc1c(CN2CCOCC2)ccc(CN2CCOCC2)c1O</smiles>

c)<smiles>O=C1C=C(S(=O)(=O)O)C=C(S(=O)(=O)O)C1=O</smiles><smiles>O=S(=O)(O)c1cc(O)c(O)c(S(=O)(=O)O)c1</smiles>

d)<smiles>O=c1c([S+](=O)(=O)O)cc2c(=O)c3ccccc3c(=O)c(=O)c1=2</smiles><smiles>C1CCCCC1</smiles><smiles>O=C1c2ccccc2C(=O)c2c1cc(S(=O)(=O)O)c(O)c2O</smiles><smiles>C=Cc1ccc2c(O)c3cc(S(=O)(=O)O)c(O)c(O)c3c(O)c2c1</smiles>

carbon papers $^{8-10,14-20}$ and graphitic felts. ${ }^{21-24}$ Usually, these materials are submitted to thermal ${ }^{8,9,15,17,19,23}$ or chemical treatments $^{10,14,15,20}$ or modification with nanomaterials ${ }^{22,24,25}$ to improve wettability and electrochemical performance.

The effects of chemical and thermal treatments on the electrode have been extensively discussed in the literature in the context of vanadium RFBs. ${ }^{26-28}$ Generally, the presence of edge-plane-like defects and oxygenated functional groups is reported to influence electrode performance in vanadium redox reactions. ${ }^{26-28}$ However, in the context of AORFBs, the literature is lacking any information about how carbon-based electrode materials can influence the electrochemical behavior of organic molecules, such as quinones. Glassy carbon (GC) electrodes have been widely used to study the redox reactions of quinone molecules that exhibit Nernstian behavior in quiescent solution, ${ }^{7-10,16,17}$ before testing the quinones in full cells. In this paper we show that some quinones exhibit electrochemical behavior strongly dependent on the carbon material structure.

To gain a better understanding of the quinone and carbonbased electrode system, we studied how carbon-based material surfaces can influence the electrochemical kinetics of quinone derivatives in quiescent solution. We evaluated the separation between anodic and cathodic peaks in cyclic voltammetry and determined adsorbed quinone surface excesses. We used molecular dynamics simulation and density functional theory (DFT) calculations to have atomistic insights and evaluate the adsorption energy at the quinone-carbon electrode surface interface. We used three carbon materials with distinct surface structure and composition: GC, highly ordered pyrolytic graphite (HOPG), and high-edge-density graphite electrode (HEDGE). We studied the electrochemical behavior of four different quinone derivatives with these electrodes. We selected molecules that are candidates to be used as posolytes (positive electrolyte) or in symmetrical AORFBs. We included benzoquinone- and anthraquinone-based compounds functionalized with sulfonic acid, hydroxyl, and amine groups. To interpret the experimental results, we modeled the interaction between quinone derivatives and carbon surfaces using molecular dynamics simulations and quantum mechanics calculations. This work contributes new insights into how carbon-based materials can be tuned to obtain electrodes with superior performance in semisolid AORFBs and solid-batteries involving adsorbed redox-active species. The presence of functionalities and microstructure of carbon-based electrodes should be carefully considered in electrochemical systems that involve redox processes of species in solution: although adsorption enhances the electron transfer kinetics, if it is too strong, however, it is expected to suppress the mass transfer kinetics. Therefore, this study benefits the fields of materials science and electrochemical energy storage.

\section{RESULTS AND DISCUSSION}

2.1. Molecular Electrochemistry of Quinones on Different Carbon-Based Surfaces. We studied the electrochemical behavior of four different quinone derivatives that are of interest for application in AORFBs. We synthesized two of these compounds: 2,3,5,6-tetrakis((dimethylamino)methyl)benzene-1,4-diol $\left(\mathrm{FQH}_{2}\right)$ and 3,6-bis(morpholinomethyl)cyclohexa-3,5-diene-1,2-diol $\left(\mathrm{CQH}_{2}\right)$. Their oxidized forms 

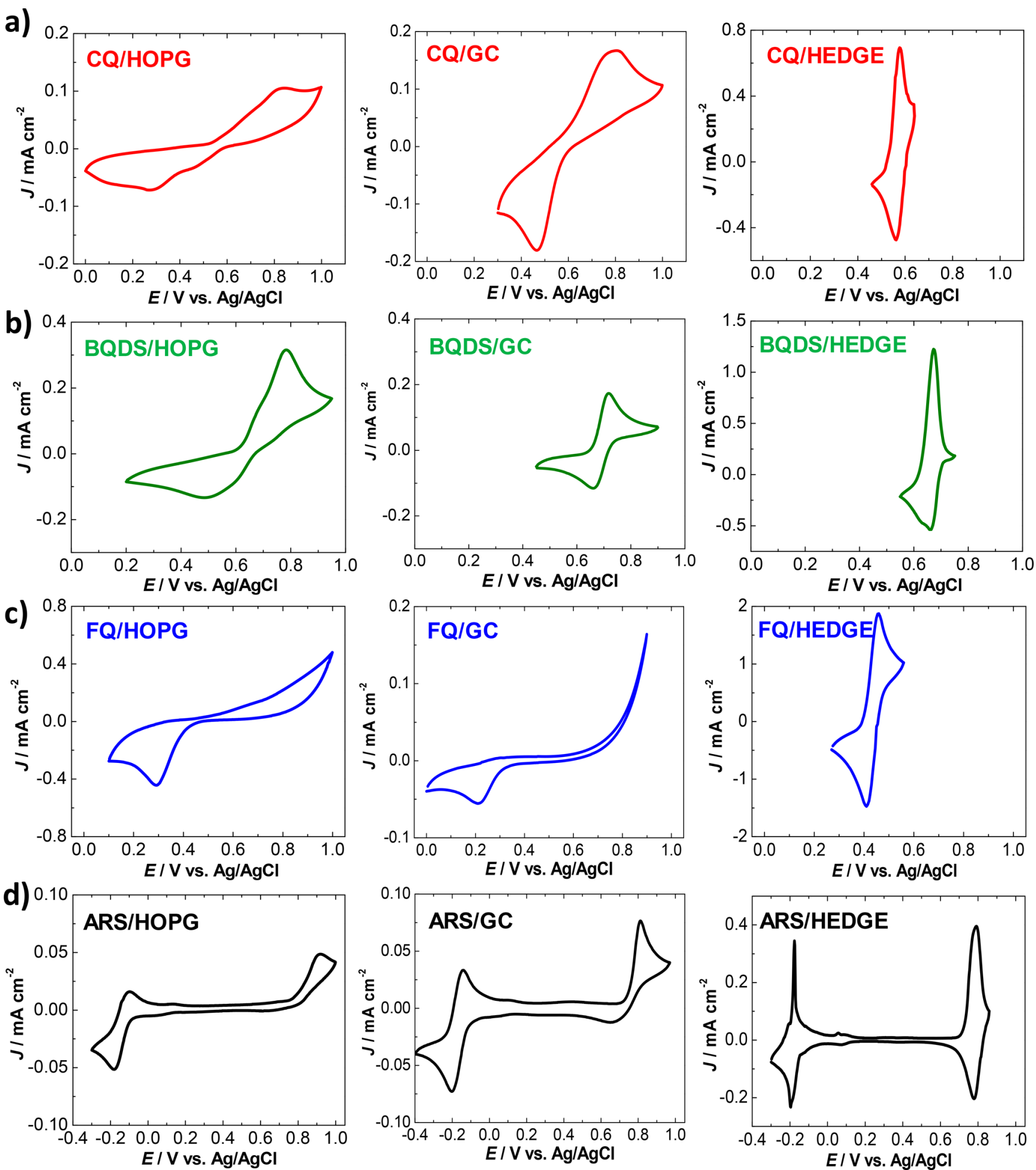

Figure 1. CVs (third cycle) of GC, HOPG, and HEDGE in $1.0 \mathrm{~mol} \mathrm{~L}^{-1} \mathrm{H}_{2} \mathrm{SO}_{4}$ containing (a) $1.0 \mathrm{mmol} \mathrm{L}^{-1} \mathrm{CQ}$ (b) $1.0 \mathrm{mmol} \mathrm{L} \mathrm{mQDS}^{-1} \mathrm{BQ}$ (c) $10.0 \mathrm{mmol} \mathrm{L}^{-1} \mathrm{FQ}$ and (d) $1.0 \mathrm{mmol} \mathrm{L}^{-1}$ ARS. Scan rate: $50 \mathrm{mV} \mathrm{s}^{-1}$ (for FQ CQ and BQDS) and $5 \mathrm{mV} \mathrm{s}^{-1}$ (for ARS). Reference electrode is $\mathrm{Ag} / \mathrm{AgCl}$ in $3 \mathrm{~mol} \mathrm{~L}^{-1} \mathrm{NaCl}$.

are 2,3,5,6-tetrakis((dimethylamino)methyl)cyclohexa-2,5diene-1,4-dione, which we call frog quinone (FQ), and 3,6bis(morpholinomethyl)cyclohexa-3,5-diene-1,2-dione, which we call crab quinone (CQ). The other two are commercial compounds: 1,2-dihydroxybenzene-3,5-disulfonic acid (BQDS) and 3,4-dihydroxy-9,10-dioxoanthracene-2-sulfonic acid, called Alizarin red S (ARS). The structures of all four molecules in their oxidized and reduced forms are shown in Scheme 1 .

FQ is a $p$-benzoquinone functionalized with four trimethylamine groups (see structure in Scheme 1). ${ }^{29}$ FQ is cheap and easy to synthesize (Section 1, Supporting Information). CQ is an o-benzoquinone and has attached two heterocyclic structures with morpholine groups. This compound (Section 
2, Supporting Information) was previously reported as a precursor for the synthesis of antioxidants. ${ }^{30}$ However, this molecule has never been used in an AORFB. BQDS is a commercial $o$-benzoquinone functionalized with two sulfonic acid groups; it was previously reported as the active material in an AORFB posolyte. ${ }^{16}$ The presence of electron-withdrawing side groups in $F Q, C Q$ and $B Q D S$ shifts the reduction potentials to higher values when compared to the analogous nonfunctionalized compounds. ${ }^{12,31}$ The relatively high reduction potentials of these compounds make them candidates for application in the posolyte of an AORFB. Similar to previous work about quinone derivatives in strongly acidic conditions $(\mathrm{pH} \approx 0),{ }^{7,10,16} \mathrm{FQ}, \mathrm{CQ}$ and BQDS are expected to show a rapid and reversible reduction of quinone to hydroquinone form by transfer of two protons and two electrons on electrodes.

ARS is a $p$-anthraquinone derivative having additionally an 3,4-hydroquinone motif and one sulfonic acid group attached to the molecular skeleton. ARS contains both electron-proton donor hydroxyl groups and electron-proton acceptor carbonyl groups. Therefore, ARS exhibits three redox states instead of two, as shown in Scheme 1. Consequently, ARS has been considered for use as both a posolyte and negolyte of the same AORFB. ${ }^{32,33}$

It is well-known that the structure of carbon electrodes and the presence of functionalities influence the electron transfer kinetics of several redox reactions. ${ }^{28,34-38}$ Here, we present a series of experiments designed to probe the effect of the electrode surface on quinone electrochemistry. For that, three carbon-based electrodes with distinctive features were used: GC, HOPG, and HEDGE. GC is a standard carbon-based electrode used to investigate the electrochemical behavior of redox-active compounds and to study new molecules for application in ORFBs. ${ }^{4-7,14,18,36}$ Microscopic, spectroscopic, and diffraction studies ${ }^{40,41}$ have revealed that GC mainly consists of curved carbon sheets that contain an $\mathrm{sp}^{2}$-bonded network of hexagons interspersed with pentagons and heptagons. Models for GC show a predominance of nanosized graphite-like domains in its structure. These features are independent of the thermal treatment used in the GC production process. ${ }^{40}$ In GC production, the material is subjected to high temperature that leads to a noticeable ordering of aromatic nanoclusters. ${ }^{40}$ Thus, it is expected that the surface of GC has more edge-plane sites than HOPG but fewer edge-plane sites than HEDGE. The Raman spectrum of GC (Figure S5, Supporting Information) indicates that its structure contains nanosized disordered $\mathrm{sp}^{2}$ domains, which is consistent with the literature. ${ }^{40,41}$

Differently, HOPG and HEDGE have graphitic structures, however, with very distinct characteristics. In HOPG, the graphene layers lie parallel to the surface; thus, this structure provides a basal plane surface with very few defects. ${ }^{42}$ In contrast, HEDGE is produced in a way that exposes a high density of edge-plane-like defect sites on the surface, by manually polishing single-crystalline graphite at a large misorientation to the basal plane (Section 3, Supporting Information). Previous studies report that edge-plane carbon electrodes ${ }^{35,43,44}$ improve the electrochemical kinetics of several compounds, including ascorbic acid, ${ }^{36}$ nicotinamide adenine dinucleotide, ${ }^{36,37}$ epinephrine, ${ }^{37}$ quinones, ${ }^{45,46}$ ferricyanide, ${ }^{36,37}$ ferrocene derivatives, ${ }^{35}$ and molecular oxygen. ${ }^{38}$ Recently, the presence of defects on carbon electrodes has been shown to enhance the performance of vanadium ${ }^{26-28,34}$ and zinc-bromine ${ }^{14}$ RFBs.

In this context, the electrochemical behavior of the quinone derivatives was investigated by cyclic voltammetry (Section 3, Supporting Information) on HOPG, GC, and HEDGE, as shown in Figure 1. In Figure 1a, we can observe that the cyclic voltammogram (CV) of CQ recorded on HOPG exhibits a broad oxidation peak at $0.84 \mathrm{~V}$ and a major reduction peak at $0.27 \mathrm{~V}$, with a large peak-to-peak separation $\left(\Delta E_{\mathrm{p}}\right)$ of $570 \mathrm{mV}$. $\mathrm{CV}$ of $\mathrm{CQ}$ on GC shows broad oxidation and reduction peaks at 0.80 and $0.47 \mathrm{~V}$, respectively, with a smaller $\Delta E_{\mathrm{p}}, 330 \mathrm{mV}$, compared to HOPG. However, the wide values of $\Delta E_{\mathrm{p}}$ indicates a quasi-reversible redox reaction on both HOPG and GC electrodes. In contrast, the CV of CQ on HEDGE shows a well-defined redox couple with half-wave potential $\left(E_{1 / 2}\right)$ equal to $0.57 \mathrm{~V}$ and $\Delta E_{\mathrm{p}}$ equal to $17 \mathrm{mV}$. This measured value of $\Delta E_{\mathrm{p}}$ is smaller than the value of $30 \mathrm{mV}$ expected for a reversible two-electron process involving freely diffusing species. This deviation suggests that the electron transfer process occurs between adsorbed species and the HEDGE surface.

Similarly to CQ the CV of BQDS on HOPG (Figure $1 \mathrm{~b}$ ) also shows very broad oxidation and reduction peaks at 0.78 and $0.49 \mathrm{~V}$, respectively, with $\Delta E_{\mathrm{p}}$ equal to $290 \mathrm{mV}$. However, the CV of BQDS on GC shows a pair of well-defined redox peaks with $E_{1 / 2}$ equal to $0.69 \mathrm{~V}$ and $\Delta E_{\mathrm{p}}$ of $57 \mathrm{mV}$, which suggests a quasi-reversible electrochemical reaction, as it involves two electrons. Also, CV of BQDS on HEDGE exhibits a well-defined redox couple at $E_{1 / 2}=0.67 \mathrm{~V}$. The small value of $\Delta E_{\mathrm{p}}, 12 \mathrm{mV}$, suggests that the electron transfer process occurs by adsorbed species on the HEDGE surface. For FQ a similar voltammetric profile (Figure 1c) is observed on HOPG and GC. On both electrodes, FQ does not show a well-defined oxidation peak; nevertheless, the onset oxidation current is observed at $\sim 0.5-0.6 \mathrm{~V}$. In the reverse scan, a reduction peak is observed at 0.29 and $0.21 \mathrm{~V}$ on HOPG and GC, respectively. In contrast, reversible $\mathrm{CV}$ of FQ was notably obtained by using the HEDGE. FQ exhibits a pair of well-defined redox peaks at $E_{1 / 2}=0.43 \mathrm{~V}$ with a $\Delta E_{\mathrm{p}}$ of $43 \mathrm{mV}$, which is close to the value of $30 \mathrm{mV}$ that characterizes a reversible one-step two-electron, two-proton redox reaction. With regard to ARS, the CVs (Figure 1d) show several redox processes, which are very similar on HOPG and GC. The first quasi-reversible redox couple has been assigned to the 9,10-quinone functionality ${ }^{47,48}$ and appears at $-0.14 \mathrm{~V}$ with $\Delta E_{\mathrm{p}}$ equal to $80 \mathrm{mV}$ on HOPG and at $-0.17 \mathrm{~V}$ with $\Delta E_{\mathrm{p}}$ equal to $63 \mathrm{mV}$ on $\mathrm{GC}$, indicating quasi-reversible redox reactions on those electrodes. On HEDGE, the same redox couple is observed at $-0.19 \mathrm{~V}$ with $\Delta E_{\mathrm{p}}$ of $21 \mathrm{mV}$. The second anodic peak of ARS is be attributed to the oxidation of 3,4-dihydroxyl groups ${ }^{47,48}$ and appears at $0.92 \mathrm{~V}$ on HOPG and at $0.81 \mathrm{~V}$ on GC. However, the minuscule return peak at high potentials shows an irreversible redox reaction of the 1,2-oxygenated functional groups on HOPG and GC. In contrast, on the HEDGE, ARS presents a well-defined high-potential redox couple with $E_{1 / 2}$ of $0.78 \mathrm{~V}$ and $\Delta E_{\mathrm{p}}$ of $11 \mathrm{mV}$. This result indicates a reversible redox reaction involving adsorbed species on the HEDGE surface. Reversible behavior for both redox couples of ARS has been previously reported by Tong et al. ${ }^{33}$ The CV results indicate that the electron transfer kinetics of the different quinone derivatives is strongly affected by the structure of carbon electrode. We interpret the shapes of the CVs obtained with the HEDGE to mean that all quinones studied have fast 
electron transfer on edge sites of graphitic structures. This electron transfer rate is controlled by adsorbed species on the electrode surface, as shown by the values of $\Delta E_{\mathrm{p}}$ and the linear correlation between the peak current densities and the scan rate (Figure S4). HEDGE exhibits an electrochemical surface area (ECSA) that is higher than that of HOPG by a factor of 29 (Section 9, Supporting Information); after normalization by ECSA, the faradaic currents obtained with the HEDGE remain higher than those obtained with HOPG. Therefore, we conclude that the higher faradaic current densities recorded on the HEDGE are not an area effect, but they are occasioned by the greater electrochemical kinetic rate constants. These observations warn that GC may not be the most appropriate electrode to evaluate the electrochemistry of new organic molecules in quiescent solution for subsequent application in AORFBs. $^{7-10,17,21,39}$ This may lead to discarding molecular candidates that would show rapid and reversible electron transfer kinetics at another carbon electrode.

2.2. Origin of Defects on the HEDGE Surface. To investigate the origin of the electrochemical behavior of quinones on defects on the HEDGE surfaces, we characterized the microstructure, morphology, and chemical composition of carbon-based electrodes using Raman spectroscopy, scanning electron microscopy (SEM), and X-ray photoelectron spectroscopy (XPS), respectively, as shown below (Sections 6-8, Supporting Information). Raman spectra of HOPG and HEDGE in Figures $2 \mathrm{a}$ and $2 \mathrm{~b}$, respectively, show the expected D- and G-bands centered at 1335 and $1581 \mathrm{~cm}^{-1}$, respectively.
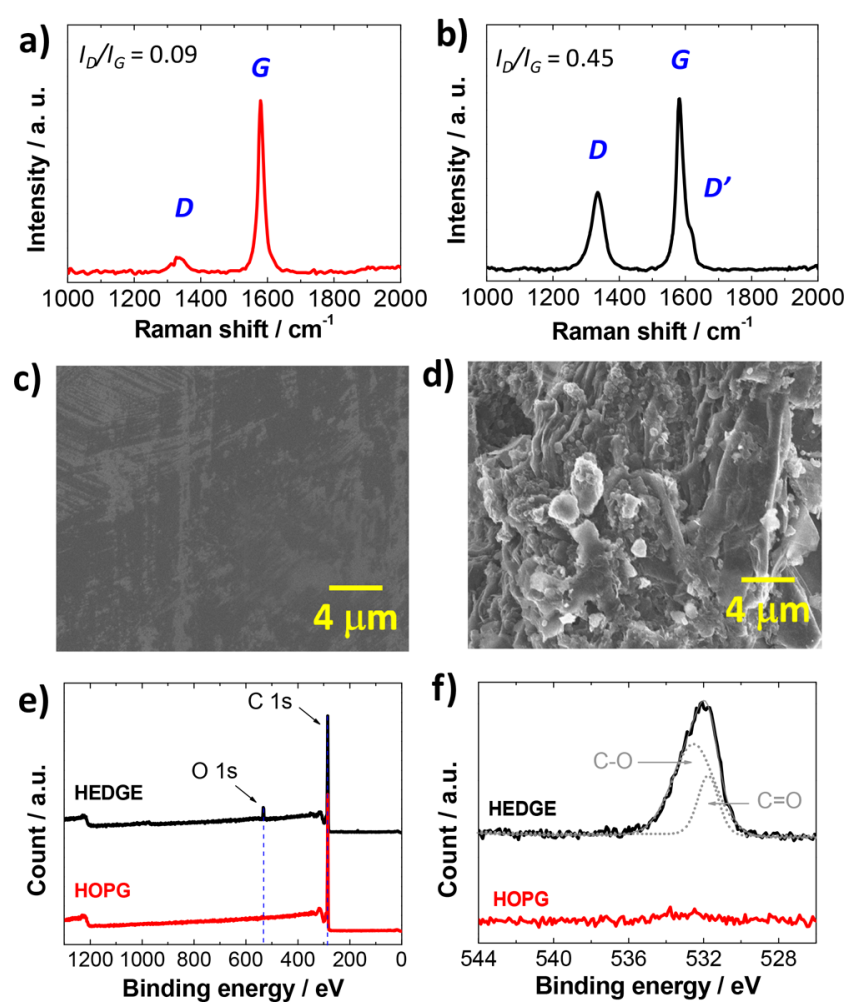

Figure 2. Raman spectra of HOPG (a) and HEDGE (b) obtained with $633 \mathrm{~nm}$ excitation laser. SEM images of HOPG (c) and HEDGE (d). XPS survey spectra (e) of HOPG and HEDGE and their highresolution spectra in $\mathrm{O} 1 \mathrm{~s}$ region (f), where solid red and solid black curves represent raw spectra of HOPG and HEDGE, respectively, and dotted gray lines and solid gray line represent respectively the deconvoluted peaks and the sum of the deconvoluted peaks.
The G-band is associated with the presence of the hexagonal $\mathrm{sp}^{2}$ carbon network, whereas D-band is a defect-induced Raman feature that is forbidden in perfect graphite. ${ }^{49,50}$ HOPG exhibits a sharp symmetry-allowed G-band and a very small defect-induced D-band, indicating highly crystalline graphite. In contrast, the Raman spectrum measured on the HEDGE presents a pronounced D-band as well as a $\mathrm{D}^{\prime}$-band at 1620 $\mathrm{cm}^{-1}$. These bands are originated from two scattering processes consisting of one elastic scattering event by defects of the crystal and one inelastic scattering event by emitting or absorbing a phonon. The D-band originates from an intervalley double-resonance process, involving electronic states around two inequivalent $\mathrm{K}$ points in the Brillouin zone of graphite, whereas the $\mathrm{D}^{\prime}$-band originates from an intravalley doubleresonance process involving electronic states around the same K point. ${ }^{49}$ The ratio of the intensity of $\mathrm{D}$ - and G-bands $\left(I_{\mathrm{D}} / I_{\mathrm{G}}\right)$ was used to quantify the defect densities in both electrodes. The $I_{\mathrm{D}} / I_{\mathrm{G}}$ ratio of 0.45 for the HEDGE indicates more defects on the HEDGE compared to $I_{\mathrm{D}} / I_{\mathrm{G}}$ of 0.09 for the HOPG electrode. As observed in SEM images (Figures $2 \mathrm{c}, \mathrm{d}$ ), the electrodes show drastic differences in terms of microstructure and morphology. The HOPG electrode (Figure 2c) exhibits a flat surface with few scratches, whereas the HEDGE (Figure 2d) has a densely packed microfractured surface. These SEM results are in agreement with the Raman spectroscopic results, where the presence of defects on the HEDGE is confirmed by the higher $I_{\mathrm{D}} / I_{\mathrm{G}}$ ratio. Some authors have discussed the edgeplane-like defects on carbon materials in terms of the presence of oxygenated functional groups. ${ }^{14,26-28,34}$ It is expected that the HEDGE presents more oxygen atoms on the surface compared with HOPG because the HEDGE is prepared by an abrasive procedure in atmospheric conditions to produce a high density of edge-plane-like defect sites on the surface (Section 3, Supporting Information).

To examine the presence of oxygenated functional groups in both HEDGE and HOPG electrodes, XPS measurements were performed. XPS wide scan surveys (Figure 2e) indicate the presence of carbon atoms on both electrode surfaces; however, oxygen atoms were detected only on the HEDGE surface. The high-resolution spectrum (Figure 2f) of HOPG shows a very small and broad peak at around $533 \mathrm{eV}$, which is related to oxygen; however, this signal is close to the level of background noise. This result is consistent with the Raman and SEM results, which indicate that there are very few defects on HOPG where oxygenated functional groups could form. The atomic ratio of oxygen to carbon $(\mathrm{O} / \mathrm{C})$ was considerably higher on the HEDGE $(\mathrm{O} / \mathrm{C}=0.069)$, as shown by the peak at $532 \mathrm{eV}$ attributed to $\mathrm{O} 1 \mathrm{~s}$ in Figure 2e. The type of oxygenated functional groups on the HEDGE can be determined by deconvolution of the high-resolution spectra in the $\mathrm{O} 1 \mathrm{~s}$ region (Figure $2 \mathrm{f}$ ). The deconvolution shows two peaks, which are assigned to $\mathrm{C}=\mathrm{O}(531.8 \pm 0.2 \mathrm{eV})$ and $\mathrm{C}-$ $\mathrm{O}(532.6 \pm 0.2 \mathrm{eV}) .{ }^{51}$ Based on the area of deconvoluted peaks, the percentage of the oxygenated functional groups was calculated to be $66.3 \%$ of $\mathrm{C}-\mathrm{O}$ and $33.7 \%$ of $\mathrm{C}=\mathrm{O}$. XPS results suggest that oxygen in the edge-plane structures is in the form of hydroxyl, ether, and carbonyl functional groups (see high-resolution XPS spectrum in the C 1s region in Figure S6).

2.3. Adsorption of Quinones on the HEDGE Surface. We have observed by $\mathrm{CV}$ that quinones can be adsorbed on the HEDGE surface; on the basis of that, we performed a detailed investigation on how the molecular structure of 
quinone-based molecules influences the adsorption phenomena. The amount of quinone adsorbed under applied overpotential conditions was measured by using anodic stripping voltammetry. ${ }^{52}$ The details of the procedure can be found in Section 10 of the Supporting Information. FQ CQ BQDS, and ARS were first electroadsorbed from their solutions onto the HEDGE surface at high potential. After electroadsorption, the quinones (adsorbate) on the HEDGE surface were quantified by the faradaic current from the CVs, as shown in Figure $3 \mathrm{a}-\mathrm{d}$. To obtain the faradaic current, the
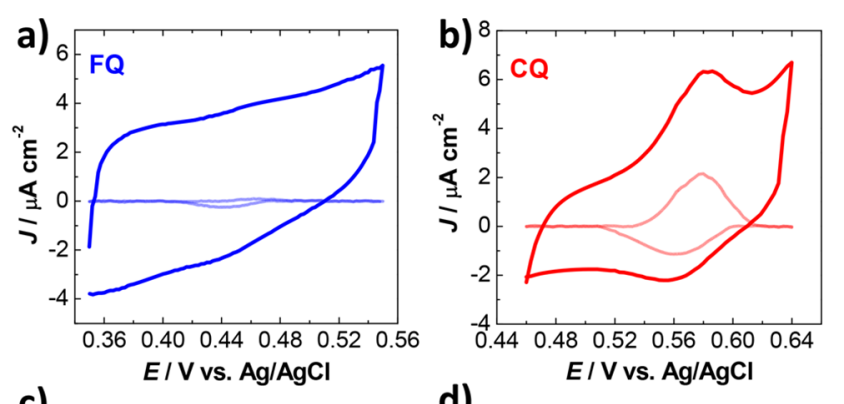

c)
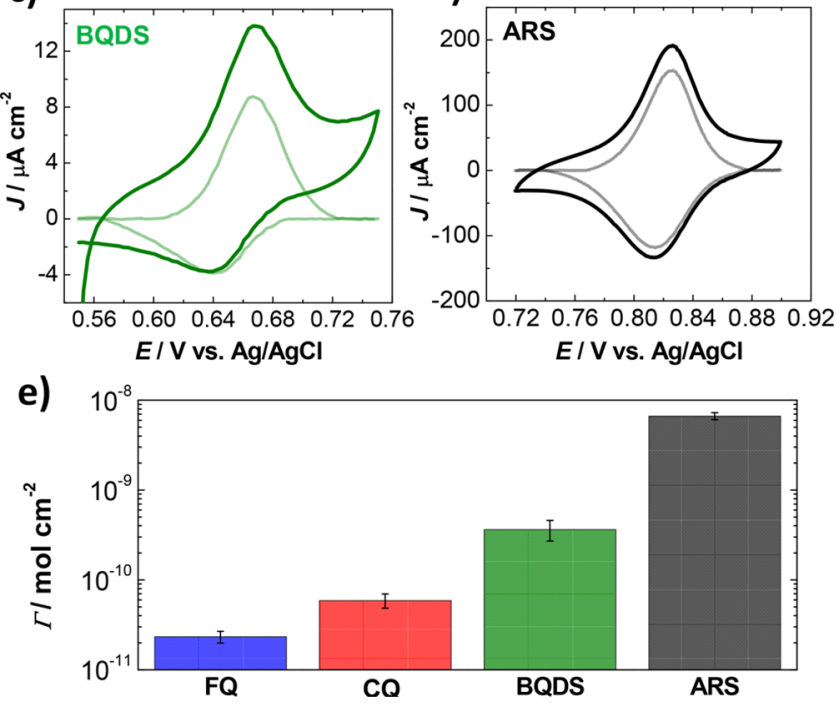

Figure 3. $\mathrm{CVs}$ recorded at $5 \mathrm{mV} \mathrm{s}^{-1}$ in $1.0 \mathrm{~mol} \mathrm{~L}^{-1} \mathrm{H}_{2} \mathrm{SO}_{4}$ on HEDGE after electroadsorption of FQ (a), CQ (b), BQDS (c), and ARS (d). Thin lines: CVs after subtraction of the capacitive current. (e) Surface excess $(\Gamma)$ of quinones on the HEDGE surface obtained from anodic peak of the first $\mathrm{CV}$; the plot shows the mean $\Gamma$ obtained from three HEDGE electrodes, and error values were obtained based on a $t$-distribution with $95 \%$ confidence interval.

capacitive current was subtracted from the original CVs, as shown in the insets of Figure $3 a-d$. Because the faradaic current is related to the quantity of adsorbed molecules (eqs S4 and S5, Supporting Information), the surface excess $(\Gamma)$ of each quinone was determined (Section 10, Supporting Information) to be $(2.3 \pm 0.3) \times 10^{-11},(5.9 \pm 1.0) \times$ $10^{-11},(3.6 \pm 0.9) \times 10^{-10}$, and $(6.7 \pm 0.6) \times 10^{-9} \mathrm{~mol} \mathrm{~cm}^{-2}$ for FQ CQ BQDS, and ARS, respectively. As shown in Figure $3 \mathrm{e}$, the amount of adsorbed species follows the ascending order: $\mathrm{FQ}<\mathrm{CQ}<\mathrm{BQDS}<\mathrm{ARS}$.

The desorption process of FQ CQ BQDS, and ARS from the HEDGE surface was also investigated. For this, successive CVs of quinones previously adsorbed onto HEDGE were recorded in clean (without quinone) $1.0 \mathrm{~mol} \mathrm{~L}^{-1} \mathrm{H}_{2} \mathrm{SO}_{4}$ electrolyte, as shown in Figure $4 \mathrm{a}-\mathrm{d}$. The desorption behavior is visualized by the plot of anodic faradaic peak current densities against the successive cycles, as shown in Figure $4 \mathrm{e}-$ h. Each quinone presents a different desorption profile, which suggests that molecular structure influences the interaction with the HEDGE surface. ARS is the only quinone that remains significantly adsorbed on the HEDGE surface after $\sim 10$ consecutive CVs. In contrast, FQ, CQ and BQDS are rapidly released from the electrode surface, which is evidenced by the pronounced decay of the anodic peak current densities over successive CV cycles. These results suggest that these species possess different adsorption energies on HEDGE. Insight into the adsorption behavior and the molecular interaction between quinone-based molecules and HEDGE is provided by molecular dynamics and quantum mechanics simulations, as shown below.

2.4. Molecular Dynamics Simulation and DFT Calculations. We used molecular dynamics simulation and DFT calculations to model the interactions of FQ CQ, BQDS, and ARS with a HEDGE surface (Section 11, Supporting Information). To simulate the HEDGE structure, we have used a melting-quenching-annealing schedule using NVT molecular dynamics with a Nosé-Hoover thermostat and Tersoff many-body potentials, which gives structures with different degrees of graphitization, defects, and orientations (Figure S10). Some $\mathrm{C}-\mathrm{C}$ bonds were broken to introduce oxygenated functional groups, such as carbonyl and hydroxyl groups, based on XPS experimental results for HEDGE. The structure and geometry were optimized by using the QuantumESPRESSO (QE) package.

As previously reported, ${ }^{53,54}$ this methodology provides accurate and optimized carbon structures with low computational cost, showing some advantages over other methodologies that employ a reverse Monte Carlo technique, which requires experimental data, or $a b$ initio molecular dynamics, which is computationally expensive. ${ }^{3}$

After the simulation and optimization of the HEDGE structure, we investigated the interaction between this structure and the oxidized forms of ARS, BQDS, CQ and FQ. Figure $5 a-d$ shows the lowest energy configurations for the fully oxidized forms of FQ CQ BQDS, and ARS on a HEDGE surface containing $\mathrm{C}=\mathrm{O}$ and $\mathrm{C}-\mathrm{O}$ groups. The zoom view can identify which atoms of the quinone molecules are close to the HEDGE surface. The HEDGE-molecule distances shorter than $5 \AA$ are highlighted in Figure $5 \mathrm{a}-\mathrm{d}$, as attractive forces between organic compounds and carbon surfaces can be significant up to this distance. ${ }^{55}$ The lowest energy configuration shows the interaction between FQ and HEDGE surface (Figure 5a) probably occurs through the carbon $(3.05 \AA)$ and nitrogen $(3.12 \AA)$ atoms from the tertiary amine group and oxygen (4.65 $\AA$ ) from the quinone functionality. For CQ (Figure $5 \mathrm{~b}$ ), the closest atoms to the carbon surface are carbon (3.49 $\AA$ ) and oxygen (3.89 and 3.91 $\AA)$ atoms from $\mathrm{C}=\mathrm{O}$ groups and nitrogen $(4.73 \AA)$ from the morpholine side group. In the case of BQDS (Figure $5 \mathrm{c}$ ), the interaction with the surface possibly occurs through oxygen $(2.77$ and $3.28 \AA)$ and sulfur $(3.63 \AA)$ atoms from sulfonic acid groups and carbon atoms $(3.66 \AA)$ from $\mathrm{C}=\mathrm{O}$ groups. Similarly, sulfonic acid and carbonyl groups of ARS is also involved in the interaction with the HEDGE surface (Figure 5d) through the sulfur (4.48 $\AA$ ), oxygen (2.89 and $3.17 \AA$ ), and carbon $(2.91 \AA)$ atoms. In addition, in all four systems studied here, oxygenated functional groups in the HEDGE structure are the closest regions to the molecules, suggesting they play 

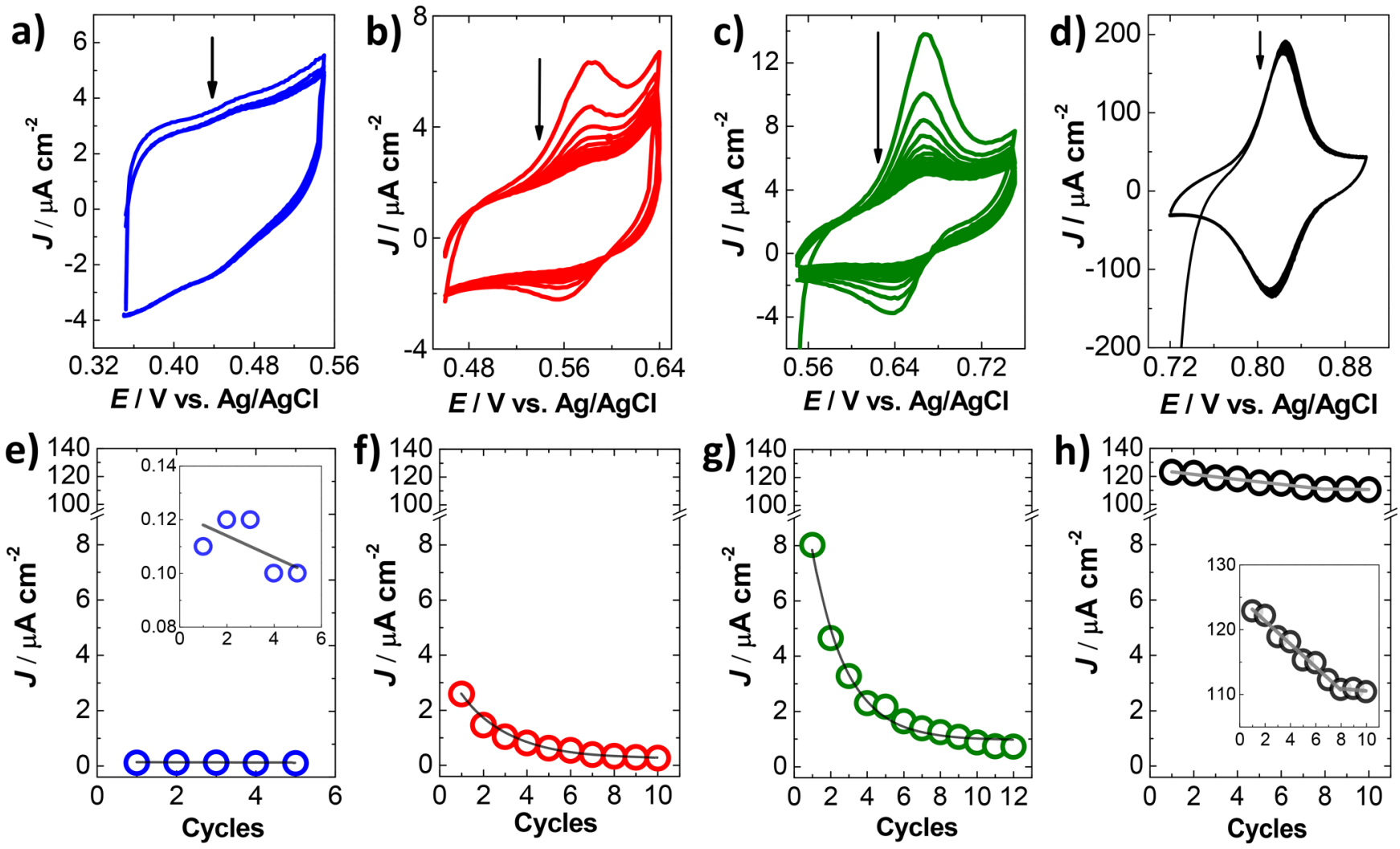

Figure 4. Successive CVs recorded at $5 \mathrm{mV} \mathrm{s}^{-1}$ in $1.0 \mathrm{~mol} \mathrm{~L}^{-1} \mathrm{H}_{2} \mathrm{SO}_{4}$ on HEDGE after electroadsorption of FQ (a), CQ (b), BQDS (c), and ARS (d); the vertical arrows indicate the decrease in the anodic peak currents. Anodic peak current density over successive CVs after electroadsorption of FQ (e), CQ (f), BQDS (g), and ARS (h). Insets show zoomed-in views of the curves.

an important role in the attraction forces with the quinones. The molecule-surface distances indicate weak short-range van der Waals forces ${ }^{56}$ are responsible for interaction, without forming chemical bonds. Otherwise, in the case of covalent bonds, molecule-surface distances would be expected to be smaller than $2 \AA^{57}$

The adsorption energy $\left(\Delta E_{\text {ads }}\right)$ of each molecule on the HEDGE surface in the lowest energy configuration was calculated by eq 1 :

$$
\Delta E_{\mathrm{ads}}=E_{\mathrm{G}+\mathrm{M}}-E_{\mathrm{G}}-E_{\mathrm{M}}
$$

where $E_{\mathrm{G}+\mathrm{M}}$ is the geometry-optimized energy of the HEDGE surface with the molecule over it, $E_{M}$ is the geometryoptimized isolated molecule inside the simulation box, and $E_{\mathrm{G}}$ is the geometry-optimized energy of the carbon surface in the simulation box. Based on these optimized configurations, $\Delta E_{\text {ads }}$ values were calculated to be $-17.98,-19.10,-22.65$, and $-30.69 \mathrm{kcal} \mathrm{mol}^{-1}$, for FQ, CQ BQDS, and ARS, respectively (Figure 5e). $\Delta E_{\text {ads }}$ values represent the total adsorption energy of the molecules and are in good agreement with the three or four points of van der Waals interactions between the quinone derivatives and HEDGE surface, as shown in Figure $5 a-d$, implying that these molecules interact with a HEDGE surface by physisorption. In addition, the calculated $\Delta E_{\text {ads }}$ corroborates the experimental data of the surface excess (Figure $3 \mathrm{e}$ ). Among the four studied quinones, ARS showed the highest value of $\Delta E_{\mathrm{ads}}$, which is consistent with the high surface excess observed experimentally. Likewise, FQ showed the lowest value of $\Delta E_{\mathrm{ads}}$, which is consistent with the lowest surface excess obtained.
The relationship between the experimental surface excess of the quinone-based molecules and the calculated $\Delta E_{\text {ads }}$ can be visualized in Figure 6. The $\Delta E_{\mathrm{ads}} / k T$ values represent the adsorption energy per molecule entity, where $k$ is Boltzmann's constant $\left(0.001987 \mathrm{kcal} \mathrm{mol}^{-1} \mathrm{~K}^{-1}\right)$ and $T$ is the absolute temperature $(300 \mathrm{~K})$. Figure 6 shows that a higher $\Delta E_{\text {ads }}$ per molecule leads to a higher quantity of adsorbed molecules observed in the electrochemical measurements. In addition, the presence of sulfonic acid groups in BQDS and ARS may contribute to a higher stabilization of these molecules on HEDGE surfaces, indicated by the higher $\Delta E_{\text {ads }}$ values per molecule entity, which lead to higher surface excesses. Also, the number of aromatic rings in the molecular structure seems to influence the adsorption process, as the anthraquinone ARS shows the highest $\Delta E_{\text {ads }}$ value per molecule entity and highest surface excess when compared to the benzoquinones $\mathrm{FQ} C \mathrm{CQ}$ and BQDS.

To distinguish the effect of edge-plane-like defects in the carbon structure and that of the oxygen-containing functional groups on quinone adsorption, we performed a computational simulation and calculations with a HEDGE structure without oxygen-containing functional groups (HEDGE-nO) using the same electronic parameters as in the previous ones (Section 12, Supporting Information). On HEDGE-nO, the preferred interaction sites of the four quinone-based molecules are the carbon atoms on the edges of the carbon structure (Figure S11). The molecules interact with the HEDGE-nO structure by the same functional groups observed with HEDGE, with the only difference being the closest atom of the functional group of FQ and ARS. The closest atoms to the HEDGE-nO surface are hydrogen from the tertiary amino group of FQ and oxygen 

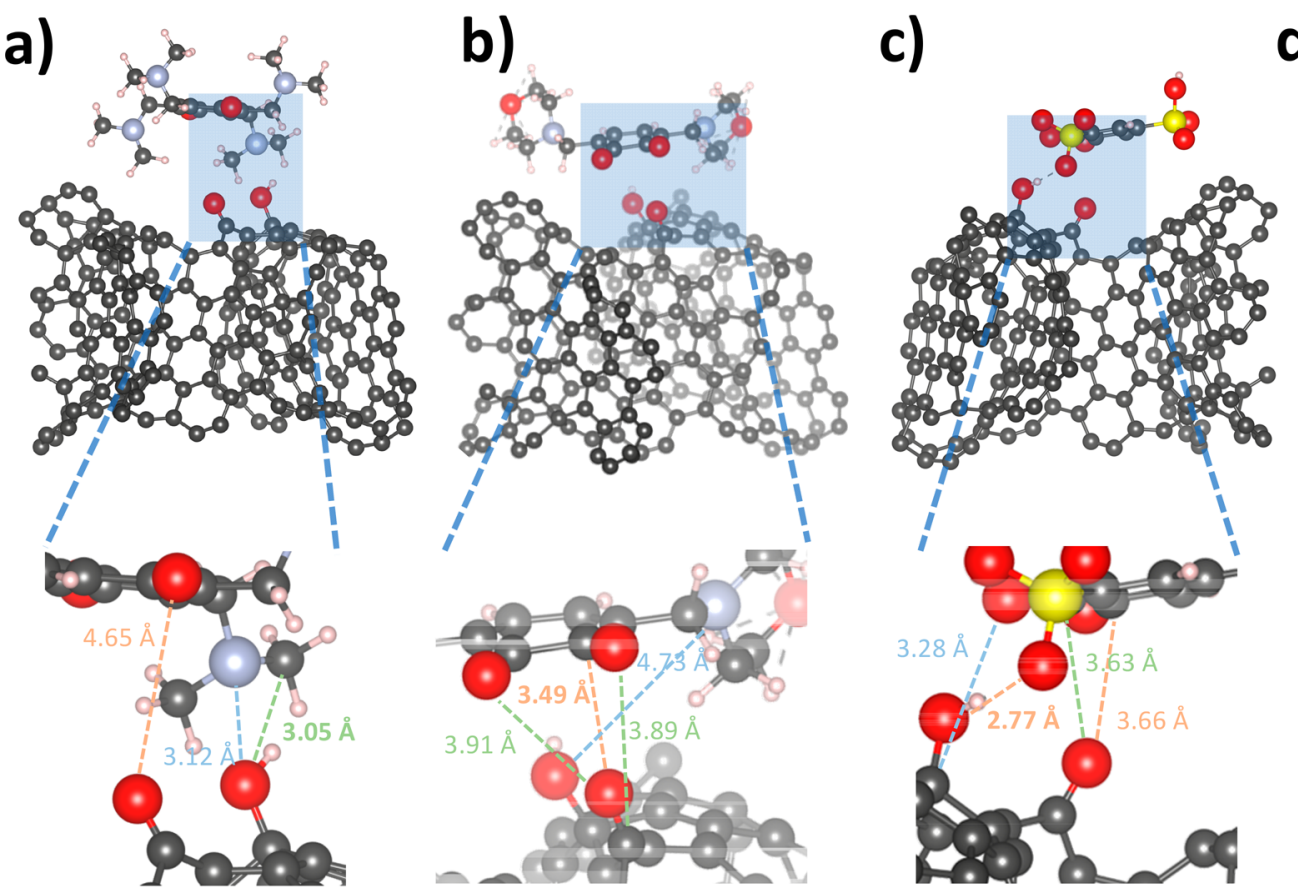

d)

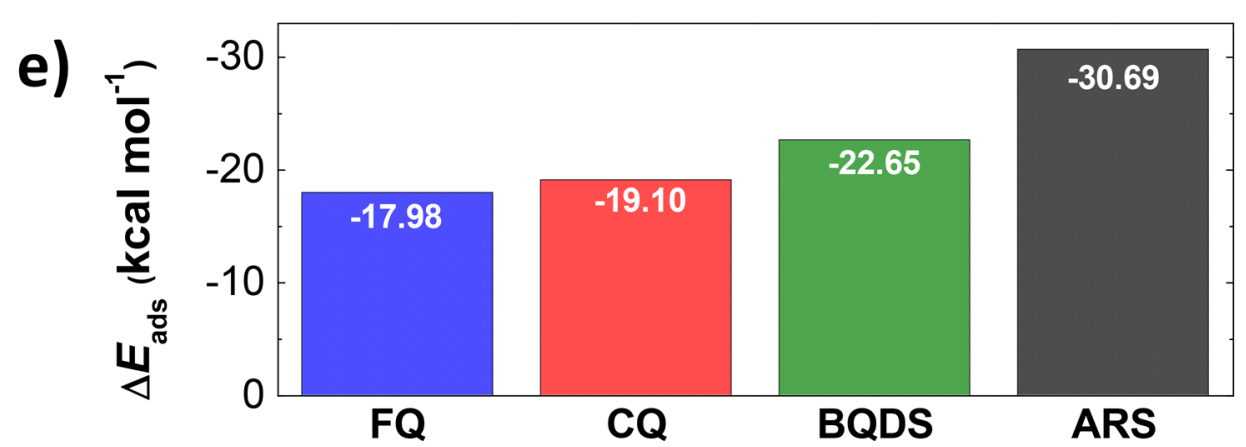

Figure 5. Lowest energy configurations of the fully oxidized form of FQ (a), CQ (b), BQDS (c), and ARS (d) on HEDGE. The arrows indicate the sites with which the quinone-based compound interacts. Gray, white, yellow, red, and blue spheres represent carbon, hydrogen, sulfur, oxygen, and nitrogen atoms, respectively. (e) $\Delta E_{\text {ads }}$ at $300 \mathrm{~K}$ of each quinone on HEDGE surface calculated by DFT.

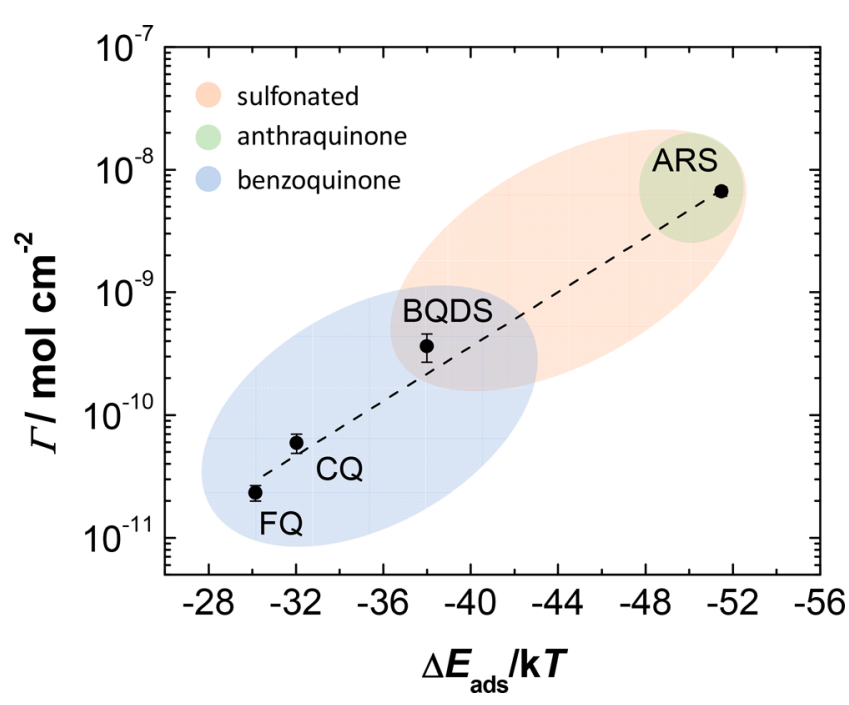

Figure 6. Surface excess vs calculated $\Delta E_{\text {ads }} / k T(T=300 \mathrm{~K})$ for each quinone on the HEDGE.

from the 9,10-quinone functionality. As observed for HEDGE, the molecule-surface distances $(2.8-3.7 \AA)$ are corresponding to the van der Waals force range, which suggest physisorption of the molecules on HEDGE-nO. The values of $\Delta E_{\text {ads }}$ of the quinone derivatives on HEDGE-nO were calculated to be $-16.22,-17.43,-34.26$, and $-29.83 \mathrm{kcal} \mathrm{mol}^{-1}$, for FQ, CQ BQDS, and ARS, respectively.

Comparing the calculated $\Delta E_{\text {ads }}$ values on HEDGE and HEDGE-nO, it is observed that the presence of oxygencontaining functional groups on the surface differentially affects its interaction with some quinone derivatives. Notably, $\Delta E_{\text {ads }}$ of BQDS is higher on HEDGE-nO than HEDGE, whereas the $\Delta E_{\text {ads }}$ of the other molecules are slightly lower on HEDGE-nO, as expected, given oxygenated functional groups present on HEDGE surface can contribute to slightly stronger attraction through dipole-dipole or dipole-induced dipole interactions. In addition, a deviation from the correlation between the experimental values of surface excess and $\Delta E_{\text {ads }}$ per molecule entity on HEDGE-nO is obtained (Figure S12). The calculated $\Delta E_{\text {ads }}$ per BQDS molecule on HEDGE-nO is higher than that calculated for ARS; however, the quantity of adsorbed BQDS on the electrode obtained by electrochemical measurements is lower than ARS. This deviation means the presence of oxygenated functional groups on the electrode surface significantly influences the experimental results of surface excess. In summary, the agreement of the calculated 
$\Delta E_{\text {ads }}$ with experimental adsorption results implies that the oxygen functional groups, $\mathrm{C}=\mathrm{O}$ and $\mathrm{C}-\mathrm{O}$, on a HEDGE surface play an important role in the interaction with quinone derivatives.

\section{CONCLUSIONS}

Electron transfer kinetics of the different quinone derivatives is strongly affected by the structure of carbon-based electrode. The electrochemical reversibility of all studied quinone-based molecules was improved by using a HEDGE, which presents oxygenated functional groups, such as $\mathrm{C}-\mathrm{O}$ and $\mathrm{C}=\mathrm{O}$, and a higher density of edge-like defects compared to GC and HOPG. The electron transfer kinetics is controlled by species adsorbed onto HEDGE. The quantity of adsorbed molecules varies among the quinone derivatives by more than 2 orders of magnitude, with surface excess ascending in the order FQ < $\mathrm{CQ}<\mathrm{BQDS}<$ ARS. Quantum mechanics with molecular dynamics provided atomistic insight into the quinone adsorption. The lowest energy configurations showed molecules interact with HEDGE surfaces by three or four points, with interatomic distances from 2.77 to $4.73 \AA$, and total $\Delta E_{\text {ads }}$ of $-17.98,-19.10,-22.65$, and $-30.69 \mathrm{kcal} \mathrm{mol}^{-1}$ for $\mathrm{FQ}$, CQ BQDS, and ARS, respectively, revealing a physisorption process. Adsorption appears to be driven by interactions between $\mathrm{C}=\mathrm{O}$ and $\mathrm{C}-\mathrm{O}$ functional groups on the HEDGE surface and the functional groups of quinone-based molecules. The presence of sulfonic acid side groups and the greater number of aromatic rings in the molecular structure may contribute to a higher stabilization of quinone derivatives on HEDGE, which is suggested by $\Delta E_{\text {ads }}$ and surface excess values. Therefore, this study provides a first glimpse into how carbon-based surfaces with edge-like defects and oxygenated functional groups lead to fast electron transfer kinetics and the adsorption of quinone derivatives. We suggest that this study can guide the development of high-performance carbon-based electrodes for organic electrochemical devices.

\section{ASSOCIATED CONTENT}

\section{SI Supporting Information}

The Supporting Information is available free of charge at https://pubs.acs.org/doi/10.1021/acsaem.9b02357.

Synthesis and characterization of the FQ and $C Q$; detailed experimental procedures and computational calculations (PDF)

\section{AUTHOR INFORMATION}

\section{Corresponding Authors}

Frank N. Crespilho - São Carlos Institute of Chemistry, University of São Paulo (USP), São Carlos, São Paulo 13560970, Brazil; Harvard John A. Paulson School of Engineering and Applied Sciences, Cambridge, Massachusetts 02138, United

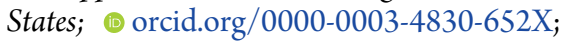

Email: frankcrespilho@iqsc.usp.br

Michael J. Aziz - Harvard John A. Paulson School of Engineering and Applied Sciences, Cambridge, Massachusetts 02138, United States; 이이. orcid.org/0000-0001-9657-9456; Email: maziz@harvard.edu

\section{Authors}

Graziela C. Sedenho - São Carlos Institute of Chemistry, University of São Paulo (USP), São Carlos, São Paulo 13560970, Brazil; Harvard John A. Paulson School of Engineering and Applied Sciences, Cambridge, Massachusetts 02138, United States; orcid.org/0000-0001-8696-5978

Diana De Porcellinis - Harvard John A. Paulson School of Engineering and Applied Sciences, Cambridge, Massachusetts 02138, United States

Yan Jing - Department of Chemistry and Chemical Biology, Harvard University, Cambridge, Massachusetts 02138, United States; 이이.org/0000-0002-5669-4609

Emily Kerr - Department of Chemistry and Chemical Biology, Harvard University, Cambridge, Massachusetts 02138, United States

Luis Martin Mejia-Mendoza - Department of Chemistry and Chemical Biology, Harvard University, Cambridge, Massachusetts 02138, United States

Álvaro Vazquez-Mayagoitia - Argonne Leadership Computing Facility, Argonne National Laboratory, Argonne, Illinois 60439, United States

Alán Aspuru-Guzik - Department of Chemistry and Chemical Biology, Harvard University, Cambridge, Massachusetts 02138, United States; Department of Chemistry and Department of Computer Science, University of Toronto, Toronto, Ontario M5S 3H6, Canada; 이이.org/0000-0002-8277-4434

Roy G. Gordon - Department of Chemistry and Chemical Biology, Harvard University, Cambridge, Massachusetts 02138, United States; 10 orcid.org/0000-0001-5980-268X

Complete contact information is available at:

https://pubs.acs.org/10.1021/acsaem.9b02357

\section{Notes}

The authors declare no competing financial interest.

\section{ACKNOWLEDGMENTS}

Research at Harvard was supported by U.S. DOE Award DEAC05-76RL01830 through PNNL Subcontract 428977. G.C.S. and F.N.C. gratefully acknowledge the financial support provided by the FAPESP (Projects 2015/22973-6, 2017/ 15714-0, and 2013/14262-7) and CNPq (Project 203299/ 2017-5). L.M.M.-M. thanks the support of FONCICYT under Contracts FONCICYT/51/2017 and FONCICYT/56/2018. A.V.-M. acknowledges the Leadership Computing Facility at Argonne National Laboratory for the computing resources for this work. We thank Dr. Liuchuan Tong for bringing to our attention the reversibility of the high-potential redox transition of ARS when adsorbed. A.A.-G. is thankful to Anders G. Fröseth for his support.

\section{REFERENCES}

(1) Soloveichik, G. L. Flow Batteries: Current Status and Trends. Chem. Rev. 2015, 115 (20), 11533-11558.

(2) Alotto, P.; Guarnieri, M.; Moro, F. Redox Flow Batteries for the Storage of Renewable Energy: A Review. Renewable Sustainable Energy Rev. 2014, 29, 325-335.

(3) Barnhart, C. J.; Benson, S. M. On the Importance of Reducing the Energetic and Material Demands of Electrical Energy Storage. Energy Environ. Sci. 2013, 6 (4), 1083-1092.

(4) Milton, R. D.; Hickey, D. P.; Abdellaoui, S.; Lim, K.; Wu, F.; Tan, B.; Minteer, S. D. Rational Design of Quinones for High Power Density Biofuel Cells. Chem. Sci. 2015, 6, 4867-4875.

(5) Giroud, F.; Milton, R. D.; Tan, B.; Minteer, S. D. Simplifying Enzymatic Biofuel Cells: Immobilized Naphthoquinone as a Biocathodic Orientational Moiety and Bioanodic Electron Mediator. ACS Catal. 2015, 5, 1240-1244.

(6) Gross, A. J.; Chen, X.; Giroud, F.; Abreu, C.; Le Goff, A.; Holzinger, M.; Cosnier, S. A High Power Buckypaper Biofuel Cell: 
Exploiting 1,10- Phenanthroline-5,6-Dione with FAD-Dependent Dehydrogenase for Catalytically-Powerful Glucose Oxidation. ACS Catal. 2017, 7, 4408-4416.

(7) Gerhardt, M. R.; Tong, L.; Gómez-Bombarelli, R.; Chen, Q.; Marshak, M. P.; Galvin, C. J.; Aspuru-Guzik, A.; Gordon, R. G.; Aziz, M. J. Anthraquinone Derivatives in Aqueous Flow Batteries. Adv. Energy Mater. 2017, 7 (8), 1601488.

(8) Yang, Z.; Tong, L.; Tabor, D. P.; Beh, E. S.; Goulet, M. A.; De Porcellinis, D.; Aspuru-Guzik, A.; Gordon, R. G.; Aziz, M. J. Alkaline Benzoquinone Aqueous Flow Battery for Large-Scale Storage of Electrical Energy. Adv. Energy Mater. 2018, 8 (8), 1-9.

(9) Lin, K.; Chen, Q.; Gerhardt, M. R.; Tong, L.; Kim, S. B.; Eisenach, L.; Valle, A. W.; Hardee, D.; Gordon, R. G.; Aziz, M. J.; Marshak, M. P. Alkaline Quinone Flow Battery. Science 2015, 349 (6255), 1529-1532.

(10) Huskinson, B.; Marshak, M. P.; Suh, C.; Er, S.; Gerhardt, M. R.; Galvin, C. J.; Chen, X.; Aspuru-Guzik, A.; Gordon, R. G.; Aziz, M. J. A Metal-Free Organic-Inorganic Aqueous Flow Battery. Nature 2014, 505 (7482), 195-198.

(11) Bailey, S. I.; Ritchie, I. M. A Cyclic Voltammetric Study of the Aqueous Electrochemistry of Some Quinones. Electrochim. Acta 1985, 30 (1), 3-12.

(12) Song, Y.; Buettner, G. R. Thermodynamic and Kinetic Considerations for the Reaction of Semiquinone Radicals to Form Superoxide and Hydrogen Peroxide. Free Radical Biol. Med. 2010, 49 (6), 919-962.

(13) Winsberg, J.; Hagemann, T.; Janoschka, T.; Hager, M. D.; Schubert, U. S. Redox-Flow Batteries: From Metals to Organic Redox-Active Materials. Angew. Chem., Int. Ed. 2017, 56 (3), 686711.

(14) Suresh, S.; Ulaganathan, M.; Aswathy, R.; Ragupathy, P. Enhancement of Bromine Reversibility Using Chemically Modified Electrodes and Their Applications in Zinc Bromine Hybrid Redox Flow Battery. ChemElectroChem 2018, 5, 3411-3418.

(15) Chen, Q.; Gerhardt, M. R.; Hartle, L.; Aziz, M. J. A QuinoneBromide Flow Battery with $1 \mathrm{~W} / \mathrm{Cm} 2$ Power Density. J. Electrochem. Soc. 2016, 163 (1), A5010-A5013.

(16) Yang, B.; Hoober-Burkhardt, L.; Wang, F.; Surya Prakash, G. K.; Narayanan, S. R. An Inexpensive Aqueous Flow Battery for LargeScale Electrical Energy Storage Based on Water-Soluble Organic Redox Couples. J. Electrochem. Soc. 2014, 161 (9), A1371-A1380.

(17) Lin, K.; Gómez-Bombarelli, R.; Beh, E. S.; Tong, L.; Chen, Q.; Valle, A.; Aspuru-Guzik, A.; Aziz, M. J.; Gordon, R. G. A Redox-Flow Battery with an Alloxazine-Based Organic Electrolyte. Nat. Energy 2016, 1 (9), 1-8.

(18) Kwabi, D. G.; Lin, K.; Ji, Y.; Kerr, E. F.; Goulet, M.-A.; De Porcellinis, D.; Tabor, D. P.; Pollack, D. A.; Aspuru-Guzik, A.; Gordon, R. G.; Aziz, M. J. Alkaline Quinone Flow Battery with Long Lifetime at $\mathrm{pH}$ 12. Joule 2018, 2, 1894-1906.

(19) Pezeshki, A. M.; Clement, J. T.; Veith, G. M.; Zawodzinski, T. A.; Mench, M. M. High Performance Electrodes in Vanadium Redox Flow Batteries through Oxygen-Enriched Thermal Activation. J. Power Sources 2015, 294, 333-338.

(20) He, Z.; Jiang, Y.; Li, Y.; Zhu, J.; Zhou, H.; Meng, W.; Wang, L.; Dai, L. Carbon Layer-Exfoliated, Wettability-Enhanced, SO3HFunctionalized Carbon Paper: A Superior Positive Electrode for Vanadium Redox Flow Battery. Carbon 2018, 127, 297-304.

(21) Liu, T.; Wei, X.; Nie, Z.; Sprenkle, V.; Wang, W. A Total Organic Aqueous Redox Flow Battery Employing a Low Cost and Sustainable Methyl Viologen Anolyte and 4-HO-TEMPO Catholyte. Adv. Energy Mater. 2016, 6 (3), 1501449.

(22) Wei, L.; Zhao, T. S.; Zhao, G.; An, L.; Zeng, L. A HighPerformance Carbon Nanoparticle-Decorated Graphite Felt Electrode for Vanadium Redox Flow Batteries. Appl. Energy 2016, 176, 74-79.

(23) Kabtamu, D. M.; Chen, J.-Y.; Chang, Y.-C.; Wang, C.-H. WaterActivated Graphite Felt as a High-Performance Electrode for Vanadium Redox Flow Batteries. J. Power Sources 2017, 341, 270279.
(24) González, Z.; Flox, C.; Blanco, C.; Granda, M.; Morante, J. R.; Menéndez, R.; Santamaría, R. Outstanding Electrochemical Performance of a Graphene-Modified Graphite Felt for Vanadium Redox Flow Battery Application. J. Power Sources 2017, 338, 155-162.

(25) Mustafa, I.; Lopez, I.; Younes, H.; Susantyoko, R. A.; Al-Rub, R. A.; Almheiri, S. Fabrication of Freestanding Sheets of Multiwalled Carbon Nanotubes (Buckypapers) for Vanadium Redox Flow Batteries and Effects of Fabrication Variables on Electrochemical Performance. Electrochim. Acta 2017, 230, 222-235.

(26) Park, M.; Jeon, I. Y.; Ryu, J.; Baek, J. B.; Cho, J. Exploration of the Effective Location of Surface Oxygen Defects in Graphene-Based Electrocatalysts for All-Vanadium Redox-Flow Batteries. Adv. Energy Mater. 2015, 5 (5), 1-7.

(27) Pour, N.; Kwabi, D. G.; Carney, T.; Darling, R. M.; Perry, M. L.; Shao-Horn, Y. Influence of Edge-and Basal-Plane Sites on the Vanadium Redox Kinetics for Flow Batteries. J. Phys. Chem. C 2015, 119 (10), 5311-5318.

(28) Taylor, S. M.; Pătru, A.; Perego, D.; Fabbri, E.; Schmidt, T. J. Influence of Carbon Material Properties on Activity and Stability of the Negative Electrode in Vanadium Redox Flow Batteries: A Model Electrode Study. ACS Appl. Energy Mater. 2018, 1, 1166-1174.

(29) Park, M.; Beh, E. S.; Fell, E. M.; Jing, Y.; Kerr, E. F.; Porcellinis, D.; Goulet, M.-A.; Ryu, J.; Wong, A. A.; Gordon, R. G.; Cho, J.; Aziz, M. J. A High-Voltage Aqueous Zinc-Organic Hybrid Flow Battery. Adv. Energy Mater. 2019, 9, 1900694.

(30) Imai, K.; Nakanishi, I.; Ohno, A.; Kurihara, M.; Miyata, N.; Matsumoto, K. I.; Nakamura, A.; Fukuhara, K. Synthesis and RadicalScavenging Activity of a Dimethyl Catechin Analogue. Bioorg. Med. Chem. Lett. 2014, 24 (11), 2582-2584.

(31) Er, S.; Suh, C.; Marshak, M. P.; Aspuru-Guzik, A. Computational Design of Molecules for an All-Quinone Redox Flow Battery. Chem. Sci. 2015, 6 (2), 885-893.

(32) Carretero-González, J.; Castillo-Martínez, E.; Armand, M. Highly Water-Soluble Three-Redox State Organic Dyes as Bifunctional Analytes. Energy Environ. Sci. 2016, 9 (11), 3521-3530.

(33) Tong, L.; Jing, Y.; Gordon, R. G.; Aziz, M. J. Symmetric AllQuinone Aqueous Battery. ACS Appl. Energy Mater. 2019, 2, 40164021.

(34) Kabir, H.; Gyan, I. O.; Francis Cheng, I. Electrochemical Modification of a Pyrolytic Graphite Sheet for Improved Negative Electrode Performance in the Vanadium Redox Flow Battery. J. Power Sources 2017, 342, 31-37.

(35) Zhong, J. H.; Zhang, J.; Jin, X.; Liu, J. Y.; Li, Q.; Li, M. H.; Cai, W.; Wu, D. Y.; Zhan, D.; Ren, B. Quantitative Correlation between Defect Density and Heterogeneous Electron Transfer Rate of Single Layer Graphene. J. Am. Chem. Soc. 2014, 136 (47), 16609-16617.

(36) Yuan, W.; Zhou, Y.; Li, Y.; Li, C.; Peng, H.; Zhang, J.; Liu, Z.; Dai, L.; Shi, G. The Edge- and Basal-Plane-Specific Electrochemistry of a Single-Layer Graphene Sheet. Sci. Rep. 2013, 3 (Cvd), 1-7.

(37) Moore, R. R.; Banks, C. E.; Compton, R. G. Basal Plane Pyrolytic Graphite Modified Electrodes: Comparison of Carbon Nanotubes and Graphite Powder as Electrocatalysts. Anal. Chem. 2004, 76 (10), 2677-2682.

(38) Tao, L.; Wang, Q.; Dou, S.; Ma, Z.; Huo, J.; Wang, S.; Dai, L. Edge-Rich and Dopant-Free Graphene as a Highly Efficient MetalFree Electrocatalyst for the Oxygen Reduction Reaction. Chem. Commun. 2016, 52 (13), 2764-2767.

(39) Beh, E. S.; De Porcellinis, D.; Gracia, R. L.; Xia, K. T.; Gordon, R. G.; Aziz, M. J. A Neutral PH Aqueous Organic-Organometallic Redox Flow Battery with Extremely High Capacity Retention. ACS Energy Lett. 2017, 2 (3), 639-644.

(40) Harris, P. J. F. Fullerene-Related Structure of Commercial Glassy Carbons. Philos. Mag. 2004, 84 (29), 3159-3167.

(41) Bukalov, S. S.; Zubavichus, Y. V.; Leites, L. A.; Sorokin, A. I.; Kotosonov, A. S. Structural Changes in Industrial Glassy Carbon As a Function of Heat Treatment Temperature According To Raman Spectroscopy and X-Ray. Nanosyst. Phys., Chem. Math. 2014, 5 (1), 186-191. 
(42) Banks, C. E.; Davies, T. J.; Wildgoose, G. G.; Compton, R. G. Electrocatalysis at Graphite and Carbon Nanotube Modified Electrodes: Edge-Plane Sites and Tube Ends Are the Reactive Sites. Chem. Commun. 2005, No. 7, 829-841.

(43) Macedo, L. J. A.; Lima, F. C. D. A.; Amorim, R. G.; Freitas, R. O.; Yadav, A.; Iost, R. M.; Balasubramanian, K.; Crespilho, F. N. Interplay of Non-Uniform Charge Distribution on the Electrochemical Modification of Graphene. Nanoscale 2018, 10, 1504815057.

(44) McCreery, R. L. Advanced Carbon Electrode Materials for Molecular Electrochemistry. Chem. Rev. 2008, 108 (7), 2646-2687.

(45) Sites, E. P.; Neumann, C. C. M.; Batchelor-McAuley, C.; Downing, C.; Compton, R. G. Anthraquinone Monosulfonate Adsorbed on Graphite Shows Two Very Different Rates of Electron Transfer: Surface Heterogeneity Due to Basal. Chem. - Eur. J. 2011, $17,7320-7326$.

(46) Maldonado, S.; Morin, S.; Stevenson, K. J. Electrochemical Oxidation of Catecholamines and Catechols at Carbon Nanotube Electrodes. Analyst 2006, 131, 262-267.

(47) Dai, H. P.; Shiu, K. K. Voltammetric Behavior of Alizarin Red S Adsorbed on Electrochemically Pretreated Glassy Carbon Electrodes. Electrochim. Acta 1998, 43 (18), 2709-2715.

(48) Schumacher, S.; Nagel, T.; Scheller, F. W.; Gajovic-Eichelmann, N. Alizarin Red $S$ as an Electrochemical Indicator for Saccharide Recognition. Electrochim. Acta 2011, 56 (19), 6607-6611.

(49) Pimenta, M. A.; Dresselhaus, G.; Dresselhaus, M. S.; Cançado, L. G.; Jorio, A.; Saito, R. Studying Disorder in Graphite-Based Systems by Raman Spectroscopy. Phys. Chem. Chem. Phys. 2007, 9 (11), 1276-1290.

(50) Ferrari, A. C.; Robertson, J. Interpretation of Raman Spectra of Disordered and Amorphous Carbon. Phys. Rev. B: Condens. Matter Mater. Phys. 2000, 61 (20), 14095-14107.

(51) Kozlowski, C.; Sherwood, P. M. A. X-Ray PhotoelectronSpectroscopic Studies of Carbon-Fibre Surfaces. J. Chem. Soc., Faraday Trans. 1 1985, 81, 2745-2756.

(52) Zhao, L.; Wu, G.; Cai, Z.; Zhao, T.; Yao, Q.; Chen, X. Ultrasensitive Non-Enzymatic Glucose Sensing at near-Neutral PH Values via Anodic Stripping Voltammetry Using a Glassy Carbon Electrode Modified with Pt3Pd Nanoparticles and Reduced Graphene Oxide. Microchim. Acta 2015, 182 (11-12), 2055-2060.

(53) Mejía-Mendoza, L. M.; Valdez-Gonzalez, M.; Muñiz, J.; Santiago, U.; Cuentas-Gallegos, A. K.; Robles, M. A Theoretical Approach to the Nanoporous Phase Diagram of Carbon. Carbon 2017, 120, 233-243.

(54) Deringer, V. L.; Merlet, C.; Hu, Y.; Lee, T. H.; Kattirtzi, J. A.; Pecher, O.; Csányi, G.; Elliott, S. R.; Grey, C. P. Towards an Atomistic Understanding of Disordered Carbon Electrode Materials. Chem. Commun. 2018, 54 (47), 5988-5991.

(55) Ortmann, F.; Schmidt, W. G.; Bechstedt, F. Attracted by LongRange Electron Correlation: Adenine on Graphite. Phys. Rev. Lett. 2005, 95, 186101.

(56) Ashino, M.; Schwarz, A.; Behnke, T.; Wiesendanger, R. AtomicResolution Dynamic Force Microscopy and Spectroscopy of a SingleWalled Carbon Nanotube: Characterization of Interatomic van Der Waals Forces. Phys. Rev. Lett. 2004, 93, 136101.

(57) Allen, F. H.; Watson, D. G.; Brammer, L.; Orpen, A. G.; Taylor, R. Typical Interatomic Distances: Organic Compounds. Int. Tables Crystallogr. 2006, C, 790-811. 


\section{SUPPORTING INFORMATION}

\section{Effect of molecular structure of quinones and carbon electrode surfaces on the interfacial electron transfer process}

Graziela C. Sedenho ${ }^{1,2}$, Diana De Porcellinis², Yan Jing ${ }^{3}$, Emily Kerr ${ }^{3}$, Luis Martin MejiaMendoza $^{3}$, Álvaro Vázquez-Mayagoitia ${ }^{4}$, Alán Aspuru-Guzik ${ }^{3,5}$, Roy G. Gordon ${ }^{2,3}$, Frank N. Crespilho $^{1,2 *}$, Michael J. Aziz ${ }^{2 *}$

${ }^{1}$ São Carlos Institute of Chemistry, University of São Paulo (USP), São Carlos, São Paulo 13560-970, Brazil.

${ }^{2}$ Harvard John A. Paulson School of Engineering and Applied Sciences, Cambridge, Massachusetts 02138, USA.

${ }^{3}$ Department of Chemistry and Chemical Biology, Harvard University, Cambridge, Massachusetts 02138, USA.

${ }^{4}$ Argonne Leadership Computing Facility, Argonne National Laboratory, Argonne, Illinois 60439, USA.

${ }^{5}$ Department of Chemistry, Department of Computer Science, University of Toronto,Toronto, Ontario M5S 3H6, Canada.

*Corresponding authors:

Michael J. Aziz

E-mail: maziz@harvard.edu

Frank N. Crespilho

E-mail: frankcrespilho@iqsc.usp.br 


\section{Table of Contents}

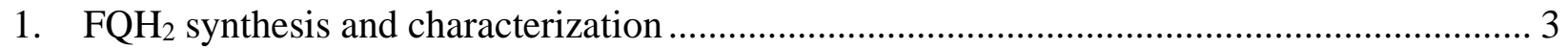

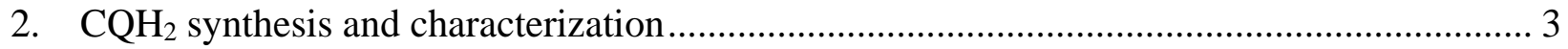

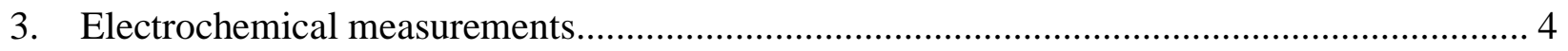

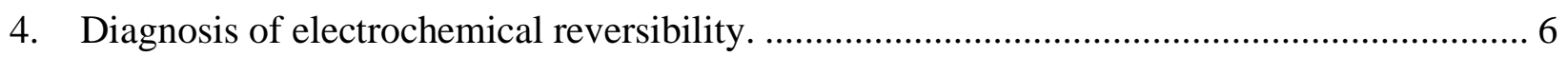

5. Dependence of peak current density on scan rate..................................................... 7

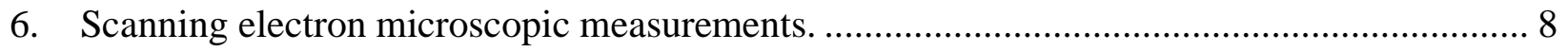

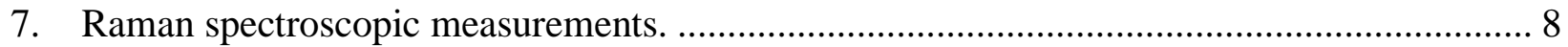

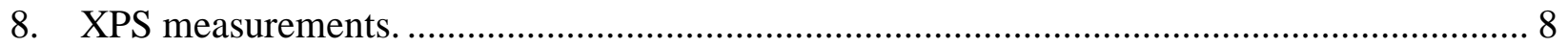

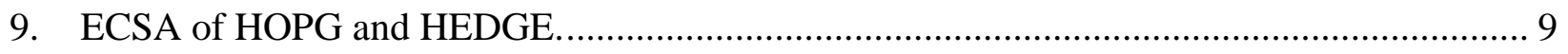

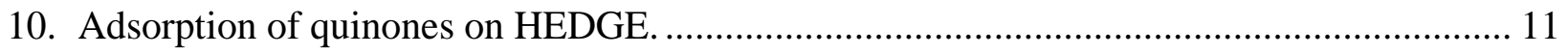

11. Molecular dynamics simulation and DFT calculations. .............................................. 13

12. HEDGE without oxygenated functional groups. ......................................................... 16

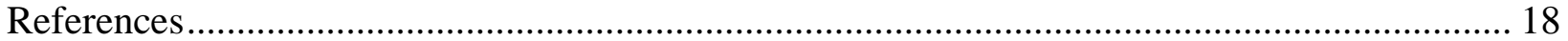


1. $\mathbf{F Q H}_{2}$ synthesis and characterization. 10 grams of 1,4-hydroquinone $(90.8 \mathrm{mmol})$ was added to a $1 \mathrm{~L}$ round bottom flask with $134 \mathrm{~mL}$ of $37 \mathrm{wt} \%$ formaldehyde solution $(1801 \mathrm{mmol})$ and $272 \mathrm{ml}$ of 40 weight percent dimethyl amine in water $(2148 \mathrm{mmol})$. The reaction was stirred at reflux for 5 hours and then vacuum filtered. The product was analyzed by ${ }^{1} \mathrm{H}$ NMR without further purification (yield: $51.2 \%)^{1}$

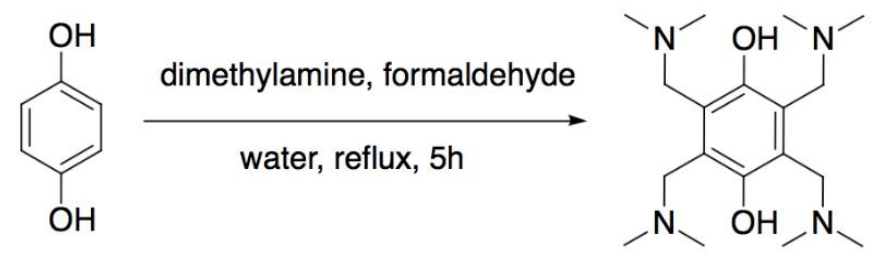

Scheme S1 Synthesis of $\mathrm{FQH}_{2}$.

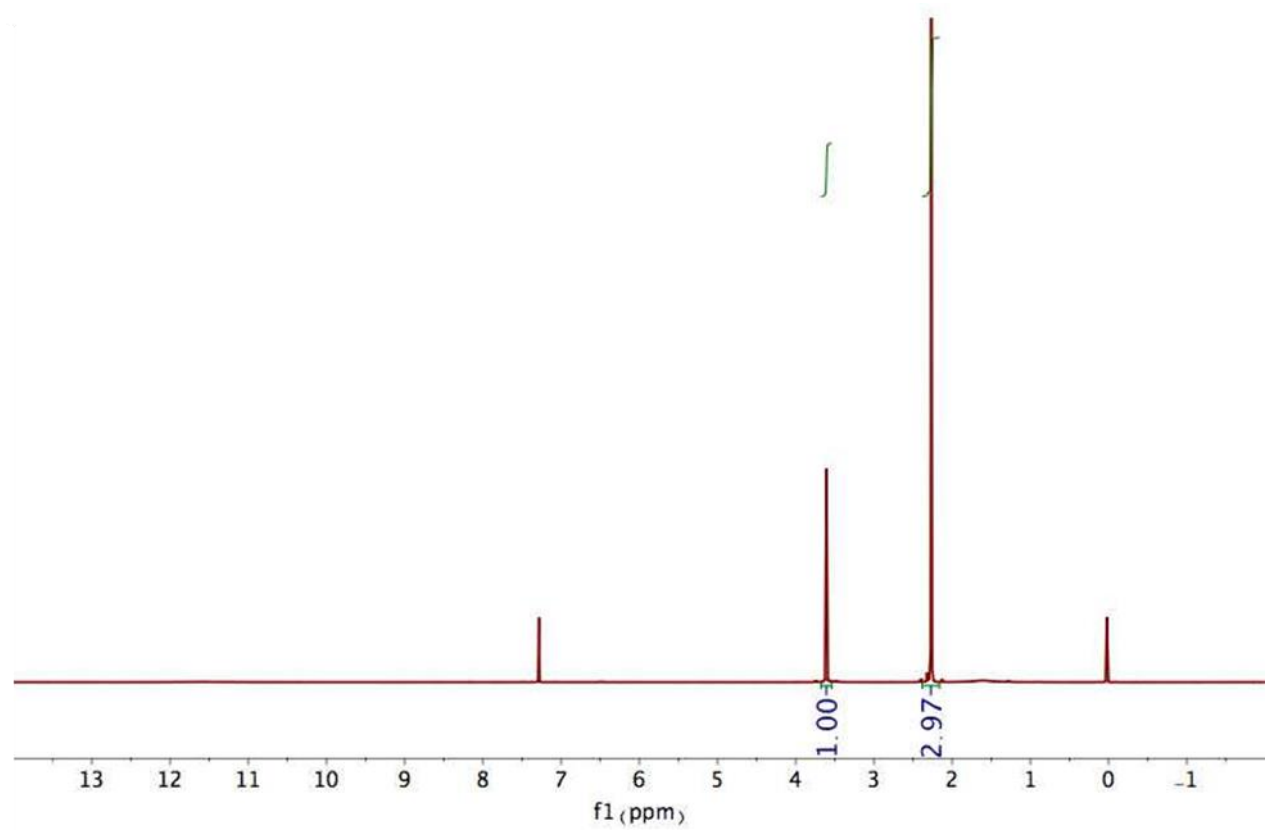

Figure S1. ${ }^{1} \mathrm{H}$ NMR spectrum of $\mathrm{FQH}_{2} .{ }^{1} \mathrm{H}$ NMR $\left(500 \mathrm{MHz}, \mathrm{CDCl}_{3}\right): \delta 3.63(\mathrm{~s}, 8 \mathrm{H}), 2.27(\mathrm{~s}$, $24 \mathrm{H})$.

2. $\mathrm{CQH}_{2}$ synthesis and characterization. A mixture of formaldehyde $37 \mathrm{wt} \%$ water solution $(16.2 \mathrm{~g}, 0.2 \mathrm{~mol})$ and morpholine $(17.4 \mathrm{~g}, 0.2 \mathrm{~mol})$ in isopropanol $(70 \mathrm{~mL})$ was added to a $250 \mathrm{~mL}$ 
round-bottom Schlenk flask, under nitrogen protection. Catechol (11.0 g, $0.1 \mathrm{~mol})$ was added and the solution was refluxed for overnight. After that, the solution was cooled down to room temperature and filtered, and washed by ethanol to give the final product (21.6 g, yield: $70 \%)$. Figure S2 shows ${ }^{1} \mathrm{H}$ NMR of the obtained product. The chemical shifts are same as the values previously reported for $\mathrm{CQH}_{2}{ }^{2}$

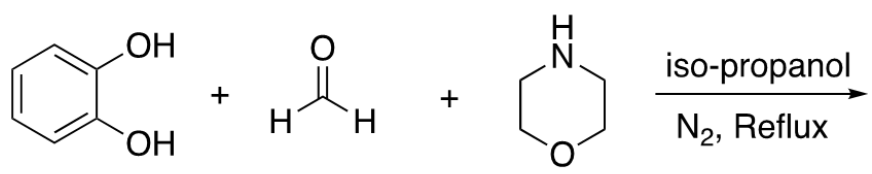<smiles>Oc1c(CN2CCOCC2)ccc(CN2CCOCC2)c1O</smiles>

Scheme S2 Synthesis of $\mathrm{CQH}_{2}$.

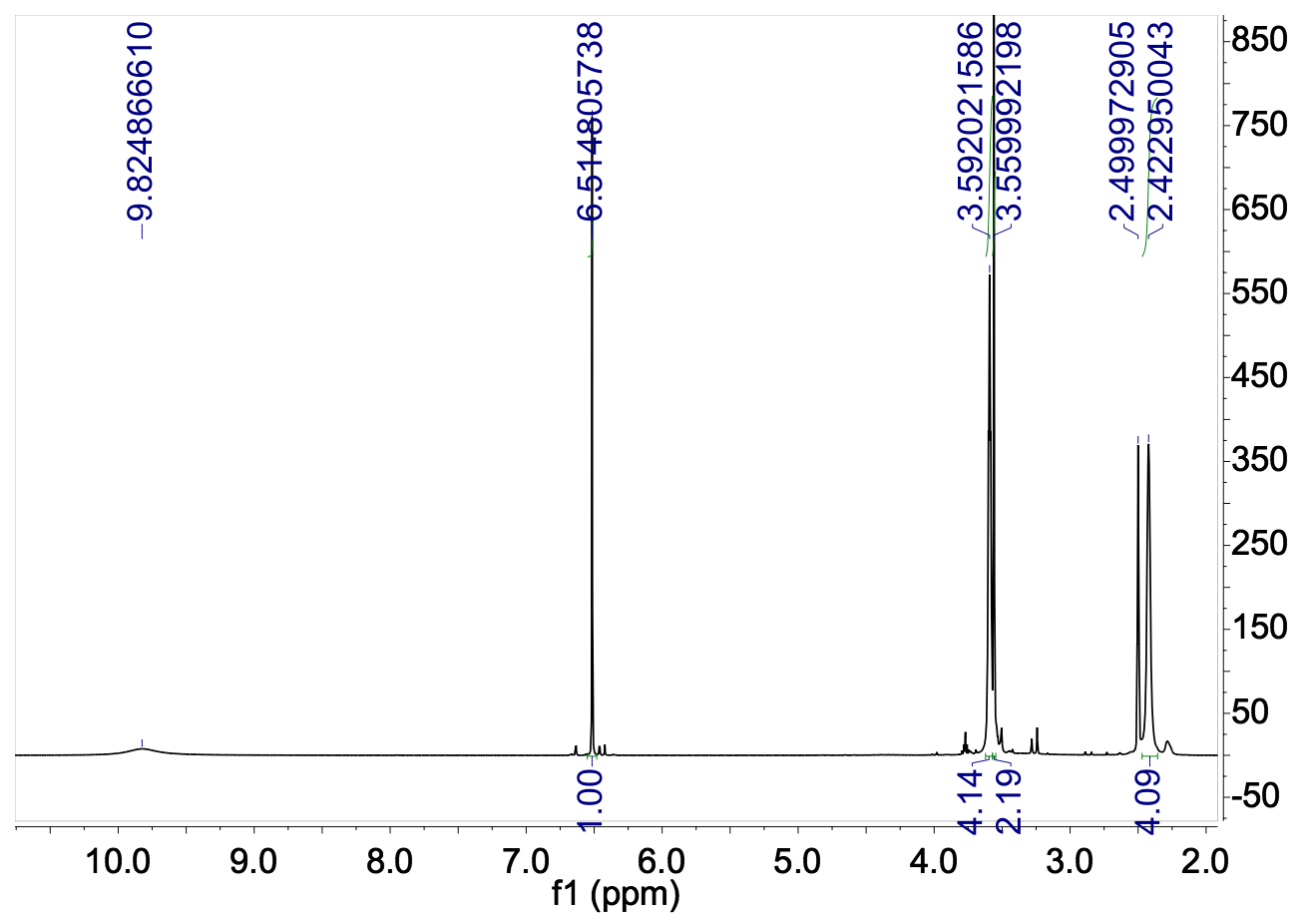

Figure S2. ${ }^{1} \mathrm{H} \mathrm{NMR}$ of $\mathrm{CQH}_{2}$ in DMSO-d6.

3. Electrochemical measurements. All electrochemical measurements were conducted on a Gamry Reference 3000 potentiostat (Gamry Instruments, United States) using Pt wire and $\mathrm{Ag} / \mathrm{AgCl}$ electrode $\left(3 \mathrm{~mol} \mathrm{~L}^{-1} \mathrm{NaCl}\right.$ filling solution) as counter and reference electrodes, 
respectively. Both electrodes were obtained from BASi ${ }^{\circledR}$ (United States). The potential of the $\mathrm{Ag} / \mathrm{AgCl}$ reference electrode is $+0.213 \mathrm{~V}$ versus the standard hydrogen electrode (SHE). Glassy carbon electrode (from BASi ${ }^{\circledR}$, United States) with area of $0.071 \mathrm{~cm}^{2}$, highly ordered pyrolytic graphite (HOPG) plate (from SPI Supplies Division of Structure Probe, Inc., United States) and high edge-density graphite electrode (HEDGE) were used as working electrodes. Before the experiments, glassy carbon electrode was cleaned by polishing in $0.3 \mu \mathrm{m}$ and $0.05 \mu \mathrm{m}$ alumina slurry, followed by sonication in deionized water for 5 minutes. HEDGE was freshly prepared before the electrochemical experiments. HEDGE was prepared by manually polishing a graphite rod with diameter of $6.1 \mathrm{~mm}$ on abrasive sheet 413Q $240\left(3 \mathrm{M}^{\mathrm{TM}}\right.$ Wetordry ${ }^{\mathrm{TM}}$, United States) at an inclination of approximately $45^{\circ}$. After the polishing, the electrode surface was washed with deionized water to remove the unattached particles. This polishing process exposes the edge planes of the graphitic structure, obtaining an electrode with higher density of exposed edge planes compared to the pristine graphite. HOPG was cleaned before the measurements by the scotch tape method. The tape was pressed onto the HOPG surface and then pulled off taking the top layers of the HOPG. The area of HEDGE and HOPG electrodes were delimited by nitrocellulose resin, in order to expose only the polished face with edge planes and the basal-plane surface, respectively to the electrolyte (see Figure S3). The exposed areas of HEDGE and HOPG were $0.559 \pm 0.017 \mathrm{~cm}^{2}$ and $0.291 \mathrm{~cm}^{2}$, respectively.

All electrochemical measurements were performed at room temperature in degassed $1.0 \mathrm{~mol}$

$\mathrm{L}^{-1} \mathrm{H}_{2} \mathrm{SO}_{4}$ solution as supporting electrolyte. Sulfuric acid $\left(\mathrm{H}_{2} \mathrm{SO}_{4} ; 96 \%\right)$ was purchased from KMG Electronic Chemical, Inc. (United States), and the commercial quinones BQDS disodium salt monohydrate (97\%) and ARS sodium salt were obtained from Alfa Aesar (United States) and Sigma-Aldrich (United States), respectively. 
a)

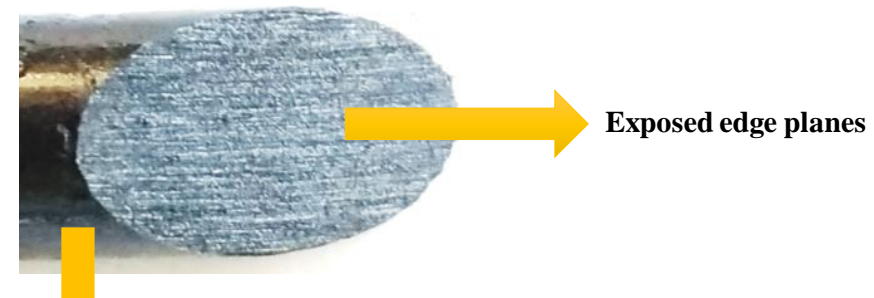

The electrode area is delimited by an insulator layer (nitrocellulose resin)

b)

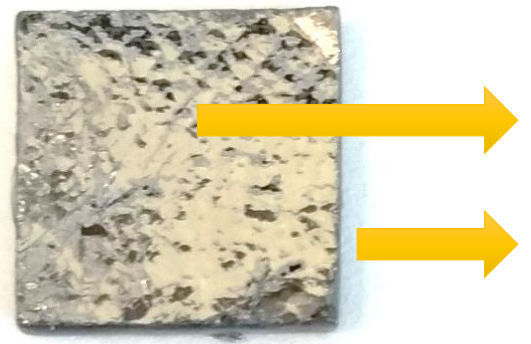

Exposed basal planes

Side faces are isolated by an insulator layer (nitrocellulose resin)

Figure S3. (a) HEDGE (geometric area $=0.559 \pm 0.017 \mathrm{~cm}^{2}$ ) and (b) HOPG (geometric area $=0.291 \mathrm{~cm}^{2}$ ) electrodes. The area of both electrodes was delimited by nitrocellulose resin, exposing only the edge plane or basal plane faces.

4. Diagnosis of electrochemical reversibility. To investigate the electrochemical reversibility of redox reactions by cyclic voltammetry, the difference between the anodic and cathodic peak potentials, or peak-to-peak separation $\left(\Delta E_{\mathrm{p}}\right)$ was used. Assuming ideal Nernstian behavior, the equilibrium electrode potential obeys the Nernst equation, and we ignore the influence of electron transfer kinetics at the electrode/electrolyte interface. For a reversible system involving freely diffusing redox species, $\Delta E_{\mathrm{p}}$ is given by Equation $\mathrm{S} 1$ :

$$
\Delta E_{\mathrm{p}}=2.22 \mathrm{R} T / n \mathrm{~F} \quad(\text { Equation } \mathrm{S} 1)
$$

where, $\mathrm{R}$ is the gas constant, $T$ is the absolute temperature, $n$ is the number of electrons involved in the reaction, and $\mathrm{F}$ is the Faraday constant. ${ }^{3}$ According to that, $\Delta E_{\mathrm{p}}$ for a reversible two-electron redox reaction is approximately $30 \mathrm{mV}$ at $25{ }^{\circ} \mathrm{C}$. Higher values suggest a quasi-reversible or irreversible electron transfer reaction, whereas smaller values of $\Delta E_{\mathrm{p}}$ indicate electron transfer may occur by surface-adsorbed species. ${ }^{3}$ 


\section{Dependence of peak current density on scan rate.}
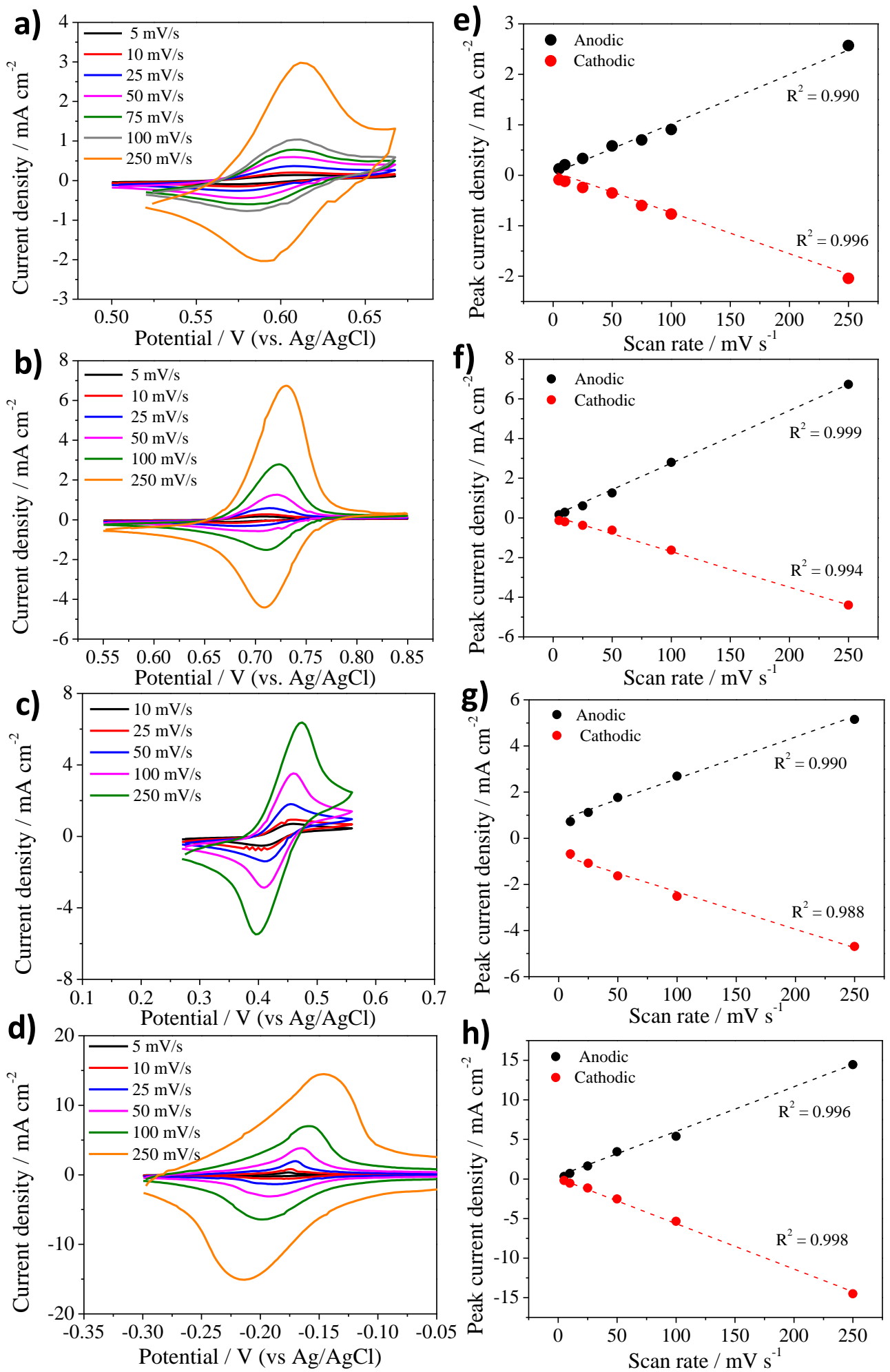

Figure S4. CVs (third cycle) of HEDGE in $1.0 \mathrm{~mol} \mathrm{~L}^{-1} \mathrm{H}_{2} \mathrm{SO}_{4}$ containing (a) $1.0 \mathrm{mmol} \mathrm{L}^{-1} \mathrm{CQ}$, (b) $1.0 \mathrm{mmol} \mathrm{L}^{-1} \mathrm{BQDS}$, (c) $10.0 \mathrm{mmol} \mathrm{L}^{-1} \mathrm{FQ}$, and (d) $1.0 \mathrm{mmol} \mathrm{L}^{-1} \mathrm{ARS}$ at different scan rates. Dependence of peak current density on scan rate for (e) CQ, (f) BQDS, (g) FQ and (h) ARS. 
6. Scanning electron microscopic measurements. The morphology of HEDGE and HOPG electrodes was investigated by Scanning Electron Microscopes (Zeiss Ultra55). The field emitted is $10 \mathrm{kV}$, which gives a resolution of around $10 \mu \mathrm{m}$.

7. Raman spectroscopic measurements. A Horiba Multiline Raman Spectrometer (model LabRam Evolution) with a 50x lens was used to investigate the near-to-surface structure of the HOPG, HEDGE and GC. The measurements were carried out with a $633 \mathrm{~nm}$ excitation laser, grating of 600 line/mm and a laser power of $20 \mathrm{~mW}$. First order Raman spectra were recorded in the range $1000-2000 \mathrm{~cm}^{-1}$. After data acquisition, the baselines of Raman spectra were corrected, and Lorentzian function was used to fit the peaks. Each spectrum was then normalized by the intensity of the highest peaks in order to enable the spectra comparison.

Raman spectrum of GC in Figure S5 shows broad $D$ and $G$-bands centered at $1330 \mathrm{~cm}^{-1}$ and $1604 \mathrm{~cm}^{-1}$. The intensity ratio, $I_{D} / I_{G}>1$ indicates nano-sized disordered $\mathrm{sp}^{2}$ carbon. ${ }^{4}$



Figure S5. Raman spectrum of GC obtained with $633 \mathrm{~nm}$ excitation laser.

8. XPS measurements. For identifying the surface chemistry of the carbon electrodes, a Thermo Scientific K-Alpha X-ray photoelectron spectrometer was used. A monochromatic Al Ka X-ray $(\mathrm{h} v=1486.6 \mathrm{eV})$ radiation was used as excitation source. The operating pressure in the ultra-high 
vacuum chamber during the analyses was $8 \times 10^{-8}$ mbar. The XPS survey spectra were recorded at pass energy of $200.0 \mathrm{eV}$ with a $1.00 \mathrm{eV}$ per step. The high-resolution spectra were recorded at pass energy of $50.0 \mathrm{eV}$ with a $0.100 \mathrm{eV}$ per step. In all measurements the spot size was $40 \mu \mathrm{m}$. Curve fitting of the high-resolution XPS spectra was performed following a Shirley-type background subtraction and the spectra were deconvoluted using Voigtian type functions, with combinations of Gaussian (70\%) and Lorentzian (30\%).

Figure S6 shows the high-resolution XPS spectrum of HEDGE in C 1s region. The spectrum was deconvoluted in four peaks, which can be assigned to: i) $\mathrm{C}=\mathrm{C}(284.5 \mathrm{eV})$; ii) $\mathrm{C}-\mathrm{C}$ or $\mathrm{C}-\mathrm{H}(285.1$ $\mathrm{eV})$; iii) $\mathrm{C}=\mathrm{O}$ (aromatic), $\mathrm{C}-\mathrm{O}-\mathrm{H}$ and/or $\mathrm{C}-\mathrm{O}-\mathrm{C}(287.0 \mathrm{eV})$; and iv) $\pi-\pi^{*}$ shake-up (290.5 eV), according to literature. ${ }^{5}$ On basis of the area of deconvoluted peaks, the percentage of each carbon peak was found: $69.3 \%$ for $\mathrm{C}=\mathrm{C} ; 21.6 \%$ for $\mathrm{C}-\mathrm{C}$ or $\mathrm{C}-\mathrm{H} ; 3.6 \%$ for $\mathrm{C}=\mathrm{O}$ (aromatic), $\mathrm{C}-\mathrm{O}-\mathrm{H}$ and/or C-O-C; and $5.5 \%$ for $\pi-\pi^{*}$ shake-up.

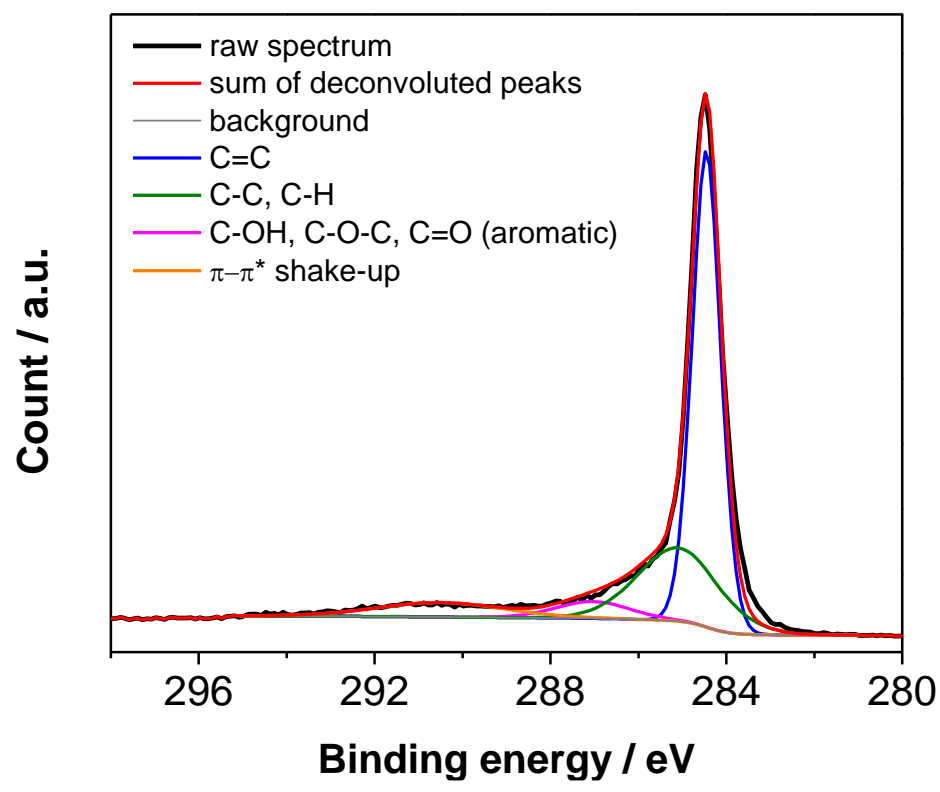

Figure S6. High-resolution spectrum of HEDGE in C 1s region.

9. ECSA of HOPG and HEDGE. The ECSA of the carbon electrodes were investigated by analysis of the double-layer capacitance, based on the method described in the literature. ${ }^{6}$ For this, 
we recorded CVs in $1.0 \mathrm{~mol} \mathrm{~L}^{-1} \mathrm{H}_{2} \mathrm{SO}_{4}$ supporting electrolyte at various scan rates from 5 to $100 \mathrm{mV} \mathrm{s}^{-1}$ in the non-faradic potential region of $0.20 \mathrm{~V}$ to $0.30 \mathrm{~V}$ as displayed in the Figures S7a and S7b. Usually, the qualitatively larger CV indicates the higher electrical double layer capacitance $\left(C_{\mathrm{dl}}\right)$ of the electrode and it is a reliable indicator of higher ECSA. The $C_{\mathrm{dl}}$ of the electrodes was calculated by plotting the difference between the anodic $\left(j_{\mathrm{a}}\right)$ and cathodic $\left(j_{\mathrm{c}}\right)$ capacitive current densities $\left(\Delta j=j_{\mathrm{a}}-j_{\mathrm{c}}\right)$ at $0.25 \mathrm{~V}(\mathrm{vs} \mathrm{Ag} / \mathrm{AgCl})$ against the scan rates (see Figures S7c and S7d). The slope of this plot was divided by 2 to obtain double layer capacitance of the electrode, according to the Equation S2.

$$
C_{\mathrm{dl}}=\frac{1}{2} \frac{\partial\left(j_{a}-j_{c}\right)}{\partial(\text { scan rate })} \quad(\text { Equation S2) }
$$

Thus, $C_{\mathrm{dl}}$ of HOPG and HEDGE were calculated to be $5.31 \mu \mathrm{F} \mathrm{cm}^{-2}$ and $169.55 \times 10^{-5} \mu \mathrm{F} \mathrm{cm}^{-2}$, respectively.

For the estimation of ECSA, a specific capacitance $\left(C_{\mathrm{s}}\right)$ value of $4.3 \mu \mathrm{F} \mathrm{cm} \mathrm{cm}^{-2}$ was adopted because this is the typical $C_{\mathrm{s}}$ for a flat graphite surface. ${ }^{7}$ Thus, the ECSAs can be calculated according to the following Equation S3.

$$
\mathrm{ECSA}=\frac{C_{\mathrm{dl}}}{C_{\mathrm{s}}} \quad \text { (Equation S3) }
$$

The ECSAs of HOPG and HEDGE were $1.24 \mathrm{~cm}^{2}$ and $35.53 \mathrm{~cm}^{2}$, respectively. 

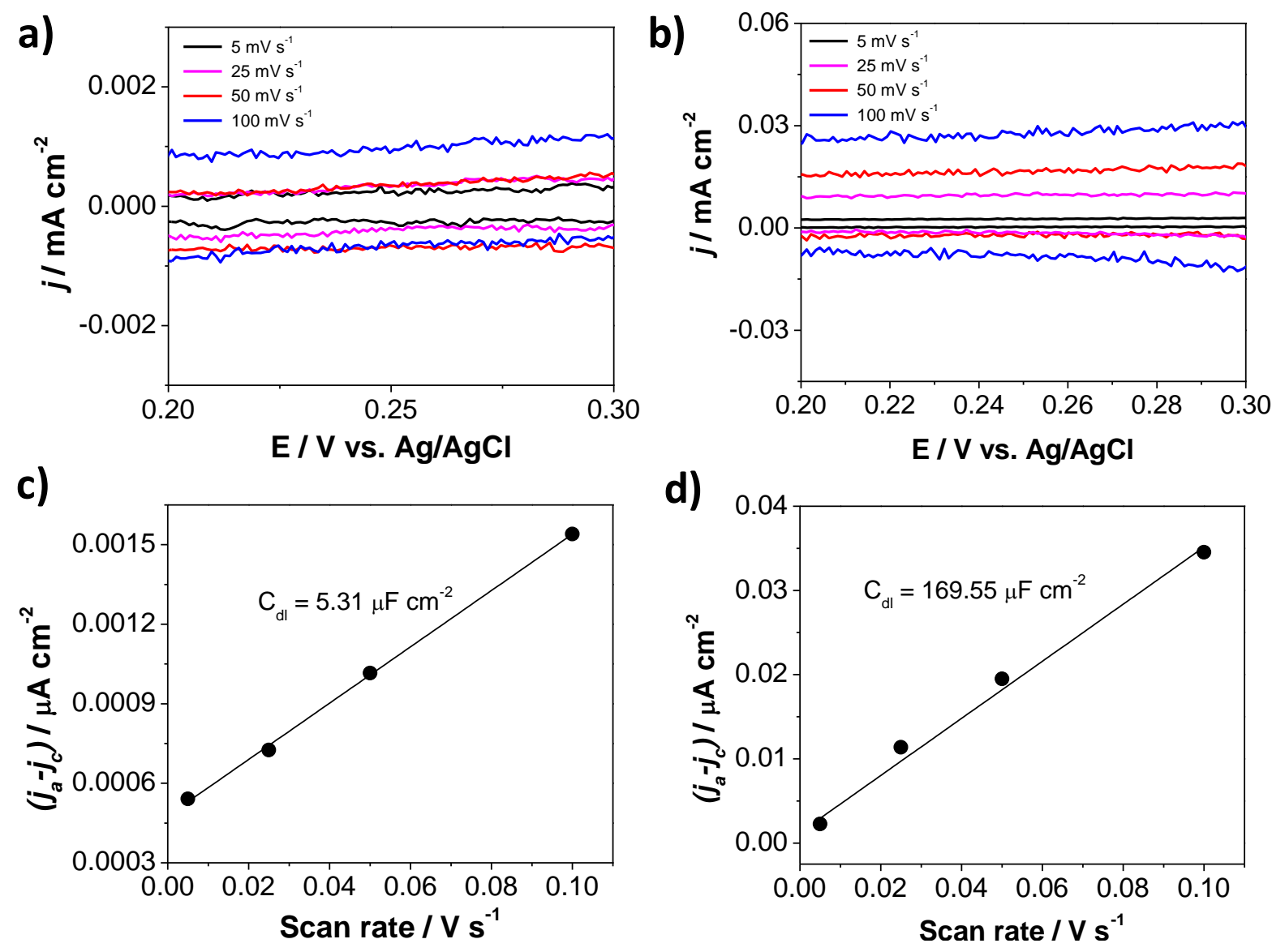

Figure S7. CVs of HOPG (a) and HEDGE (b) and difference between the anodic $\left(j_{\mathrm{a}}\right)$ and cathodic $\left(j_{c}\right)$ capacitive current densities at $0.25 \mathrm{~V}$ of HOPG (c) and HEDGE (d) plotted against scan rates fitted to linear regression enables the estimation of $C_{\mathrm{dl}}$.

10. Adsorption of quinones on HEDGE. The adsorption of quinone derivative compounds onto HEDGE surfaces was investigated by anodic stripping voltammetry. ${ }^{8}$ Freshly prepared HEDGE was exposed to a solution of $1.0 \mathrm{mmol} \mathrm{L}^{-1}$ of quinone in degassed $1.0 \mathrm{~mol} \mathrm{~L}^{-1} \mathrm{H}_{2} \mathrm{SO}_{4}$, then a potential of approximately $50 \mathrm{mV}$ more positive than peak oxidation potential of redox species was applied for $120 \mathrm{~s}$ (the chronoamperograms are shown in Figure S8). After that, the electrode was dipped into $1.0 \mathrm{~mol} \mathrm{~L}^{-1} \mathrm{H}_{2} \mathrm{SO}_{4}$ and kept in $1.0 \mathrm{~mol} \mathrm{~L}^{-1} \mathrm{H}_{2} \mathrm{SO}_{4}$ for $30 \mathrm{~s}$ under magnetic stirring of $60 \mathrm{rpm}$ to remove the non-adsorbed species from the electrode surface. Thereafter, the amount of adsorbed species was evaluated by $\mathrm{CVs}$ in clean (without redox species) $1.0 \mathrm{~mol} \mathrm{~L}^{-1} \mathrm{H}_{2} \mathrm{SO}_{4}$. Figure S9 shows the experimental setup. The surface excess $(\Gamma)$ of each quinone derivative on HEDGE surface was calculated according Equation S4 based on anodic peak charge. 

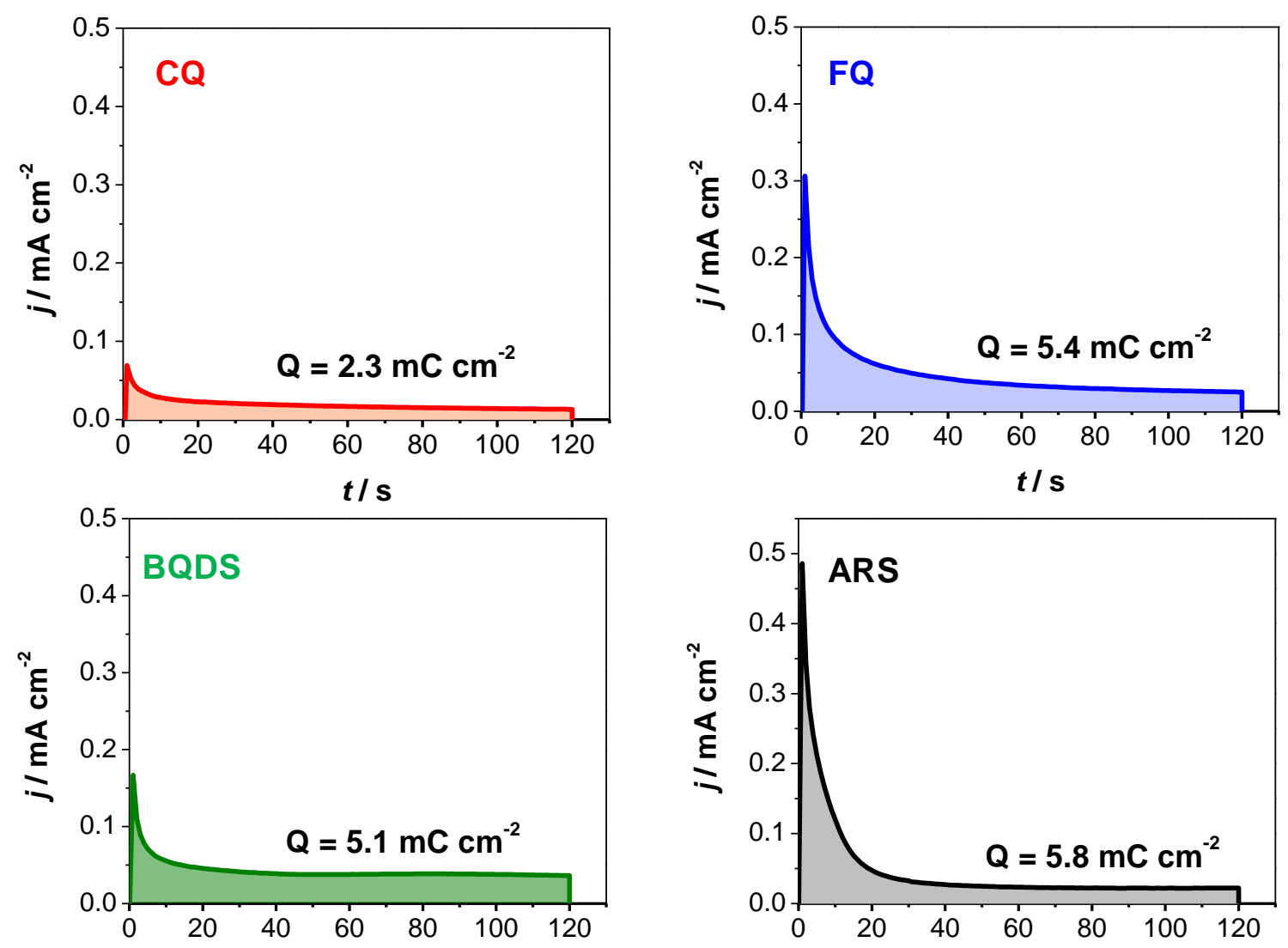

Figure S8. Chronoamperograms of the electro-adsorption in $1.0 \mathrm{~mol} \mathrm{~L}^{-1} \mathrm{H}_{2} \mathrm{SO}_{4}$ containing $1.0 \mathrm{mmol} \mathrm{L}^{-1}$ of each quinone derivative at a potential $50 \mathrm{mV}$ more positive than peak oxidation potential of each species. The backgrounds were previously subtracted.

a)

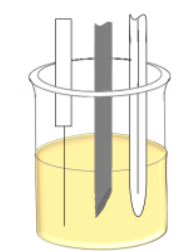

Electroadsorption at

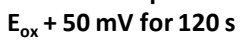
in $1.0 \mathrm{~mol} \mathrm{~L}^{-1} \mathrm{H}_{2} \mathrm{SO}_{4}$ containing $1.0 \mathrm{mmol} \mathrm{L}^{-1}$ quinone b)

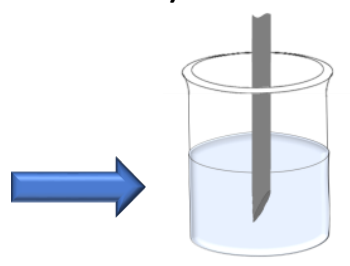

Dipping in $1.0 \mathrm{~mol} \mathrm{~L}^{-1} \mathrm{H}_{2} \mathrm{SO}_{4}$

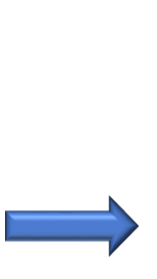

c)

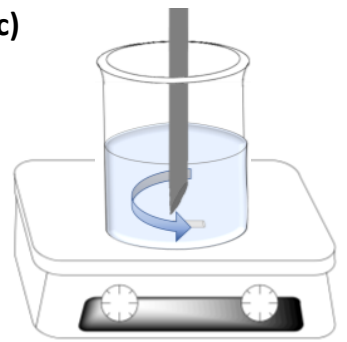

Rinsing for $30 \mathrm{~s}$ in $1.0 \mathrm{~mol} \mathrm{~L}^{-1}$ $\mathrm{H}_{2} \mathrm{SO}_{4}$ under magnetic stirring of $60 \mathrm{rpm}$

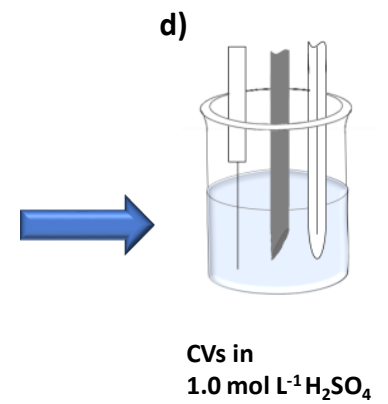

$1.0 \mathrm{~mol} \mathrm{~L}^{-1} \mathrm{H}_{2} \mathrm{SO}_{4}$

Figure S9. Adsorption quinone experimental setup. (a) Electro-adsorption in degassed $1.0 \mathrm{~mol} \mathrm{~L}^{-1}$ $\mathrm{H}_{2} \mathrm{SO}_{4}$ containing $1.0 \mathrm{mmol} \mathrm{L} \mathrm{m}^{-1}$ of quinone, for $120 \mathrm{~s}$ at a potential approximately $50 \mathrm{mV}$ more positive than peak oxidation potential of the species; (b) electrode dipping in $1.0 \mathrm{~mol} \mathrm{~L}^{-1} \mathrm{H}_{2} \mathrm{SO}_{4}$; (c) electrode rinsing in $1.0 \mathrm{~mol} \mathrm{~L}^{-1} \mathrm{H}_{2} \mathrm{SO}_{4}$ for $30 \mathrm{~s}$ under magnetic stirring of $60 \mathrm{rpm}$; and (d) electrochemical measurements in clean electrolyte. 


$$
\Gamma=\frac{Q}{n \mathrm{~F} A} \quad(\text { Equation } \mathrm{S} 4)
$$

where, $Q$ is the charge of anodic peak $(\mathrm{C}), n$ is the number of electrons involved in the reaction $(n=2), \mathrm{F}$ is Faraday constant $\left(96,485 \mathrm{C} \mathrm{mol}^{-1}\right)$ and $A$ is the geometric area of the electrode $\left(\mathrm{cm}^{2}\right)$. $Q$ can be calculated by the integration of anodic peak, according Equation S5.

$$
Q=\int \frac{j}{v} d E \quad(\text { Equation S5) }
$$

where, $j$ is the faradaic current density, $v$ is the scan rate $\left(\mathrm{V} \mathrm{s}^{-1}\right)$ and $E$ is the electrical potential. $\Gamma$ of each quinone was determined to be $(2.3 \pm 0.3) \times 10^{-11} \mathrm{~mol} \mathrm{~cm}^{-2},(5.9 \pm 1.0) \times 10^{-11} \mathrm{~mol} \mathrm{~cm}^{-2}$, $(3.6 \pm 0.9) \times 10^{-10} \mathrm{~mol} \mathrm{~cm}^{-2}$ and $(6.7 \pm 0.6) \times 10^{-9} \mathrm{~mol} \mathrm{~cm}^{-2}$ for FQ, CQ, BQDS and ARS, respectively. Assuming the molecules are orientated with their aromatic rings parallel to the electrode surface (as shown in Figure 5a-d), packing with the adsorbed molecules side by side, and the geometric area of the electrodes, it is estimated BQDS and ARS are adsorbed on HEDGE surface forming 2 layers and 46 layers, respectively. In contrast, the small quantities of FQ and CQ adsorbed are not enough to completely cover the HEDGE area forming a layer.

11. Molecular dynamics simulation and DFT calculations. To account for orientation of the carbon electrode, we built carbon structures with different degree of graphitization. To reproduce the defects of graphite exposed in its $(01 \overline{1} 0)$ orientation, we have reproduced graphite-like structures using Tersoff potential and DFT geometry optimizations, as described in the manuscript.

First, we constructed the initial supercells consisting of 200 atoms of carbon using an orthogonalized version of the hexagonal graphite lattice in order to expose the 'edge' structure. Since we are interested in the interaction of organic molecules, such as quinones, with different morphologies of carbon electrodes, we explored the adsorption energies of quinones over three types of graphite-like structures.

The construction of the graphite-like structures is the following, we first use a meltingquenching-annealing schedule using NVT molecular dynamics with Nose-Hoover thermostat and Tersoff many body potential, using a previously reported methodology. ${ }^{9}$ To account for porous carbon, we simulated in a low-density regime. We used densities from 0.50 to $0.9 \mathrm{~g} \mathrm{~cm}^{-3}$ in steps 
of $0.04 \mathrm{~g} \mathrm{~cm}^{-3}$, due to this region's high surface area carbon structure. These structures were constructed as orthogonal versions of the hexagonal lattices in order to expose the edge $\mathrm{AB}$ stacking of the graphite-like structure, that is, we want to reproduce the defects of graphite exposed in its $(01 \overline{1} 0)$ orientation.

The simulated carbon materials were produced by a linear heating from 300 to $4000 \mathrm{~K}$ in 50000 time-steps of 1 fs in duration, using NVT molecular dynamics and the Noose-Hoover thermostat, implemented in LAMMPS software. We have decided to test three different quenching rates, $0.03 \mathrm{~K} \mathrm{fs}^{-1}, 0.05 \mathrm{~K} \mathrm{fs}^{-1}$, and $0.08 \mathrm{~K} \mathrm{fs}^{-1}$ to get a total of 33 carbon samples (eleven densities and three quenching rates) with different atomic environments due to density and quenching rates. This procedure gave us nanoporous structures with different degree of graphitization and different orientations. All these structures were geometry optimized using the QuantumESPRESSO (QE) package. We have used no spin-polarized calculations and the GGA Burke-Perdew-Ernzehof exchange and correlation functional with VDW-DF dispersion correction functionals. We also used Ultrasoft-scalar-relativistic- pseudopotentials generated by the Rappe-Rabe-KaxirasJoannopoulos methodology. We have set the cut-off energy for the plane waves at $55 \mathrm{Ry}(748 \mathrm{eV})$. For the convergence of the optimizations, the force and energy thresholds in the BFGS routine were $10^{-4} \mathrm{Ha} / \mathrm{a}_{0}\left(5.14 \times 10^{-3} \mathrm{eV} \AA^{-1}\right)$ and $10^{-6} \mathrm{eV}$, respectively. The $\Gamma$-point was used for the reciprocal space integration due to the lack of symmetry in real space. In figure S10a we have schematized the process for the production of the carbon structures.

We chose three possible geometries among the carbon structures generated: graphene-like structure, exposed edge structure (HEDGE), and amorphous-like structure (see Figure S10b). The characterization of these structures was performed using radial distribution functions, as can be seen from Figure S10b; both graphene-like structure and HEDGE show graphite like peaks due to graphene sheets at 2.8 and $3.7 \AA$. The amorphous-like carbon does not show that structure, suggesting a more amorphous structure than graphene-like structure and HEDGE. The simulated amorphous structure shows $\mathrm{sp}^{2}$ and $\mathrm{sp}^{3}$ bonded carbons in a randomly dispersed network. The simulated graphene-like structure shows a higher graphitization level, where the carbon atoms are mostly $\mathrm{sp}^{2}$-bonded. This structure is mostly sheets of hexagons with some pentagons and octagons. Similarly, HEDGE structure also shows sheets of $\mathrm{sp}^{2}$ bonded carbons, however a large number of edge sites can be visualized. 
After the construction of the carbon structures, in order to produce a material more similar to the experimental conditions, some oxygen functionalities, such as carbonyl and hydroxyl functional groups, were introduced in the structure. For that, C-C bounds in HEDGE were broken, and oxygen and hydrogen atoms were added in the previously simulated HEDGE structure. Finally, the structure with oxygenated-functional groups was geometry optimized using the electronic parameters used in the previous simulations.
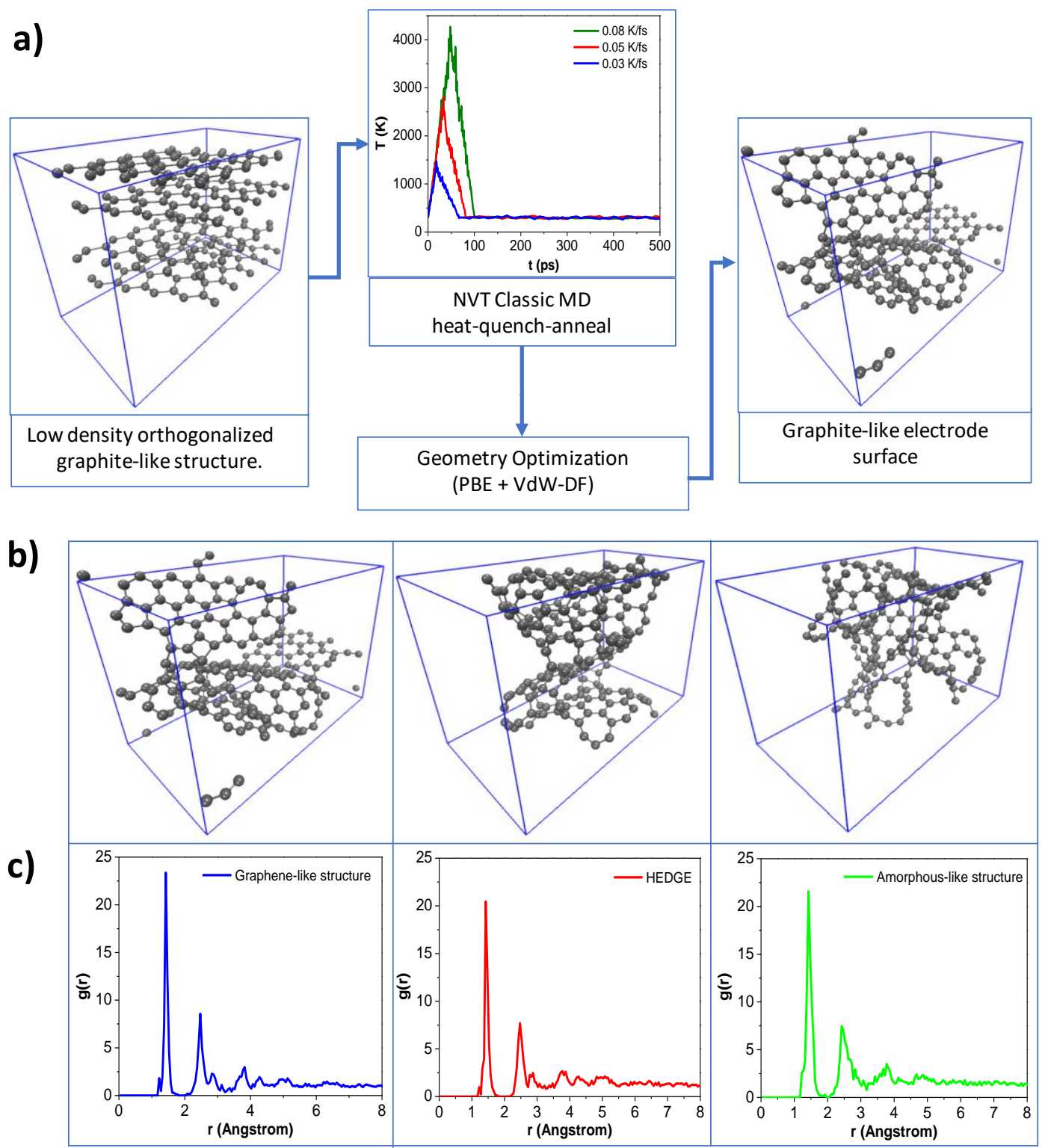

Figure S10. (a) Simulation process to generate the carbon electrode surfaces with some degree of graphitization. (b) Example of the three different degrees of graphitization using RDF. (c) radial distribution functions of graphene-like structure, HEDGE and amorphous-like structure. 
The geometries of the four quinones were constructed and optimized using the Merck Molecular Forcefield (MMFF94) in order to find the lowest energy conformer of each quinone. These conformers were geometry-optimized using QE and the same parameters were used in the optimizations of the carbon structures. The HEDGE samples, both oxidized and not oxidized, have a complex geometry in which finding suitable places for docking becomes a difficult task in terms from both a geometric, and theoretical point of view. For this reason, we have used a classical potentials based docking code, SMINA, ${ }^{10}$ to find the best docking positions of the molecules on the carbon surface. Once we find these docking positions, we proceed to calculate the adsorption energies by DFT geometry optimization calculations, Equation S6:

$$
\Delta E_{a d s}=E_{G+M}-E_{G}-E_{M} \quad \text { (Equation S6) }
$$

where $E_{G+M}$ is geometry-optimized energy of the carbon surface with the molecule docked over it, $E_{M}$ is the geometry-optimized isolated molecule inside the simulation box, and $E_{G}$ is the geometryoptimized energy of carbon surface in the simulation box. The geometry optimizations have the same simulation parameters and the same size of the simulation box. $\Delta E_{a d s}$ shows an attractive interaction between the surface and molecule, and has a magnitude on the order of $\mathrm{kcal} \mathrm{mol}^{-1}$.

12. HEDGE without oxygenated functional groups. We performed the same computational simulation and calculations with a HEDGE structure without oxygen-containing functional groups (HEDGE-nO) using the same electronic parameters used in the oxidized HEDGE structures in order to observe the behavior of the adsorption energy as oxygen functional groups are added to the carbon surface. 
a)

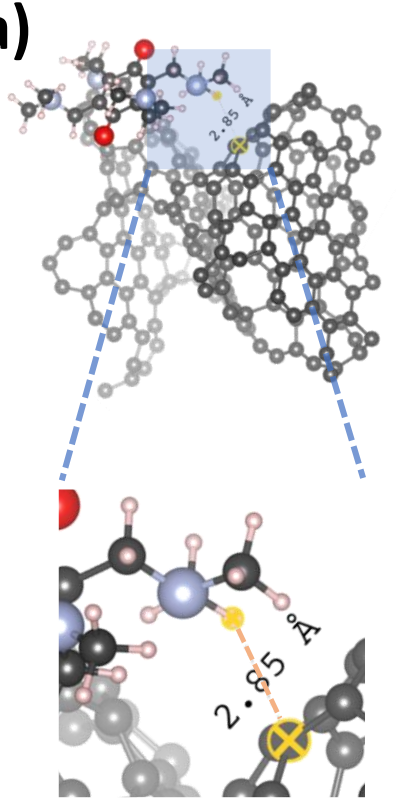

b)

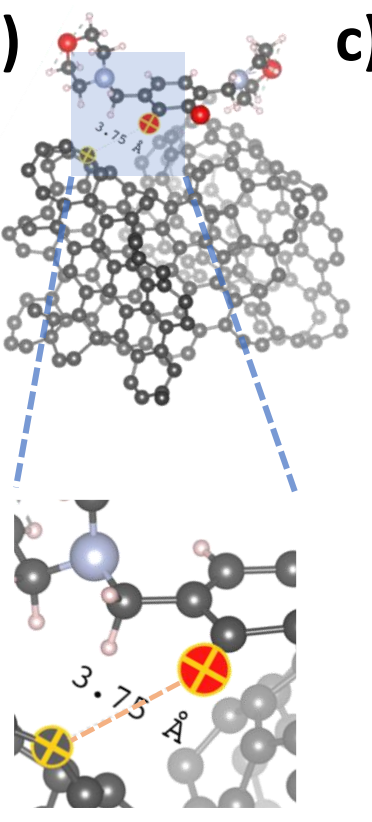

c)

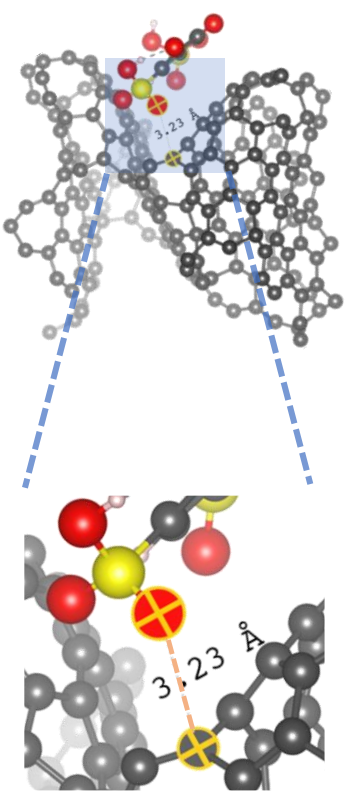

d)
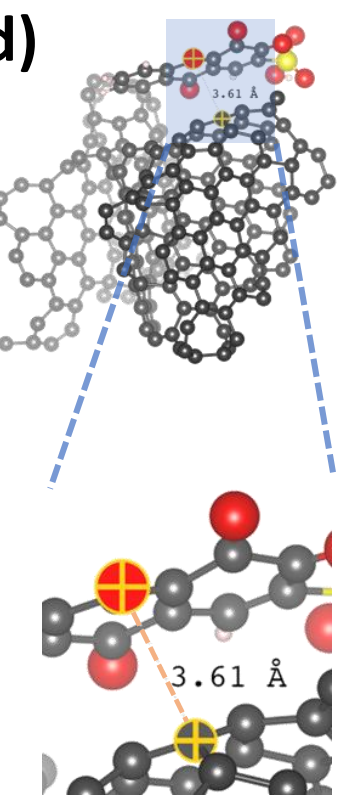

e)

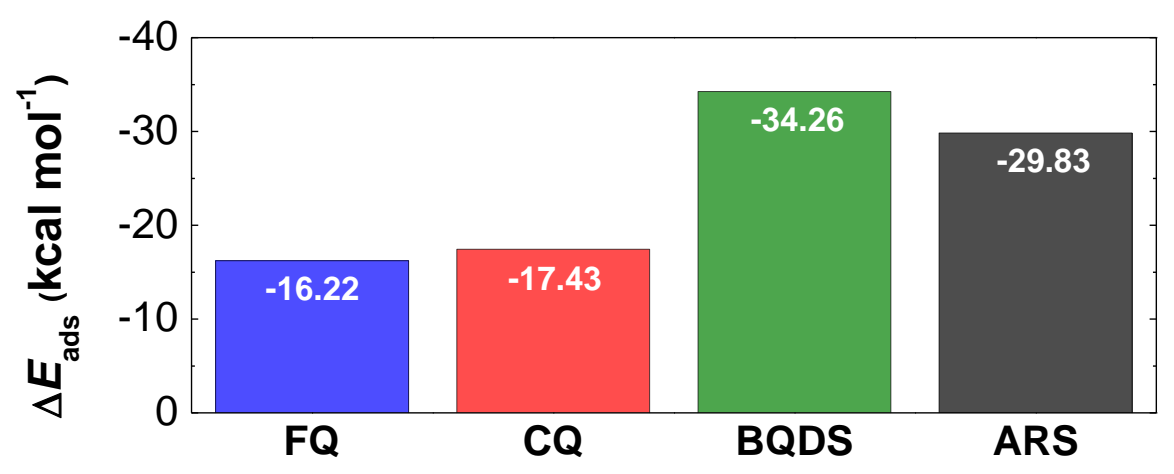

Figure S11. Lowest energy configurations of the fully-oxidized form of ARS (a), BQDS (b), CQ (c) and FQ (d) on HEDGE-nO surface. The arrows indicate edge sites with which the quinone-based compound interacts; gray, white, yellow, red and blue spheres represent carbon, hydrogen, sulfur, oxygen and nitrogen atoms, respectively. (e) Calculated $\Delta E_{\text {ads }}$ of each compound on HEDGE-nO. 


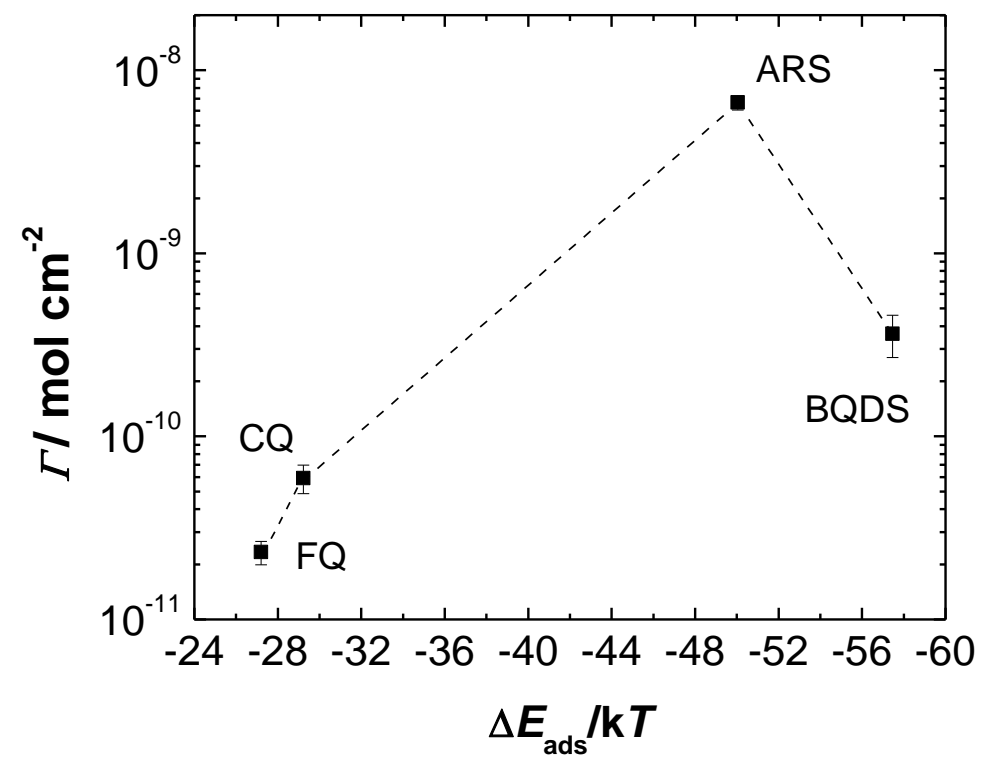

Figure S12. Surface excess vs. calculated $\Delta E_{\text {ads }} / \mathrm{k} T(T=300 \mathrm{~K})$ for each quinone on HEDGE-nO.

\section{References}

(1) Park, M.; Beh, E. S.; Fell, E. M.; Jing, Y.; Kerr, E. F.; De Porcellinis, D.; Goulet, M.-A.; Ryu, J.; Wong, A. A.; Gordon, R. G.; et al. A High-Voltage Aqueous Zinc-Organic Hybrid Flow Battery. Adv. Energy Mater. 2019, 9, 1900694.

(2) Imai, K.; Nakanishi, I.; Ohno, A.; Kurihara, M.; Miyata, N.; Matsumoto, K. I.; Nakamura, A.; Fukuhara, K. Synthesis and Radical-Scavenging Activity of a Dimethyl Catechin Analogue. Bioorganic Med. Chem. Lett. 2014, 24 (11), 2582-2584.

(3) Bard, A. J.; Faulkner, L. R. Electrochemical Methods: Fundamentals and Applications; 2001; Vol. 8.

(4) Bukalov, S. S.; Zubavichus, Y. V.; Leites, L. A.; Sorokin, A. I.; Kotosonov, A. S. Structural Changes in Industrial Glassy Carbon As a Function of Heat Treatment Temperature According To Raman Spectroscopy and X-Ray. Nanosyst. Physics, Chem. Math. 2014, 5 (1), 186-191.

(5) Blyth, R. I. R.; Buqa, H.; Netzer, F. P.; Ramsey, M. G.; Besenhard, J. O.; Golob, P.; Winter, M. XPS Studies of Graphite Electrode Materials for Lithium Ion Batteries. Appl. Surf. Sci. 2000, 167, 99106.

(6) Khalid, M.; Hassan, A.; Honorato, A. M. B.; Crespilho, F. N.; Varela, H. Nano-Flocks of Bimetallic Organic Framework for Efficient Hydrogen Evolution Electrocatalysis. Chem. Commun. 2018, 54, 11048-11051.

(7) Zou, Y.; Walton, A. S.; Kinloch, I. A.; Dryfe, R. A. W. Investigation of the Differential Capacitance of Highly Ordered Pyrolytic Graphite as a Model Material of Graphene Investigation of the Differential Capacitance of Highly Ordered Pyrolytic Graphite as a Model Material of Graphene. Langmuir 2016, 32, 11448. 
(8) Zhao, L.; Wu, G.; Cai, Z.; Zhao, T.; Yao, Q.; Chen, X. Ultrasensitive Non-Enzymatic Glucose Sensing at near-Neutral PH Values via Anodic Stripping Voltammetry Using a Glassy Carbon Electrode Modified with Pt3Pd Nanoparticles and Reduced Graphene Oxide. Microchim. Acta 2015, 182 (11-12), 2055-2060.

(9) Mejía-Mendoza, L. M.; Valdez-Gonzalez, M.; Muñiz, J.; Santiago, U.; Cuentas-Gallegos, A. K.; Robles, M. A Theoretical Approach to the Nanoporous Phase Diagram of Carbon. Carbon 2017, 120, 233-243.

(10) Koes, D. R.; Baumgartner, M. P.; Camacho, C. J. Lessons Learned in Empirical Scoring with Smina from the CSAR 2011 Benchmarking Exercise. J. Chem. Inf. Model. 2013, 53 (8), 1893-1904. 


\section{CHAPTER II - Non-corrosive, low-toxicity gel-based microbattery from organic and organometallic molecules}

Author contributions: F. N. Crespilho: conceived the project; designed the experiments; collected and analyzed the electrochemical data; wrote and revised the manuscript. G. C. Sedenho: designed the experiments, collected and analyzed the electrochemical data; wrote and revised the manuscript. D. De Porcellinis: collected and analyzed the electrochemical data; revised the manuscript. E. Kerr: synthesized, purified, and characterized BTMAP-Vi and

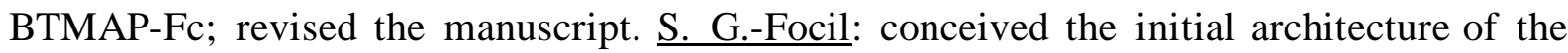
system; proposed hydrogel composition; measured the diffusion coefficients of BTMAP-Vi and BTMAP-Fc into agarose hydrogel. R. G. Gordon: supervised synthesis, purification, and characterization of BTMAP-Vi and BTMAP-Fc; revised the manuscript. M. J. Aziz: guided manuscript writing; revised the manuscript.

This second work, published in 2019 in the Journal of Materials Chemistry A, reports the first non-corrosive, non-flammable, and low-toxicity semi-solid microbattery for safe application in biomedical microdevices and system-on-chip bioelectronics. The commercially available lithium-manganese button-cells and alkaline silver-oxide disk microbatteries represent great risks for use in biomedical microdevices, as an accidental leakage can result in damage and tissue perforation, causing severe human injuries.

This safe microbattery able to meet the power needs of medical microdevices was achieved by the incorporation of organic and organic metallic compounds in agarose hydrogel, as electrolyte-supporting matrix. This design was inspired by the architecture of the respiratory chain, which uses redox-active organic and organometallic molecules and complexes embedded within the mitochondrial membrane to efficiently channel electrons. In addition, chemicallytreated flexible carbon fibers were used as electrodes, as they show features able to enhance the interfacial electron transfer kinetics of organic molecules, as shown in Chapter I. The same redox-active organic and organic metallic compounds have been already reported in large-scale electrochemical energy storage systems, and in this work were successfully applied in a miniaturized semi-solid battery for safe and cost-effective small-scale energy storage. 


\section{COMMUNICATION}

Check for updates

Cite this: J. Mater. Chem. A, 2019, 7, 24784

Received 8th August 2019

Accepted 10th October 2019

DOI: $10.1039 / c 9 t a 08685 d$

rsc.li/materials-a

\section{Non-corrosive, low-toxicity gel-based microbattery from organic and organometallic molecules $\uparrow$}

\author{
Frank N. Crespilho, (D)*ab Graziela C. Sedenho, (D) ab Diana De Porcellinis, (D) b \\ Emily Kerr, ${ }^{c}$ Sergio Granados-Focil, (D) ${ }^{d}$ Roy G. Gordon (D) ${ }^{c}$ and Michael J. Aziz (D)*b
}

Microbatteries with safe, non-corrosive electrolyte chemistries can have an immediate positive impact on modern life applications, such as ingestible electronic pills and system-on-chip bioelectronics. Here a safe, non-corrosive and non-flammable microbattery is reported. A natural agarose hydrogel is the electrolyte-supporting matrix, and organic and organometallic molecules are the redox-active species. This device can safely meet the needs of ingestible medical microdevices as a primary battery. Additionally, this redox gel system can be used as a secondary battery for on-chip electronics applications, potentially enabling safe and cost-effective small-scale energy storage.

The current and future generations of micro- and nanoelectronics include applications requiring a safe microbattery technology not available today. There is an increasing demand for microbatteries for applications such as environmental sensors, ingestible sensors (e-medical), ${ }^{1-3}$ wireless communication devices, ${ }^{4}$ autonomous microelectromechanical systems, ${ }^{5}$ the internet of things, ${ }^{6,7}$ sensor fusion, ${ }^{\mathbf{8}, 9}$ wearable devices ${ }^{7,9,10}$ and quantum computers. ${ }^{11}$ Nanomaterials-based systems-on-achip have been specifically designed to be directly attached to a battery featuring ultra-low-power output, e.g. operation at near-threshold voltages of $0.6 \mathrm{~V}$ with a few microamperes of current. $^{6}$ Due to the challenges of miniaturizing energy storage technologies, microchips typically use power supplied off-chip,

\footnotetext{
${ }^{a}$ São Carlos Institute of Chemistry, University of São Paulo (USP), Av. Trabalhador São-carlense, 400, São Carlos, São Paulo 13560-970, Brazil. E-mail: frankcrespilho@usp.br

${ }^{b}$ Harvard School of Engineering and Applied Sciences, 29 Oxford Street, Cambridge, Massachusetts 02138, USA.E-mail: maziz@harvard.edu

${ }^{c}$ Department of Chemistry and Chemical Biology, Harvard University, 12 Oxford Street, Cambridge, Massachusetts 02138, USA

${ }^{d}$ Gustaf Carlson School of Chemistry and Biochemistry, Clark University, Worcester, Massachusetts 01610-1477, USA

$\dagger$ Electronic supplementary information (ESI) available: Synthesis of BTMAP-Vi and BTMAP-Fc, cyclic voltammetry, hydrogel preparation and cost, microbattery assembly and measurements, and capability of the microbattery to hold its charge. See DOI: 10.1039/c9ta08685d
}

limiting their autonomy, or use microbatteries with corrosive electrolytes, restricting their range of application..$^{\mathbf{1 - 4 , 1 2}}$ Despite the fast-paced advances in microelectronics miniaturization ${ }^{3,6}$ and integration, ${ }^{6}$ there has been relatively slow progress in the miniaturization of power sources.

Here we report the development of a microbattery based on redox-gel active components that are non-corrosive, low-toxicity and non-flammable in contact with air or water. The gel is composed entirely of Earth-abundant elements and is safe to use in medical devices. We report the ability of organic redox active molecules to be incorporated into the hydrogel to form a redox-active gel (Fig. 1a) that acts as a stable, non-corrosive electrolyte at $\mathrm{pH} 7.0$ in the body environment. This system can help to resolve corrosion and safety concerns of microbattery chemistries currently available in the market, such as lithium ion ${ }^{1,3}$ and silver-oxide. ${ }^{3}$

As illustrated in Fig. 1b the gel-based microbattery is composed of four parts: hydrogel-based negative side (gel-N), hydrogel-based positive side (gel-P), two flexible carbon fiber (FCF) microelectrodes, and a separator. Both gel-N and gel-P are composed of agarose, $\mathrm{KCl}$, water, and a redox molecule. Bis(3trimethylammonio) propyl viologen tetrachloride (BTMAP-Vi) and bis((3-trimethylammonio)propyl)ferrocene (BTMAP-Fc) were used in the gel-N and gel-P, respectively. ${ }^{13}$ The redox active molecules were synthetized and purified as reported by Beh et al. ${ }^{13}$ These molecules are well suited for gel batteries because both BTMAP-Fc and BTMAP-Vi show reversible and stable cyclic voltammetry behavior on FCF electrodes in $1.0 \mathrm{M} \mathrm{KCl}$ at $\mathrm{pH} 7.0$ (Fig. 1c). Based on voltammetry, the theoretical cell voltage using these two molecules is expected to be approximately $0.75 \mathrm{~V}$ (Fig. 1c). The hydrogels are attractive due their structure and morphology, allowing diffusion of the redox active species, while maintaining predetermined shapes, as shown in Fig. 1b.

Agarose was chosen as the inert electrolyte support because it is widely available, low cost, mechanically versatile, safe for human consumption, stable at body temperature and prepared from naturally sourced polymers. One dollar's worth of agarose can be used to produce 770 batteries with $100 \mu \mathrm{L}$ of gel filling 
a)

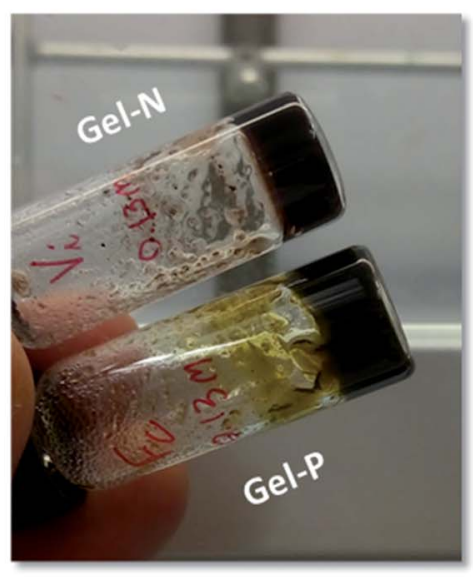

c)

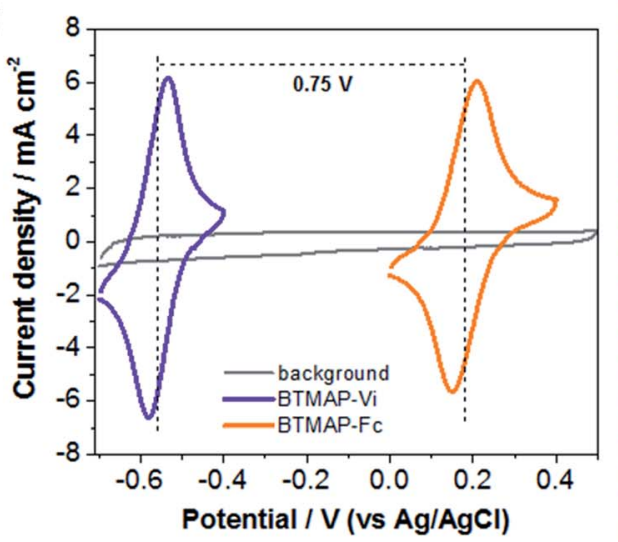

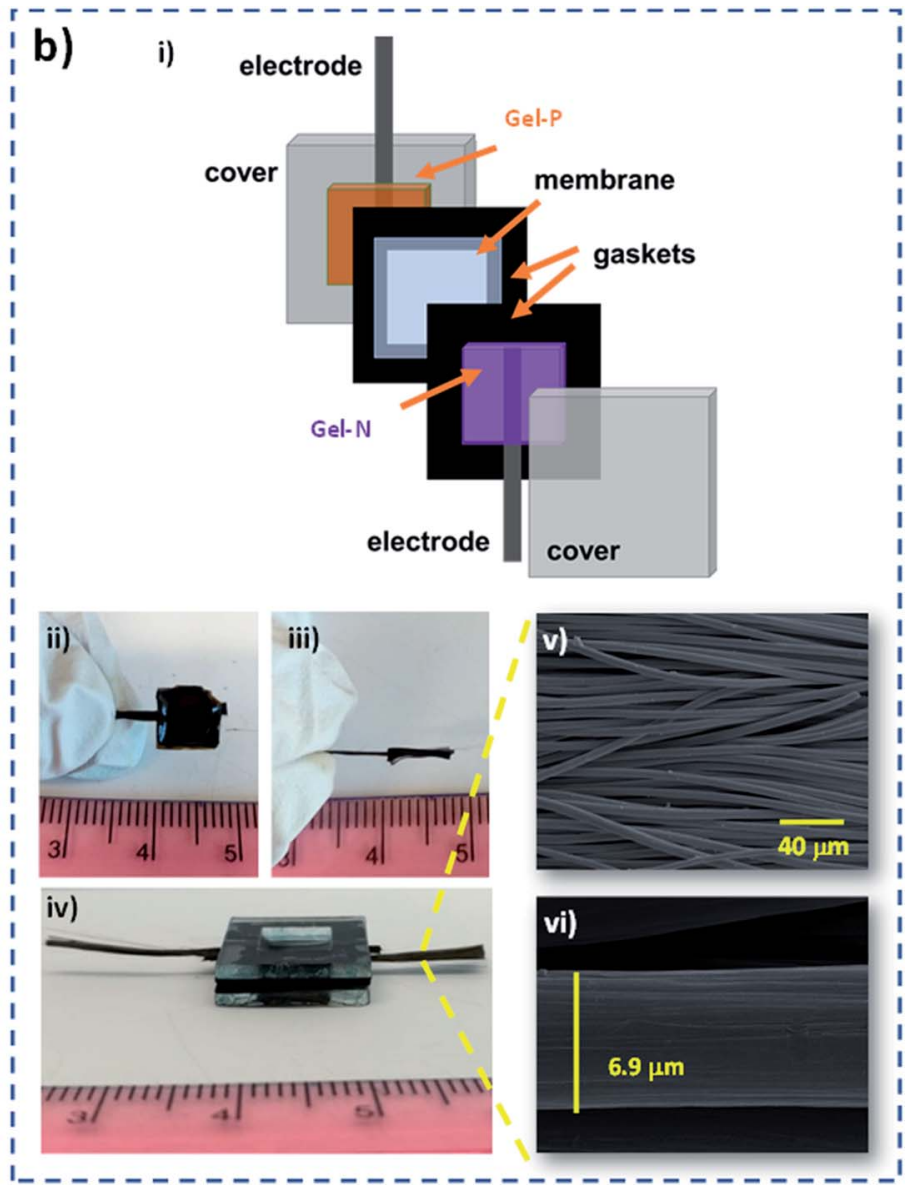

Fig. 1 (a) Gels containing agarose, $\mathrm{KCl}$, and BTMAP-Vi (gel-N) and BTMAP-Fc (gel-P). (b) Scheme of the microbattery (i), photos of the gel on FCF electrode (ii and iii) and of the device (iv), and scanning electron microscopic images of FCF at different magnifications (v and vi). (c) Cyclic voltammograms of BTMAP-Vi and BTMAP-Fc and background recorded on FCF microelectrodes. Conditions: 2.0 mM of BTMAP-Vi and BTMAPFC in $1.0 \mathrm{M} \mathrm{KCl}, 50 \mathrm{mV} \mathrm{s}^{-1}$, Ar atmosphere. The expected cell potential is indicated.

each electrode compartment (see the calculation in the ESI $\dagger$ ). The redox-gel was prepared using redox-active compounds (BTMAP-Fc or BTMAP-Vi) dissolved in an agarose gel. BTMAP-Fc and BTMPA-Vi exhibit relatively high diffusion coefficients in the hydrogel electrolyte, $2.4 \times 10^{-6} \mathrm{~cm}^{2} \mathrm{~s}^{-1}$ for BTMAP-Fc and $2.8 \times 10^{-6} \mathrm{~cm}^{2} \mathrm{~s}^{-1}$, for BTMAP-Vi, as measured by PFGE- ${ }^{1} \mathrm{H}-$ NMR (see ESI $\dagger$ ). These values are $20-27 \%$ lower than those for the same molecules measured at the same concentration in a KCl solution, $\left(3.29 \times 10^{-6} \mathrm{~cm}^{2} \mathrm{~s}^{-1}\right.$ for BTMAP-Fc and $3.45 \times$ $10^{-6} \mathrm{~cm}^{2} \mathrm{~s}^{-1}$ for BMAP-Vi). ${ }^{13}$ Our measurements are consistent with a previous report. ${ }^{14}$ Using the gel composition described in the ESI, $\dagger$ the redox-active molecules can readily diffuse through the hydrogel pores. In order to prevent redox-active molecule crossover, we inserted an anion-conducting membrane as a separator between the electrolyte gels, producing the cell shown in Fig. 1b. The concentration of redox molecules in each gel was $0.50 \mathrm{M}$ and a Selemion DSV anion exchange membrane was used as the separator.

Fig. 2 shows the performance of these microbatteries. First, the cell was charged at $1.10 \mathrm{~V}$ for $30 \mathrm{~min}$ (to reach approximately $20 \%$ state of charge, SOC), and then a discharge curve was recorded at a constant current density of $20 \mu \mathrm{A} \mathrm{cm}^{-2}$ (Fig. 2a).
This curve indicates that the microbattery can be discharged steadily over $100 \mathrm{~h}$ and provides a volumetric capacity of 0.021 $\mu \mathrm{A} \mathrm{h} \mathrm{cm}{ }^{-2} \mu \mathrm{m}^{-1}$. The microbattery can hold its charge for at least $48 \mathrm{~h}$ when no current is drained (Fig. S3 of the ESI†). The power curve in terms of current and power densities are shown in Fig. 2b. From this curve, we obtained an OCV of approximately $0.70 \mathrm{~V}$ and a maximum volumetric power density of 3.4 $\mu \mathrm{W} \mathrm{cm} \mathrm{cm}^{-2} \mu \mathrm{m}^{-1}$ at $8.7 \mu \mathrm{A} \mathrm{cm}^{-2} \mu \mathrm{m}^{-1}$ (20\% SOC).

In order to evaluate the volumetric capacity, the microbattery was charged and discharged at a constant voltage of $1.10 \mathrm{~V}$ (to $92 \%$ SOC) and $0.30 \mathrm{~V}$, respectively, as illustrated in Fig. $2 \mathrm{c}$. The experimental volumetric capacity was calculated to be $1.42 \mathrm{mC}$ $\mathrm{cm}^{-2} \mu \mathrm{m}^{-1}$, which corresponds to $0.39 \mu \mathrm{A} \mathrm{h} \mathrm{cm}^{-2} \mu \mathrm{m}^{-1}$ (or 3.94 $\mu \mathrm{A} \mathrm{h} \mu \mathrm{L}^{-1}$ ), giving a total capacity of $0.79 \mathrm{~mA} \mathrm{~h}$. This total capacity is lower than those measured for commercial lithium and silver-oxide microbatteries, $5 \mathrm{~mA} \mathrm{~h}$ and $80 \mathrm{~mA} \mathrm{~h}$, respectively. ${ }^{3}$ Nevertheless, these redox-gel microbatteries can power an ingestible sensor, requiring $4.69 \mu \mathrm{A},{ }^{1}$ for $168 \mathrm{~h}$, and also other medical microdevices, as shown in Table 1.

Cycling tests were performed to evaluate the potential use of these redox-gel microbatteries as a secondary batteries, (Fig. 2d and e). The coulombic efficiency for the galvanostatic cycling at 
a)

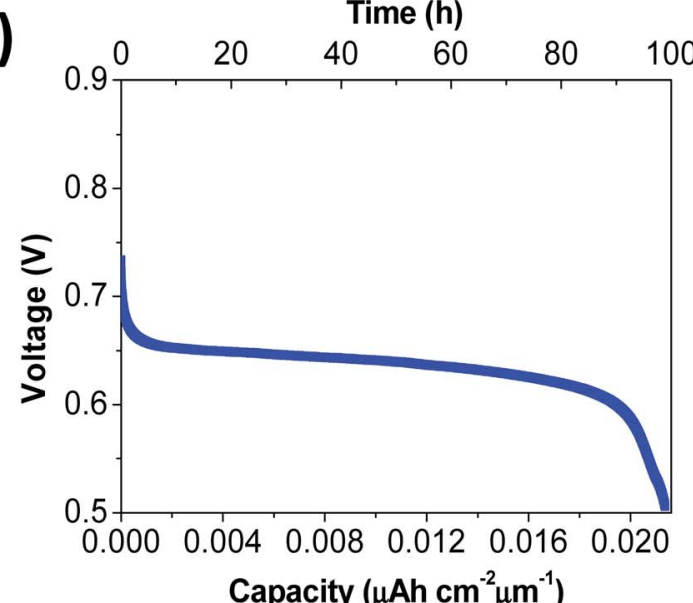

c)

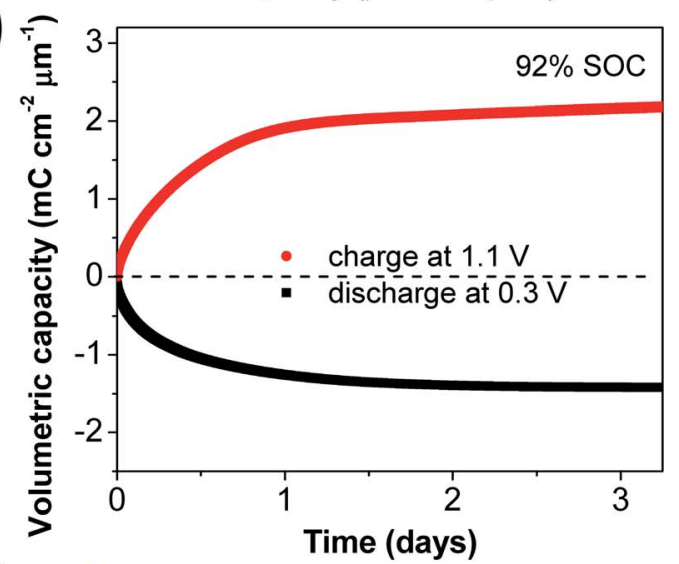

b)

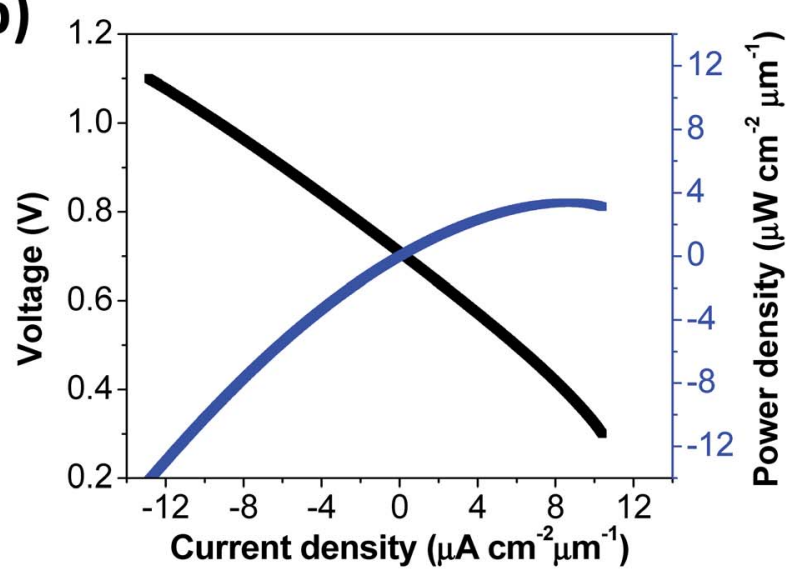

d)

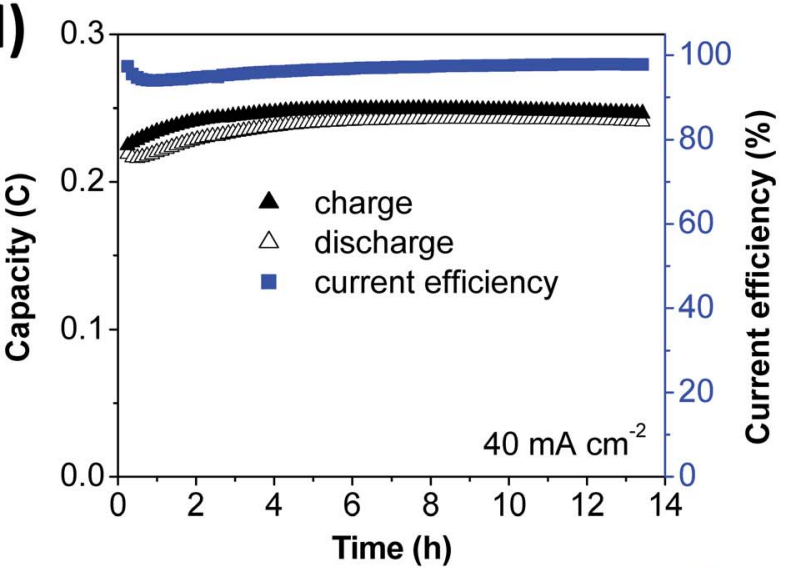

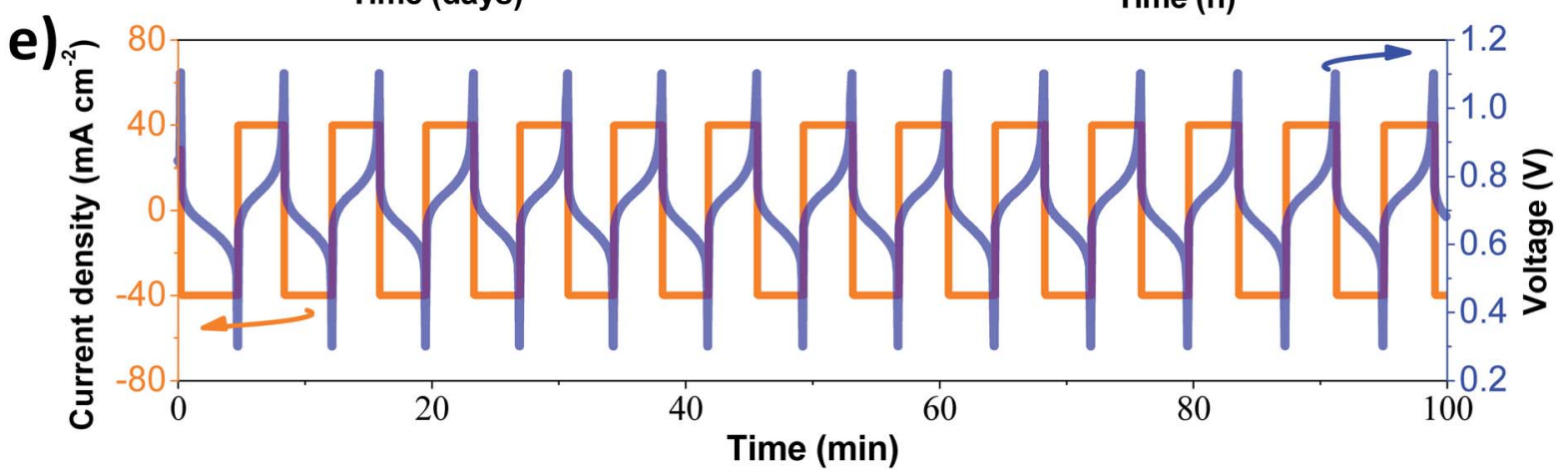

Fig. 2 (a) Voltage vs. time for galvanostatic discharge at $40 \mu \mathrm{A} \mathrm{cm}^{-2}$. (b) Cell voltage and power density vs. current density at $20 \%$ SOC. (c) Charge and discharge curves at $1.10 \mathrm{~V}$ and $0.30 \mathrm{~V}$, respectively. (d) Capacity and current efficiency values of 100 cycles. (e) Representative voltage and current density vs. time curves during 100 charging-discharging cycles at $40 \mathrm{~mA} \mathrm{~cm}{ }^{-2}$. All data here were collected at room temperature, under $\mathrm{N}_{2}$ atmosphere, and using gel containing $1.0 \mathrm{M} \mathrm{KCl}$ and $0.50 \mathrm{M} \mathrm{BTMAP-FC}$ on the positive side and gel containing $1.0 \mathrm{M} \mathrm{KCl}$ and $0.50 \mathrm{M}$ BTMAP-Vi on the negative side, and Selemion DSV as anion exchange membrane.

$40 \mathrm{~mA} \mathrm{~cm}^{-2}$ ranges between $94 \%$ and 97\% during $13 \mathrm{~h}$, corresponding to 100 cycles. The cycles are highly reproducible and indicate good electrochemical stability and a highly efficient storage system.

The size and non-corrosive composition of these redox-gel microbatteries constitute attractive advantages compared to typical lithium manganese button-cell and alkaline silver-oxide disk batteries. ${ }^{1}$ The cells described in this work can be encased in volumes suitable to replace the traditional power sources within ingestible wireless endoscopy capsules, ${ }^{15}$ or probiotic biosensors to monitor gastrointestinal health. ${ }^{1}$ In contrast with the low toxicity and non-corrosive nature of the microbatteries described here, accidental leakage of the electrolyte solution within alkaline silver-oxide disk batteries, can result in damage and in perforation of the esophagus if not removed surgically. ${ }^{\mathbf{1 6}}$ Similarly, a lithium microbattery ${ }^{\mathbf{1}}$ has a risk of burning in air or releasing a strongly corrosive solution and flammable hydrogen when in contact with water causing severe injuries. ${ }^{17}$ The amounts of redox active molecules used in our redox-gel microbatteries are too small to produce harmful effects on humans. In terms of toxicity, viologens similar to those used in our battery have an oral LD 50 (lethal dose) of $126 \mathrm{mg} \mathrm{kg}^{-1}$ for 
Table 1 Examples of low-power medical microdevices

\begin{tabular}{|c|c|c|c|c|}
\hline System & $\begin{array}{l}\text { Operation current } \\
\left(\mu \mathrm{A}^{a} \text { or } \mu \mathrm{A} \mathrm{MHz}^{-1 b}\right)\end{array}$ & $\begin{array}{l}\text { Operation } \\
\text { voltage }(\mathrm{V})\end{array}$ & $\begin{array}{l}\text { Power } \\
\text { consumption (nW) }\end{array}$ & Ref. \\
\hline Ingestible biosensor to monitor gastrointestinal health & $4.69^{a}$ & $\mathrm{n} / \mathrm{a}$ & $\mathrm{n} / \mathrm{a}$ & 1 \\
\hline $\begin{array}{l}\text { Integrated system-on-chip for internet of things, sensor fusion, } \\
\text { wearables, and e-medical applications }\end{array}$ & $9^{b}$ & $0.5-0.6$ & $\mathrm{n} / \mathrm{a}$ & 6 \\
\hline Integrated circuit for miniature sensor nodes & $\mathrm{n} / \mathrm{a}$ & 0.6 & 3 & 20 \\
\hline Temperature sensor for low power wireless sensor nodes & $\mathrm{n} / \mathrm{a}$ & 0.075 & 71 & 21 \\
\hline $\begin{array}{l}\text { Sensing, controlling and signal processing circuit for } \\
\text { implantable CMOS }\end{array}$ & $\mathrm{n} / \mathrm{a}$ & $\mathrm{n} / \mathrm{a}$ & 921 & 22 \\
\hline
\end{tabular}

rats, $22 \mathrm{mg} \mathrm{kg}^{-1}$ for pigs, and $50 \mathrm{mg} \mathrm{kg}^{-1}$ for monkeys. The lethal dose in humans is estimated to be about $7000 \mathrm{mg} \cdot{ }^{18}$ Our redox-gel microbatteries use a total of $29 \mathrm{mg}$ of viologen derivative, which is 240 times smaller. Ferrocene derivatives show LD 50 of $25 \mathrm{mg} \mathrm{kg}^{-1}$ for rats and $50 \mathrm{mg} \mathrm{kg}^{-1}$ for mice. ${ }^{19}$ Considering our microbattery contains $23 \mathrm{mg}$ of ferrocene derivative, no harmful effect is expected for humans. In the event of accidental rupture while in the digestive system, this viologen/ferrocenebased microbattery poses a lower risk than the commercially available alternatives.

In summary, we describe a gel-based microbattery for use as a safe primary power source for several ingestible and implantable medical microdevices (Table 1). This gel-based approach can be expanded to include other redox molecules (e.g. natural product-based redox molecules) and can be further miniaturized. The combination of hydrogel and redox-active organic and organometallic molecules could represent an attractive strategy for developing non-toxic rechargeable microbatteries.

\section{Conflicts of interest}

There are no conflicts to declare.

\section{Acknowledgements}

This work was funded by the CNPq Brazil, FAPESP Brazil and U. S. NSF grant CBET-1509041. G. C. S. and F. N. C. gratefully acknowledge the financial support provided by the FAPESP (project numbers: 2015/22973-6, 2017/15714-0 and 2013/142627) and CNPq (project number: 203299/2017-5).

\section{References}

1 M. Mimee, P. Nadeau, A. Hayward, S. Carim, S. Flanagan, L. Jerger, J. Collins, S. Mcdonnell, R. Swartwout, R. J. Citorik, V. Bulović, R. Langer, G. Traverso, A. P. Chandrakasan and T. K. Lu, Science, 2018, 918, 915.

2 A. T. Kutbee, R. R. Bahabry, K. O. Alamoudi, M. T. Ghoneim, M. D. Cordero, A. S. Almuslem, A. Gumus, E. M. Diallo, J. M. Nassar, A. M. Hussain, N. M. Khashab and M. M. Hussain, npj flexible electronics, 2017, 1, 7.

3 K. Kalantar-zadeh, N. Ha, J. Z. Ou and K. J. Berean, ACS Sens., 2017, 2, 468.
4 H. Chen, S. Cartmell, Q. Wang, T. Lozano, Z. D. Deng, H. Li, X. Chen, Y. Yuan, M. E. Gross, T. J. Carlson and J. Xiao, Sci. Rep., 2014, 4, 3790.

5 R. M. Iost, F. N. Crespilho, K. Kern and K. Balasubramanian, Nanotechnology, 2016, 27, 29 LT01.

6 Y. Pu, C. Shi, G. Samson, D. Park, K. Easton, R. Beraha, A. Newham, M. Lin, V. Rangan, K. Chatha, D. Butterfield and R. Attar, IEEE J. Solid-State Circuits, 2018, 53, 936.

7 M. Haghi, K. Thurow and R. Stoll, Healthc. Inform. Res., 2017, 23, 4.

8 R. Gravina, P. Alinia, H. Ghasemzadeh and G. Fortino, Inform. Fusion, 2017, 35, 1339.

9 V. J. Kartsch, S. Benatti, P. D. Schiavone, D. Rossi and L. Benini, Inform. Fusion, 2018, 43, 66.

10 Z. Liu, H. Li, M. Zhu, Y. Huang, Z. Tang, Z. Pei, Z. Wang, Z. Shi, J. Liu, Y. Huang and C. Zhi, Nano Energy, 2018, 44, 164.

11 M. Mohseni, P. Read and H. Neven, Nature, 2017, 543, 171.

12 K. Liu, Y. Liu, D. Lin, A. Pei and Y. Cui, Sci. Adv., 2018, 4, eaas9820.

13 E. S. Beh, D. D. Porcellinis, R. L. Gracia, K. T. Xia, R. G. Gordon and M. J. Aziz, ACS Energy Lett., 2017, 2, 639.

14 J. R. Lead, K. Starchev and K. J. Wilkinson, Environ. Sci. Technol., 2003, 37, 482.

15 G. Iddan, G. Meron, A. Glukhovsky and P. Swain, Nature, 2000, 405, 417.

16 M. Lupa, J. Magne, J. L. Guarisco and R. Amedee, Ochsner J., 2009, 9, 54.

17 K. R. Jatana, K. Rhoades, S. Milkovich and I. N. Jacobs, Laryngoscope, 2017, 127, 1276.

18 U.S. National Library of Medicine, Toxicology Data Network: Paraquat, https://toxnet.nlm.nih.gov/cgi-bin/sis/search/a? dbs+hsdb:@term+@DOCNO+1668, accessed, January, 2019.

19 U.S. National Library of Medicine, Toxicology Data Network: 1-Acetylferrocene, https://chem.nlm.nih.gov/chemidplus/rn/ 1271-55-2, accessed, March, 2019.

20 P. Harpe, H. Gao, R. V. Dommele, E. Cantatore and A. H. M. van Roermund, IEEE J. Solid-State Circuits, 2015, 51, 240.

21 S. Jeong, Z. Foo, Y. Lee, J. Y. Sim, D. Blaauw and D. Sylvester, IEEE J. Solid-State Circuits, 2014, 49, 1682.

22 M. Poustinchi and S. Musallam, Middle East Conference on Biomedical Engineering, 2014, pp. 131-134. 


\section{Electronic Supplementary Information}

\section{Non-corrosive, Low-Toxicity Gel-based Microbattery from Organic and Organometallic Molecules}

Frank N. Crespilho, ${ }^{* a, b}$ Graziela C. Sedenho, ${ }^{a, b}$ Diana De Porcellinis, ${ }^{b}$ Emily Kerr, ${ }^{c}$ Sergio

Granados-Focil, ${ }^{d}$ Roy G. Gordon, ${ }^{c}$ and Michael J. Aziz ${ }^{* b}$

a. São Carlos Institute of Chemistry, University of São Paulo (USP), Av. Trabalhador Sãocarlense, 400, São Carlos, São Paulo 13560-970, Brazil.

b. Harvard School of Engineering and Applied Sciences, 29 Oxford Street, Cambridge, Massachusetts 02138, USA.

c. Department of Chemistry and Chemical Biology, Harvard University, 12 Oxford Street,

d. Cambridge, Massachusetts 02138, USA.

e. Gustaf Carlson School of Chemistry and Biochemistry, Clark University, Worcester, MA 01610-1477, USA.

\section{Corresponding Authors}

*E-mails: frankcrespilho@usp.br,maziz@harvard.edu 


\section{Experimental Methods}

Synthesis of BTMAP-Vi: BTMAP-Vi was synthetized as previously described by Beh et al. ${ }^{1}$ The scheme of its synthesis is shown in Figure S1a. Initially, $9.91 \mathrm{~g}(62.9 \mathrm{mmol})$ of 1-bromo3-chloropropane was stirred with $6.6 \mathrm{~mL}(210.0 \mathrm{mmol})$ of a $25 \%$ solution of trimethylamine in methanol. After stirring at room temperature for 15 hours, the reaction mixture was diluted with $\sim 50 \mathrm{~mL}$ of methyl tert-butyl ether (MTBE) and the suspended solid collected by vacuum filtration. The solid was rinsed with MTBE and dried in vacuo to give trimethyl(3chloropropyl)ammonium bromide (1). Yield: $4.38 \mathrm{~g}(85.7 \%)$ of a fine white powder. This material was used without purification in the following step.

Then, $3.98 \mathrm{~g}$ (18.4 mmol) of 1 and $1.41 \mathrm{~g}$ (9.0 mmol) of 4,4'-dipyridyl were suspended in $\sim 10 \mathrm{~mL}$ of anhydrous DMF and heated to reflux under argon. Upon heating, all solids dissolved, followed shortly after by the formation of a large amount of pale yellow precipitate. After heating for 1 hour, the reaction mixture had partially solidified and had turned greenish. The reaction was cooled to room temperature and solid was collected by vacuum filtration, and then finally dried in vacuo to give (3-trimethylammonio)propyl viologen dibromide dichloride. The product was recrystallized by the addition of DMF to an aqueous solution. (2). Yield: $1.71 \mathrm{~g}(32.1 \%)$ of a pale-yellow powder.

A solution of $11.48 \mathrm{~g}(19.48 \mathrm{mmol})$ of 2 in $\sim 100 \mathrm{~mL}$ of deionized $\mathrm{H}_{2} \mathrm{O}$ was passed through $\sim 0.5 \mathrm{~kg}$ of wet Amberlite IRA-900 resin (chloride form). The resin was washed with $\sim 1$ L of deionized $\mathrm{H}_{2} \mathrm{O}$. The eluted solution was evaporated in vacuo to give pure (3trimethylammonio)propyl viologen tetrachloride (BTMAP-Vi). Yield: $9.76 \mathrm{~g}$ (99.9\%) of an off-white deliquescent solid. ${ }^{1} \mathrm{H}$ NMR spectrum of the final product BTMAP-Vi is shown in Figure S1b. 
(a)
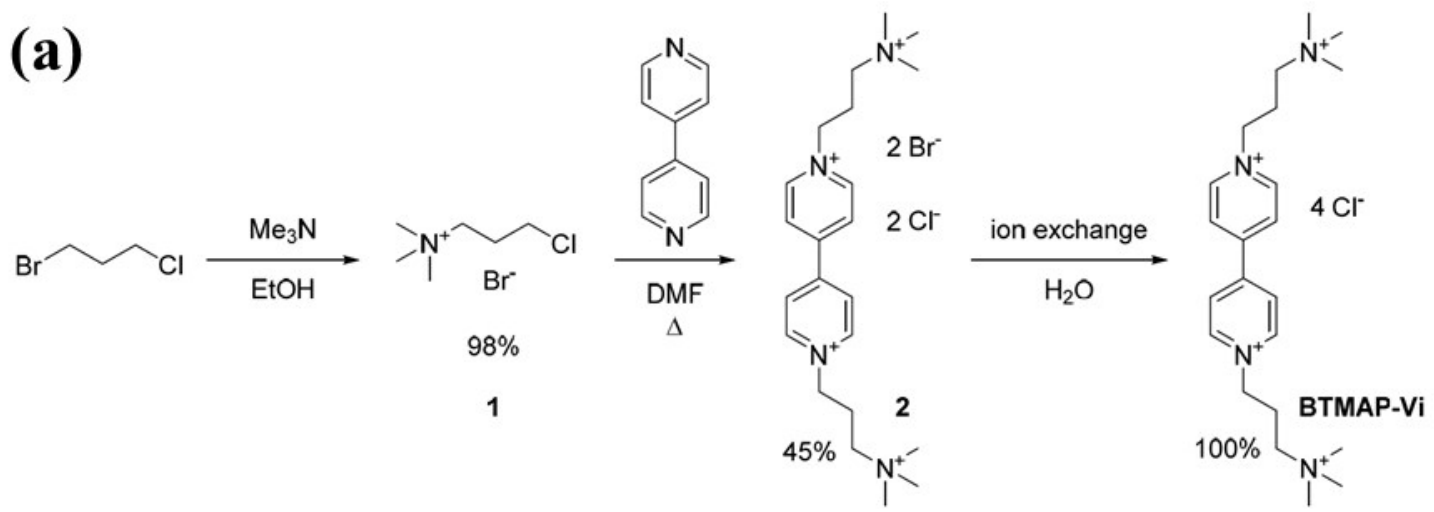

(b)

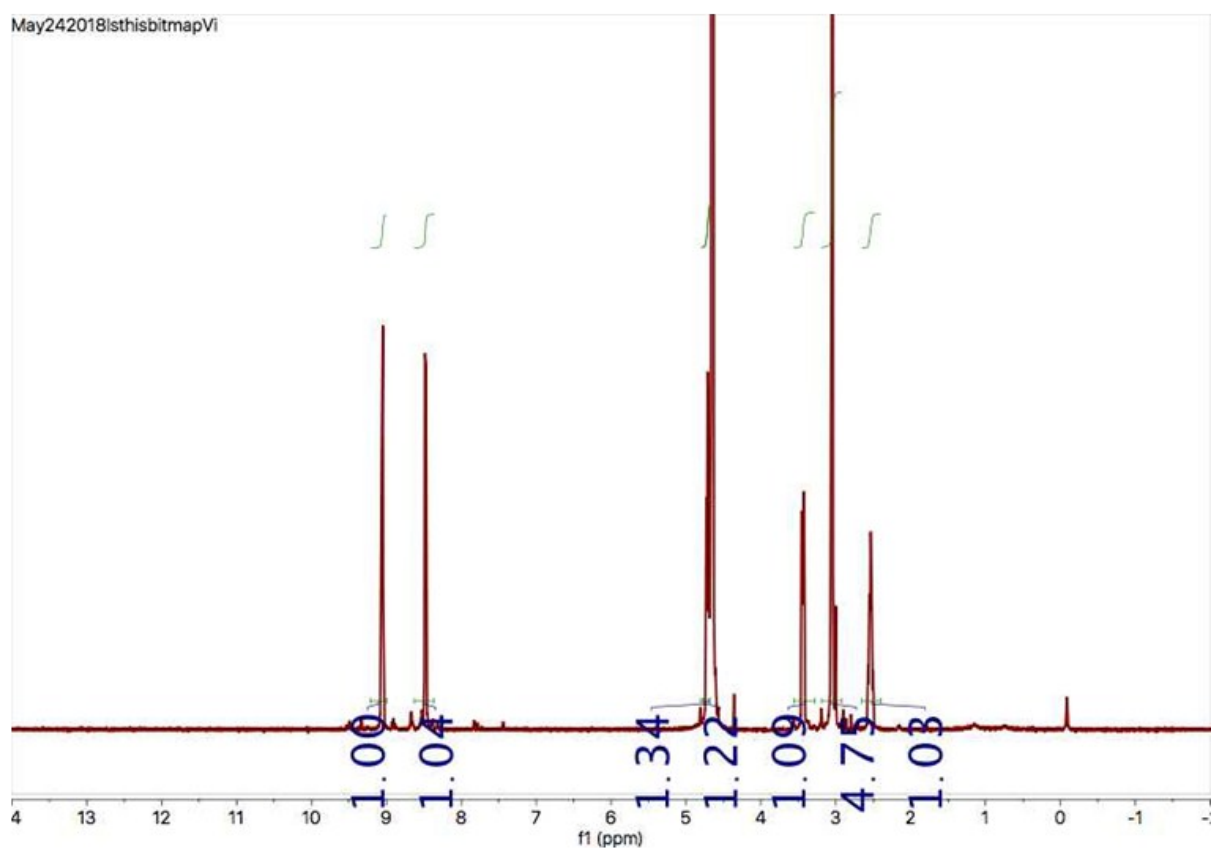

Figure S1. (a) Scheme of synthesis of BTMAP-Vi and (b) ${ }^{1} \mathrm{H}$ NMR spectrum of BTMAP-Vi recorded at $500 \mathrm{MHz}$, in $\mathrm{D}_{2} \mathrm{O} . \delta 9.12(\mathrm{~d}, 4 \mathrm{H}), 8.63(\mathrm{~d}, 4 \mathrm{H}), 4.87(\mathrm{t}, 4 \mathrm{H}), 3.61(\mathrm{~m}, 4 \mathrm{H}), 3.22(\mathrm{~s}$, $18 \mathrm{H}), 2.72(\mathrm{~m}, 4 \mathrm{H})$.

Synthesis of BTMAP-Fc: BTMAP-Fc was synthetized as previously described by Beh et al. ${ }^{1}$ The scheme of its synthesis is shown in Figure S2a. Initially, $14.67 \mathrm{~g}(110.0 \mathrm{mmol})$ of $\mathrm{AlCl}_{3}$ was suspended in $\sim 100 \mathrm{~mL}$ of anhydrous $\mathrm{CH}_{2} \mathrm{Cl}_{2}$. A solution of $12.70 \mathrm{~g}(100.0 \mathrm{mmol})$ of 3chloropropionyl chloride in $\sim 50 \mathrm{~mL}$ of anhydrous $\mathrm{CH}_{2} \mathrm{Cl}_{2}$ was added by syringe and the mixture stirred at room temperature for 2 hours. Once this was complete, the resulting slightly turbid golden-yellow solution was transferred via cannula into another flask, which had been 
cooled to $0{ }^{\circ} \mathrm{C}$, containing a solution of $9.30 \mathrm{~g}(50.0 \mathrm{mmol})$ of ferrocene in $\sim 100 \mathrm{~mL}$ of anhydrous $\mathrm{CH}_{2} \mathrm{Cl}_{2}$. After stirring overnight, the reaction mixture was again cooled to $0{ }^{\circ} \mathrm{C}$ and a solution of $200 \mathrm{~mL}$ of $0.5 \mathrm{M} \mathrm{NaBH}_{4}(100.0 \mathrm{mmol})$ in anhydrous diglyme was added via cannula and stirring was continued for a further 4 hours. Following that, the reaction was carefully quenched by the addition of $\sim 500 \mathrm{~mL}$ of $1 \mathrm{M}$ aqueous $\mathrm{HCl}$. The organic phase was isolated and the aqueous phase extracted with $\mathrm{CH}_{2} \mathrm{Cl}_{2}(3 \times 100 \mathrm{~mL})$. The extracts were combined, dried over anhydrous $\mathrm{Na}_{2} \mathrm{SO}_{4}$, filtered and evaporated to give the crude product of 1,1'-bis(3-chloropropyl)ferrocene (3). Yield: $16.02 \mathrm{~g}$ (94.5\%) of a red-brown oil.

$16.02 \mathrm{~g}(47.3 \mathrm{mmol})$ of column purified 3 was dissolved in $\sim 100 \mathrm{~mL}$ of a $4.2 \mathrm{M}$ solution of trimethylamine in ethanol. The solution was sealed in a heavy-walled glass tube and heated to $60{ }^{\circ} \mathrm{C}$ for 5 days. Following that, all volatiles were removed in vacuo to give a dark brown oil. The oil was stirred in $\mathrm{H}_{2} \mathrm{O}(\sim 400 \mathrm{~mL})$ and filtered to remove unreacted ferrocene and other water-insoluble impurities. The filtrate was evaporated in vacuo to give pure BTMAPFc. Yield: $20.76 \mathrm{~g}(96.1 \%)$ of a dark brown glassy solid. ${ }^{1} \mathrm{H}$ NMR spectrum of the final product BTMAP-Fc is shown in Figure S2b.

(a)

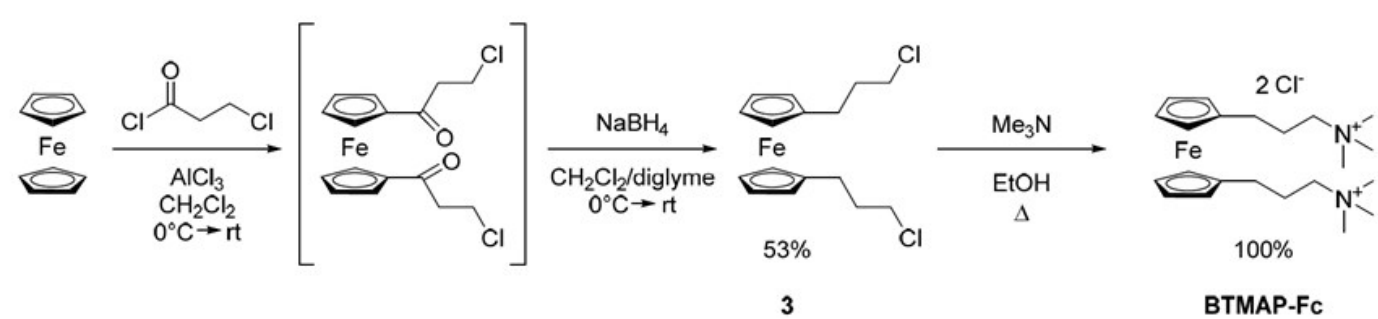


(b)

03282018 bitmapFefraction11
$-78 \mathrm{C}$ to 0 (for workup)

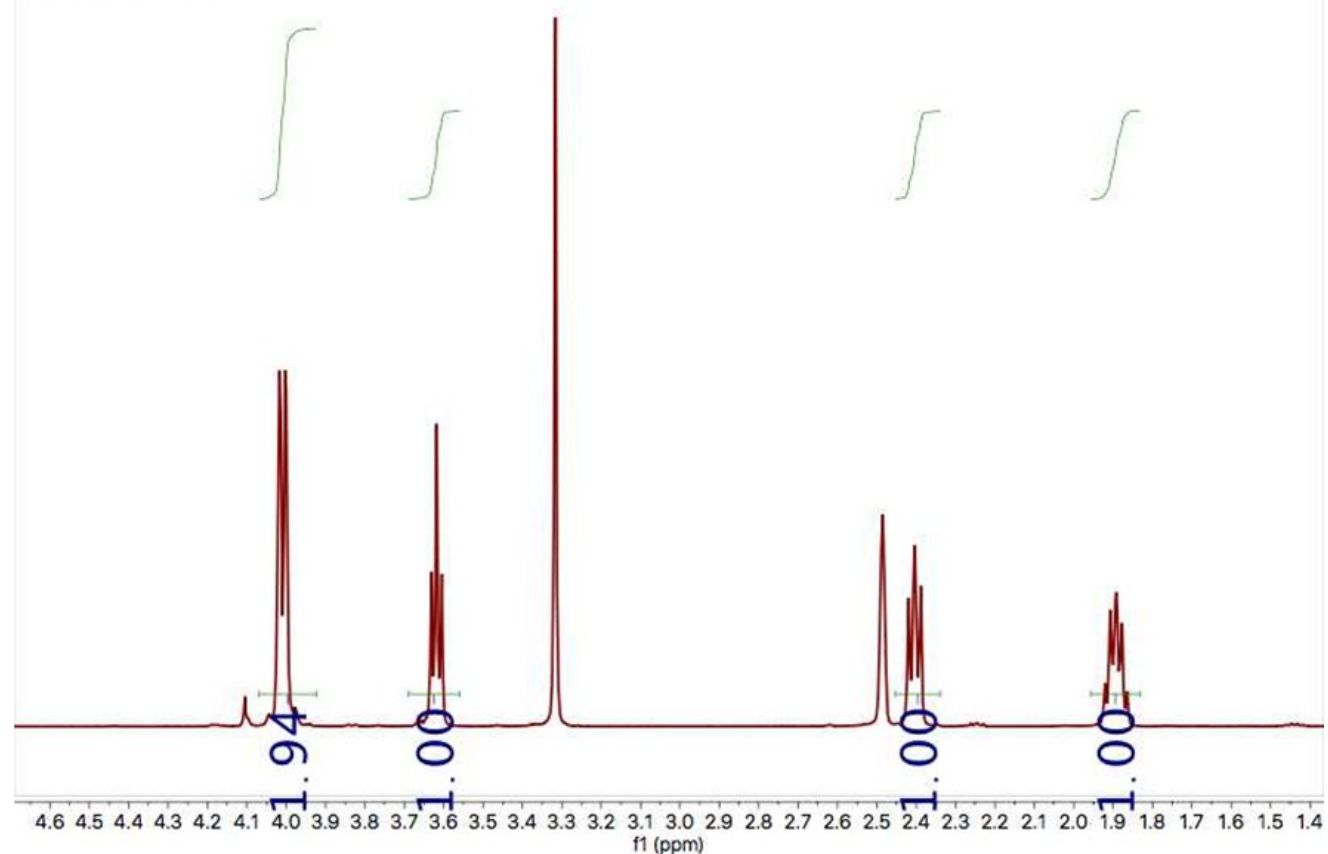

Figure S2. (a) Scheme of synthesis of BTMAP-Fc and ${ }^{1} \mathrm{H}$ NMR spectrum of BTMAP-Fc recorded at $500 \mathrm{MHz}$, in $\mathrm{D}_{2} \mathrm{O} . \delta 4.15(\mathrm{~m}, 8 \mathrm{H}), 3.27(\mathrm{~m}, 4 \mathrm{H}), 3.05(\mathrm{~s}, 18 \mathrm{H}), 2.55(\mathrm{t}, 4 \mathrm{H}), 1.94$ $(\mathrm{m}, 4 \mathrm{H})$.

Cyclic voltammetry: Cyclic voltammograms (CVs) were recorded in a Gamry Reference 3000 potentiostat (Gamry Instruments, United States) using an array of flexible carbon fibers (FCFs), $\mathrm{Pt}$ wire and $\mathrm{Ag} / \mathrm{AgCl}$ electrode (3 $\mathrm{M} \mathrm{KCl}$ filling solution) as working, counter and reference electrodes, respectively. Pt wire and $\mathrm{Ag} / \mathrm{AgCl}$ electrode were obtained from $\mathrm{BASi}{ }^{\circledR}$ (United States). Before the measurements, an array of FCFs was extracted from a carbon cloth (from Biolinker, Brazil) and chemically treated with $\mathrm{KMnO}_{4}$ in $\mathrm{H}_{2} \mathrm{SO}_{4}$ solution. ${ }^{2}$

Hydrogel preparation: The hydrogels with BTMAP-Vi and BTMAP-Fc were prepared suspending $1.5 \%(\mathrm{w} / \mathrm{w})$ agarose in $1.0 \mathrm{M} \mathrm{KCl}$ containing $0.50 \mathrm{M}$ of BTMAP-Vi and BTMAP-Fc. After, the suspensions were heated until $90{ }^{\circ} \mathrm{C}$, because agarose dissolves in near-boiling water. Then, $100 \mu \mathrm{L}$ of each mixture was dropped on the top of FCF electrodes. 
The system was cooled to room temperature to form the gels. The composition of the hydrogels is shown in table S1. At pH 7.0 both BTMAP-Fc and BTMAP-Vi are positively charged and highly soluble in water, almost up to $2.0 \mathrm{M}$ for both reactants. However, BTMAP-Vi and BTMAP-Fc concentrations higher than $0.5 \mathrm{M}$ were not used in the microbattery because they affect the agarose gelling. In addition, the agarose forms a waterswollen polymer network at room temperature, the crosslink density, and thus the diffusion of species absorbed within the hydrogel, can be controlled by tuning the agarose concentration.

Table S1. Composition of the BTMAP-Vi and BTMAP-Fc hydrogels.

\begin{tabular}{lcc}
\hline Component & $\begin{array}{c}\%(w / w) \text { in the } \\
\text { BTMAP-Fc hydrogel }\end{array}$ & $\begin{array}{c}\% / w) \text { in the } \\
\text { BTMAP-Vi hydrogel }\end{array}$ \\
\hline Agarose & $1.1 \%$ & $1.1 \%$ \\
KCI & $5.6 \%$ & $5.4 \%$ \\
BTMAP-Fc & $17.4 \%$ & - \\
BTMAP-Vi & - & $21.0 \%$ \\
Water & $75.8 \%$ & $72.5 \%$ \\
\hline
\end{tabular}

PFGE- ${ }^{1}$ H-NMR measurements: The diffusion coefficients of both BMAP-Vi and BTMAPFc were measured in $1 \mathrm{M} \mathrm{KCl}$ solution in $\mathrm{D}_{2} \mathrm{O}$ and in a hydrogel with the same composition as table $\mathrm{S} 1$ using $\mathrm{D}_{2} \mathrm{O}$ instead of water. The measurements were made using a Varian INOVA, $600 \mathrm{MHz}$ NMR spectrometer using a 5mm TRX/PFG triple resonance probe with a 70 gauss/cm maximum Z-gradient. Experiments were done using a $2 \mathrm{~ms}$ diffusion gradient length and a $150 \mathrm{~ms}$ diffusion delay time. The NMR data was processed using the built-in VNMR-J software from Varian. 
Microbattery assembly: A microbattery with a Selemion DSV anion exchange separator was built with two polyacrylate pieces $(1.50 \mathrm{~cm} \times 1.50 \mathrm{~cm} \times 1.50 \mathrm{~mm})$ with a pool $(0.72 \mathrm{~cm} \times$ $0.72 \mathrm{~cm} \times 1.50 \mathrm{~mm}$ ) in the center to give a compartment for each gel. The dimensions of the entire microbattery are mainly attributed to the polyacrylate package. The separator was placed between the two compartments. The cell was gasketed by Viton sheets of $270 \mu \mathrm{m}$ in thickness. $100 \mu \mathrm{L}$ of heated mixture containing 0.50 M BTMAP-Fc (positive side) and 0.50 M BTMAP-Vi (positive side) in $1.0 \mathrm{M} \mathrm{KCl}$ and $1.5 \%$ agarose were dropped in each compartment and cooled to room temperature to form the gel. One array of FCF was used as the electrode in each side of the battery, the geometric area exposed to the hydrogel was 0.025 $\mathrm{cm}^{2}$. The microbattery was sealed with silicone resin.

Microbattery measurements: Full cell tests were performed with a BioLogic BCS-815 battery cycling system. All measurements were carried out at room temperature and inside a glove bag in a $\mathrm{N}_{2}$ atmosphere. The charge and discharge current densities were calculated based on the anode area, which is $0.025 \mathrm{~cm}^{2}$. The measurements were carried out immediately after assembly of the microbattery. The microbattery was charged at $1.10 \mathrm{~V}$ for $30 \mathrm{~min}$. If we define $100 \%$ SOC as the theoretical capacity $(4.8 \mathrm{C})$, then charging the battery at constant potential for $30 \mathrm{~min}$, achieves $20 \% \mathrm{SOC}(0.89 \mathrm{C})$. The polarization curve was obtained at $\sim 20 \%$ SOC by cyclic voltammetry where the potential is swept from $0.30 \mathrm{~V}$ to $1.10 \mathrm{~V}$ with a scan rate of $100 \mathrm{mV} \mathrm{s}^{-1}$. During the sweep in potential, the cell discharged less than $0.05 \mathrm{C}$.

\section{Hydrogel cost}

Agarose is a natural and low-cost polysaccharide used for preparation of hydrogels. ${ }^{3}$ The price of laboratory grade agarose powder is around $\$ 6.50$ per $15 \mathrm{~g}$. With $15 \mathrm{~g}$ it is possible to 
prepare $1.0 \mathrm{~L}$ of $1.5 \%$ agarose gel. Considering one microbattery is composed of $200 \mu \mathrm{L}$ of agarose gel $(100 \mu \mathrm{L}$ of negolyte $+100 \mu \mathrm{L}$ of posolyte), with $1.0 \mathrm{~L}$ of gel it is possible to fabricate 5,000 microbatteries. This means that with $\$ 1$ it is possible to prepare hydrogel for 770 microbatteries at laboratory-scale prices.

\section{Capability of the microbattery to hold its charge}



Figure S3. Measurement of cell voltage after $48 \mathrm{~h}$ of storage (no current drained).

\section{References}

1. E. S. Beh, D. De Porcellinis, R. L. Gracia, K. T. Xia, R. G. Gordon, M. J. Aziz. ACS Energy Lett., 2017, 2, 639-644.

2. M. V. Martins, A. R. Pereira, R. S. Luz, R. M. Iost, F. N. Crespilho. Phys. Chem. Chem. Phys., 2014, 16, 17426-17436.

3. R. Armisen, F. Galata. Production, Properties and Uses of Agar. In Production and utilization of products from commercial seaweeds, Food and Agriculture Organization: Rome, Italy, 1987. 


\section{CHAPTER III - Stabilization of bilirubin oxidase in a biogel matrix for high- performance gas diffusion electrodes}

Author contributions: G. C. Sedenho: conceived the project; designed all the experiments; collected and analyzed all data; wrote and revised the manuscript. A. Hassan: collected and analyzed FTIR data; revised the manuscript. L. J. A. Macedo: collected and analyzed FTIR data, revised the manuscript. F. N. Crespilho: conceived the project; designed the experiments; guided manuscript writing, revised the manuscript.

This third work, published in 2021 in the Journal of Power Sources, reports a simple methodology for bilirubin oxidase (BOD) immobilization and stabilization on carbon-based gas diffusion electrode for four-electron electrochemical oxygen reduction reaction. Inspired by final step of the respiratory chain, we immobilized BOD in a gel matrix for promoting the enzyme stabilization and efficient molecular oxygen reduction to water.

The enzyme immobilization method always plays a crucial role in achieving highperformance bioelectrochemical systems. This is because the biocatalyst immobilization on an electrode surface must enable electronic connection between the enzyme and the electrode, guarantee the catalytic activity and the integrity of the enzyme, and promote efficient substrate mass transport to the biocatalysts. Here, the incorporation of BOD into a Nafion matrix and the enzyme crosslinking by reaction with glutaraldehyde provided a suitable microenvironment for direct-electron transfer between BOD and carbon electrode and long-term enzymatic activity. Simultaneously, this enzyme immobilization method created the three-interface (aqueous electrolyte, biocatalyst on solid electrode, $\mathrm{O}_{2}$ substrate) involved electrochemical reaction. For the first time, it is shown a BOD-based biocathode with satisfactory reduction current combined with long-term stability under continuous operation. This work provides new insights into the enzyme immobilization field, overcoming the crucial factor of long-term stability for practical applications of bioelectrochemical energy conversion systems. 


\title{
Stabilization of bilirubin oxidase in a biogel matrix for high-performance gas diffusion electrodes
}

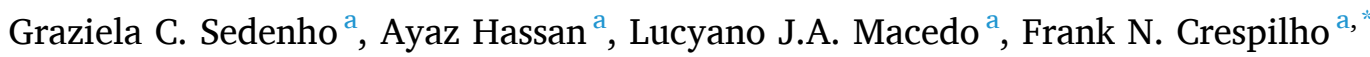 \\ ${ }^{\text {a }}$ São Carlos Institute of Chemistry, University of São Paulo (USP), Avenida Trabalhador São-carlense, 400, São Carlos, SP, 13560-970, Brazil
}

\section{H I G H L I G H T S}

- BOD is incorporated into a polymeric matrix producing a BOD-based biogel.

- The biogel allows the DET-type bioelectrocatalysis toward four-electron ORR.

- BOD-GDE showed $-1.52 \mathrm{~mA} \mathrm{~cm}-2$ at $0.19 \mathrm{~V}$ and high stability under continuous operation.

- Biogel layer thickness and BOD entrapment into Nafion network are crucial for biocathode stability.

- Biogel provides suitable microenvironment for long-term enzymatic activity involving three-phase interfacial reaction.

\section{A R T I C L E I N F O}

\section{Keywords:}

Bilirubin oxidase

Gas diffusion electrode

Enzyme immobilization

Oxygen reduction reaction

Direct electron transfer

\section{G R A P H I C A L A B S T R A C T}
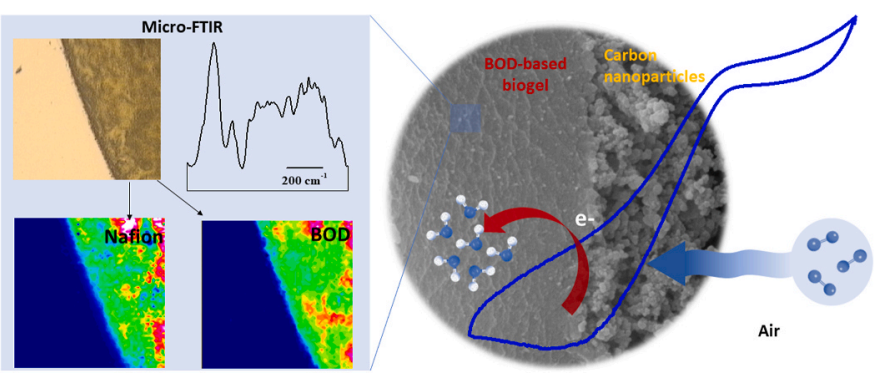

\begin{abstract}
A B S T R A C T
Enzyme immobilization on solid conducting surfaces faces challenges for practical applications in technologies such as biosensors and biofuel cells. Short-term stability, poor electrochemical performance, and enzyme inhibition are some unsolved issues. Here, we show a simple methodology for bilirubin oxidase (BOD) immobilization on carbon-based gas diffusion electrode for four-electron electrochemical oxygen reduction reaction. BOD is incorporated into a Nafion ${ }^{\circledR}$ matrix and crosslinked with glutaraldehyde by a one-pot reaction in buffered solution, producing a stable BOD-based biogel. The biogel provides stable electrode performance and allows the direct electron-transfer mechanism of multicopper centers buried in the enzyme. A biocatalytic reduction current of $-1.52 \pm 0.24 \mathrm{~mA} \mathrm{~cm}^{-2}$ at $0.19 \pm 0.06 \mathrm{~V}$ was observed under gas diffusion conditions. Additionally, the bioelectrode showed unprecedented long-term stability under continuous operation combined with satisfactory catalytic current without redox mediator. The BOD-based biogel layer thickness and the entrapment of BOD into Nafion network are crucial for the biocathode stability, and BOD crosslinking by glutaraldehyde contributes to enhance the catalytic currents. Further, the BOD-based biogel provides a suitable microenvironment for longterm enzymatic activity involving three-phase interfacial reaction. The present study provides new insights into enzyme immobilization to overcome the critical short-term stability of enzyme-based electrochemical devices for practical applications.
\end{abstract}

\footnotetext{
* Corresponding author.

E-mail address: frankcrespilho@iqsc.usp.br (F.N. Crespilho).
} 


\section{Introduction}

The term "enzyme immobilization" was first used in 1971 to designate "enzymes physically confined or localized in a certain defined region of space with retention of their catalytic activities, and which can be used repeatedly and continuously" [1]. The use of immobilized enzymes in biocatalysis is of great interest in several areas, such as industrial processes and biodevices, because the anchoring of the enzyme on the support facilitates the handling of the enzyme, may solve the solubility problem of some enzymes, and enables the recovery and re-use of the enzyme [2]. However, to be attractive, the enzyme immobilization method should be easy, inexpensive, and reproducible. Especially in the development of electrochemical biodevices, such as biofuel cells (BFCs) and biosensors, the enzyme immobilization on the electrode surface plays a crucial role in achieving high-performance systems [3-6]. This is because the method of enzyme immobilization should promote an effective electronic connection between the redox site of the protein and the electrode surface, preserve the catalytic activity and the integrity of the enzyme, and allow an efficient substrate mass transport to the biocatalysts [3-6].

Adsorption by the drop-casting method is a traditional approach used to immobilize redox enzymes on electrode surfaces [7-12], because it is simple, fast, inexpensive, and suitable for different types of electrode materials and surfaces. However, because of the omnipresent coffee-ring effect, this method creates biocatalyst aggregates [13], which may contribute to a poor surface homogeneity, poor electrical communication and kinetic losses, and unsatisfactory cohesion due to the weak forces that keep the biomolecules adsorbed on the electrode surface, harming the electrode stability. A simple strategy to minimize the enzyme desorption from the electrode surface is by physical entrapment in a polymeric matrix or gel, for example Nafion ${ }^{\circledR}$ and chitosan [14], but these materials can represent a diffusion barrier [3]. Chemical binding between the functional groups of the enzyme molecules (crosslinking) and/or electrode surface covalent immobilization are alternative strategies to overcome the issues related to the biocatalyst leaching and mass transport, but they cause high enzyme activity loss [3]. Therefore, the development of robust and efficient bioelectrodes requires special attention to the method of enzyme immobilization, which will depend on the type of enzyme and substrate involved.

The enzyme immobilization should be carefully evaluated in oxygen reduction reactions (ORR) catalyzed by multicopper oxidases (MCOs), such as bilirubin oxidase (BOD) and laccase, because a gaseous substrate is involved. It is well known that the utilization of gas diffusion electrodes (GDEs) is extremely attractive, because they allow the gas permeability through a hydrophobic layer to reach the hydrophilic catalytic layer usually composed of MCOs immobilized on materials such as carbon nanotubes and nanoparticles [7,11,12,15-18], and porous carbon particles $[19,20]$. In this configuration, high catalytic current densities for ORR, even without redox mediators, have been reached $[12,18]$.

Despite considerable advances in bioelectrodes for ORR, some limitations remain. The underappreciated long-term stability and robustness restrict the use of BFCs in the medical field or in others that require a long-term application. In this context, here, we present a simple and efficient method for the immobilization and stabilization of BOD onto a carbon-based electrode by its incorporation into a gel matrix for efficient ORR in GDE. The gel matrix prevents the formation of enzyme aggregates by the coffee-ring effect, creates a suitable microenvironment for long-term enzyme activity, and simultaneously promotes a bio-threephase involved in the ORR: a gas phase, where the reacting molecular oxygen is present; the solid phase, composed of the biocatalyst; and the aqueous liquid electrolyte, which is important for enzyme functioning and is the destination of the reaction product.

\section{Experimental}

\subsection{Materials}

BOD (EC 1.3.3.5) from Myrothecium sp. was purchased from Amano Enzyme Inc. and used without further purification. The glutaraldehyde (GA) solution (25\%), Nafion ${ }^{\circledR} 117$ solution (5\%), carbon nanopowder $\left(<500 \mathrm{~nm}, 50-250 \mathrm{~m}^{2} \mathrm{~g}^{-1},>99.95 \%\right)$, nitric acid (70\%), and isopropanol (99.5\%) were obtained from Sigma-Aldrich. The poly(1,1,2,2tetrafluoroethylene) suspension (PTFE T-30, 60\%) was purchased from DuPont. The carbon black (Vulcan XC-72) was purchased from Cabot, and the carbon cloth was obtained from Stackpole Electronics, Inc. Prior to use, the carbon black and the carbon cloth were cleaned by a heating treatment at $450{ }^{\circ} \mathrm{C}$ in ambient atmosphere, followed by chemical treatment at $80{ }^{\circ} \mathrm{C}$ for $1 \mathrm{~h}$ with a $25 \%(\mathrm{v} / \mathrm{v})$ nitric acid solution. The phosphate buffer solution, pH $7.2\left(0.10 \mathrm{~mol} \mathrm{~L}^{-1}\right)$, was prepared with sodium phosphate monobasic (98-102\%) and sodium phosphate dibasic (98-102\%), which were obtained from Synth. All solutions were prepared with deionized water.

\subsection{BOD-based biogel preparation}

Initially, the Nafion ${ }^{\circledR} 117$ solution (5\%) was diluted in the phosphate buffer, $\mathrm{pH} 7.2$, at a 1:1 (v/v) ratio to obtain a Nafion salt solution and to prevent denaturation of the enzyme by local acidification [21]. The GA solution (25\%) was also diluted in the phosphate buffer $(\mathrm{pH} 7.2)$ at a $1: 10(\mathrm{v} / \mathrm{v})$ ratio. Then, a $0.14 \mathrm{mg} \mu \mathrm{L}^{-1}$ BOD solution in phosphate buffer $(\mathrm{pH} 7.2)$ was mixed with the Nafion diluted salt solution and GA diluted solution at a 1:1:1 (v/v/v) ratio. Afterward, this mixture was kept at $4{ }^{\circ} \mathrm{C}$ for $3 \mathrm{~h}$ in order to obtain the biogel (see Fig. 1a).

\subsection{BOD-based biogel/C GDE preparation}

The gas diffusion layer (GDL) was prepared as previously described by Paganin et al. [22] A homogeneous aqueous suspension composed of $70 \%(\mathrm{w} / \mathrm{w})$ carbon black and $30 \%(\mathrm{w} / \mathrm{w})$ PTFE was filtered under vacuum onto one face of the pre-treated carbon cloth to form the GDL using a loading (carbon + PTFE) of $3.0 \mathrm{mg} \mathrm{cm}^{-2}$. Next, the carbon + PTFE layer was baked onto the carbon cloth at $280{ }^{\circ} \mathrm{C}$ for $30 \mathrm{~min}$ to remove the dispersion agent contained in the PTFE suspension. Finally, it was sintered at $330^{\circ} \mathrm{C}$ for $30 \mathrm{~min}$, to obtain a thin film GDL over the entire surface of the carbon cloth [23]. After the preparation of the GDL, a suspension of carbon nanoparticles in isopropanol was dropped onto the top of it and homogenously spread with a brush until a loading of $1.0 \mathrm{mg} \mathrm{cm}^{-2}$ was obtained. After that, the isopropanol was dried under atmospheric conditions for approximately $2 \mathrm{~h}$. Next, $36.3 \mu \mathrm{L}$ of the previously prepared BOD-based biogel were dropped onto the top of the carbon nanoparticle layer (geometric area $=1.18 \mathrm{~cm}^{2}$ ) to form the catalytic layer on the GDE (BOD-based biogel/C GDE). Prior to use, the electrode was incubated at $4{ }^{\circ} \mathrm{C}$ overnight. An array of flexible carbon fibers was used as the electrical contact. The actual photo and schematic representation of the BOD-based biogel/C GDE are shown in Fig. 1b.

\subsection{Scanning electron microscopic measurements}

The samples were covered with a 6-nm-thick Au layer and kept in a desiccator until the analysis. SEM images were obtained using a FEI Magellan $400 \mathrm{~L}$ field-emission scanning electron microscope. The obtained images were used to evaluate the detailed morphology of the electrode surface.

\subsection{Micro-FTIR spectroscopic experiments}

For micro-FTIR spectroscopic measurements, seven different samples, including GA, Nafion salt and BOD, the binary mixtures Nafion + GA, BOD + Nafion and BOD + GA, and BOD-based biogel containing all 
a)
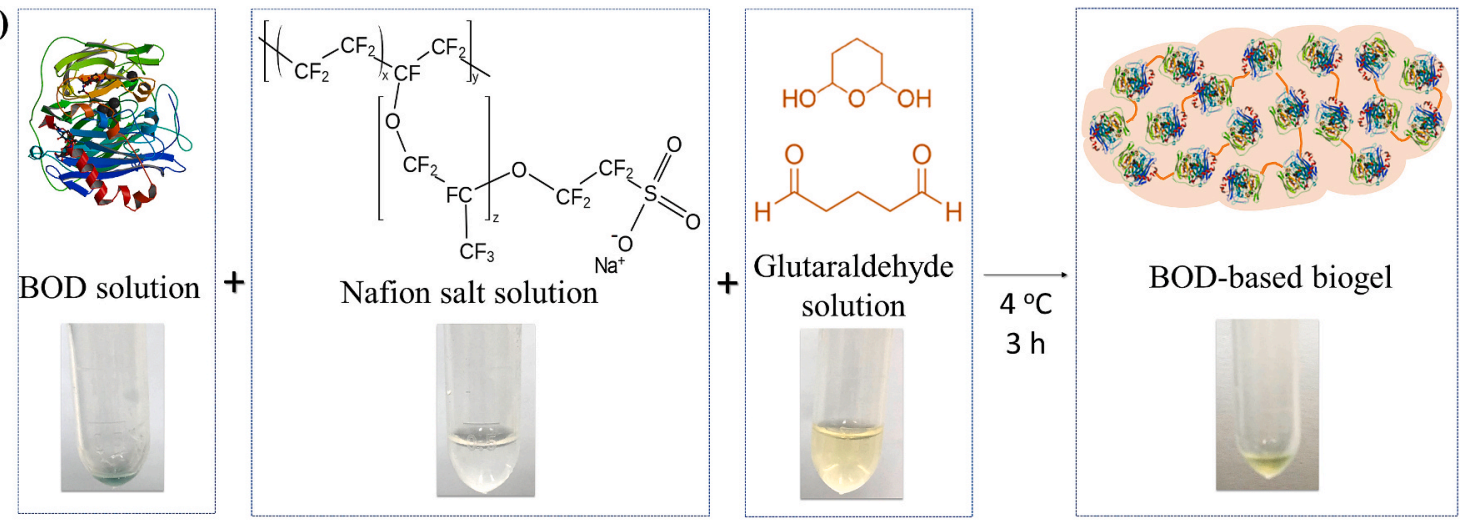

b)
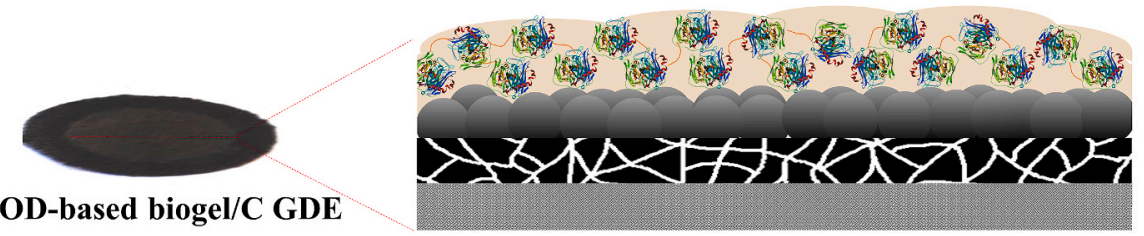

Catalytic layer

Gas-diffusion layer

Carbon cloth

Fig. 1. (a) Scheme of one-pot reaction for obtaining BOD-based biogel and (b) photo and schematic representation of BOD-based biogel/C GDE.

three constituents in phosphate buffer ( $\mathrm{pH}$ 7.2), were prepared. Approximately $2 \mu \mathrm{L}$ of each sample were initially drop-casted on the surface of a clean gold-coated glass substrate and on a glassy carbon (GC) plate, incubated at $4{ }^{\circ} \mathrm{C}$ overnight, and then dried in vacuum before analysis. The vibrational spectra were recorded in the reflectance mode using a Hyperion 3000 (Bruker) microscope coupled to a Vertex 70v FTIR spectrometer (Bruker). Each spectrum is a resultant of 32 scans with a spectral resolution of $4 \mathrm{~cm}^{-1}$. The absorption signals corresponding to the background were subtracted from the spectra of the samples.

FTIR chemical images were collected using a $64 \times 64$ element liquid $\mathrm{N}_{2}$-cooled focal plane array (FPA) detector. Each element of the FPA works as an individual detector, making the measurement of a full spectrum from a single point with a spatial resolution of $2.7 \mu \mathrm{m}$ possible when a $15 \times$ objective is used. Thus, this experimental setup allows the simultaneous collection of 4096 spectra, as previously reported [24]. To obtain the chemical maps, the area under an absorption band corresponding to a characteristic functional group from the sample was integrated and a color-coded image was built. Here, the blue color in the chemical maps represents regions in the sample with the lowest concentration of the compound of interest, and the pink color shows regions with the highest concentration of each particular signal. These chemical images were obtained in order to investigate the homogeneity and spatial distribution of the components in the BOD-based biogel.

\subsection{Electrochemical measurements}

Electrochemical measurements were performed using an Autolab PGSTAT128 N (Metrohm, Switzerland) galvanostat/potentiostat apparatus. BOD-based biogel/C GDE was used as working electrode in the electrochemical measurements under non-gas diffusion and gas diffusion conditions. The electrochemical measurements under non-gas diffusion condition were performed with the working electrode completely immersed in electrolyte and in a conventional electrochemical cell thermostated with a water jacket. Conversely, the electrochemical measurements under the gas diffusion condition were performed in a homemade glass electrochemical cell, as shown in Fig. S1. In this configuration, the catalytic layer (geometric area $=1.18$ $\mathrm{cm}^{2}$ ) of the BOD-based biogel/C GDE working electrode faces the electrolyte and the carbon cloth faces the air. A platinum mesh and an $\mathrm{Ag}$ / $\mathrm{AgCl} / \mathrm{KCl}_{\text {sat }}$ were used as the counter and reference electrodes, respectively. The measurements were performed in a phosphate buffer solution, pH $7.2\left(0.10 \mathrm{~mol} \mathrm{~L}^{-1}\right)$, under quiescent and atmospheric conditions. The temperature was controlled by using a thermostatic bath (GE-MultiTemp IV Thermostatic Circulator, $0.01{ }^{\circ} \mathrm{C}$ resolution).

For the rotatory disc electrode (RDE) experiments, a Pine Instruments Rotator (Pine Research Instrumentation, USA) coupled to an Autolab PGSTAT128 N (Metrohm, Switzerland) galvanostat/potentiostat was used. A GC electrode (from Pine Research Instrumentation, USA) with geometric area equal to $0.196 \mathrm{~cm}^{2}$ was employed as the working electrode. Prior to the measurements, the GC electrode was polished in alumina $0.05 \mu \mathrm{m}$, sonicated in deionized water for $5 \mathrm{~min}$, and then dried in a $\mathrm{N}_{2}$ atmosphere. A suspension of carbon nanoparticles was dropped onto the GC surface until the load of $1.0 \mathrm{mg} \mathrm{cm} \mathrm{cm}^{-2}$ was attained, as previously described. Next, an appropriate volume of the previously prepared BOD-based biogel was dropped onto the top of the carbon nanoparticles layer. The electrode was incubated at $4{ }^{\circ} \mathrm{C}$ overnight before the measurements.

\section{Results and discussion}

\subsection{Crosslinking between the components of the BOD-based biogel}

FTIR spectroscopy in the mid-region is a sensitive technique for probing the structural changes of bio-organic compounds based on the changes observed in the spectral band positions and their intensities. The FTIR spectra of the BOD-based biogel, its individual components, and binary mixtures recorded in the reflectance mode are shown in Fig. 2a. The vibrational assignments of the absorption signals observed in the spectra of the individual components are given in Table S1, according to previous reports [25-30]. The characteristic vibrational modes corresponding to the specific functional groups of each compound are clearly observed in the respective spectra (Fig. S2). For example, the FTIR spectrum of the GA shows absorption signals at 1713 and $1128 \mathrm{~cm}^{-1}$ that are attributed to $\mathrm{C}=\mathrm{O}$ stretching and deformation modes, respectively $[27,28]$, which indicate the presence of a free aldehyde form in the conditions that the biogel was prepared. In addition, the signals at 1677 and $1063 \mathrm{~cm}^{-1}$ are assigned to $\mathrm{O}-\mathrm{H}$ bending and $\mathrm{C}-\mathrm{O}$ (from alcohol) stretching vibrational modes and indicate the cyclization of GA (Eq. S1) [31]. With regard to Nafion, the characteristic absorption signals are observed at 980 (C-O-C stretching), 1060, and $1315 \mathrm{~cm}^{-1}$, (sulfonic group symmetric and asymmetric stretching, 


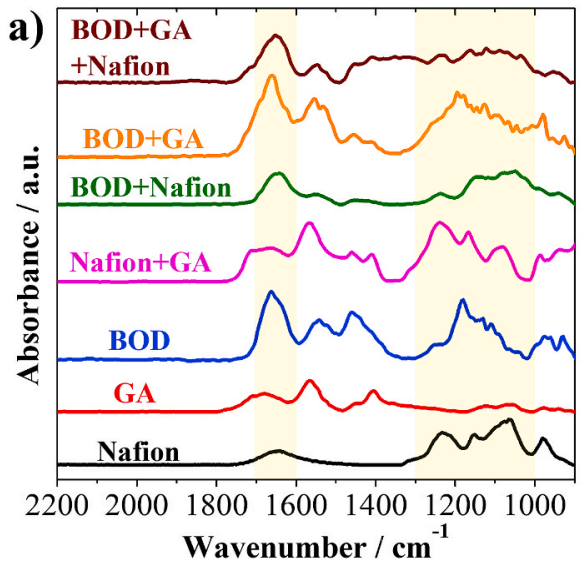

c)

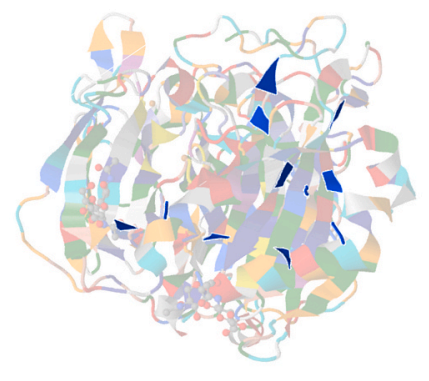

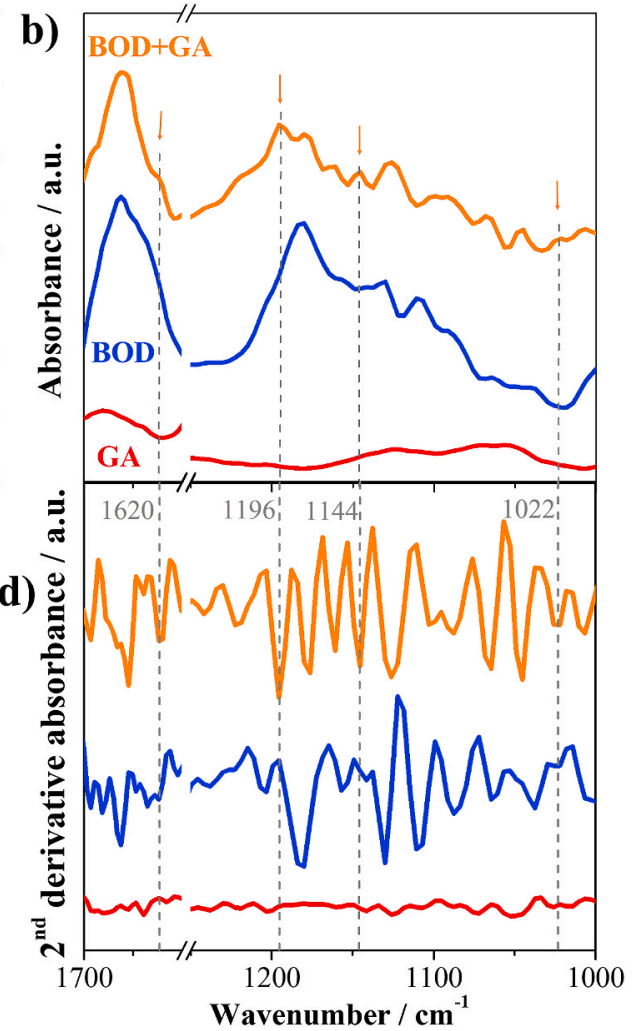

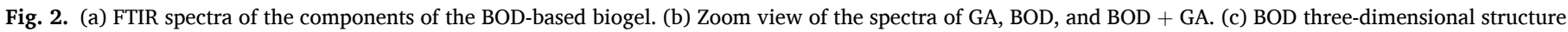

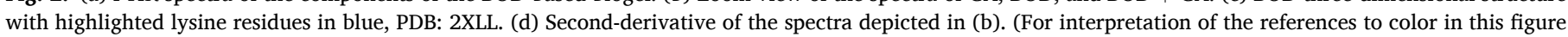
legend, the reader is referred to the Web version of this article.)

respectively), 1150 and $1233 \mathrm{~cm}^{-1}\left(\mathrm{CF}_{2}\right.$ symmetric and asymmetric stretching, respectively) [26]. Likewise, in the spectrum of the BOD sample, the characteristic amide-I and amide-II vibrational modes can be observed at 1663 and $1543 \mathrm{~cm}^{-1}$, respectively [30].

Most of the above-mentioned absorption signals in the GA, Nafion, and BOD spectra are also observed in the mixtures of these components. Nevertheless, the interaction between some of the components of the biogel was confirmed from the appearance of some peaks in the FTIR spectra of the mixtures that are not present in the spectra of the individual components. For instance, some new peaks appear at various positions in the FTIR spectrum of the mixture of GA + BOD when compared to the individual spectra of each component, as shown in Fig. 2b. The emergence of the peaks at 1620, 1196, 1144, and $1022 \mathrm{~cm}^{-1}$ are possibly due to the $\mathrm{C}=\mathrm{N}$ stretching mode in the first case, and $\mathrm{C}-\mathrm{N}$ stretching modes in the latter cases (Eqs. S2-S3). These vibrational modes indicate the crosslinking of enzyme molecules through the reaction with GA. The aldehyde functional groups in GA are expected to form Schiff bases upon nucleophilic attack by the side-chain amino group of lysine residues of BOD (Fig. 2c) [32]. To maximize the visualization of overlapped absorption signals [33], the second-derivative spectra are presented (Fig. 2d). The second-derivative spectra show the spectral features of the samples and some low intensity signals, which are considered as spectral noise. The second-derivative spectra of GA, BOD and GA + BOD allows a clearer visualization of the emerged peak in the GA + BOD mixture, which are not present in the spectra of the individual compounds. Conversely, no significant changes are observed in the FTIR spectra when Nafion is combined with GA or BOD, as visualized in Fig. S3. Finally, the spectrum of the biogel exhibits practically the same profile as the mixture of GA and BOD, alongside some features from Nafion, suggesting that the same kind of interaction occurs in the biogel as in the mixtures of GA and BOD and no chemical bonds are formed between Nafion and the other components of the biogel. These observations are expected, and they confirm that Nafion works only as a polymeric network for physical entrapment of BOD. Although Nafion is known for promoting enzyme denaturation in some cases, previous circular dichroism results showed that the secondary structure of BOD is not affected in presence of buffered Nafion membrane, confirming the integrity of the enzyme structure upon immobilization by entrapment into Nafion when in a buffered environment [21].

\subsection{BOD-based biogel homogeneity}

The homogeneity of a BOD-based biogel film compared with a film of bare-BOD in a phosphate buffer was qualitatively evaluated by optical microscopy (reflectance mode) and micro-FTIR spectroscopy (Fig. 3a). A bare BOD-film (Fig. 3b and c) and BOD-based biogel (Fig. 3d and e) were assembled on a gold-coated glass substrate by drop-casting few microliters of each sample onto the substrate. The difference in contrast across the optical microscopic images can be related to the local concentrations and local thicknesses of the samples. Fig. 3d shows a thin film of BODbased biogel on the gold substrate, without any visible aggregate over the border area (Fig. 3e). Some aggregates are observed in the inner region of the droplet (Fig. 3d), which are caused by the phosphate salt crystallization, as the sample was fully dried before analysis, or nonreacting GA. Conversely, the microscopic images of the bare BOD-film on the gold substrate (Fig. $3 \mathrm{~b}$ and c) reveal ring-shaped structures indicated by a darker contrast over the border and in the inner region of the droplet, where enzyme molecules were accumulated. In addition, phosphate salt precipitate is also observed in the bare BOD film. The deposition of matter along the original drop edge after the evaporation of a solvent is known as the coffee-ring effect [34]. This phenomenon has been reported during the redox enzyme immobilization [13] and happens during the solvent evaporation, when the edges of the drop become 


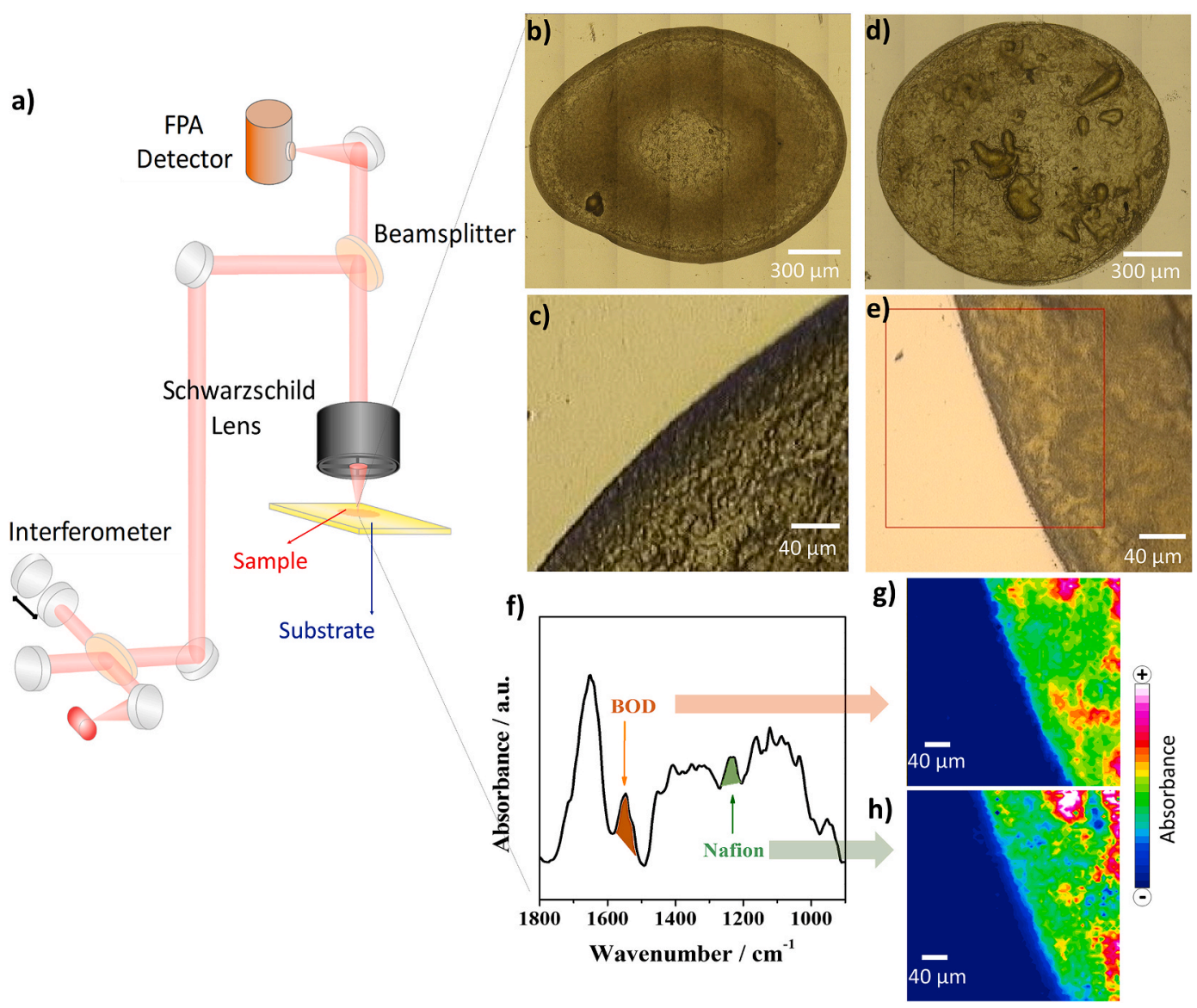

Fig. 3. (a) Micro-FTIR setup with FPA detector. (b-e) Optical images of the bare-BOD film (b, c) and BOD-based biogel (d, e) on gold-coated glass substrate. The red square in (e) indicates the area selected to record the spectra and used to build the chemical images. (f) FTIR spectrum of the BOD-based biogel showing the signals integrated for obtaining the chemical images. $(\mathrm{g}, \mathrm{h})$ Chemical images showing the distribution of $1543 \mathrm{~cm}^{-1}$ (amide-II) and $1233 \mathrm{~cm}^{-1}\left(\mathrm{CF}_{2}\right.$ asymmetric stretching) spectral bands of BOD and Nafion, respectively. (For interpretation of the references to color in this figure legend, the reader is referred to the Web version of this article.)

pinned to the solid substrate, and the outward capillary flow from the center of the drop brings the nonvolatile component to the edge of the droplet [35]. Characteristics similar to those of the BOD-based biogel and bare-BOD films immobilized on the gold substrate are also obtained for the GC platform; the BOD-based biogel film (Figs. S3a-b) shows some salt aggregates and no coffee-ring feature, whereas a ring-like deposit is observed for the bare-BOD film (Figs. S3c-d) on the carbon-based platform. These observations indicate the interactions between the BOD molecules by the crosslinking via the reaction with GA, and its entrapment into a Nafion network prevents the BOD agglomeration during the enzyme immobilization on the gold and GC substrates, which can be used as electrode surfaces.

The micro-distribution of the compounds in the biogel was investigated by micro-FTIR chemical imaging (Fig. $3 \mathrm{f}-\mathrm{h}$ ). The red square area in Fig. 3e was selected for the collection of the spectra to build the chemical images. The FTIR spectrum of the BOD-based biogel in Fig. $3 \mathrm{f}$ highlights the bands that are mostly attributed to BOD and Nafion; these bands were integrated to obtain the spatial distributions (Fig. $3 g$ and $h$ ) of these components in the biogel. No specific absorption signal could be assigned exclusively to GA; therefore, its distribution within the biogel could not be investigated. The spatial distribution of the BOD (amide-II signal) at the interfacial region is shown in Fig. $3 \mathrm{~g}$, where it is observed the presence of some islands indicating accumulation of enzyme or a thicker layer of biogel in those regions. A similar type of distribution is observed for Nafion $\left(\mathrm{CF}_{2}\right.$ asymmetric stretching) in Fig. 3h, which suggests that BOD is incorporated into the Nafion network in the structure of the biogel. Based on the measurement of similar micrometer-scaled chemical distribution of the components into the biogel, we conclude that BOD is effectively entrapped into the Nafion polymeric network. In addition, the chemical maps show no accumulation of BOD or Nafion into the edge of the samples, evidencing that the coffee-ring effect does not occur when the BOD-based biogel is immobilized on a flat surface.

\subsection{Bioelectrochemical performance of BOD-based biogel/C electrode}

The electrochemical behavior of the BOD-based biogel/C on GDL platform was first investigated by cyclic voltammetry (CV) in the absence of $\mathrm{O}_{2}$. The $\mathrm{CV}$ curve in Fig. 4a shows two distinctive redox couples that are absent in the enzyme-free electrode. The redox couple I/ II with formal potential $\left(E^{0}\right)$ equal to $0.51 \mathrm{~V}$ (all potentials reported here are referenced to $\mathrm{Ag} / \mathrm{AgCl} / \mathrm{KCl}_{\text {sat }}$ ) is attributed to the $\mathrm{Cu}^{+} / \mathrm{Cu}^{2+}$ redox reaction in the $\mathrm{T} 1$ site of $\mathrm{BOD}$, which is the primary center where electrons from the electrode are received [36-38]. The second redox couple with $E^{0}$ equal to $0.16 \mathrm{~V}$ is in good agreement with the data reported for reduction and oxidation of the T2/T3 $\mathrm{Cu}$ center of the enzyme [39], which acts as an electronic bridge in the internal electron transfer mechanism to promote the reduction of dioxygen [21]. As previously reported, the peaks corresponding to reduction and oxidation of the T1 $\mathrm{Cu}$ site are less defined in neutral media as a result of the change of bond length between this $\mathrm{Cu}$ atom and the ligand groups and the special arrangement of this site $[39,40]$. These results indicate an efficient direct electrical communication between the enzyme and the carbon nanoparticles, which is usually desirable in enzyme-based BFCs and 

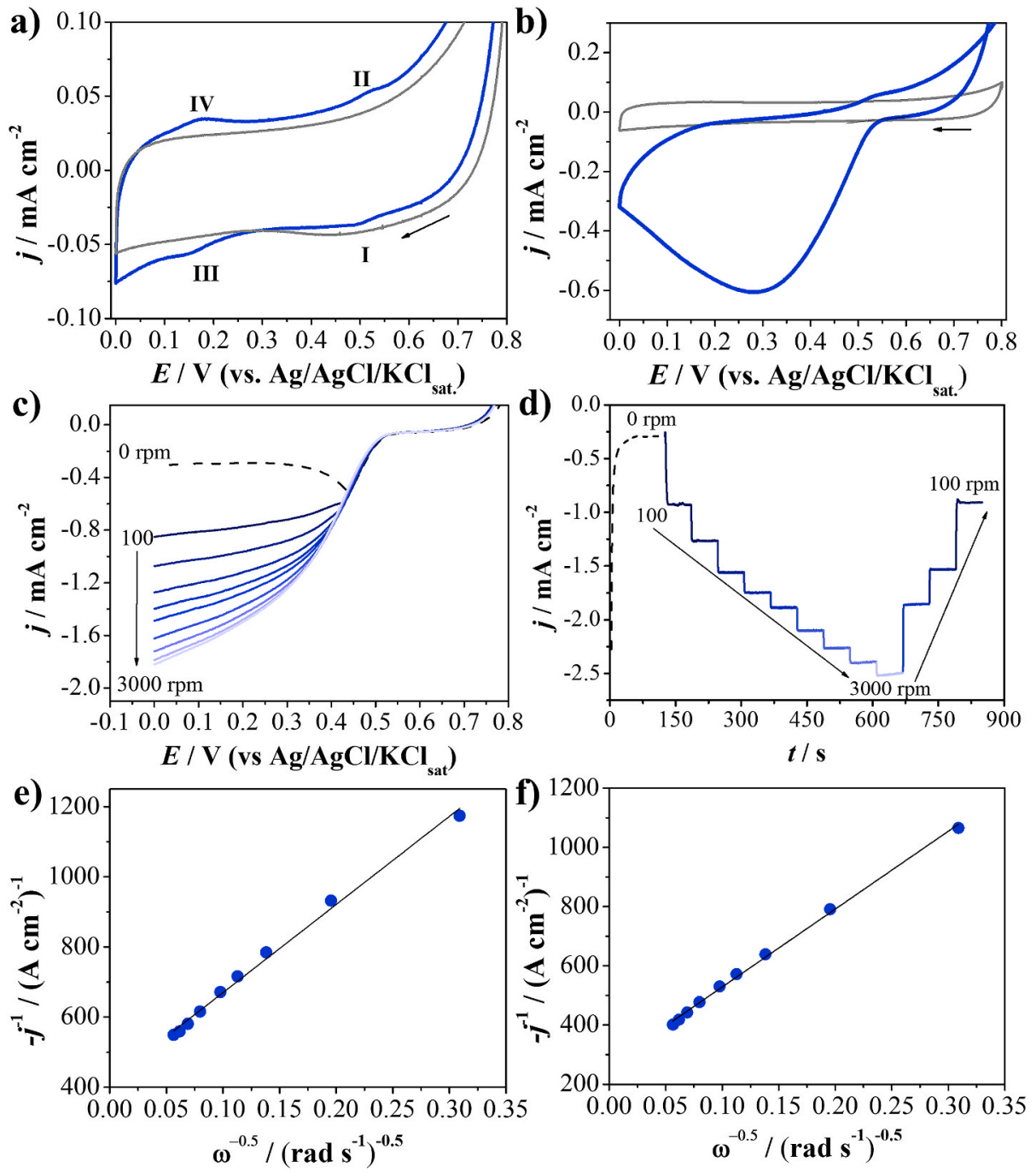

Fig. 4. $\mathrm{CVs}$ at $5 \mathrm{mV} \mathrm{s}^{-1}$ in phosphate buffer $\mathrm{pH} 7.2$ at $25{ }^{\circ} \mathrm{C}$ obtained with BOD-based biogel/C on the GDL platform (blue curves) and enzyme-free electrode (gray curves) in absence of $\mathrm{O}_{2}$ (a) and in electrolyte saturated with $\mathrm{O}_{2}$ in non-gas diffusion mode (b). The arrows indicate the potential scan direction. (c) Linear voltammograms at $5 \mathrm{mV} \mathrm{s}^{-1}$ and (d) chronoamperogram at $0.00 \mathrm{~V}$ of BOD-based biogel/C on $\mathrm{GC} \mathrm{RDE}$ in $\mathrm{O}_{2}$-saturated phosphate buffer $\mathrm{pH} 7.2$ at $25{ }^{\circ} \mathrm{C}$, at quiescent condition (dashed lines) and under different electrode rotation rates $(100,250,500,750,1000,1500,2000,2500$, and $3000 \mathrm{rpm}$, solid lines). Koutecky-Levich plots obtained from linear voltammograms (e) and chronoamperograms (f). (For interpretation of the references to color in this figure legend, the reader is referred to the Web version of this article.) biosensors. Therefore, we demonstrate the direct electron-transfer (DET) between BOD and nonfunctionalized carbon particles, which had been previously only observed on gold electrodes [40], carbon nanotube-based electrodes [7,12,18,38,39,41-43], and spectrographic graphite electrodes [40,44].

The reduction of dissolved dioxygen in phosphate buffer ( $\mathrm{pH} 7.2$ ) catalyzed by BOD was initially investigated by CV. Fig. 4b shows the CV obtained with the BOD-based biogel/C on the GDL platform, in non-gas diffusion mode, and in the presence of $\mathrm{O}_{2}$ dissolved in the electrolyte and in the absence of $\mathrm{O}_{2}$ for comparison. In the presence of $\mathrm{O}_{2}$, a large cathodic wave with onset potential at ca. $550 \mathrm{mV}$ is observed, which is very close to the thermodynamic potential of ORR to water $(607 \mathrm{mV}$ vs. $\mathrm{Ag} / \mathrm{AgCl} / \mathrm{KCl}_{\text {sat }}, \mathrm{pH}$ 7.2) and agrees with the previously reported potential of non-mediated ORR catalyzed by BOD [40,45]. In contrast, on an enzyme-free carbon electrode, the ORR occurs with high overpotential, with onset potential at ca. $-40 \mathrm{mV}$ (Fig. S5). The peak-shaped catalytic wave observed in Fig. 4b indicates that the electrochemical process is controlled by the diffusion of $\mathrm{O}_{2}$ species toward the electrode surface. The mass transport effect is evident when the electroactive coverage of the enzyme is very high, and often occurs when the enzyme is embedded in a gel or if a very rough surface is employed, such as that made by nanoparticulated materials [46].

In order to investigate the effect of the $\mathrm{O}_{2}$ mass transport and to obtain information about the bioelectrochemical reaction, experiments with RDE were performed. Fig. $4 c$ shows the linear voltammograms obtained with a BOD-based biogel/C on GC RDE at different rotation rates. Typical and sigmoidal cathodic waves are observed under RDE conditions. It can be seen that in the potential range from 0.55 to $0.45 \mathrm{~V}$, the current densities are independent on the electrode rotation rate, which indicates that in this potential range the observed current densities are almost purely controlled by electron-transfer kinetics [47]. At high overpotentials (potentials close to $0 \mathrm{~V}$ ), where the interfacial electron transfer is very fast, the reduction currents increase gradually with the electrode rotation rate, indicating a diffusion-convection control. It is worth mentioning that the CVs were recorded under quiescent and $\mathrm{O}_{2}$-saturated electrolyte and in non-gas diffusion mode (blue curve in Fig. $4 \mathrm{~b}$ and dashed curve in Fig. 4c) show different shapes. This difference occurs because when BOD-based biogel is immobilized on the GDL platform, $\mathrm{O}_{2}$ can additionally reach the BOD-catalytic layer (Fig. 4b) from the back side to the electrode (GDL face), whereas in the case of BOD-based biogel immobilized on GC RDE (Fig. 4c), the $\mathrm{O}_{2}$ can only reach the catalytic layer by the electrode face (catalytic layer). Therefore, in the first case, the $\mathrm{O}_{2}$ diffusion is enhanced and the related CV shows a higher reduction peak current density and a wider peak. Fig. $4 \mathrm{~d}$ presents the chronoamperograms at $0.00 \mathrm{~V}$ of the BOD-based biogel/C electrode under RDE conditions, where the dependence of the limiting current on the increase and decrease of the electrode rotation rate can be observed. The stability of the BOD-based biogel/C electrode is demonstrated by the agreement between the limiting reduction currents at the same rotation rate in the beginning and at the end of the experiments (Fig. 4d). From Koutecky-Levich plots (Fig. 4e and $f$ ) and the Levich equation (Eq. S4), the number of electrons 
involved in the ORR was calculated to be $3.9 \pm 0.2$ ( $95 \%$ of confidence interval, and $\mathrm{n}=4$ ), as expected for the ORR catalyzed by BOD, even at near $\mathrm{pH} 7$.

\subsection{BOD-based biogel/C GDE}

Because the catalytic current is limited by the slow diffusion of $\mathrm{O}_{2}$ toward the electrode surface and by the very low solubility of this reacting specie in aqueous solution, the use of a gas diffusion biocathode is imperative to reach high-performance biodevices, such as BFCs and bioreactors $[48,49]$. In this context, the BOD-based biogel/C (catalytic layer) was assembled onto a hydrophobic GDL supported on the carbon cloth to form the GDE, as shown in Fig. 1b. The SEM images of the GDL in Fig. 5a show the presence of PTFE strands that promote the agglomeration of the carbon black nanoparticles, providing a porous structure formed by microstructured channels (Fig. 5a), which allow the efficient supply of $\mathrm{O}_{2}$. In addition, the combination of carbon black and PTFE simultaneously ensures electrical conductivity, mechanical stability, and water repellency for the electrode. Additionally, carbon nanoparticles were deposited on the top of the GDL to provide a higher effective surface area for enzyme immobilization and high electrical conductivity. The SEM images of the carbon nanoparticles layer in Fig. 5b show near spherical nanoparticles with a diameter of $38 \pm 2 \mathrm{~nm}$ (Fig. S6).

The SEM images displayed in Fig. 5c show a dense and homogenous layer of the BOD-based biogel with $2.1 \pm 0.2 \mu \mathrm{m}$ in thickness on top of the carbon nanoparticles. Additionally, the presence of several cracks in this layer is observed, which can generate the bio-three-interface (as represented in Fig. 6a): gas phase, where the reacting molecular oxygen is present; the solid phase, where the biocatalyst is present; and the aqueous liquid electrolyte, which is important for enzyme functioning and is the destination of the reaction product. a)

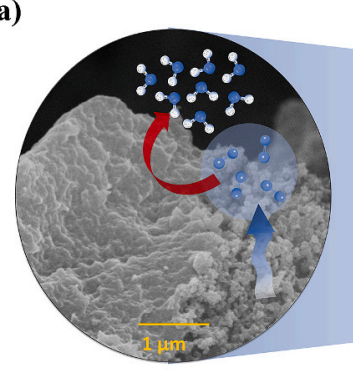

c)

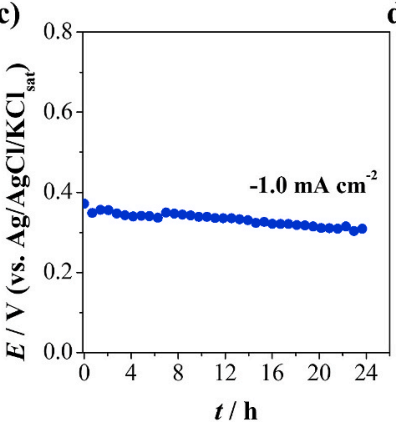

b)

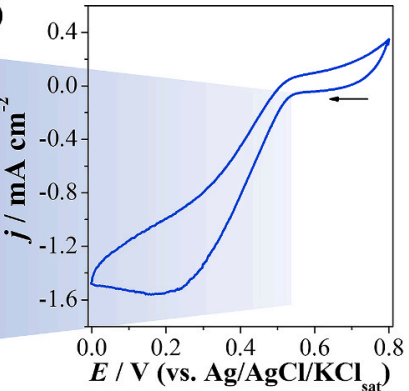

d)

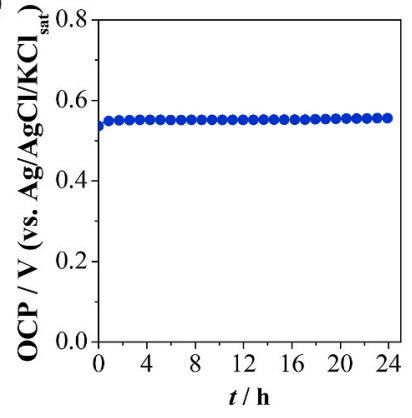

Fig. 6. (a) Scheme of ORR on BOD-based biogel/C GDE. The blue and white spheres represent the oxygen and hydrogen atoms, respectively. The blue arrow indicates the diffusion of atmospheric dioxygen and the red arrow represents the ORR catalyzed by BOD-based biogel. (b) $\mathrm{CV}$ at $5 \mathrm{mV} \mathrm{s}^{-1}$, (c) operational stability at $-1.00 \mathrm{~mA} \mathrm{~cm}^{-2}$, and (d) at open circuit potential of the BOD-based biogel/C GDE in phosphate buffer (pH 7.2) at $25{ }^{\circ} \mathrm{C}$, under atmospheric condition. (For interpretation of the references to color in this figure legend, the reader is referred to the Web version of this article.)
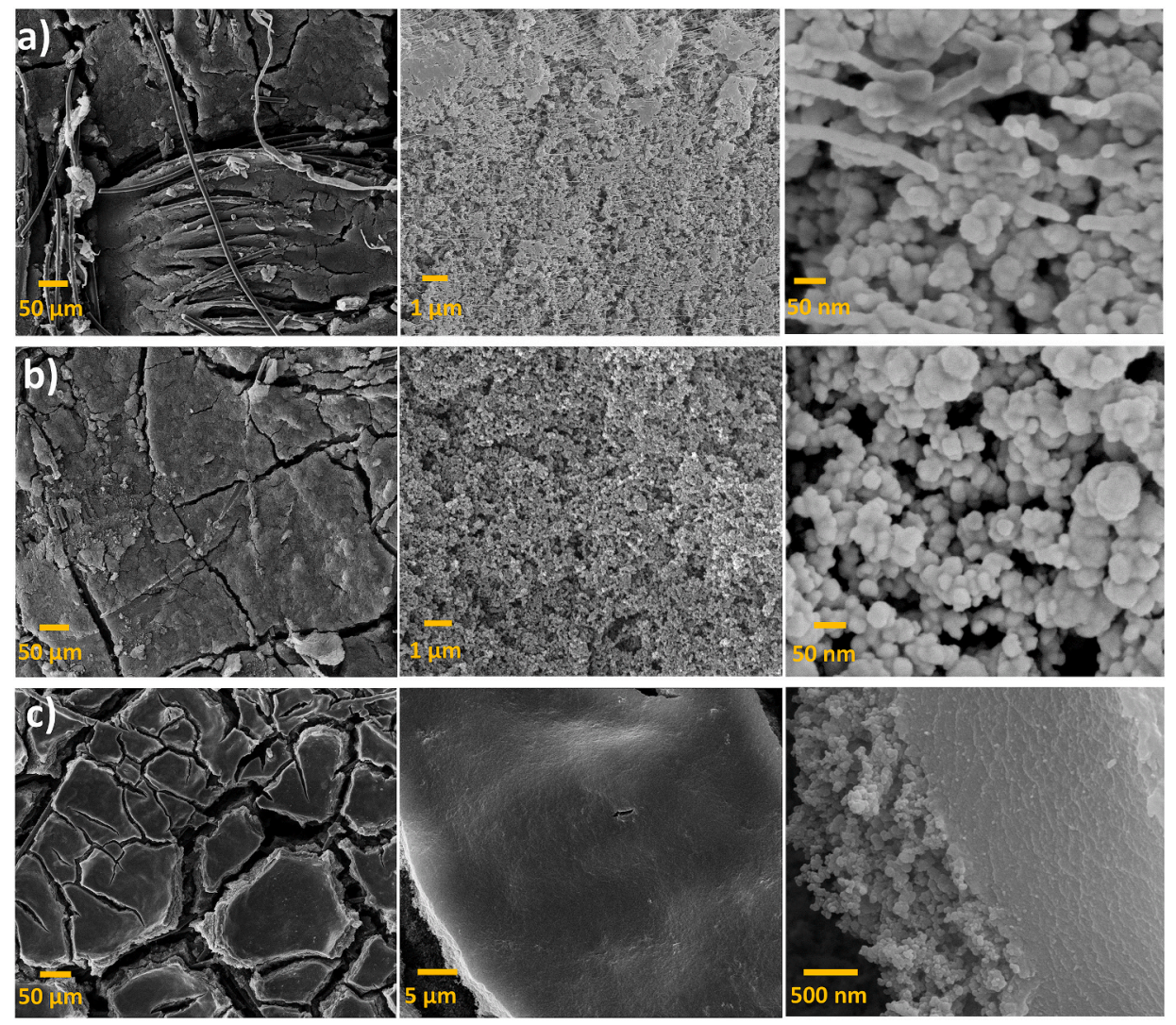

Fig. 5. SEM images at different magnifications of the (a) GDL, (b) carbon nanoparticles layer on the top of GDL, and (c) BOD-based biogel on the top of carbon nanoparticles layer. 
The electrochemical performance of the BOD-based biogel/C GDE toward the ORR was evaluated under atmospheric conditions. Fig. 6b shows the CV obtained with the BOD-based biogel/C GDE, where we observe an onset potential value of ca. $555 \mathrm{mV}$ for ORR, which agrees well with the onset potential value of the reduction reaction of $\mathrm{O}_{2}$ dissolved in the electrolyte (Fig. 4b). The maximum current density reached $-1.52 \pm 0.24 \mathrm{~mA} \mathrm{~cm}^{-2}$ at $0.19 \pm 0.06 \mathrm{~V}$ (based on a t-distribution with $90 \%$ confidence interval, and $n=4$ ), which is about 2.5 times higher than the maximum current density obtained in dissolved $\mathrm{O}_{2}$ in the quiescent electrolyte (Fig. $4 \mathrm{~b}$ ). To investigate the effect of cracks in the catalytic layer on the maximum reduction current, the BOD-based biogel on the top of the carbon nanoparticles was dried under different atmospheric conditions, because the solvent evaporation rate governs the pattern of cracks [34]. When the evaporation rate is lowered by the drying procedure at $25 \pm 5^{\circ} \mathrm{C}$ and humidity about $60 \%$ overnight, fewer cracks are expected, and the maximum catalytic current density obtained is $0.99 \mathrm{~mA} \mathrm{~cm}^{-2}$ at $0.00 \mathrm{~V}$ (Fig. S7a), which represents a decrease of $35 \%$ as compared with the electrode dried at $4{ }^{\circ} \mathrm{C}$. Moreover, when the electrode is quickly dried in vacuum and room temperature, and more cracks are produced, the maximum catalytic current density obtained is $1.43 \mathrm{~mA} \mathrm{~cm}$ c $^{-2}$ at $0.11 \mathrm{~V}$ (Fig. S7b), similar to that observed in Fig. 6a. The results indicate that the number of cracks on BOD-based biogel layer directly affects the BOD-based biogel/C GDE performance, improving the effective bio-three-phase interface for ORR. When fewer cracks are formed in the catalytic layer, this interface occurs only in the electrolyte channels formed by Nafion polymeric network [22] in the BOD-based biogel layer.

For practical use, the long-term stability of gas diffusion bioelectrodes toward ORR is a crucial factor. Although there are some reports $[7,12,18,50-53]$ that show higher catalytic currents without redox mediators, to the best of our knowledge, none of them details about the long-time performance of the BOD-based GDEs (Table S2), reflecting the challenge of simultaneously attaining long-term stability and satisfactory catalytic current. In this context, the stability of the BOD-based biogel/C GDE was further examined under constant operation for $24 \mathrm{~h}$ in galvanostatic regime. At $-1.00 \mathrm{~mA} \mathrm{~cm}^{-2}$ (Fig. 6c), initially the gas diffusion bioelectrode shows a potential equal to $0.37 \mathrm{~V}$, which is the expected potential according to the CV (Fig. 6b), and over $24 \mathrm{~h}$, the potential slightly decreases to $0.31 \pm 0.01 \mathrm{~V}$. After $24 \mathrm{~h}$ of operation, the CV (Fig. S8) shows a similar profile to that initially obtained (Fig. 6b). The smaller current densities observed corroborate the stability measurements over $24 \mathrm{~h}$. The electrode stability was also evaluated at smaller current density, $-0.20 \mathrm{~mA} \mathrm{~cm}^{-2}$, when the current is controlled by electron-transfer rate (Fig. S9). Under those conditions, biocathode potential slightly decreases from 0.50 to $0.45 \pm 0.01 \mathrm{~V}$. The slight decline in the biocathode operation performance may indicate the denaturation or leaching of a small portion of enzyme from the electrode surface. Despite the slight performance decrease, the results demonstrate unprecedented stability of a BOD-based electrode under constant operation, which is desirable for practical application in biofuel cells. Additionally, the biocathode storage stability in electrolyte was evaluated for $24 \mathrm{~h}$, under open-circuit potential (OCP), as shown in Fig. 6d. Under non-operation condition, the bioelectrode potential is maintained at $0.55 \mathrm{~V}$ over $24 \mathrm{~h}$, evidencing a high storage stability.

As shown in Fig. $5 \mathrm{c}$, a thick layer $(2.1 \pm 0.2 \mu \mathrm{m})$ of BOD-based biogel covers the carbon nanoparticle layer, therefore it is expected that only the enzyme portion closer to the biogel-electrode interface is electrically connected to the electrode surface and contributes to the biocatalytic current. To investigate the portion of enzymes that is active toward ORR, GDEs with lower amounts of BOD-based biogel were prepared to produce $30 \%$ and $50 \%$ thinner catalytic layers. All bioelectrodes show the same voltammetric behavior under atmospheric conditions (Fig. S10a). It is observed that the decrease by $30 \%$ of BOD-based biogel amount does not significantly affect the maximum current density toward ORR compared to the regular BOD-based biogel/C GDE $(-1.52 \pm 0.24 \mathrm{~mA}$ $\mathrm{cm}^{-2}$ ), whereas the decrease by $50 \%$ of BOD-based biogel amount provide a slight decrease in the maximum current density to $-1.29 \pm$ $0.04 \mathrm{~mA} \mathrm{~cm}^{-2}$ (Fig. S10b). This result indicates that only around $50 \%$ of BOD molecules embedded in the biogel can electrically connect to the electrode surface, otherwise current density would decrease at the same proportion of the BOD-based biogel amount. However, the operational stability of the bioelectrode is drastically affected when the amount of BOD-based biogel is reduced to $50 \%$ (Fig. S10c). The electrode potential severely decreases from $0.38 \mathrm{~V}$ to $0.10 \mathrm{~V}$ in $5 \mathrm{~h}$ at $-0.50 \mathrm{~mA} \mathrm{~cm}$. Therefore, it can be concluded that, although only around $50 \%$ of BODbased biogel contributes to the ORR current of the GDE, the thick biocatalytic layer $(2.1 \pm 0.2 \mu \mathrm{m})$ is important to guarantee the operational stability of the bioelectrode. The higher stability of the bioelectrodes with thicker BOD-based biogel film may be attributed to the mitigation of leaching of enzyme molecules electrically connected to the electrode surface. The thick film works as a protective layer against leaching of the BOD molecules electrically connected to the carbon nanoparticles, contributing to the operational stability of our bioelectrode. Thick catalytic layer has been already reported to contribute to the operational stability of metal-based GDEs toward ORR because mitigates the loss of catalyst active sites [54].

The satisfactory reduction current density and high electrode stability can be also attributed to the stabilization of BOD resulting from confinement in the gel matrix. For this, a systematic study was performed to investigate the role of Nafion and GA in the biocathode performance. UV-Vis measurements (Fig. S11) shows that the BOD entrapment into Nafion polymeric network in the structure of biogel is responsible to reduce the enzyme leaching to $44 \%$ as compared to BOD immobilized on the GDL (BOD/C GDE). This latter was obtained by the simple drop-casting method, which consists of the direct application of the enzyme solution to the carbon nanoparticles, followed by drying. Also, this traditional method of enzyme immobilization provided lower catalytic current density at small and high overpotentials, indicating a slower electron transfer rate and poorer $\mathrm{O}_{2}$ mass transport (Fig. S12a) compared to the BOD-based biogel/C GDE. As expected, the operational stability of the BOD/C GDE (Fig. S12b) is drastically decreased, as the enzyme can easily leach from the electrode surface. In addition, the effect of crosslinking by GA reaction on the biocathode performance was investigated (Fig. S13). The immobilization of BOD on carbon nanoparticles by the entrapment into Nafion matrix (BOD-Nafion/C GDE) without crosslinking of enzyme molecules by GA, similarly to BOD/C GDE, provided lower catalytic current density toward ORR at small and high overpotentials, compared to BOD-based biogel/C GDE. The results demonstrate that GA contributes to enhance the catalytic currents, as more enzyme molecules can be electrically connected to the electrode due to the crosslinking effect. However, it is not expected that BOD crosslinking by GA reaction affects the operational stability of the BODbased biogel/C GDE, as the crosslinked BOD molecules easily leach from the electrode surface, as on BOD/C GDE (Fig. S11).

Based on the electrochemical and spectroscopic studies we can state that the BOD confinement in the gel matrix, with concomitant crosslinking by GA reaction and physical entrapment into Nafion polymeric network, is important to reach high bioelectrode performance and stability toward ORR. Several combined factors can contribute to that, as follows:

- The incorporation of BOD into the gel matrix avoids the accumulation of enzyme into the edge of the electrode surface, preventing the coffee-ring effect (Fig. $3 \mathrm{~b}$ and c).

- The gel matrix provides a microenvironment able to maintain the integrity of the enzyme structure and the redox activity (Fig. 4).

- BOD-based biogel enables a more effective interaction and higher electron transfer rate between BOD molecules and the electrode surface compared to the enzyme immobilization by the simple dropcasting method (Fig. S12).

- BOD is effectively entrapped into the Nafion polymeric network (Fig. 3f). That entrapment is responsible to reduce the enzyme 
leaching compared to BOD immobilized on the GDL by drop-casting method and enzyme crosslinking with GA (Fig. S11).

- GA effectively provides the crosslinking of BOD molecules (Fig. 2) and this effect contributes to enhance the catalytic currents, as more enzyme molecules can be electrically connected to the electrode (Fig. S13).

- The thick BOD-based biogel catalytic layer (ca. $2 \mu \mathrm{m}$ ) is important to reach longer operational stability (Fig. S10). The thick film works as a protective layer against leaching of the BOD molecules electrically connected to the carbon nanoparticles.

\section{Conclusions}

This study shows a simple method for the immobilization and stabilization of BOD for application in a carbon-based gas diffusion bioelectrode toward dioxygen reduction. The enzyme was incorporated into a gel matrix by the BOD crosslinking inside of a polymeric matrix composed of GA and Nafion. The microscopic and spectroscopic measurements showed that the BOD-based biogel prevents the formation of enzyme aggregates on hydrophobic surfaces by suppressing the coffeering effect. Additionally, the electrochemical measurements showed that the biogel creates a suitable microenvironment for the DET-type bioelectrocatalysis of BOD toward four-electron electrochemical ORR. The BOD-based biogel/C GDE showed a satisfactory reduction current density of $-1.52 \pm 0.24 \mathrm{~mA} \mathrm{~cm}^{-2}$ at $0.19 \pm 0.06 \mathrm{~V}$ and unprecedented long-term stability under continuous operation. The BOD-based biogel layer thickness, in addition to entrapment into Nafion polymeric network, play important roles in the electrochemical stability of the biocathode, avoiding the leaching of the BOD molecules electrically connected to the electrode surface. This study also provides new insights into the enzyme immobilization field for application in bioelectrocatalytic systems involving a three-phase reaction (electrolyte-electrode-gas), overcoming the crucial factor of long-term stability for practical applications.

\section{CRediT authorship contribution statement}

Graziela C. Sedenho: Conception, Methodology, Validation, Formal analysis, Investigation, Data . Ayaz Hassan: Formal analysis, Investigation, Writing - review \& editing, Funding acquisition. Lucyano J.A. Macedo: Formal analysis, Writing - review \& editing, Funding acquisition. Frank N. Crespilho: Conception, Writing - original draft, Writing review \& editing, Visualization, Supervision, Funding acquisition.

\section{Declaration of competing interest}

The authors declare that they have no known competing financial interests or personal relationships that could have appeared to influence the work reported in this paper.

\section{Acknowledgements}

The authors gratefully acknowledge the financial support provided by CNPq, CAPES, and The São Paulo Research Foundation - FAPESP (G. C.S process 2015/22973-6, L.J.A.M. process 2017/20493-2, and F.N.C. processes 2019/12053-8 and 2019/15333-1). A.H. thanks CAPES-PNPD (process 88887.358060/2019-00) for the postdoctoral fellowship. The authors thank Dr. Valdecir A. Paganin from Electrochemistry Group (São Carlos Institute of Chemistry, University of São Paulo) for the technical support in the preparation of the GDL diffusion layer of the electrodes.

\section{Appendix A. Supplementary data}

Supplementary data to this article can be found online at https://doi. org/10.1016/j.jpowsour.2020.229035.

\section{References}

[1] E. Katchalski-katzir, Immobilized enzymes - learning from past successes and failures, Trends Biotechnol. 11 (1993) 471-478, https://doi.org/10.1016/0167. 7799(93)90080-S.

[2] R.A. Sheldon, S. van Pelt, Enzyme immobilisation in biocatalysis: why, what and how, Chem. Soc. Rev. 42 (2013) 6223-6235, https://doi.org/10.1039/ c3cs60075k.

[3] R.A.S. Luz, A.R. Pereira, J.C.P. de Souza, F.C.P.F. Sales, F.N. Crespilho, Enzyme biofuel cells: thermodynamics, kinetics and challenges in applicability, ChemElectroChem 1 (2014) 1751-1777, https://doi.org/10.1002/ celc. 201402141.

[4] M. Rasmussen, S. Abdellaoui, S.D. Minteer, Enzymatic biofuel cells: 30 years of critical advancements, Biosens. Bioelectron. 76 (2016) 91-102, https://doi.org/ 10.1016/j.bios.2015.06.029.

[5] N.D.J. Yates, M.A. Fascione, A. Parkin, Methodologies for " wiring " redox proteins/enzymes to electrode surfaces, Chem. Eur J. 24 (2018) 12164-12182, https://doi.org/10.1002/chem.201800750.

[6] X. Xiao, H. Xia, R. Wu, L. Bai, L. Yan, E. Magner, S. Cosnier, E. Lojou, Z. Zhu, A. Liu, Tackling the challenges of enzymatic (Bio)Fuel cells, Chem. Rev. 119 (2019) 9509-9558, https://doi.org/10.1021/acs.chemrev.9b00115.

[7] A. De Poulpiquet, R. Haddad, A. Le Goff, M. Holzinger, M. Mermoux, P. Infossi, N. Mano, E. Lojou, S. Cosnier, A membraneless air-breathing hydrogen biofuel cell based on direct wiring of thermostable enzymes on carbon nanotube electrodes, Chem. Commun. 51 (2015) 7447-7450, https://doi.org/10.1039/C5CC02166A.

[8] H. Xia, Y. Kitazumi, O. Shirai, K. Kano, Enhanced direct electron transfer-type bioelectrocatalysis of bilirubin oxidase on negatively charged aromatic compoundmodified carbon electrode, J. Electroanal. Chem. 763 (2016) 104-109, https://doi. org/10.1016/j.jelechem.2015.12.043.

[9] S. Tsujimura, K. Kano, T. Ikeda, Bilirubin oxidase in multiple layers catalyzes fourelectron reduction of dioxygen to water without redox mediators, J. Electroanal. Chem. 576 (2005) 113-120, https://doi.org/10.1016/j.jelechem.2004.09.031.

[10] K. So, Y. Kitazumi, O. Shirai, K. Kano, Analysis of factors governing direct electron transfer-type bioelectrocatalysis of bilirubin oxidase at modified electrodes, J. Electroanal. Chem. 783 (2016) 316-323, https://doi.org/10.1016/j. jelechem.2016.10.062.

[11] C. Santoro, S. Babanova, B. Erable, A. Schuler, P. Atanassov, Bilirubin oxidase based enzymatic air-breathing cathode: operation under pristine and contaminated conditions, Bioelectrochemistry 108 (2016) 1-7, https://doi.org/10.1016/j. bioelechem.2015.10.005.

[12] K. So, M. Onizuka, T. Komukai, Y. Kitazumi, O. Shirai, K. Kano, Binder/surfactantfree biocathode with bilirubin oxidase for gas-diffusion-type system, Electrochem. Commun. 66 (2016) 58-61, https://doi.org/10.1016/j.elecom.2016.02.023.

[13] H. Li, D. Buesen, R. Williams, J. Henig, S. Stap, K. Mukherjee, E. Freier, W. Lubitz, M. Winkler, T. Happe, N. Plumeré, Preventing the coffee-ring effect and aggregate sedimentation by in situ gelation of monodisperse materials, Chem. Sci. 9 (2018) 7596-7605, https://doi.org/10.1039/c8sc03302a.

[14] T.L. Klotzbach, M. Watt, Y. Ansari, S.D. Minteer, Improving the microenvironment for enzyme immobilization at electrodes by hydrophobically modifying chitosan

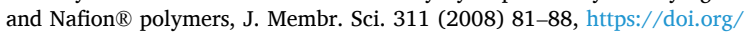
10.1016/j.memsci.2007.11.043.

[15] C. Lau, E.R. Adkins, R.P. Ramasamy, H.R. Luckarift, G.R. Johnson, P. Atanassov, Design of carbon nanotube-based gas-diffusion cathode for $\mathrm{O} 2$ reduction by multicopper oxidases, Adv. Energy Mater. 2 (2012) 162-168, https://doi.org/ 10.1002/aenm.201100433.

[16] G.P.M.K. Ciniciato, C. Lau, A. Cochrane, S.S. Sibbett, E.R. Gonzalez, P. Atanassov, Development of paper based electrodes: from air-breathing to paintable enzymatic cathodes, Electrochim. Acta 82 (2012) 208-213, https://doi.org/10.1016/j. electacta.2012.06.094.

[17] G. Gupta, C. Lau, B. Branch, V. Rajendran, D. Ivnitski, P. Atanassov, Direct bioelectrocatalysis by multi-copper oxidases: gas-diffusion laccase-catalyzed cathodes for biofuel cells, Electrochim. Acta 56 (2011) 10767-10771, https://doi.org/ 10.1016/j.electacta.2011.01.089.

[18] N. Lalaoui, M. Holzinger, A. Le Goff, S. Cosnier, Diazonium functionalisation of carbon nanotubes for specific orientation of multicopper oxidases: controlling electron entry points and oxygen diffusion to the enzyme, Chem. Eur J. 22 (2016) 10494-10500, https://doi.org/10.1002/chem.201601377.

[19] I. Shitanda, K. Takamatsu, A. Niiyama, T. Mikawa, Y. Hoshi, M. Itagaki, S. Tsujimura, High-power lactate/O2 enzymatic biofuel cell based on carbon cloth electrodes modified with MgO-templated carbon, J. Power Sources 436 (2019), 226844, https://doi.org/10.1016/j.jpowsour.2019.226844.

[20] A. Niiyama, K. Murata, Y. Shigemori, A. Zebda, S. Tsujimura, High-performance enzymatic biofuel cell based on flexible carbon cloth modified with MgOtemplated porous carbon, J. Power Sources 427 (2019) 49-55, https://doi.org/ 10.1016/j.jpowsour.2019.04.064.

[21] L.J.A. Macedo, A. Hassan, G.C. Sedenho, F.N. Crespilho, Assessing electron transfer reactions and catalysis in multicopper oxidases with operando X-ray absorption spectroscopy, Nat. Commun. 11 (2020) 316, https://doi.org/10.1038/s41467-01914210-1.

[22] V.A. Paganin, E.A. Ticianelli, E.R. Gonzalez, Development and electrochemical studies of gas diffusion electrodes for polymer electrolyte fuel cells, J. Appl. Electrochem. 26 (1996) 297-304, https://doi.org/10.1007/BF00242099.

[23] K.A. Klinedinst, W.M. Vogel, P. Stonehart, Rheological characterization and thermal degradation of PTFE, J. Mater. Sci. 11 (1976) 794-800, https://doi.org/ 10.1007/BF00542293. 
[24] L.J.A. Macedo, F.N. Crespilho, Multiplex infrared spectroscopy imaging for monitoring spatially resolved redox Chemistry, Anal. Chem. 90 (2018) 1487-1491, https://doi.org/10.1021/acs.analchem.7b04438.

[25] D. Guo, S. Fu, Z. Dai, A highly porous nafion membrane templated from polyoxometalates-based supramolecule composite for ion-exchange polymer-metal composite actuator, J. Mater. Chem. 20 (2010) 10159-10168, https://doi.org/ 10.1039/c0jm01161d.

[26] N. Ramaswamy, T.M. Arruda, W. Wen, N. Hakim, M. Saha, A. Gullá, S. Mukerjee, Enhanced activity and interfacial durability study of ultra low Pt based electrocatalysts prepared by ion beam assisted deposition (IBAD) method, Electrochim. Acta 54 (2009) 6756-6766, https://doi.org/10.1016/j. electacta.2009.06.040.

[27] N.R. Kil'deeva, P.A. Perminov, L.V. Vladimirov, V.V. Novikov, S.N. Mikhailov, On the mechanism of the reaction of glutaraldehyde with chitosan, Russ. J. Bioorg Chem. 35 (2009) 360-369, https://doi.org/10.1134/S106816200903011X.

[28] H. Hu, J.H. Xin, H. Hu, A. Chan, L. He, Glutaraldehyde - chitosan and poly (vinyl alcohol) blends , and fluorescence of their nano-silica composite films, Carbohydr. Polym. 91 (2013) 305-313, https://doi.org/10.1016/j.carbpol.2012.08.038.

[29] D. Kishore, M. Talat, O.N. Srivastava, A.M. Kayastha, Immobilization of bgalactosidase onto functionalized graphene nano-sheets using response surface methodology and its analytical applications, PloS One 7 (2012), e40708, https:// doi.org/10.1371/journal.pone.0040708.

[30] A. Barth, Infrared spectroscopy of proteins, Biochim. Biophys. Acta 1767 (2007) 1073-1101, https://doi.org/10.1016/j.bbabio.2007.06.004.

[31] R. Torres, O. Barbosa, C. Ortiz, Á. Berenguer-Murci, R. Torres, R.C. Rodrigues, R. Fernandez-Lafuente, Glutaraldehyde in bio-catalysts design: a useful crosslinke and a versatile tool in enzyme immobilization, RSC Adv. 4 (2014) 1583-1600, https://doi.org/10.1039/c3ra45991h.

[32] I. Migneault, C. Dartiguenave, M.J. Bertrand, K.C. Waldron, Glutaraldehyde: behavior in aqueous solution, reaction with proteins, and application to enzyme crosslinking, Biotechniques 37 (2004) 798-802.

[33] L. Rieppo, S. Saarakkala, T. Närhi, H.J. Helminen, J.S. Jurvelin, J. Rieppo, Application of second derivative spectroscopy for increasing molecular specificity of fourier transform infrared spectroscopic imaging of articular cartilage, Osteoarthritis Cartilage 20 (2012) 451-459, https://doi.org/10.1016/j joca.2012.01.010

[34] D. Mampallil, H.B. Eral, A review on suppression and utilization of the coffee-ring effect, Adv. Colloid Interface Sci. 252 (2018) 38-54, https://doi.org/10.1016/j cis.2017.12.008.

[35] A. Crivoi, F. Duan, Amplifying and attenuating the coffee-ring effect in drying sessile nanofluid droplets, Phys. Rev. E. 87 (2013), 042303.

[36] A. Christenson, S. Shleev, N. Mano, A. Heller, L. Gorton, Redox potentials of the blue copper sites of bilirubin oxidases, Biochim. Biophys. Acta Bioenerg. 1757 (2006) 1634-1641, https://doi.org/10.1016/j.bbabio.2006.08.008.

[37] S. Tsujimura, A. Kuriyama, N. Fujieda, K. Kano, T. Ikeda, Mediated spectroelectrochemical titration of proteins for redox potential measurements by a separator-less one-compartment bulk electrolysis method, Anal. Biochem. 337 (2005) 325-331, https://doi.org/10.1016/j.ab.2004.11.017.

[38] K. Schubert, G. Goebel, F. Lisdat, Bilirubin oxidase bound to multi-walled carbon nanotube-modified gold, Electrochim. Acta 54 (2009) 3033-3038, https://doi.org 10.1016/j.electacta.2008.12.010.

[39] D. Ivnitski, K. Artyushkova, P. Atanassov, Surface characterization and direct electrochemistry of redox copper centers of bilirubin oxidase from fungi
Myrothecium verrucaria, Bioelectrochemistry 74 (2008) 101-110, https://doi.org/ 10.1016/j.bioelechem.2008.05.003.

[40] P. Ramírez, N. Mano, R. Andreu, T. Ruzgas, A. Heller, L. Gorton, S. Shleev, Direct electron transfer from graphite and functionalized gold electrodes to T1 and T2/T3 copper centers of bilirubin oxidase, Biochim. Biophys. Acta Bioenerg. 1777 (2008) 1364-1369, https://doi.org/10.1016/j.bbabio.2008.06.010.

[41] M.C. Weigel, E. Tritscher, F. Lisdat, Direct electrochemical conversion of bilirubin oxidase at carbon nanotube-modified glassy carbon electrodes, Electrochem. Commun. 9 (2007) 689-693, https://doi.org/10.1016/j.elecom.2006.10.052.

[42] R.J. Lopez, S. Babanova, Y. Ulyanova, S. Singhal, P. Atanassov, Improved interfacial electron transfer in modified bilirubin oxidase biocathodes, ChemElectroChem 1 (2014) 241-248, https://doi.org/10.1002/celc.201300085.

[43] N. Lalaoui, A. Le Goff, M. Holzinger, S. Cosnier, Fully oriented bilirubin oxidase on porphyrin-functionalized carbon nanotube electrodes for electrocatalytic oxygen reduction, Chem. Eur J. 21 (2015) 16868-16873, https://doi.org/10.1002/ chem. 201502377.

[44] S. Shleev, A. El Kasmi, T. Ruzgas, L. Gorton, Direct heterogeneous electron transfer reactions of bilirubin oxidase at a spectrographic graphite electrode, Electrochem. Commun. 6 (2004) 934-939, https://doi.org/10.1016/j.elecom.2004.07.008.

[45] G. Gupta, C. Lau, V. Rajendran, F. Colon, B. Branch, D. Ivnitski, P. Atanassov, Direct electron transfer catalyzed by bilirubin oxidase for air breathing gasdiffusion electrodes, Electrochem. Commun. 13 (2011) 247-249, https://doi.org/ 10.1016/j.elecom.2010.12.024.

[46] L. Dos Santos, V. Climent, C.F. Blanford, F.A. Armstrong, Mechanistic studies of the "blue" Cu enzyme, bilirubin oxidase, as a highly efficient electrocatalyst for the oxygen reduction reaction, Phys. Chem. Chem. Phys. 12 (2010) 13962-13974, https://doi.org/10.1039/c0cp00018c.

[47] W. Xing, G. Yin, J. Zhang, Rotating Electrode Methods and Oxygen Reduction Electrocatalysts, first ed., Elsevier, Amsterdam, The Netherlands, 2014 https://doi. org/10.1016/C2012-0-06455-1.

[48] A.E.W. Horst, K.M. Mangold, D. Holtmann, Application of gas diffusion electrodes in bioelectrochemical syntheses and energy conversion, Biotechnol. Bioeng. 113 (2016) 260-267, https://doi.org/10.1002/bit.25698.

[49] K. So, K. Sakai, K. Kano, Gas diffusion bioelectrodes, Curr. Opin. Electrochem. 5 (2017) 173-182, https://doi.org/10.1016/j.coelec.2017.09.001.

[50] K. So, H. Ozawa, M. Onizuka, T. Komukai, Y. Kitazumi, O. Shiraia, K. Kano, Highly permeable gas diffusion electrodes with hollow carbon nanotubes for bilirubin oxidase-catalyzed dioxygen reduction, Electrochim. Acta 246 (2017) 794-799, https://doi.org/10.1016/j.electacta.2017.06.117.

[51] F. Conzuelo, J. Szczesny, N. Markovic, A. Ruff, W. Schuhmann, D. Herna, An airbreathing carbon cloth-based screen-printed electrode for applications in enzymatic biofuel cells, Electroanalysis 31 (2019) 217-221, https://doi.org/ 10.1002/elan.201800462.

[52] S. Yin, Z. Jin, T. Miyake, Wearable high-powered biofuel cells using enzyme/ carbon nanotube composite fibers on textile cloth, Biosens. Bioelectron. 141 (2019), 111471, https://doi.org/10.1016/j.bios.2019.111471.

[53] S. Yin, X. Liu, Y. Kobayashi, Y. Nishina, R. Nakagawa, R. Yanai, K. Kimura, T. Miyake, A needle-type biofuel cell using enzyme/mediator/carbon nanotube composite fibers for wearable electronics, Biosens. Bioelectron. 165 (2020) 112287, https://doi.org/10.1016/j.bios.2020.112287.

[54] A. Baricci, A. Bisello, A. Serov, M. Odgaard, P. Atanassov, A. Casalegno, Analysis of the effect of catalyst layer thickness on the performance and durability of platinum group metal-free catalysts for polymer electrolyte membrane fuel cells, Sustain. Energy Fuels 16 (2019) 3375-3386, https://doi.org/10.1039/c9se00252a. 


\section{Supplementary Material}

\section{Stabilization of Bilirubin Oxidase in a Biogel Matrix for High-performance Gas Diffusion Electrodes}

Graziela C. Sedenho, Ayaz Hassan, Lucyano J. A. Macedo and Frank N. Crespilho*

São Carlos Institute of Chemistry, University of São Paulo (USP), São Carlos, SP 13560-970, Brazil.

*E-mail:frankcrespilho@iqsc.usp.br; +55 1633738783.

\section{Contents}

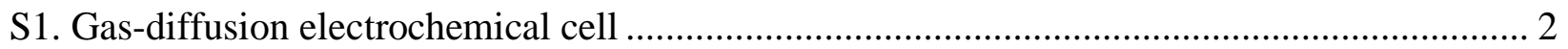

S2. Vibrational modes assignment and FTIR spectra .................................................... 2

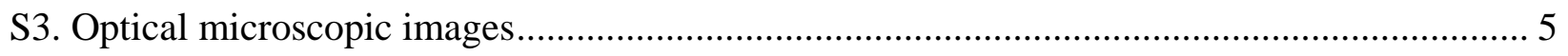

S4. Voltammetric behavior of BOD-free electrode ....................................................... 5

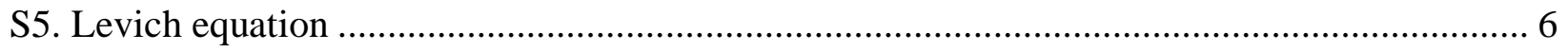

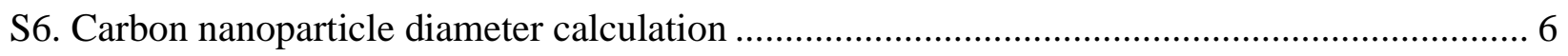

S7. Effect of catalytic layer cracks on the voltammetric behavior. ........................................ 7

S8. Comparison of BOD-based gas diffusion electrodes.................................................. 8

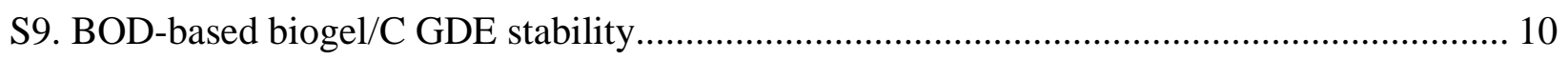

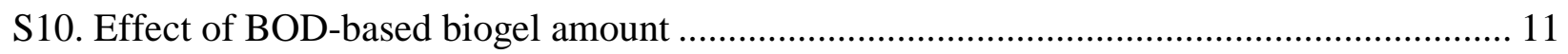

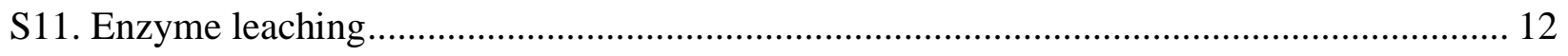

S12. Effect of Nafion and GA on the bioeletrode performance ......................................... 13

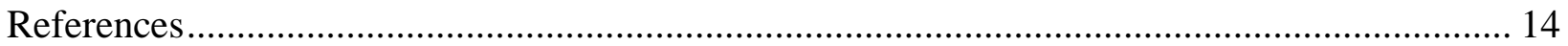




\section{S1. Gas-diffusion electrochemical cell}


Figure S1. Homemade glass electrochemical used in the gas-diffusion experiments.

\section{S2. Vibrational modes assignment and FTIR spectra}

Table S1. Vibrational modes assignment of the various functional groups of BOD-based biogel components observed in the FTIR spectra.

\begin{tabular}{|c|c|c|c|}
\hline Compound & $\begin{array}{c}\text { Band position } \\
\left(\mathrm{cm}^{-1}\right)\end{array}$ & Attribution & Reference \\
\hline \multirow[t]{6}{*}{ Nafion } & 1643 & $\mathrm{C}=\mathrm{O}$ stretching & {$[1]$} \\
\hline & 1315 & $\mathrm{~S}=\mathrm{O}$ asymmetric stretching & {$[2]$} \\
\hline & 1233 & $\mathrm{CF}_{2}$ asymmetric stretching & [2] \\
\hline & 1150 & $\mathrm{CF}_{2}$ symmetric stretching & {$[2]$} \\
\hline & 1060 & $\mathrm{O}=\mathrm{S}(\mathrm{O})=\mathrm{O}$ symmetric stretching & [2] \\
\hline & 980 & C-O-C stretching & {$[2]$} \\
\hline \multirow[t]{6}{*}{ GA } & 1713 & $\mathrm{C}=\mathrm{O}$ stretching & [3] \\
\hline & 1677 & $\mathrm{O}-\mathrm{H}$ bending & {$[4]$} \\
\hline & 1453 & $\mathrm{CH}_{2}$ bending & {$[4]$} \\
\hline & 1405 & $\mathrm{C}-\mathrm{H}$ bending & [4] \\
\hline & 1128 & $\mathrm{C}=\mathrm{O}$ deformation & {$[4]$} \\
\hline & 1063 & C-O stretching (from alcohol) & {$[5]$} \\
\hline
\end{tabular}




\begin{tabular}{|c|c|c|c|}
\hline \multirow[t]{5}{*}{ BOD } & 1663 & $\begin{array}{l}\text { Amide-I }(\mathrm{C}=\mathrm{O} \text { stretching vibration with minor } \\
\text { contributions from the out-of-phase } \mathrm{C}-\mathrm{N} \\
\text { stretching vibration, the } \mathrm{C}-\mathrm{C}-\mathrm{N} \text { deformation } \\
\text { and the N-H in-plane bend) }\end{array}$ & [6] \\
\hline & 1543 & $\begin{array}{l}\text { Amide-II (out-of-phase combination of the N- } \\
\qquad \mathrm{H} \text { in plane bend and the } \mathrm{C}-\mathrm{N} \text { stretching } \\
\text { vibration with smaller contributions from the } \\
\qquad \mathrm{C}=\mathrm{O} \text { in plane bend and the } \mathrm{C}-\mathrm{C} \text { and } \mathrm{N}-\mathrm{C} \\
\text { stretching vibrations) }\end{array}$ & [6] \\
\hline & 1456 & $\mathrm{CH}_{3}$ asymmetric bending & [6] \\
\hline & 1253 & $\mathrm{CH}_{2}$ wagging & [6] \\
\hline & 1104 & C-C stretching & [6] \\
\hline
\end{tabular}
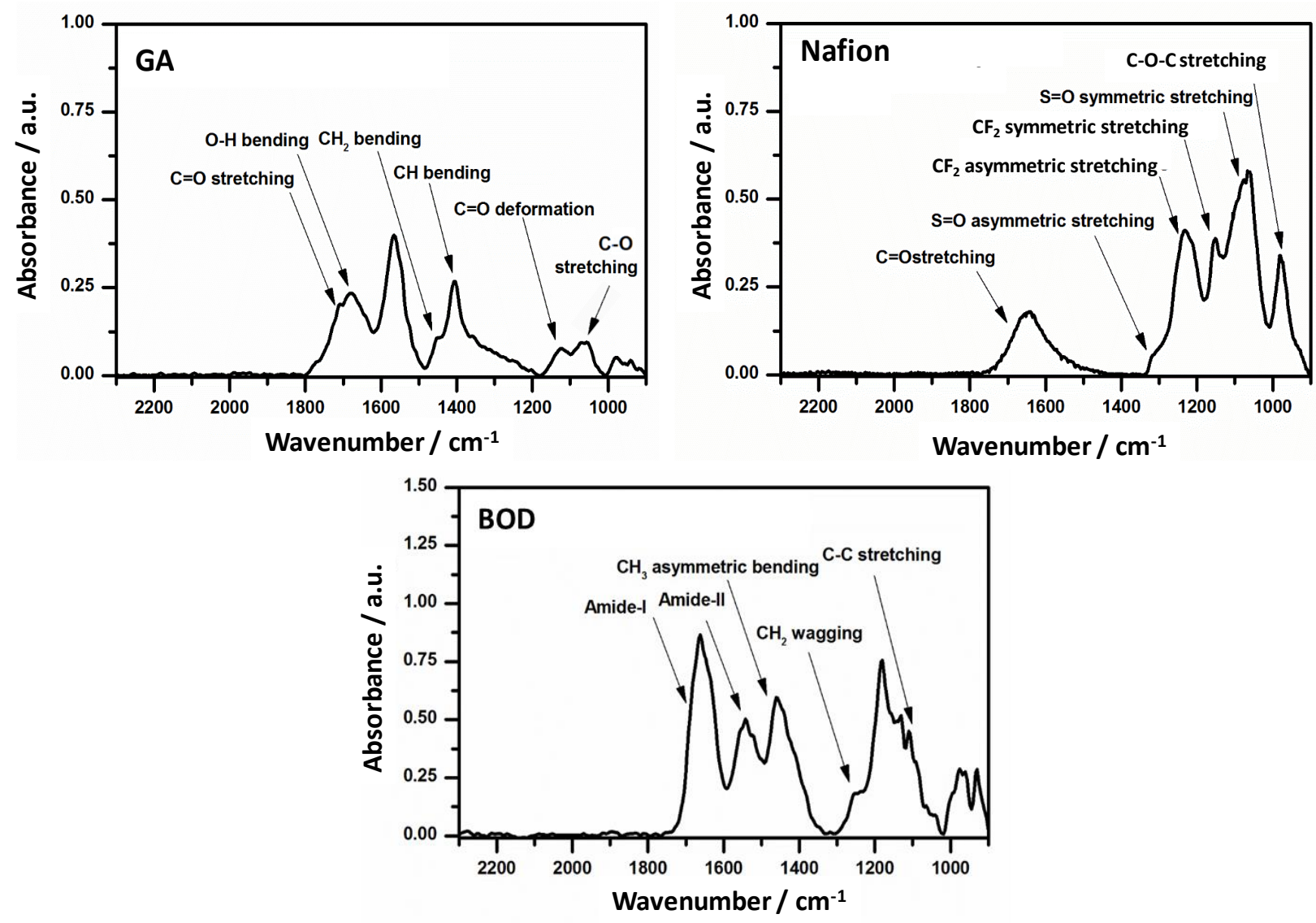

Figure S2. FTIR spectra of the components of BOD-based biogel. 
$\stackrel{\mathrm{H}}{\stackrel{\mathrm{H}}{\rightleftarrows}} \stackrel{\mathrm{H}_{2} \mathrm{O}}{\rightleftarrows} \overbrace{\mathrm{O}} \mathrm{HOH}_{\mathrm{OH}}$ (Equation S1)

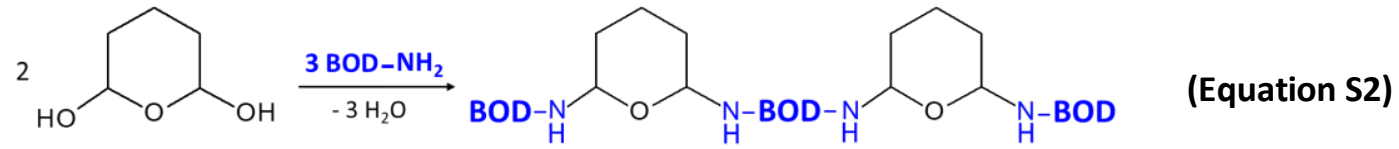

(Equation S3)
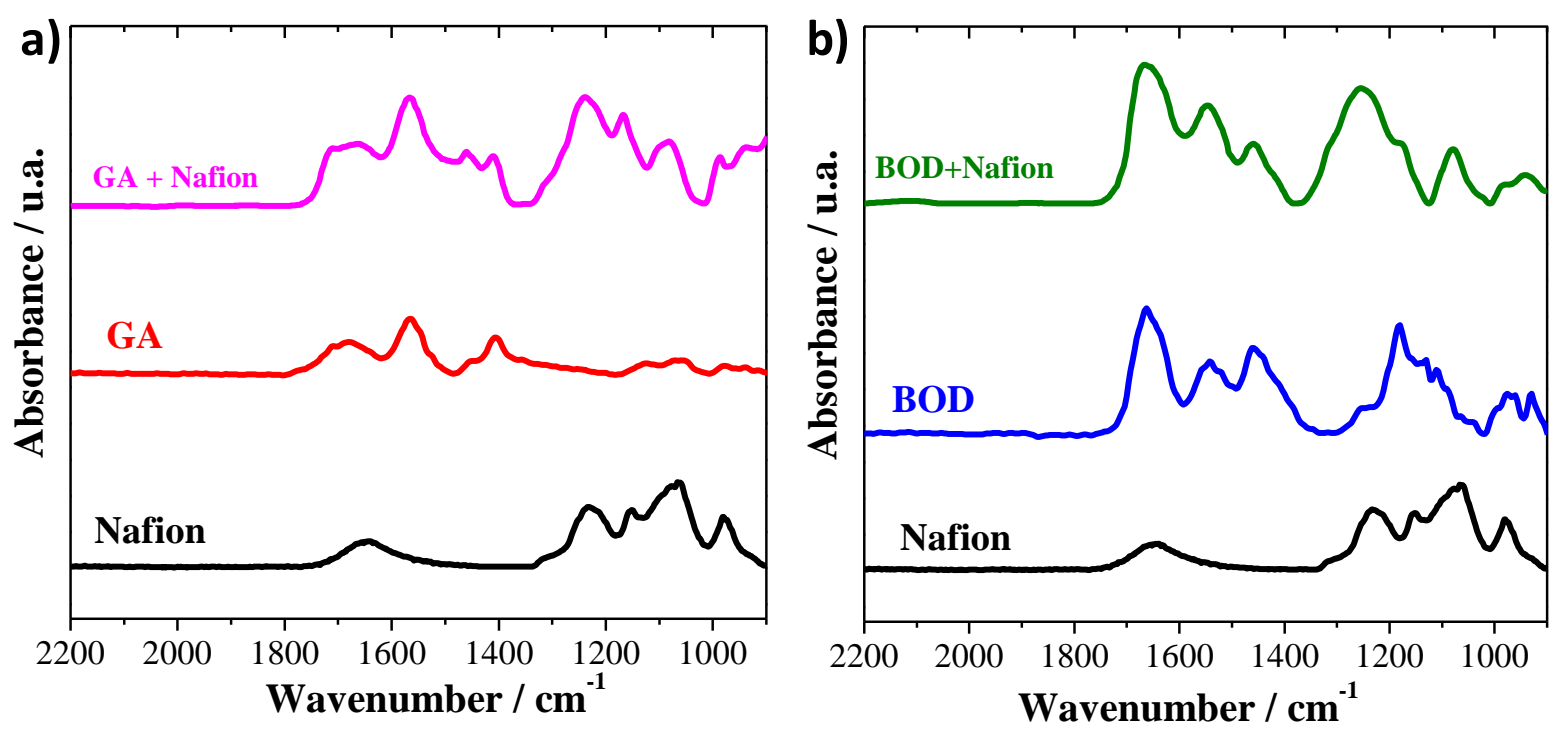

Figure S3. FTIR spectra of (a) Nafion, GA and their mixture, and (b) Nafion, BOD and their mixture. 
S3. Optical microscopic images

a)

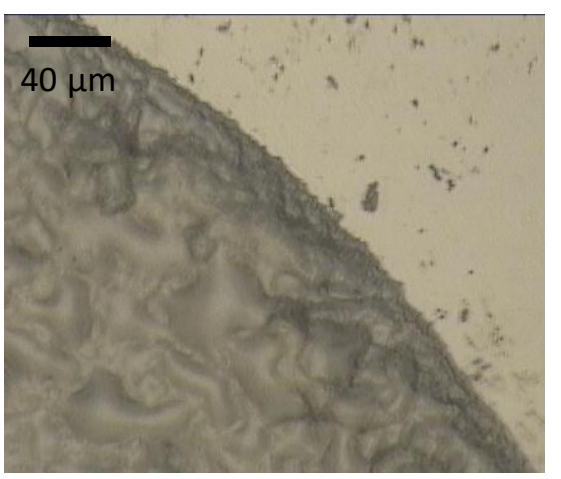

b)

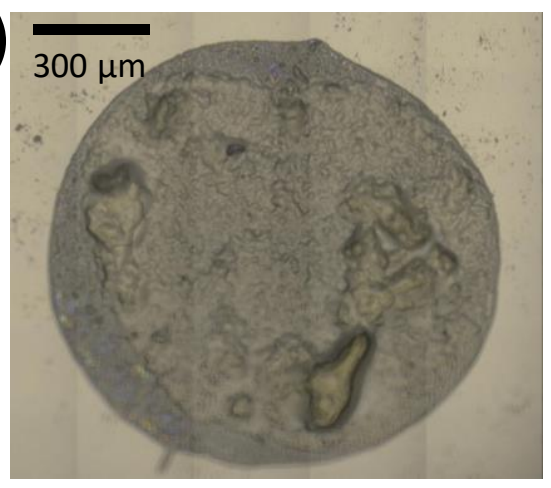

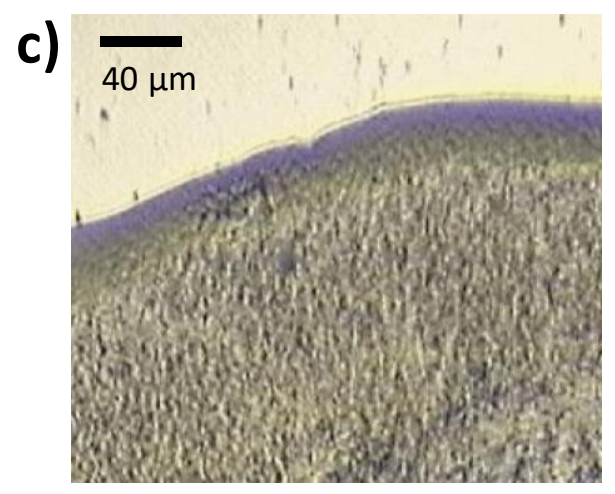

d)

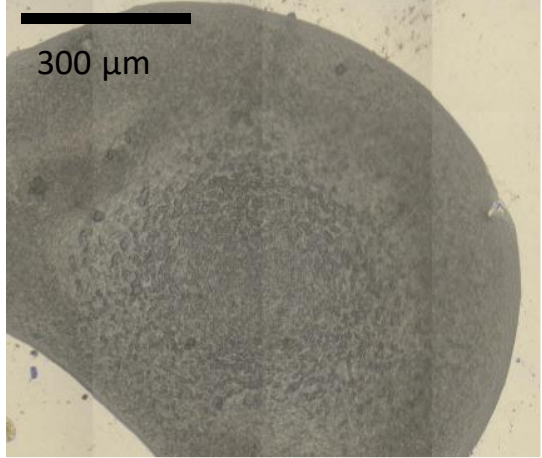

Figure S4. Optical microscopic images obtained in the reflectance mode of BOD-based biogel $(a, b)$ and bare-BOD (c, d) films obtained by drop-casting on GC substrate.

\section{S4. Voltammetric behavior of BOD-free electrode}

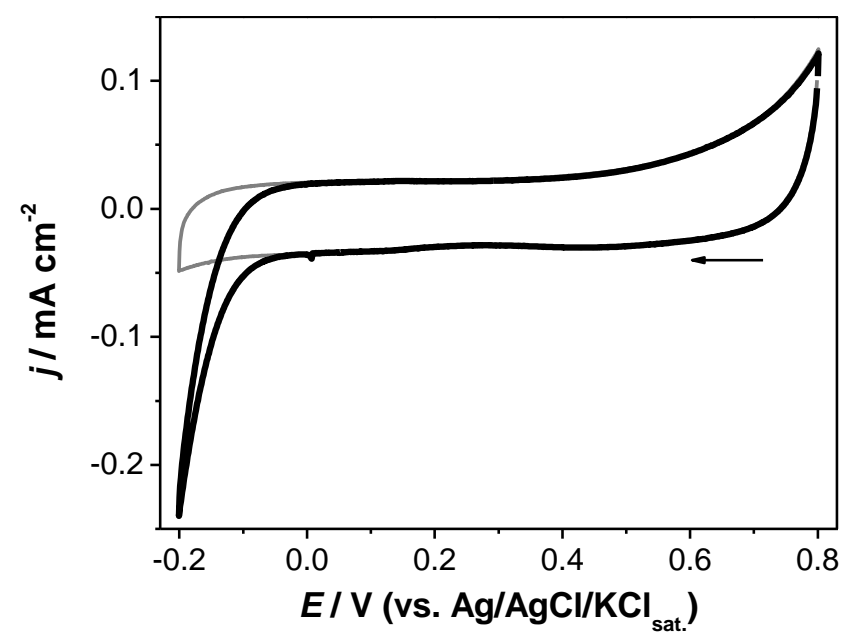

Figure S5. CVs at $5 \mathrm{mV} \mathrm{s}^{-1}$ obtained with enzyme-free carbon electrode in phosphate buffer $\mathrm{pH}$ 7.2 at $25^{\circ} \mathrm{C}$ saturated with $\mathrm{O}_{2}$ (black curve) and with Ar (gray curve). 


\section{S5. Levich equation}

$$
j_{\mathrm{mt}}=-0.62 \mathrm{n}_{\mathrm{S}} \mathrm{FD}_{\mathrm{o}}^{\frac{2}{3}} \mathrm{v}^{-\frac{1}{6}} \omega^{\frac{1}{2}} \mathrm{C}_{\mathrm{o}} \quad(\text { Equation S4) }
$$

where, $n_{s}, \mathrm{~F}, \mathrm{D}_{\mathrm{o}}, \mathrm{v}, \omega$, and $\mathrm{C}_{\mathrm{o}}$, are the number of electrons involved in the substrate redox reaction, the Faraday constant, the diffusion coefficient of $\mathrm{O}_{2}\left(1.7 \times 10^{-5} \mathrm{~cm}^{2} \mathrm{~s}^{-1}\right.$, at $25{ }^{\circ} \mathrm{C}$ in aqueous solution), the kinematic viscosity of water $\left(0.01 \mathrm{~cm}^{2} \mathrm{~s}^{-1}\right.$, at $\left.25^{\circ} \mathrm{C}\right)$, the rotation rate, and the concentration of dissolved $\mathrm{O}_{2}\left(1.2 \mathrm{mmol} \mathrm{L}^{-1}\right.$, at $25^{\circ} \mathrm{C}$, in aqueous solution).

S6. Carbon nanoparticle diameter calculation

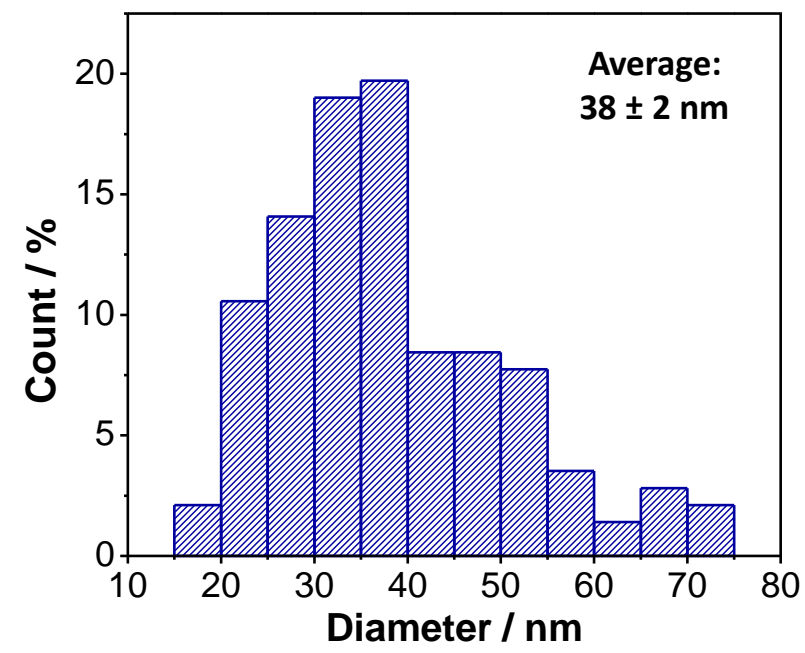

Figure S6. Histogram of the carbon nanoparticle diameter. 
S7. Effect of catalytic layer cracks on the voltammetric behavior.
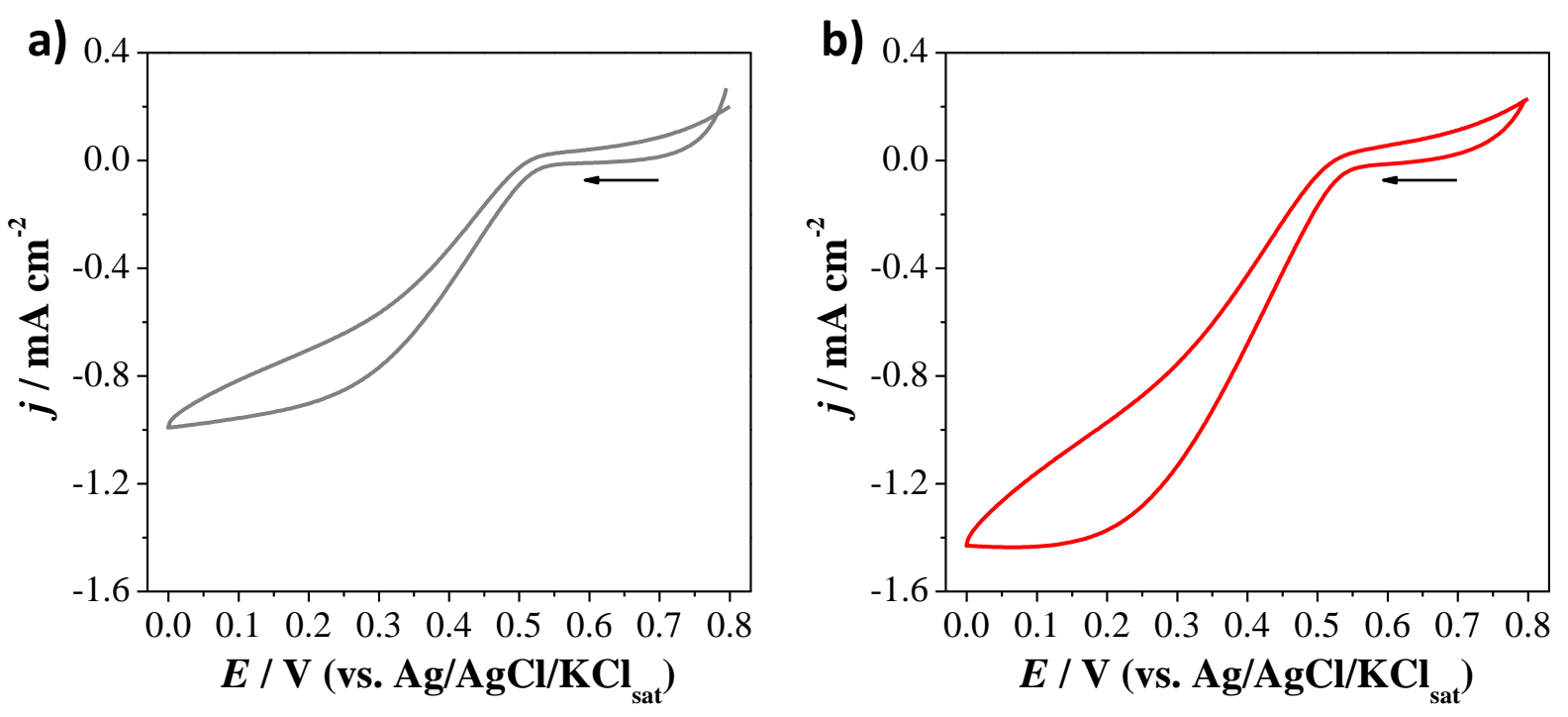

Figure S7. CV at $5 \mathrm{mV} \mathrm{s}^{-1}$ of (a) BOD-based biogel/C GDE dried at room temperature and humidity (about 60\%) and (b) dried at vacuum and room temperature. CVs were recorded in phosphate buffer ( $\mathrm{pH} 7.2)$ at $25^{\circ} \mathrm{C}$, under atmospheric condition. 


\section{S8. Comparison of BOD-based gas diffusion electrodes}

Table S2. Performance of BOD-based gas diffusion electrodes towards ORR without redox mediator.

\begin{tabular}{|c|c|c|c|c|c|c|}
\hline \multirow{2}{*}{$\begin{array}{l}\text { Carbon-based } \\
\text { material }\end{array}$} & \multicolumn{2}{|l|}{ Conditions } & \multirow[t]{2}{*}{$\begin{array}{l}\text { Current density* / } \\
\text { mA cm }\end{array}$} & \multirow[t]{2}{*}{$\begin{array}{l}\text { Measurement } \\
\text { method }\end{array}$} & \multirow[t]{2}{*}{ Reported stability } & \multirow[t]{2}{*}{ Ref. } \\
\hline & Electrolyte & Gas phase & & & & \\
\hline Carbon nanoparticle & $\begin{array}{l}\text { Phosphate buffer, } 0.1 \\
\text { mol L L }^{-1}, \mathrm{pH} 7.2,25^{\circ} \mathrm{C} \text {. }\end{array}$ & Air & $\begin{array}{l}-1.52 \pm 0.24 \text { at } 0.19 \pm \\
0.06 \mathrm{~V}\end{array}$ & $\mathrm{CV}$ at $5 \mathrm{mV} \mathrm{s}^{-1}$ & $\begin{array}{l}24 \mathrm{~h} \text { at }-1.00 \mathrm{~mA} \mathrm{~cm}^{-2}: \\
\text { electrode potential } \\
\text { decreases from } 0.37 \text { to } \\
0.31 \mathrm{~V} \text {; } \\
24 \mathrm{~h} \text { at } \mathrm{OCP}: 0.50-0.45 \mathrm{~V}\end{array}$ & $\begin{array}{l}\text { This } \\
\text { work }\end{array}$ \\
\hline MWCNT & $\begin{array}{l}\text { Phosphate buffer, } 0.2 \\
\text { mol L }{ }^{-1}, \text { pH } 7.2,45^{\circ} \mathrm{C} \text {. }\end{array}$ & Air & $3.0 \pm 0.2$ at $0 \mathrm{~V}$ & $\begin{array}{l}\mathrm{CV} \text { at } \\
10 \mathrm{mV} \mathrm{s}^{-1}\end{array}$ & N.A. & [7] \\
\hline MWCNT & $\begin{array}{l}\text { Citrate buffer } 1.5 \mathrm{~mol} \mathrm{~L}^{-} \\
1, \\
\text { pH } 5 \text {, at } 40^{\circ} \mathrm{C} \text {. }\end{array}$ & Pure $\mathrm{O}_{2}$ & 15 at $0 \mathrm{~V}$ & $\begin{array}{l}\mathrm{CV} \text { at } \\
10 \mathrm{mV} \mathrm{s}^{-1}\end{array}$ & N.A. & [8] \\
\hline $\begin{array}{l}\text { Functionalized } \\
\text { MWCNT }\end{array}$ & Mc Ilvaine buffer, pH 7. & Air & $3.9 \pm 0.5$ at $0 \mathrm{~V}$ & $\begin{array}{l}\mathrm{CV} \text { at } \\
10 \mathrm{mV} \mathrm{s}^{-1}\end{array}$ & N.A. & [9] \\
\hline Hollow CNT & $\begin{array}{l}\text { Citrate buffer } 1.5 \mathrm{~mol} \mathrm{~L}^{-} \\
{ }^{\prime}, \\
\text { pH } 5.0 \text {, at } 40{ }^{\circ} \mathrm{C} \text {. }\end{array}$ & Pure $\mathrm{O}_{2}$ & 30 at $0 \mathrm{~V}$ & $\begin{array}{l}\mathrm{LSV} \text { at } \\
10 \mathrm{mV} \mathrm{s}^{-1}\end{array}$ & $\begin{array}{l}60 \mathrm{~s} \text { at } 0 \mathrm{~V} \text {, catalytic } \\
\text { current } \\
\text { gradually decreases with } \\
\text { time. }\end{array}$ & {$[10]$} \\
\hline Ketjen black & $\begin{array}{l}\text { Citrate buffer } 1.5 \mathrm{~mol} \mathrm{~L}^{-} \\
{ }^{\prime}, \\
\text { pH } 5 \text { at } 40{ }^{\circ} \mathrm{C} .\end{array}$ & Pure $\mathrm{O}_{2}$ & 20 at $0 \mathrm{~V}$ & $\begin{array}{l}\mathrm{CV} \text { at } \\
10 \mathrm{mV} \mathrm{s}^{-1}\end{array}$ & $\begin{array}{l}60 \mathrm{~s} \text { at } 0 \mathrm{~V} \text {, catalytic } \\
\text { current } \\
\text { gradually decreases with } \\
\text { time. }\end{array}$ & {$[11]$} \\
\hline $\begin{array}{l}\text { Amine-functionalized } \\
\text { Ketjen black }\end{array}$ & $\begin{array}{l}\text { Citrate buffer } 1.5 \mathrm{~mol} \mathrm{~L}^{-} \\
{ }^{1}, \mathrm{pH} 5 \text { at } 25^{\circ} \mathrm{C} .\end{array}$ & Air & 30 at $0 \mathrm{~V}$ & $\mathrm{CA}$ at $0 \mathrm{~V}$ & $\begin{array}{l}60 \mathrm{~s} \text { at } 0 \mathrm{~V} \text { : decays from } \\
30 \text { to } 8.0 \mathrm{~mA} \mathrm{~cm}^{-2} \text {. }\end{array}$ & {$[12]$} \\
\hline $\begin{array}{l}\text { MWCNT paper } \\
\text { (Buckeye paper) }\end{array}$ & $\begin{array}{l}\text { Phosphate buffer, } 0.05 \\
\text { mol L-1, pH 7.5. }\end{array}$ & Air & 0.35 at $0.3 \mathrm{~V}$ & $\mathrm{CA}$ at $0.3 \mathrm{~V}$ & $\begin{array}{l}45 \text { days at } 0.3 \mathrm{~V} \text {. } \\
\text { Decays per day: } \\
3 \text { days: } 60 \mu \mathrm{Acm}^{-2} \text {; } \\
\text { 3-9 days: } 10 \mu \mathrm{Acm}^{-2} \text {; } \\
\text { 9-45 days: } 1.5 \mu \mathrm{Acm}^{-2} \text {. }\end{array}$ & {$[13]$} \\
\hline
\end{tabular}




\begin{tabular}{|c|c|c|c|c|c|c|}
\hline $\begin{array}{l}\text { Highly conductive } \\
\text { Buckeye paper }\end{array}$ & $\begin{array}{l}\text { Phosphate buffer, } 0.1 \\
\mathrm{~mol} \mathrm{~L}^{-1}, \mathrm{pH} 7,25^{\circ} \mathrm{C} \text {. }\end{array}$ & Air & $\begin{array}{l}0.475 \pm 0.09 \text { at } \\
0 \mathrm{~V}\end{array}$ & $\mathrm{CA}$ at $0 \mathrm{~V}$ & $\begin{array}{l}10 \mathrm{~h} \text { at } 0.3 \mathrm{~V}: \\
200 \pm 6 \mu \mathrm{A} \mathrm{cm}^{-2} .\end{array}$ & [14] \\
\hline $\begin{array}{l}\text { Porphyrin/EDC/NHS- } \\
\text { modified MWCNTs }\end{array}$ & $\begin{array}{l}\text { Phosphate buffer, } 0.245 \\
\text { mol L }{ }^{-1}, \mathrm{pH} 7,25^{\circ} \mathrm{C} .\end{array}$ & Air & 1.3 at $0.3 \mathrm{~V}$ & $\mathrm{CA}$ at $0.3 \mathrm{~V}$ & N.A. & [15] \\
\hline $\begin{array}{l}\text { Naphthoate-modified } \\
\text { MWCNTs }\end{array}$ & $\begin{array}{l}\text { Phosphate buffer, } 0.1 \\
\text { mol L }^{-1}, \mathrm{pH} 5,25^{\circ} \mathrm{C} \text {. }\end{array}$ & Pure $\mathrm{O}_{2}$ & 7.1 at $0.25 \mathrm{~V}$ & $\begin{array}{l}\mathrm{CV} \text { at } \\
10 \mathrm{mV} \mathrm{s}^{-1}\end{array}$ & $\begin{array}{l}1 \mathrm{~h} \text { at } 0.35 \mathrm{~V} \text { for } 5 \\
\text { days**. Decays: } \\
1 \text { day: } 27 \% \\
\text { 2-5 days: stable }\end{array}$ & [16] \\
\hline $\begin{array}{l}\text { Aminobenzoic acid- } \\
\text { modified microporous } \\
\text { carbon } \\
\text { cloth }\end{array}$ & $\begin{array}{l}\text { Phosphate buffer, } 0.1 \\
\text { mol L }{ }^{-1}, \mathrm{pH} 7.4,25^{\circ} \mathrm{C} \text {. }\end{array}$ & Air & $0.8^{* * *}$ at $0 \mathrm{~V}$ & $\begin{array}{l}\mathrm{CV} \text { at } \\
10 \mathrm{mV} \mathrm{s}^{-1}\end{array}$ & $\begin{array}{l}\mathrm{CV} \text { after biofuel cell test } \\
(1.3 \mathrm{~h}) \text { : maximum } \\
\text { reduction current density } \\
\text { decreases to } 0.6 \mathrm{~mA} \text {. }\end{array}$ & [17] \\
\hline $\begin{array}{l}\text { Aminobenzoic acid- } \\
\text { modified carbon } \\
\text { cloth }\end{array}$ & $\begin{array}{l}\text { Phosphate buffer, } 0.1 \\
\mathrm{~mol} \mathrm{~L}^{-1}, \mathrm{pH} 7.0,25^{\circ} \mathrm{C} \text {. }\end{array}$ & Air & 5 at $0.2 \mathrm{~V}$ & $\begin{array}{l}\mathrm{CV} \text { at } \\
10 \mathrm{mV} \mathrm{s}^{-1}\end{array}$ & $\begin{array}{l}6 \mathrm{~h} \text { at } 0 \mathrm{~V} \text { : current decays } \\
20 \% \text {. }\end{array}$ & [18] \\
\hline $\begin{array}{l}\text { Acid-treated } \\
\text { MWCNTs }\end{array}$ & $\begin{array}{l}\text { Phosphate buffer, } 0.1 \\
\mathrm{~mol} \mathrm{~L}^{-1}, \mathrm{pH} 7.0,50{ }^{\circ} \mathrm{C} \text {. }\end{array}$ & Air & 6 at $0 \mathrm{~V}$ & $\begin{array}{l}\mathrm{CV} \text { at } \\
20 \mathrm{mV} \mathrm{s}^{-1}\end{array}$ & N.A. & [19] \\
\hline Hydrophilic SWCNT & $\begin{array}{l}\text { Phosphate buffer, } 0.1 \\
\text { mol L }^{-1}, \mathrm{pH} 7.0,22^{\circ} \mathrm{C} \text {. }\end{array}$ & Pure $\mathrm{O}_{2}$ & 7 at $0 \mathrm{~V}$ & $\begin{array}{l}\mathrm{CV} \text { at } \\
20 \mathrm{mV} \mathrm{s}^{-1}\end{array}$ & N.A. & [20] \\
\hline
\end{tabular}

MWCNT: multi-walled carbon nanotube; CV: cyclic voltammetry; LSV: linear sweep voltammetry; CA: chronoamperometry; EDC: 1-(3dimethylaminopropyl)-3'ethylcarbodiimide hydrochloride; NHS: N-hydroxysuccinimide.

* Potential vs $\mathrm{Ag} / \mathrm{AgCl}$ reference electrode.

** Non-gas-diffusion condition.

*** Current in $\mathrm{mA}$. 


\section{S9. BOD-based biogel/C GDE stability}

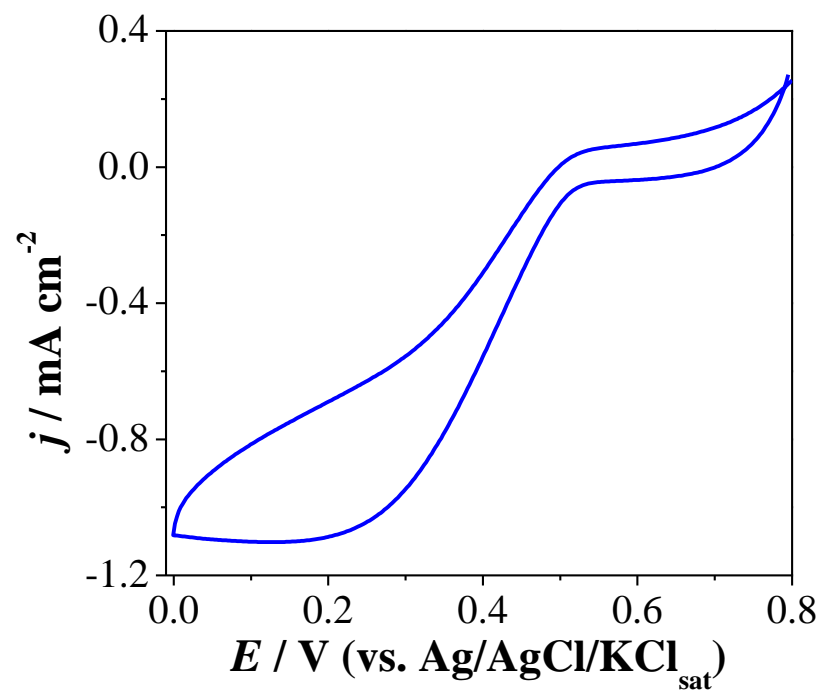

Figure S8. $\mathrm{CV}$ at $5 \mathrm{mV} \mathrm{s}^{-1}$ of BOD-based biogel/C GDE in phosphate buffer (pH 7.2) at $25{ }^{\circ} \mathrm{C}$, under atmospheric condition, after $24 \mathrm{~h}$ at $-1.00 \mathrm{~mA} \mathrm{~cm}^{-2}$.

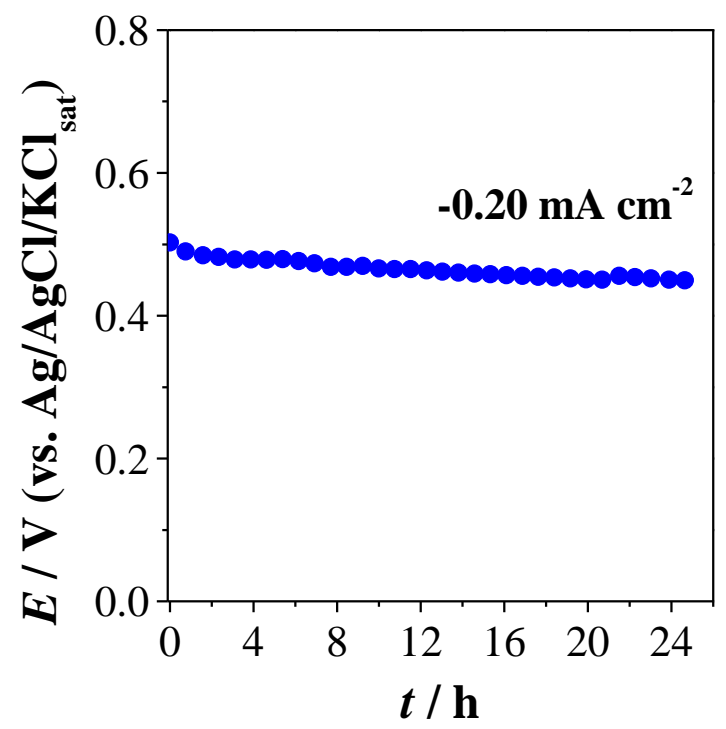

Figure S9. Operational stability at $-0.20 \mathrm{~mA} \mathrm{~cm}^{-2}$ of the BOD-based biogel/C GDE in phosphate buffer ( $\mathrm{pH} 7.2$ ) at $25^{\circ} \mathrm{C}$, under atmospheric condition. 
S10. Effect of BOD-based biogel amount
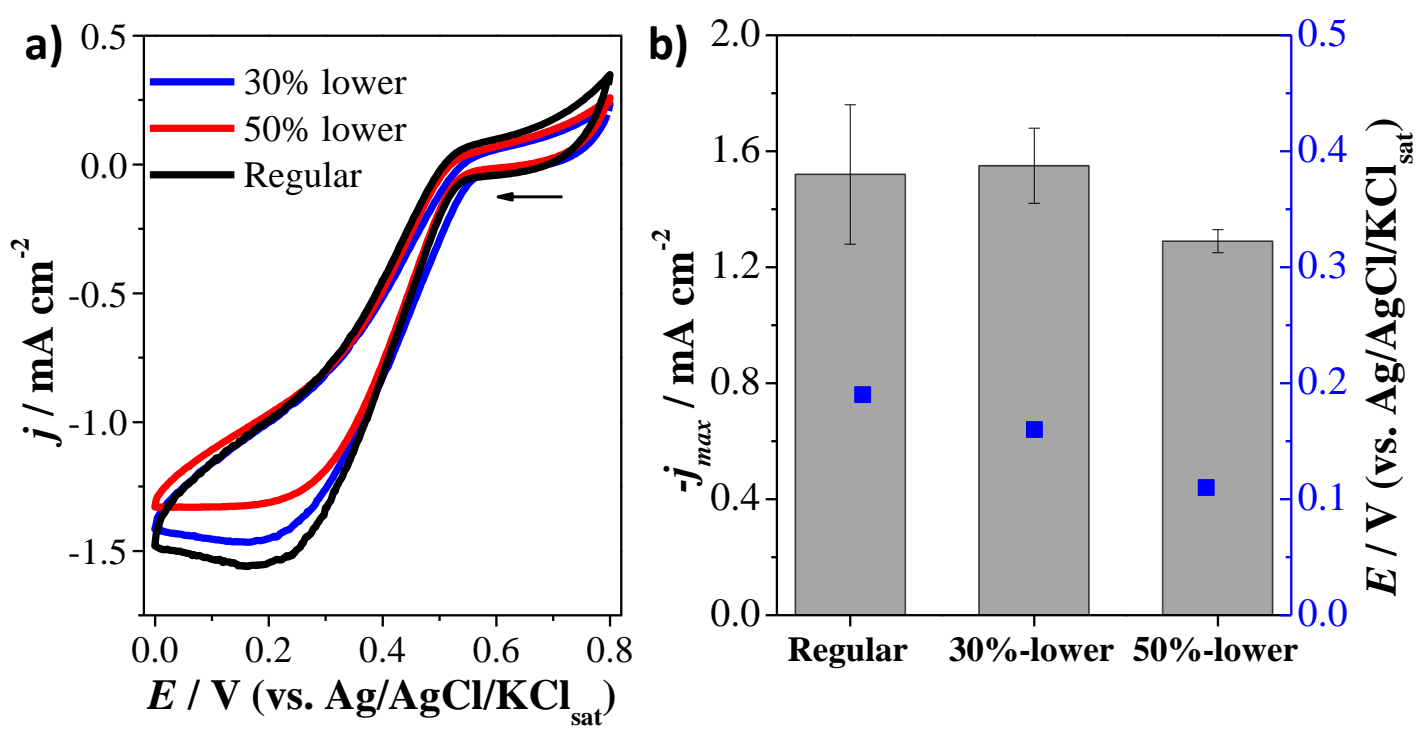

c)

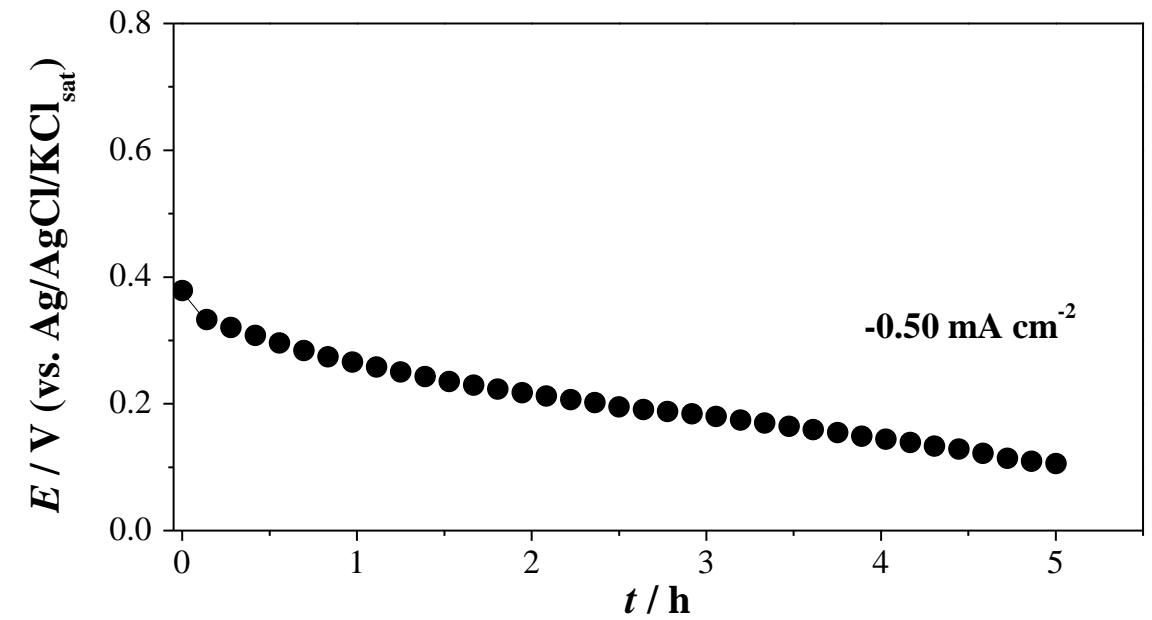

Figure S10. (a) CV at $5 \mathrm{mV} \mathrm{s}^{-1}$ of the GDEs with regular amount of BOD-based biogel (black curve), 30\% lower (blue curve), and 50\% lower (red curve). (b) Maximum current density toward ORR of the bioelectrodes and the respective potentials. (c) Operational stability at $-0.50 \mathrm{~mA} \mathrm{~cm}^{-2}$ of BOD-based biogel/C GDE with 50\% lower biogel. All measurements were recorded in phosphate buffer solution ( $\left.\mathrm{pH} 7.2,0.1 \mathrm{~mol} \mathrm{~L}^{-1}\right)$ at $25^{\circ} \mathrm{C}$ and under atmospheric conditions. 


\section{S11. Enzyme leaching}

Enzyme leaching from the electrode surface was investigated by spectroscopy in the UV-vis range. UV-vis spectra were recorded with spectrophotometer Jasco V-760 in the range of 800 to 200 $\mathrm{nm}$, with a quartz microcuvette $(1.0 \mathrm{~cm}$ pathlength). Different bioelectrodes were prepared by dropping the follow solutions onto the top of the electrodes: BOD, BOD-Nafion and BOD-GA solutions in phosphate buffer, and BOD-based biogel. The amount of enzyme applied on each electrode $\left(1 \mathrm{~cm}^{2}\right)$ was $1.4 \mathrm{mg}$. After that, the electrodes were incubated at $4{ }^{\circ} \mathrm{C}$ overnight to dry.

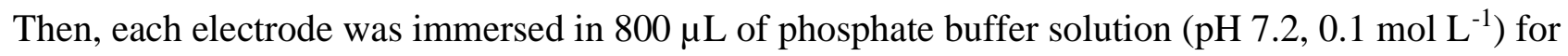
24 h. After 24 h, UV-vis spectra solutions where the electrodes were soaked were measured (Fig. S11). For comparison, UV-vis spectra of control solutions of BOD, Nafion and GA in phosphate buffer $\mathrm{pH} 7.2$ at the concentrations as if all BOD, GA, and Nafion leached from the electrodes were measured. As GA shows absorbance signals at the same wavelength of the enzyme in the visible region, the BOD leaching was monitored by the absorption band at $595 \mathrm{~nm}$ (Fig. 2b), which is attributed to the Cys $\mathrm{S} \rightarrow \mathrm{Cu}$ T1 charge-transfer.
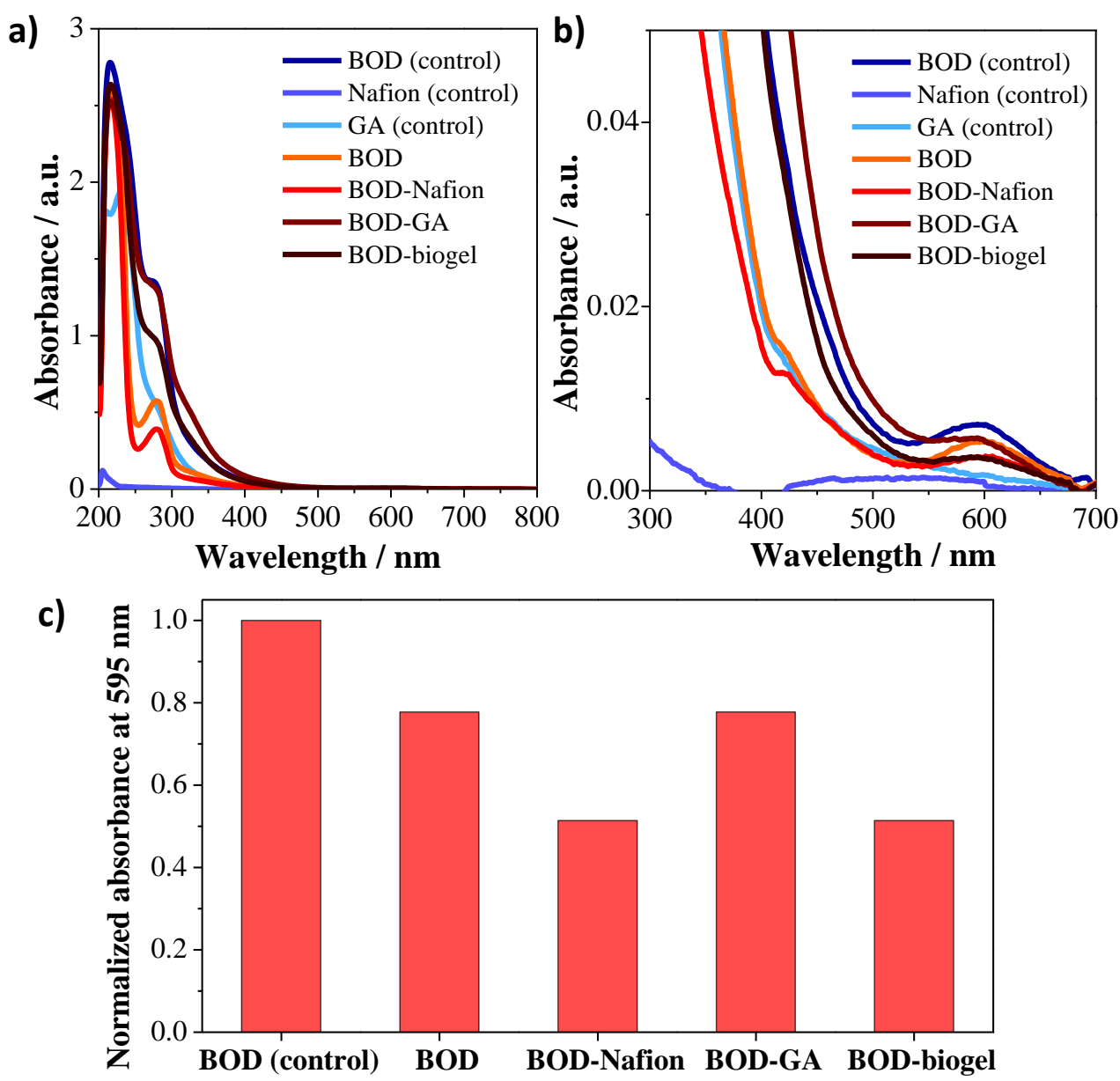

Figure S11. (a) UV-vis spectra of BOD, Nafion and GA control solutions in phosphate buffer $\left(\mathrm{pH} \mathrm{7.2,0.1} \mathrm{mol} \mathrm{L}{ }^{-1}\right)$, and of phosphate buffer $\left(\mathrm{pH} 7.2,0.1 \mathrm{~mol} \mathrm{~L}^{-1}\right.$ ) where BOD, BOD-Nafion and BOD-GA and BOD-based biogel electrodes were incubated for 24 h. (b) Zoomed UV-vis spectra 
shown in (a). (c) Normalized absorbance at $595 \mathrm{~nm}$. Absorbance intensities were normalized by the absorbance of BOD (control) sample at $595 \mathrm{~nm}$.

\section{S12. Effect of Nafion and GA on the bioeletrode performance}
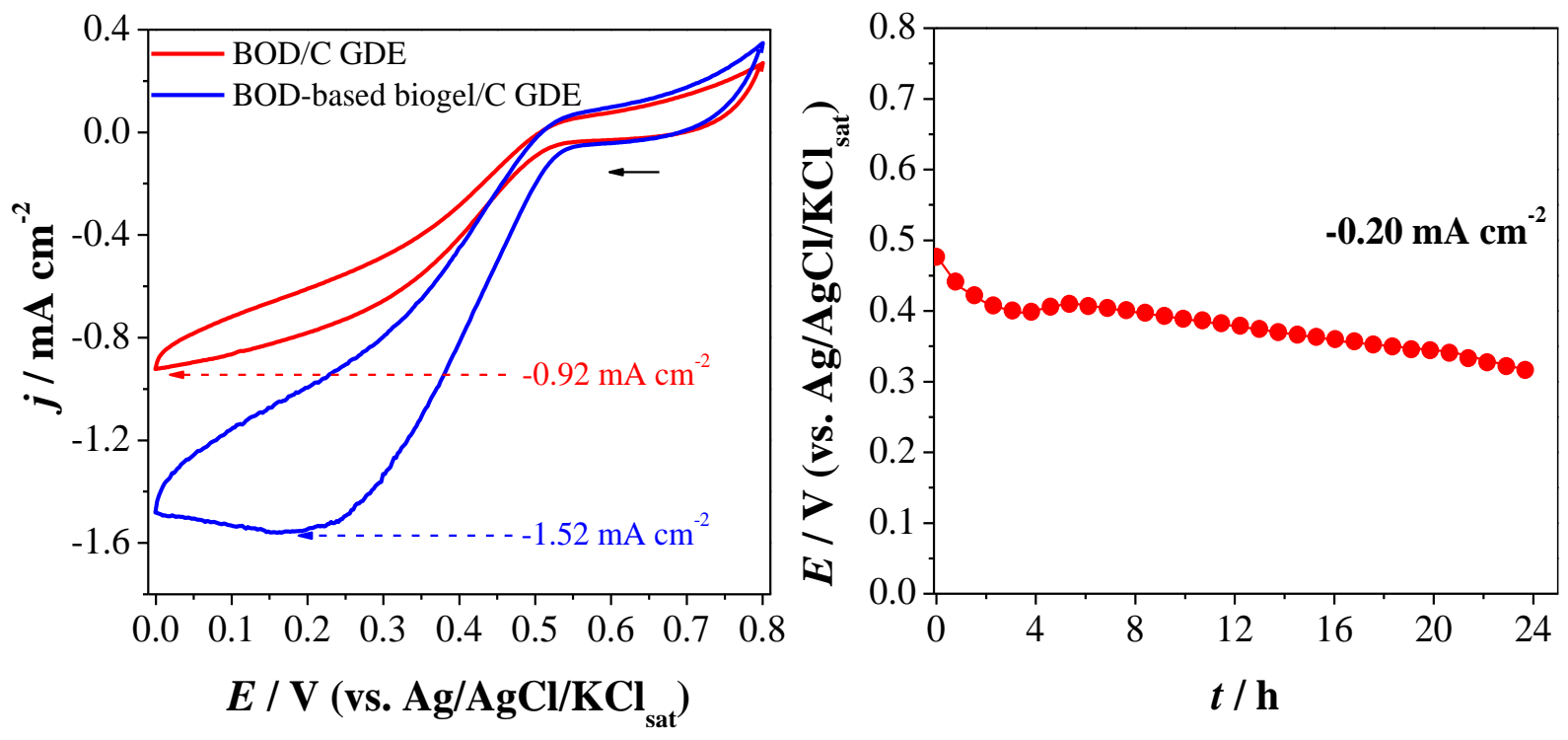

Figure S12. (a) CVs at $5 \mathrm{mV} \mathrm{s}^{-1}$ recorded with BOD/C (red) and BOD-based biogel/C (blue) GDEs. Insets show the maximum reduction current densities. (b) long-term operational stability at -0.20 $\mathrm{mA} \mathrm{cm}{ }^{-2}$ of BOD/C GDE. All measurements were performed in phosphate buffer $(\mathrm{pH} 7.2)$ at $25^{\circ} \mathrm{C}$, under atmospheric condition. 


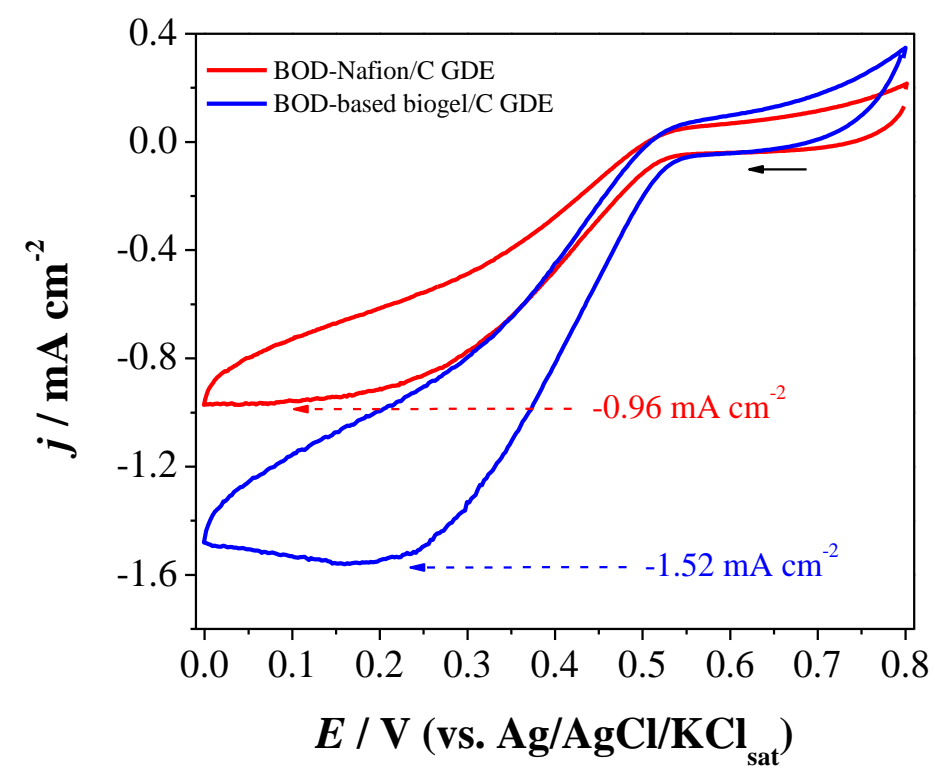

Figure S13. (a) CVs at $5 \mathrm{mV} \mathrm{s}^{-1}$ recorded with BOD-Nafion/C (red) and BOD-based biogel/C (blue) GDEs in phosphate buffer $(\mathrm{pH} 7.2)$ at $25^{\circ} \mathrm{C}$, under atmospheric condition. Insets show the maximum reduction current densities.

\section{References}

[1] D. Guo, S. Fu, Z. Dai, A highly porous nafion membrane templated from polyoxometalatesbased supramolecule composite for ion-exchange polymer-metal composite actuator, J. Mater. Chem. 20 (2010) 10159-10168.

[2] N. Ramaswamy, T.M. Arruda, W. Wen, N. Hakim, M. Saha, A. Gullá, S. Mukerjee, Enhanced activity and interfacial durability study of ultra low Pt based electrocatalysts prepared by ion beam assisted deposition (IBAD) method, Electrochim. Acta 54 (2009) 6756-6766.

[3] N.R. Kil'deeva, P.A. Perminov, L. V. Vladimirov, V. V. Novikov, S.N. Mikhailov, On the Mechanism of the Reaction of Glutaraldehyde with Chitosan, Russ. J. Bioorganic Chem. 35 (2009) 360-369.

[4] H. Hu, J.H. Xin, H. Hu, A. Chan, L. He, Glutaraldehyde - chitosan and poly (vinyl alcohol) blends, and fluorescence of their nano-silica composite films, Carbohydr. Polym. 91 (2013) 305-313.

[5] D. Kishore, M. Talat, O.N. Srivastava, A.M. Kayastha, Immobilization of b-Galactosidase onto Functionalized Graphene Nano-sheets Using Response Surface Methodology and Its Analytical Applications, PLoS One 7 (2012) e40708. 
[6] A. Barth, Infrared spectroscopy of proteins, Biochim. Biophys. Acta 1767 (2007) 1073-1101.

[7] A. De Poulpiquet, R. Haddad, A. Le Goff, M. Holzinger, M. Mermoux, P. Infossi, N. Mano, E. Lojou, S. Cosnier, A membraneless air-breathing hydrogen biofuel cell based on direct wiring of thermostable enzymes on carbon nanotube electrodes, Chem. Commun. 51 (2015) $7447-7450$.

[8] K. So, M. Onizuka, T. Komukai, Y. Kitazumi, O. Shirai, K. Kano, Binder/surfactant-free biocathode with bilirubin oxidase for gas-diffusion-type system, Electrochem. Commun. 66 (2016) 58-61.

[9] N. Lalaoui, M. Holzinger, A. Le Goff, S. Cosnier, Diazonium Functionalisation of Carbon Nanotubes for Specific Orientation of Multicopper Oxidases: Controlling Electron Entry Points and Oxygen Diffusion to the Enzyme, Chem. Eur. J. 22 (2016) 10494-10500.

[10] K. So, H. Ozawa, M. Onizuka, T. Komukai, Y. Kitazumi, O. Shiraia, K. Kano, Highly Permeable Gas Diffusion Electrodes with Hollow Carbon Nanotubes for Bilirubin OxidaseCatalyzed Dioxygen Reduction, Electrochim. Acta 246 (2017) 794-799.

[11] K. So, Y. Kitazumi, O. Shirai, K. Nishikawa, Y. Higuchi, K. Kano, Direct electron transfertype dual gas diffusion H2/O2 biofuel cells, J. Mater. Chem. A 4 (2016) 8742-8749.

[12] H. Xia, K. So, Y. Kitazumi, O. Shirai, K. Nishikawa, Dual gas-diffusion membrane- and mediatorless dihydrogen/air-breathing biofuel cell operating at room temperature, J. Power Sources 335 (2016) 105-112.

[13] C. Santoro, S. Babanova, B. Erable, A. Schuler, P. Atanassov, Bilirubin oxidase based enzymatic air-breathing cathode: Operation under pristine and contaminated conditions, Bioelectrochemistry 108 (2016) 1-7.

[14] G.P.M.K. Ciniciato, C. Lau, A. Cochrane, S.S. Sibbett, E.R. Gonzalez, P. Atanassov, Development of paper based electrodes: From air-breathing to paintable enzymatic cathodes, Electrochim. Acta 82 (2012) 208-213.

[15] E. Pinchon, M. Arugula, K. Pant, S. Singhal, Enhancement of Electrochemical Performance of Bilirubin Oxidase Modified Gas Diffusion Biocathode by Porphyrin Precursor, Adv. Phys. Chem. 2018 (2018) 4712547.

[16] H.O. Biocathodes, S. Gentil, S. Cosnier, S.Ø. Gounel, N. Mano, Direct Electrochemistry of Bilirubin Oxidase from Magnaporthe orizae on Covalently-Functionalized MWCNT for the Design of, Chem. - A Eur. J. 24 (2018) 8404-8408. 
[17] J. Szczesny, N. Markovi, F. Conzuelo, S. Zacarias, I.A.C. Pereira, N. Plumeré, W. Schuhmann, A. Ruff, W. Lubitz, A gas breathing hydrogen/air biofuel cell comprising a redox polymer/hydrogenase-based bioanode, Nat. Commun. 9 (2018) 4715.

[18] F. Conzuelo, J. Szczesny, N. Markovic, A. Ruff, W. Schuhmann, D. Herna, An Air-breathing Carbon Cloth-based Screen-printed Electrode for Applications in Enzymatic Biofuel Cells, Electroanalysis 31 (2019) 217-221.

[19] S. Yin, Z. Jin, T. Miyake, Wearable high-powered biofuel cells using enzyme/carbon nanotube composite fibers on textile cloth, Biosens. Bioelectron. 141 (2019) 111471.

[20] S. Yin, X. Liu, Y. Kobayashi, Y. Nishina, R. Nakagawa, R. Yanai, K. Kimura, T. Miyake, A needle-type biofuel cell using enzyme/mediator/carbon nanotube composite fibers for wearable electronics, Biosens. Bioelectron. 165 (2020) 112287. 


\section{CHAPTER IV - Extracellular electron transfer in Saccharomyces cerevisiae and energy conversion in a microbial fuel cell}

This chapter shows an original work, not published yet, performed during the doctorate period. It mainly dedicated to the study of the extracellular electron transfer mechanism in Saccharomyces cerevisiae. Although this is one of the first microorganism proved to be able to convert chemical energy into electricity, its EET mechanism still remained misunderstood. The origin of bioelectricity and how electrons are extracellularly transported from some microorganisms are still ones of nature's misunderstood phenomenon. Insights on how electron flows in biological cells have direct implication in the fields of microbial physiology, microbial ecology, biotechnology, and green energy generation.

In this context, by a series of systematical experiments, it is demonstrated, for the first time, a flavoprotein mostly stored in the extracellular polymeric substance on cell surface is responsible for the Saccharomyces cerevisiae bioelectricity. In addition, inspired by the cellular respiration, the energy obtention process in chemotrophs organisms, it is demonstrated the electricity generation in a mediatorless MFC, which exploits the glucose oxidation by Saccharomyces cerevisiae on the flexible-carbon fiber-based bioanode, and the oxygen reduction to water on the BOD-based gas diffusion biocathode (shown in Chapter III). This BFC showed better performance compared to the similar ones already reported. This fact emphasizes the importance of choosing suitable electrode materials, such as FCF, and stable and efficient catalysts, such as BOD incorporated into a gel matrix, to reach high-performance BFCs. 


\section{INTRODUCTION}

In 1911, M. C. Potter, based in his studies with Saccharomyces cerevisiae and bacteria, reported "The disintegration of organic compounds by micro-organisms is accompanied by the liberation of electrical energy". ${ }^{26}$ Although more than a century has passed, only in the last two decades the bioelectrochemical energy conversion systems gained space in the research and technological fields, driven by the global interest in alternative and clean energy sources. Since then, numerous studies have investigated and explored the energy conversion by several microorganisms, including bacteria, ${ }^{8-13}$ and yeasts, ${ }^{12,14,23,15-22}$ in bioelectrochemical systems named microbial fuel cell (MFC).

MFCs exploit the capacity of microorganisms to transfer the electrons derived from catabolic pathways of the cellular metabolism to an electrode surface to generate useful electricity. In some cases, the bioelectricity generation is coupled, for example, to the wastewater treatment ${ }^{18,27}$ and water desalination, ${ }^{28}$ amplifying the application possibilities of this kind of bioelectrochemical system. However, the obtention of BFCs with satisfactory energy output is not trivial and is still a challenge, impacting the wide application of this technology in the real world. Overcoming this issue is intrinsically related to the deeply understanding of the electron transfer mechanisms, cellular metabolism, and to the development of new electrode materials to improve the electron transfer rate in the interface microorganism/electrode.

Several fundamental studies have been dedicating to comprehend the interaction between microorganisms and solid electrode surfaces, and how the microorganisms extracellularly transfer electrons to these materials. ${ }^{29-31}$ Understanding how electron flows in biological cells has direct implication in the fields of microbial physiology, microbial ecology, biotechnology, and green energy. Despite the mechanisms of extracellular electron transfer (EET) in bacteria are very stablished in the literature, the same is not true for yeasts. Studies show contradictory conclusions about EET mechanisms involving yeasts, specially Saccharomyces cerevisiae, that is one of the first microorganisms proved to be able to convert chemical energy into electrical energy. ${ }^{26}$ In this context, the present chapter is dedicated to study the EET of Saccharomyces cerevisiae and to apply this microorganism in a bioanode of a glucose- $\mathrm{O}_{2}$ MFC. 


\section{BIBLIOGRAPHIC REVISION}

\subsection{Extracellular electron-transfer in microorganisms}

Electron transfer (ET) processes have fundamental importance in all living organisms, for example, they are the key of the cellular respiration, photosynthesis, nitrogen fixation, biosynthesis, bioluminescence, apoptosis, and are involved in DNA-damage repair, blood coagulation, and regulation mechanisms. ${ }^{32,33}$ These processes are facilitated by proteins, called redox proteins, and in many cases, involve electron carriers, such as reduced flavin adenine dinucleotide $\left(\mathrm{FADH}_{2}\right)$ and reduced nicotinamide adenine dinucleotide (NADH).

Concerning the cellular respiration, the living organisms oxidize organic compounds, such as carbohydrates, lipids and proteins, producing electrons, protons, and energy in form of ATP. The oxidation reactions in catabolic pathways, such as glycolysis and citric acid cycle, are coupled to the reduction of $\mathrm{NAD}^{+}$and $\mathrm{FAD}$ to $\mathrm{NADH}$ and $\mathrm{FADH}_{2}$, respectively. ${ }^{12}$ Then, the oxidized forms of the electron carriers are restored by the electron releasing to a terminal electron acceptor (TEA). In aerobic organisms, the TEA is the molecular oxygen, whereas in facultative or strict anaerobes can uses organic compounds, nitrate, sulfate, carbon dioxide, and metals (Fe(III) is a widespread anaerobic TEA). ${ }^{32,34}$

In a diversity of microorganisms, including bacteria and fungi, ET between the cell and the environment, named extracellular electron transfer (EET), is essential for survival in cases of the TEA is not easily accessible due to low solubility and/or diffusivity, for example. ${ }^{32}$ EET is crucial for the maintenance of the intracellular redox balance required to the proper functioning of the metabolism and to exchange information and energy with other organisms and/or the environment. ${ }^{12,30,32}$ The capability of some microorganisms to transfer electrons to extracellular acceptors, such as solid materials, has been exploring in energy conversion bioelectrochemical systems, the MFCs. ${ }^{12,35}$ In this approach, the microbe is able to oxidize the organic matter and transfer electrons to an electrode surface (anode), producing electricity when connected to a cathode through an external electrical circuit.

EET mechanisms in microorganisms have been divided into two main types (Figure 1): direct EET and mediated (or indirect) EET. The direct EET requires direct contact of the cells with the external electron acceptor and involves redox proteins localized in the microbial outer cellular membrane, such as cytochromes, by electroconductive nanowires (pili), or by polymeric extracellular substances (EPS) surrounding the cells. Whereas, the mediated EET 
involves endogenous or exogeneous diffusional electron mediator(s). ${ }^{35,36}$ In this case, the endogenous electron mediator is a redox molecule naturally excreted by the microorganism (a metabolite), and the exogeneous electron mediator is an artificial redox shuttle intentionally added in the environment to facilitate the EET.

Figure 1 - EET mechanisms in microorganisms.

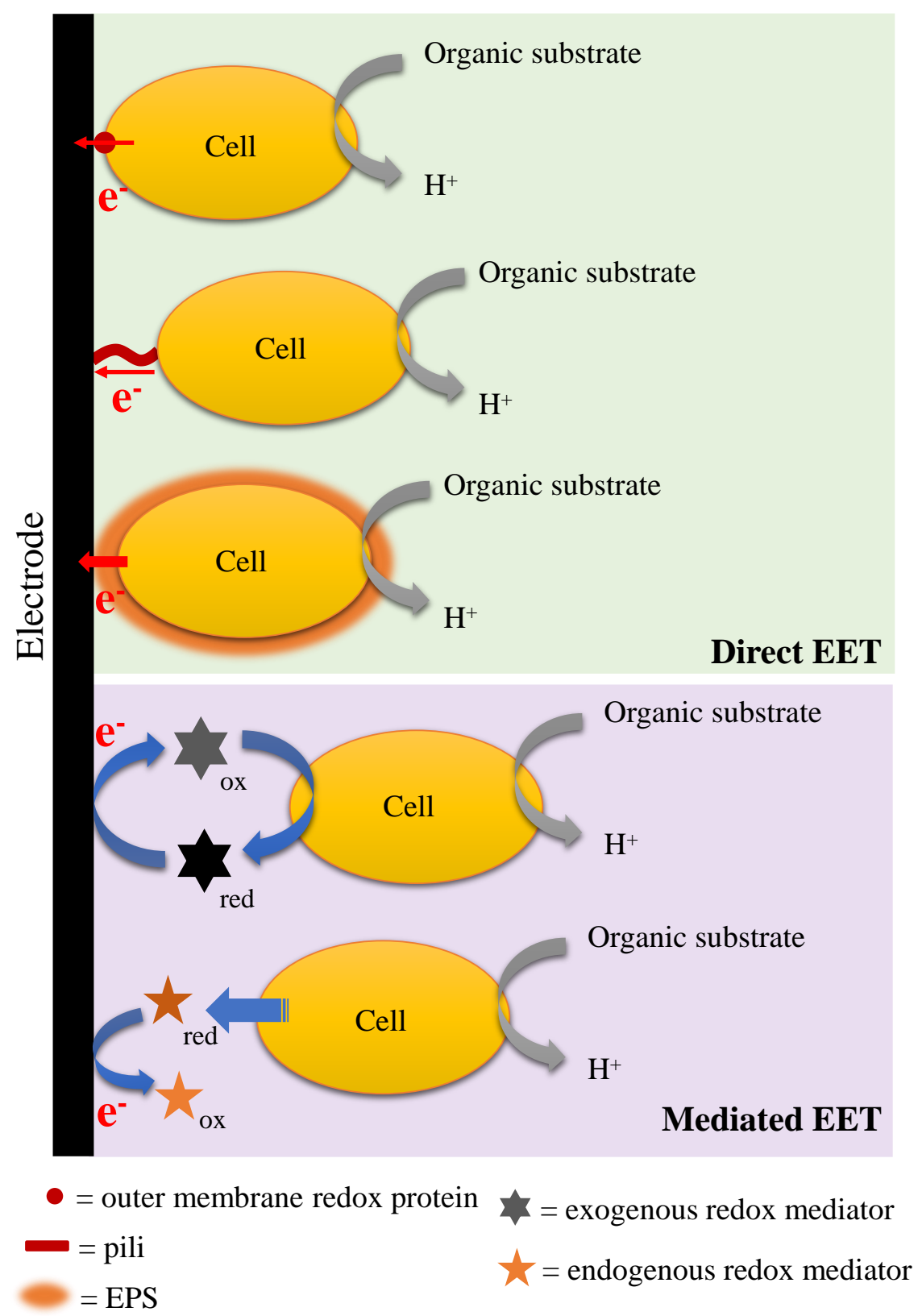

Source: own author.

The exogeneous redox mediators are usually organic dies, such as methylene blue, methyl orange, bromocresol green, neutral red, and resorufin, ${ }^{31}$ which show reversible redox reactions. They should be able to easily penetrate into the cell to accept electrons from the cell electron 
carriers, and then transfer such electrons to the anode surface. The use of exogeneous redox mediators considerably increases the performance of MFCs compared to those explore the direct EET mechanisms. However, in most cases, exogenous redox mediators are toxic and expensive, whereas, the direct EET mechanisms provide simplicity and reduce the costs of these biological energy conversion systems. ${ }^{31}$

The EET mechanism varies with the type of microorganism and the environmental or experimental conditions. For example, the EET through conductive nanowires is very common in some bacteria, such as Geobacter and Shewanella. They use conductive nanowires to exchange electrons with insoluble minerals containing Fe(III) and Mn(IV) oxides, ${ }^{37,38}$ and with electrode surfaces in bioeletrochemical systems. ${ }^{12}$ The nanowires, usually showing few nanometers in diameter and up to some micrometers in length, are able to connect cytochromes bound to the outer membrane of cells and the electron acceptor surface. ${ }^{12,37,38}$ They are formed by protein with high density of aromatic amino acid residues, which play a key role in the high conductivity along the length of the nanofilaments. ${ }^{39}$

In addition, the presence of EPS film surrounding the microbial cells has been also reported to contribute to the direct EET process of Gram-negative (Shewanella oneidensis) and Gram-positive (Bacillus sp.) bacteria, as well as, yeast (Pichia stipites). ${ }^{30,40}$ EPS is naturally secreted by microorganisms and shows several functions for the microorganisms: to accelerate the cell aggregation to form biofilms, to facilitate the cell adhesion on solid surfaces, to act as energy source in nutrient scarcity situations or to trap nutrients, and to protect the organism against external stress. ${ }^{41-44}$ EPS film is mainly formed by high-molecular-weight compounds secreted by the cells, such as polysaccharides and glycoproteins. ${ }^{41-44}$ Also, EPS may store electrochemically active compounds, probably flavins and cytochromes in bacteria, acting as electron transient media. The electron hopping is the most likely molecular mechanism for electrochemical ET through the EPS. ${ }^{30}$ As the many microorganism produce EPS and it represents a thick layer covering the cell surface, the effect and contribution of EPS to the EET should also be considered, despite it is rarely studied.

For yeasts, in particular, the conclusions about the EET mechanism considerably vary according to the species, and, in some cases, are controversial for the same species. Concerning Pichia stipites, there are reports show evidences this yeast extracellularly transfers electrons through redox compounds in the EPS,${ }^{50}$ whereas others state EET of Pichia stipites occurs by secretion of free riboflavin. ${ }^{45}$

The direct EET via redox proteins bound to the outer cell membrane of yeasts seems to be very unlikely, because they show a thick and dense cell wall (100-200 nm), composed mainly 
of polysaccharides surrounding the cell membrane, and a periplasmic space $(35-45 \AA) .{ }^{12}$ However, it has been reported Arxula adeninvorans, under anaerobic condition, shows EET takes place via redox enzymes present in the cell membrane, such as ferricyanide reductase and lactate dehydrogenase. ${ }^{20}$ Conversely, other studies with this yeast species in aerobic environment suggest electron transfer to the electrode surface via excreted redox metabolites, featuring an EET by endogenous redox mediator. ${ }^{21}$ Candida melibiosica has demonstrated to indirectly transfer electrons to electrode surface by excretion of soluble metabolites. ${ }^{22,23}$

Regards Saccharomyces cerevisiae, some observations indicate EET occurs through electrochemical active species confined on the external cell surface, ${ }^{14}$ whereas others speculate the electrons are extracellular transfer by excreted soluble redox compounds, such as NADH and $\mathrm{FADH}_{2},{ }^{18}$ or even through both mechanisms. ${ }^{46}$ The complex cellular structure of yeasts compared to bacteria, the several intracellular redox couples with different redox potentials, and the catabolic pathways occurring in both cytoplasm (glycolytic pathway) and mitochondria (acid citric and respiratory chain, only under aerobic conditions) hamper the interpretation of the results about the EET mechanism. Ironically, although Saccharomyces cerevisiae was one of the first microorganism proved to be able to convert chemical energy into electricity, its EET mechanism is still unclear, and deeper fundamental studies are required to avoid mistaken conclusions based on speculations.

\subsection{Biological fuel cells}

BFCs, like conventional fuel cells, are electrochemical devices able to convert the chemical energy into electrical energy and heat. Basically, fuel cells consist of two electrodes externally connected to an electrical circuit and immersed into an electrolyte: the anode, where the fuel is oxidized, usually small organic molecules or $\mathrm{H}_{2}$; and the cathode, where occurs the reduction of an oxidant, often atmospheric $\mathrm{O}_{2}$. The two electrodes are separated by an ionically conducting membrane, which enables the charge compensation between the anodic and cathodic compartments (Figure 2). 
Figure 2 - General representation of a fuel cell.

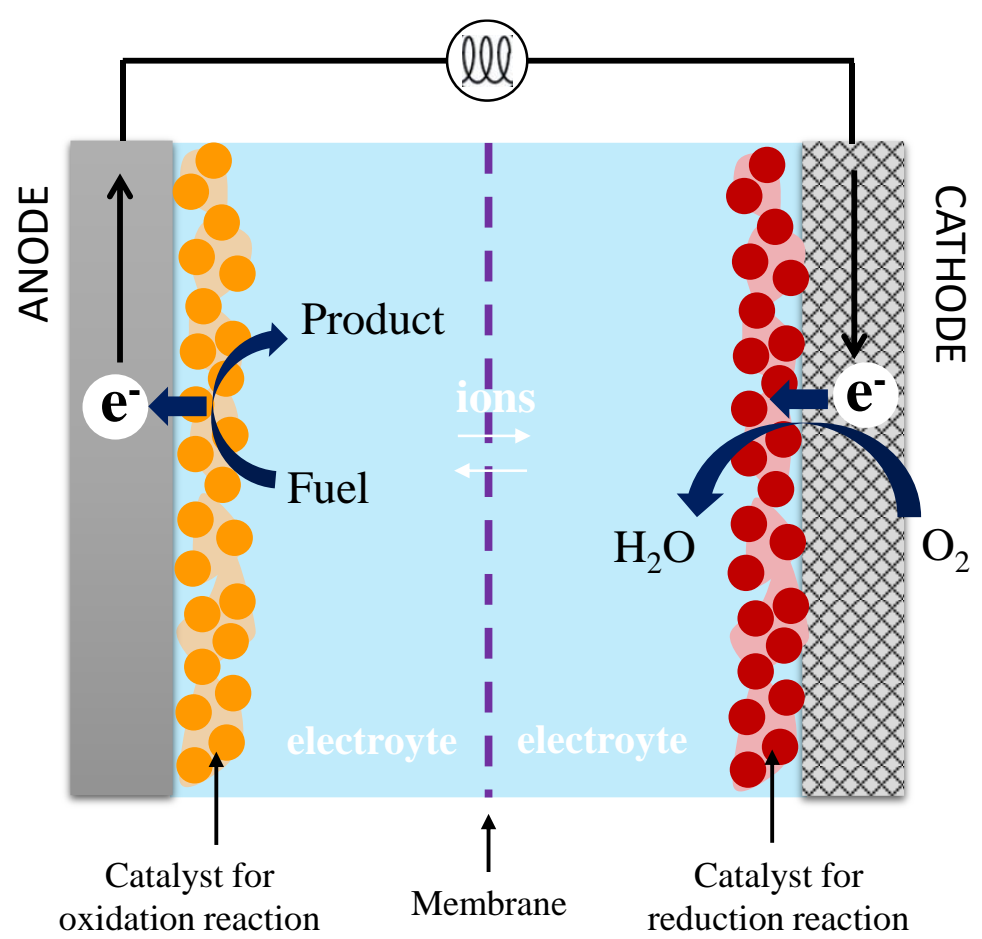

Source: own author.

The fuel cells can be dived into two main classes according to the kind of electrocatalysts used in the electrodes to catalyze the electrochemical reactions: conventional fuel cells, that employs usually noble metals, metal oxides, or alloys; and BCFs, that uses biological catalysts, such as redox enzymes, ${ }^{7,47-49}$ and/or microorganisms. ${ }^{8,12,18,35}$ Unlike the conventional electrocatalysts, the biological ones are renewable and naturally produced, can operate at mild conditions of temperature, pressure and $\mathrm{pH}$, and can oxidize a wide range of biofuels. ${ }^{7,8}$ These features make the BFCs safer and more versatile systems for electricity production, compared to the conventional fuel cells.

More specifically, BFCs that use microorganisms, typically bacteria, ${ }^{8-13}$ yeasts, ${ }^{12,14,23,15-}$ ${ }^{22}$ and algae, ${ }^{50}$ are classified as microbial fuel cells (MFCs) and those uses enzymes, as enzymatic BFCs. Also, there are hybrid BFCs that employ both, microorganisms and enzymes to catalyze the energy conversion. ${ }^{51,52}$ Both types of biocatalysts, microorganisms and redox enzymes, show advantages and limitations. In general, redox enzymes show better catalytic performance, but have shorter lifetime compared to microorganisms. The use of microorganisms to catalyze the energy conversion is advantageous because does not require the enzyme isolation and the organisms are able to naturally regenerate the required enzymes. However, the electroactive microorganisms show longer response time due to the complexity of the metabolic pathways. ${ }^{8}$ The use of microorganisms or enzymes as catalysts in BFCs is not 
only related to the advantages or limitations of these biosystems, but also to the type of application is desired. For example, MFCs have been studying and employing as power sources for low-power marine sensors and communication devices, ${ }^{11,13}$ and in wastewater treatment ${ }^{18,2753}$ and water desalination ${ }^{28}$ concomitantly to electricity generation; whereas, the use of enzymes as catalysts is more suitable in implantable, miniaturized, and biocompatible BFCs for biomedical applications. ${ }^{54,55}$

Although MFCs are attractive systems for sustainable energy conversion, as they employ abundant and renewable fuels and catalysts, and operate at mild conditions, ${ }^{56,57}$ there are still some challenges for their large-scale real-world applications: low power output caused mainly by sluggish microbial metabolic pathway kinetics and electron-transfer kinetics to electrode surface. ${ }^{7}$ To overcome some of these issues, fundamental studies are needed to understand the cellular metabolism, the EET mechanisms, the interaction microorganism-electrode, the formation of biofilms, and to develop electrode materials to improve the electron transfer rate in the interface microorganism/electrode. ${ }^{8}$

\subsection{Saccharomyces cerevisiae-based microbial fuel cells}

Saccharomyces cerevisiae belongs to the kingdom Fungi, is a simple and single-celled eukaryote, being classified as a yeast. Unlike bacteria (prokaryotes), yeasts show cell compartmentalization and rich genome. Particularly, Saccharomyces cerevisiae is extensively used in the bakery and beverage industries, as well as, in the ethanol fuel bioproduction. As previously discussed, despite the EET mechanism of this species is still unclear, its capability of extracellularly transfer electrons and act as biocatalyst for MFC is unquestionable since the pioneer studies of Potter. ${ }^{26}$ Saccharomyces cerevisiae show several attractive characteristics as biocatalyst for electrochemical energy conversion systems: is non-pathogenic, cheap, easily handed, robust, can metabolize several carbohydrates, show high growth rates, can be stored for long time in the dried state, and shows well-studied cellular structure and metabolism, serving as model eukaryotic cell. ${ }^{31,34}$

Several studies have reported Saccharomyces cerevisiae as biocatalyst in bioanodes of MFCs. ${ }^{14-19}$ To overcome slow kinetics of electron transport across the cell membrane and cell wall some of them use exogenous redox mediators, such as methylene blue and neutral red. ${ }^{15,17}$ These redox mediators easily penetrate into the yeast cell, accept electrons from the electron carriers in the cytosol and mitochondria, and then transfer them to the anode surface. Because of that, Saccharomyces cerevisiae-based MFCs (Sc-MFCs) that employ exogenous redox 
mediators show higher power density compared to those do not. However, the use of artificial electron shuttles is not desirable for practical applications, due to the increase in the operational costs and the environmental impact and toxicity in some cases.

According to the previous reports, ${ }^{14,16,18,19}$ the performance of the artificial mediatorless Sc-MFC is drastically affected by the features of the carbon-based anode, as shown in Table 1. The modification of the electrode surface with $\mathrm{C}=\mathrm{O}$ and $\mathrm{C}-\mathrm{N}$ dangled groups plays important role in the interaction and adhesion of yeast and substrate on electrode, enhancing the physical entrapment or electrostatic interactions. ${ }^{16}$ Also, cobalt layer coating carbon anode materials has shown to facilitate electron transfer between the yeast and the anode surface. ${ }^{19}$

Table 1 - Reported artificial mediatorless Sc-MFC.

\begin{tabular}{|c|c|c|c|c|c|c|}
\hline Anode & Cathode & Configuration & Substrate & $\begin{array}{l}\text { Open } \\
\text { circuit } \\
\text { voltage / V }\end{array}$ & $\begin{array}{l}\text { Max. } \\
\text { power / } \\
\text { mW m² }\end{array}$ & Ref. \\
\hline $\mathrm{CP}$ & $\mathrm{CP}-\mathrm{Pt} / \mathrm{C}$ & Double chamber & Glucose & 0.55 & 3 & 14 \\
\hline CF-PEI & $\mathrm{CF}$ & $\begin{array}{l}\text { Double chamber, } \\
\text { continuous- } \\
\text { flowing }\end{array}$ & Glucose & $\begin{array}{l}0.362 \pm \\
0.036\end{array}$ & $256.3 \pm 11.5$ & 16 \\
\hline $\begin{array}{l}\text { Graphite } \\
\text { plate }\end{array}$ & $\begin{array}{l}\text { Graphite } \\
\text { plate }\end{array}$ & $\begin{array}{l}\text { Single chamber, } \\
\text { continuous- } \\
\text { flowing }\end{array}$ & Wastewater & 0.331 & 25.51 & 18 \\
\hline $\begin{array}{l}\text { PCP- } \\
\text { cobalt } \\
\text { layer }\end{array}$ & $\mathrm{CP}-\mathrm{Pt} / \mathrm{C}$ & Double chamber & Glucose & 0.55 & 14 & 19 \\
\hline
\end{tabular}

Source: own author.

$\mathrm{CP}$ - carbon paper; $\mathrm{CF}$ - carbon felt; $\mathrm{PEI}$ - polyethyleneimine; $\mathrm{PCP}$ - porous carbon plate.

In addition, some of these reported $S c$-MFC do not use catalysts on the carbon-based material for the $\mathrm{O}_{2}$ reduction reaction on the cathode. This drastically impact the driving force (open-circuit voltage, $O C V$ ) of the MFCs, which is as lower as $0.36 \mathrm{~V},{ }^{16,18}$ whereas when platinum-based catalysts are used, the $O C V$ reaches $0.55 \mathrm{~V} .{ }^{14,19}$ This evidences that the cathode should also be carefully considered to obtain MFCs with satisfactory performance.

Interestingly, Saccharomyces cerevisiae has been also demonstrated to be able to produce fuel in situ concomitantly to energy conversion into a single system. ${ }^{51}$ That biosystem integrates yeast and alcohol dehydrogenase, a NAD-dependent redox enzyme, in the bioanode, and both cooperatively work: the first produces ethanol by the fermentation, and the latter catalyzes the oxidation of ethanol to acetaldehyde, forming NADH which is re-oxidized on the anode surface. 
The generating electrical current with the in situ ethanol production showed this system can be successfully used in a BFC. This approach allows to combine the advantage of the microorganism of using large variety of fuels (glucose, fructose, galactose, mannose, maltose e sucrose $),{ }^{58}$ and the high catalytic activity of the redox enzyme.

\subsection{Basic concepts in biofuel cells}

The power output of a biofuel cell, as a fuel cell, is mainly limited by the electrochemical reactions that occur on the two electrodes. According to the thermodynamical principles, the total energy released in any chemical reaction under constant pressure is equal to enthalpy variation $(\Delta H)$ of the reaction. However, the maximum useful work that can be extracted from a reaction is represented by the variation in Gibbs free energy $(\Delta G)$. These thermodynamic quantities are related according to Equation 1:

$$
\Delta G=\Delta H-T \Delta S
$$

where $\Delta S$ is the entropy variation of the reaction and $T$ is the absolute temperature.

For spontaneous redox reactions occurring in an electrochemical cell, $\Delta G$ represents the electrical work $\left(w_{\mathrm{el}}\right)$, and $-T \Delta S$ is the energy released in the form of heat. The electrical work is given by the product of the cell voltage $\left(E_{\text {cell }}\right)$ and the transferred charge $(Q)$, as shown in Equation 2:59

$$
\Delta G=w_{\mathrm{el}}=-Q E_{\text {cell }}=-n \mathrm{~F} E_{\text {cell }}
$$

where $n$ is the number of electrons transferred per redox species and $\mathrm{F}$ is the Faraday constant $\left(96,485 \mathrm{C} \mathrm{mol}^{-1}\right)$.

In this context, the efficiency of the conversion of the chemical energy into electricity can be calculated based on the electrical work /enthalpy ratio of the overall reaction as follows in Equation 3:

$$
\text { Efficiency }=\frac{\Delta G}{\Delta H}=\frac{-n \mathrm{~F} E_{\text {cell }}}{\Delta H}
$$


The reversible cell voltage generated by the electrochemical reactions on the cathode and anode depends on the solution composition. The Nernst equation (equation 4) relates the dependence of the cell voltage at zero current (open-circuit voltage, $O C V$ ) on the activities of the redox species, when the system is in equilibrium:

$$
E_{\text {cell }}=E_{\text {cell }}^{o}-\frac{\mathrm{RT}}{n \mathrm{~F}} \ln L
$$

where $E_{\text {cell }}^{o}$ is the cell voltage at standard conditions, $\mathrm{R}$ is the gas constant $\left(8.3145 \mathrm{~J} \mathrm{~mol}^{-1} \mathrm{~K}^{-1}\right)$, and $L$ is the overall reaction quotient.

The thermodynamic $O C V$ of a fuel cell can be predicted by the difference between the thermodynamic potentials of the cathodic $\left(E_{\mathrm{c}}^{o}\right)$ and anodic $\left(E_{\mathrm{a}}^{o}\right)$ redox reactions (Equation 5). Therefore, the anode and cathode potentials should be, respectively, as negative and as positive as possible to obtain a high $E_{\text {cell }}$.

$$
E_{\mathrm{cell}}^{o}=E_{\mathrm{c}}^{o}-E_{\mathrm{a}}^{o}
$$

Before assembling a fuel cell, it is important to investigate the half-cell responses for the cathode and anode to understand the electrochemical behavior of the electrodes individually. With a cyclic or linear voltammogram of the cathode and anode in presence of reference and counter electrodes it is possible to identify which electrode limits the current of the fuel cell, and to infer about the theoretical $O C V$ value on the experimental conditions, based on the onset potentials for oxidation and reduction.

The performance of a fuel cell is defined by its voltage, maximum current and power output. Those parameters can be obtained from polarization and power curves, as represented in Figure 3. The polarization curve is able to provide the $O C V$ ( $E_{\text {cell }}$ at zero current $)$ of the fuel cell, and the maximum cell current, which is measured at short circuit condition. 
Figure 3 - Representative (a) polarization and (b) power curves of a fuel cell.
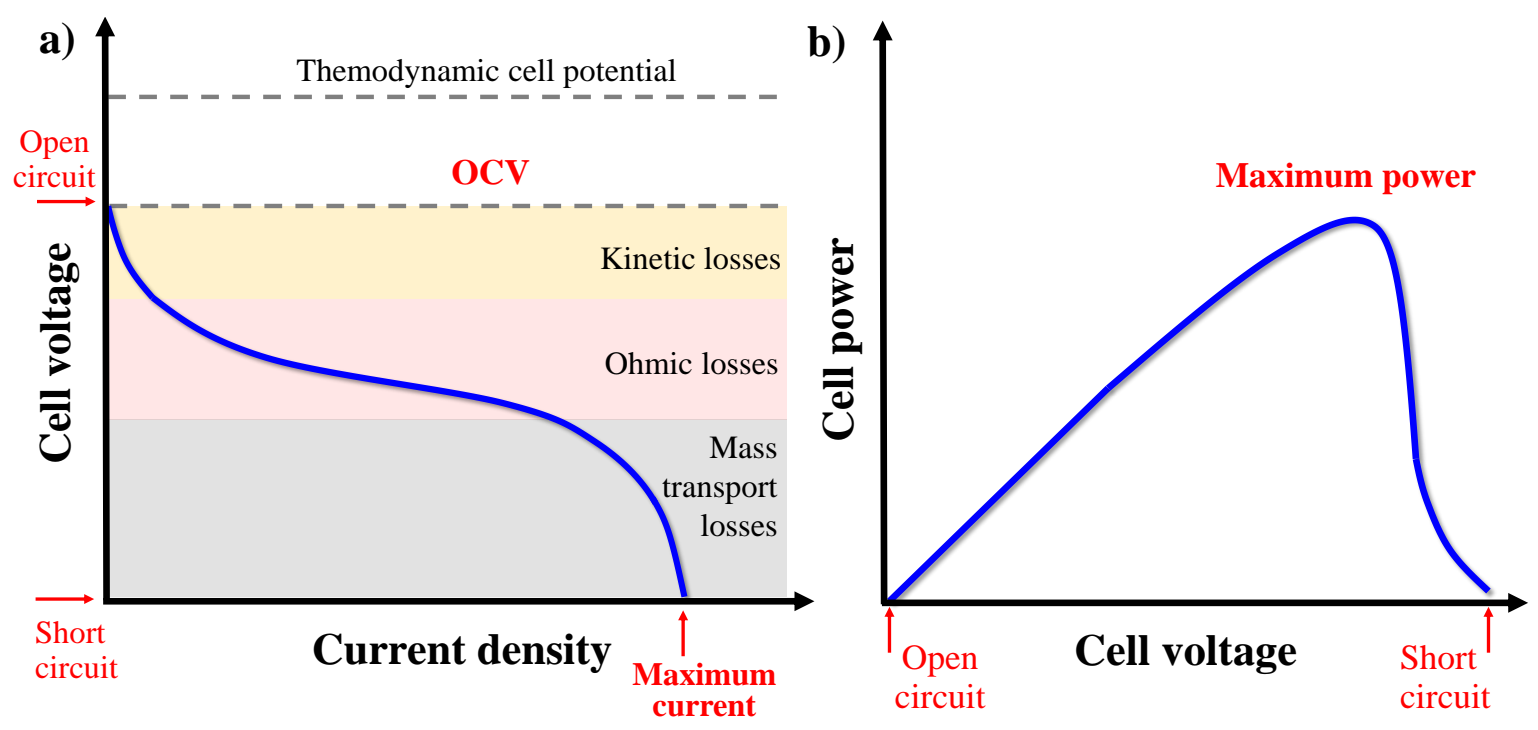

Source: own author.

Usually, the experimental $O C V$ value of a fuel cell is lower than the thermodynamic one. This because the electrochemical kinetics, the transport processes and the cell design also affect the cell voltage, besides the thermodynamics of the half-reactions. Therefore, the cell voltage can be written as in Equation 6. ${ }^{60,61}$

$$
E_{\mathrm{cell}}=E_{\mathrm{c}}^{o}-E_{\mathrm{a}}^{o}-\eta_{\mathrm{c}}-\eta_{\mathrm{a}}-\sum R_{e}-\eta_{\mathrm{mt}}
$$

where, $\eta_{\mathrm{a}}$ and $\eta_{\mathrm{c}}$ are the cathodic and anodic activation overpotentials caused by the sluggish electrode kinetics, $\sum R_{e}$ is the sum of the ohmic losses in the electrolyte, cell membrane, electrodes, and connections, and $\eta_{\mathrm{mt}}$ is mass transport overpotentials. ${ }^{61}$

The ohmic losses can be originated from the resistance to the electron flow through the electrode material and the interconnections, as well as the resistance to the ion flow through the electrolyte and cell separator membrane. Some factors can minimize those losses, such as choice of electrode material with high electronic conductivity, and optimization of cell design to decrease the gap between the electrodes. ${ }^{7}$

In addition, the shape of the polarization curve indicates the possible effects of the kinetics paraments, ohmic losses and mass transport limitations (Figure 3a). At smaller current densities, the interfacial electron transfer rate is slow, part of the energy is lost to drive the redox reaction, causing a significant cell voltage drop with the current from the open circuit condition. In intermediate conditions, the cell voltage linearly decreases with the current due to the ohmic losses, as previously discussed. At higher current densities, the reactants are faster consumed 
in the electrodes than they are transporting from the bulk solution, changing the fuel concentration on the electrode surface. Therefore, an abrupt cell voltage drop is observed up to the cell reaches zero voltage. ${ }^{7}$

The power of the fuel cell $\left(P_{\text {cell }}\right)$ can be mathematically obtained from the polarization curve by the equation 7 :

$$
P_{\text {cell }}=E_{\text {cell }} \int i d t
$$

The useful maximum power is achieved at current and voltage values between the extreme conditions of the open and short circuits (Figure 3b). Therefore, the maximum power directly depends on current, which is intrinsically related to the density of catalytic active sites on the electrodes, the rate of catalysis per active site, and the mass transport rate of reactants and products to and from electrode surface, respectively.

\section{OBJECTIVES}

Understanding the EET mechanisms of microorganisms shows direct impacts in biological electrochemical energy conversion systems. However, Saccharomyces cerevisiae EET mechanism has been little studied and hence still remains unclear in the literature. In this context, the studies in the present chapter aim contribute to the elucidation of Saccharomyces cerevisiae EET mechanism under fermentative conditions, through electrochemical, spectroscopic and microscopic evidences. In addition, a mediatorless MFC employing Saccharomyces cerevisiae-based flexible carbon fiber electrode ( $\mathrm{Sc}-\mathrm{FCF})$, as bioanode, and bilirubin oxidase-based gas diffusion electrode (BOD-GDE), as biocathode, for catalytic $\mathrm{O}_{2}$ reduction (shown in Chapter III) will be demonstrated.

\section{EXPERIMENTAL PROCEDURE}

\subsection{Materials and reactants}

Saccharomyces cerevisiae (baker's yeast) in dried state was obtained from Fleischmann ${ }^{\circledR}$. Anhydrous D-glucose $\left(\mathrm{C}_{6} \mathrm{H}_{12} \mathrm{O}_{6}, 99.9 \%\right)$, sodium dihydrogen phosphate $\left(\mathrm{NaH}_{2} \mathrm{PO}_{4}, 98 \%\right)$, sodium hydrogen phosphate $\left(\mathrm{Na}_{2} \mathrm{HPO}_{4}, 98 \%\right)$, sulfuric acid $\left(\mathrm{H}_{2} \mathrm{SO}_{4}, 95-\right.$ 
99\%), potassium permanganate $\left(\mathrm{KMnO}_{4}, 99.0 \%\right)$, sodium chloride $(\mathrm{NaCl}, 99.0 \%)$ and hydrogen peroxide $\left(\mathrm{H}_{2} \mathrm{O}_{2}, 37 \%\right)$ hydrochloric acid $(\mathrm{HCl}, 37 \%)$ were purchase from Synth®. Phosphate buffer solution $\left(0.10 \mathrm{~mol} \mathrm{~L}^{-1}\right)$ at $\mathrm{pH} 7.2$ was prepared from the mixture of suitable volumes of $0.20 \mathrm{~mol} \mathrm{~L}^{-1} \mathrm{NaH}_{2} \mathrm{PO}_{4}$ and $\mathrm{Na}_{2} \mathrm{HPO}_{4}$. All solutions were prepared with deionized water. The glassware was cleaned with permanganate solution followed by $\mathrm{HCl} / \mathrm{H}_{2} \mathrm{O}_{2} / \mathrm{H}_{2} \mathrm{O}$ solution at 1/1/5 (v/v/v) ratio. Before the measurements involving Saccharomyces cerevisiae, the glassware, MFC components and phosphate buffer solution were sterilized in an autoclave or in a UV-disinfection chamber (Solab, Brazil).

\subsection{Electrochemical measurements}

All electrochemical measurements were conducted on an Autolab PGSTAT128N (Metrohm, Swiss) potentiostat. The half-cell experiments were performed in a traditional jacket glass electrochemical cell containing homemade $\mathrm{Ag} / \mathrm{AgCl} / \mathrm{KCl}_{\text {sat. }}$ and Pt plate as reference and counter electrodes, respectively, and an array of treated FCFs as working electrode. FCFs were extracted from a carbon cloth (CCS200) and chemically treated in $1.0 \mathrm{~mol} \mathrm{~L}^{-1} \mathrm{H}_{2} \mathrm{SO}_{4}$ containing $25 \mathrm{mmol} \mathrm{L}^{-1} \mathrm{KMnO}_{4}$ for $3 \mathrm{~h}$ in ultrasonic bath, followed by washing in $\mathrm{HCl}$ and deionized water, as previously described. ${ }^{54,62,63}$ This treatment promotes the exfoliation and the formation of oxygenated carbon functional groups on the FCF surface. Phosphate buffer solution $(0.10$ mol L $\left.{ }^{-1}\right)$ at $\mathrm{pH} 7.2$ was used as supporting electrolyte. All measurements were performed at $40^{\circ} \mathrm{C}$ and under inert atmosphere $\left(\mathrm{N}_{2}\right.$ or Ar). The measured currents were normalized by the geometric area of the FCF electrode, for reporting the current density $(j)$ values.

\subsection{Spectroscopic measurements}

Vibrational spectroscopic measurements in the infrared region were performed in a Vertex 70v FTIR spectrometer (Bruker, Germany) coupled to a Hyperion 3000 microscope (Bruker, Germany). A HgCdTe (mercury cadmium telluride, MCT) detector cooled with liquid $\mathrm{N}_{2}$ was used. Spectra were collected between 4,000 and $900 \mathrm{~cm}^{-1}$, in the transmission mode, by averaging 128 interferograms at $8 \mathrm{~cm}^{-1}$ resolution. The optical images were collected with a $15 \times$ objective lens. The samples were prepared pipetting $1 \mu \mathrm{L}$ of Saccharomyces cerevisiae suspension samples on $\mathrm{CaF}_{2}$ disk previously cleaned with isopropanol. The samples were dried under vacuum at room temperature for $24 \mathrm{~h}$ before analysis. The samples were prepared from four different yeast suspensions: yeast suspended into deionized water (non-activated 
cells), and suspended into degassed phosphate buffer solution $\left(0.10 \mathrm{~mol} \mathrm{~L}^{-1}\right)$ at $\mathrm{pH} 7.2$ and $40{ }^{\circ} \mathrm{C}$, initially containing $1.00 \mathrm{~mol} \mathrm{~L}^{-1}$ glucose, after $1 \mathrm{~h}, 5 \mathrm{~h}$, and $24 \mathrm{~h}$ of fermentation. Any absorption signal from $\mathrm{CaF}_{2}$ substrate and atmosphere was subtracted from the sample spectra.

Electronic spectroscopic measurements in the ultraviolet/visible region (UV-vis) were performed in a Jasco V-760 (USA) spectrophotometer. EPS solution spectrum was collected


(1.0 cm pathlength).

Fluorescence spectroscopic measurements were performed in Hitachi F-4500 (Japan) spectrofluorometer located in Central de Análises Químicas Instrumentais of São Carlos Institute of Chemistry (CAQI/IQSC/USP). EPS emission spectrum was collected between 470 and $600 \mathrm{~nm}$ at 1,200 $\mathrm{nm} \mathrm{min}{ }^{-1}$, with a quartz cuvette. The wavelength excitation was $450 \mathrm{~nm}$.

\subsection{Scanning electron microscopy}

Scanning electron microscopy (SEM) images were obtained in Central de Análises Químicas Instrumentais of São Carlos Institute of Chemistry (CAQI/IQSC/USP) using ZEISS LEO 440 microscope (Cambridge, England) with OXFORD (model 7060) detector operating at $15 \mathrm{kV}, 2.82 \mathrm{~A}$ and I probe of $200 \mathrm{pA}$. The samples were coated with a $6 \mathrm{~nm}$ Au layer in a Coating System BAL-TEC MED 020 (BAL-TEC, Liechtenstein) and kept into desiccator until the measurements. The metallization conditions were: chamber pressure: $2.00 \times 10^{-2}$ mbar; current: $60 \mathrm{~mA}$; and deposition rate: $0.60 \mathrm{~nm} \mathrm{~s}^{-1}$.

\subsection{EPS extraction}

EPS was extracted from Saccharomyces cerevisiae cells after $24 \mathrm{~h}$ of fermentation by a thermal treatment, as previously described ${ }^{30}$ (Figure 4). Initially, the fermentation suspension was centrifuged at 5,000 $\mathrm{g}$ and $4{ }^{\circ} \mathrm{C}$ for $10 \mathrm{~min}$ for cell separation. The cells were washed in $\mathrm{NaCl} 0.9 \%(w / v)$ twice and then, resuspended into this saline solution and heated at $55^{\circ} \mathrm{C}$ for $30 \mathrm{~min}$. Next, the suspension was centrifuged at 5,000 $\mathrm{g}$ and $4^{\circ} \mathrm{C}$ for $10 \mathrm{~min}$ and the supernatant was collected. Finally, the supernatant was filtered through a $0.22 \mu \mathrm{m}$-filter to remove any suspended cell. The filtrate, called EPS solution, was stored at $4{ }^{\circ} \mathrm{C}$ until the analysis. 
Figure 4 - Scheme of EPS extraction Saccharomyces cerevisiae.

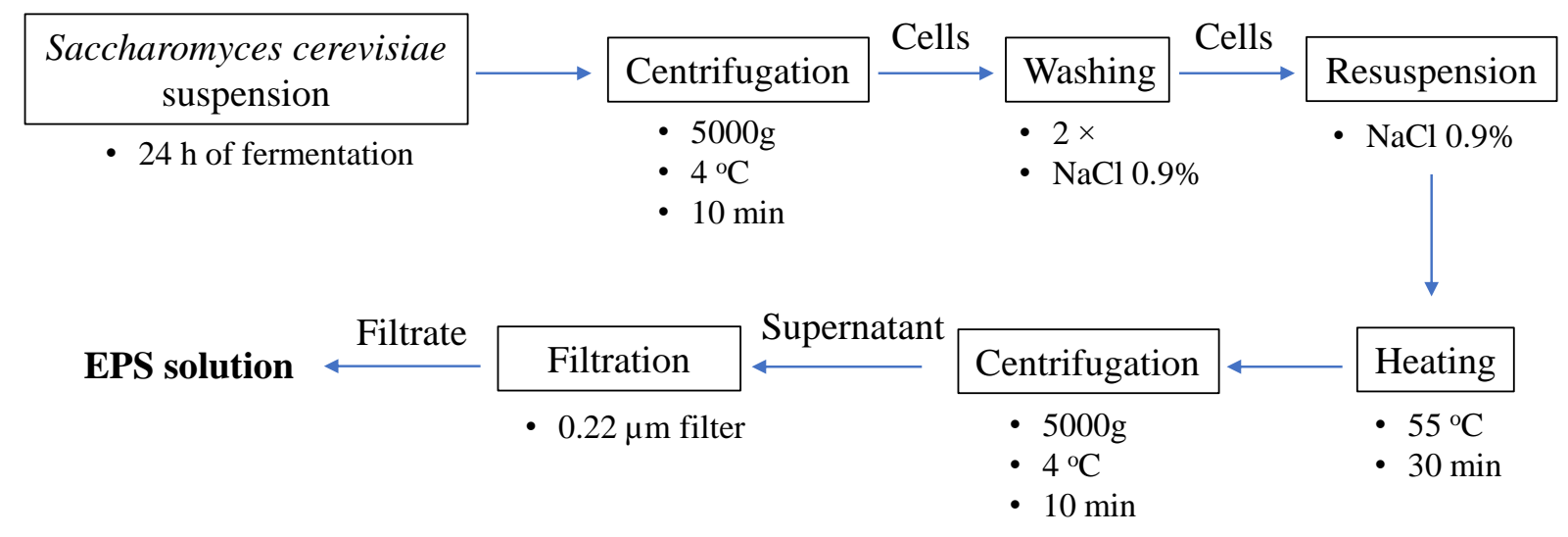

Source: own author.

\subsection{SDS-page electrophoresis}

SDS-page electrophoresis is a simple analytical technique that provides separation of proteins of a sample based on their molecular weights. It was used for separation of the proteins from EPS extracted from Saccharomyces cerevisiae. Firstly, the proteins in EPS solution were denatured and negatively charged by sodium dodecyl sulfate (SDS) detergent and the disulfide bonds between cysteine residues were cleaved by mercaptoethanol (reducing agent), to eliminate the influence of the protein structure on the separation. Next, $30 \mu \mathrm{L}$-aliquots of the EPS solution and the molecular weight standard were applied in a $4-15 \%$ polyacrylamide gel (Mini-PROTEAN® TGX, BioRad), and separated by application of $150 \mathrm{~V}$. After the run, the protein bands were stained with Coomassie blue dye.

\subsection{MFC configuration}

MFC was assembled into a double chamber system as represented in Figure 5. The ScFCF bioanode (approximately $7 \mathrm{~cm}^{2}$ ) was placed int the anodic chamber $(6 \mathrm{~mL})$ in direct contact with a pretreated Nafion 212 membrane. BOD-GDE biocathode described in Chapter III was located in the open-air cathodic chamber with catalytic layer facing the electrolyte and the carbon cloth facing the air. In this configuration, the distance between the electrodes was 3 mm. An array of FCFs was used as external electrical contact. Viton sheets with $270 \mu \mathrm{m}$ in thickness were used to gasket the MFC. Phosphate buffer solution $\left(0.10 \mathrm{~mol} \mathrm{~L}^{-1}\right)$ at $\mathrm{pH} 7.2$ was used as supporting electrolyte in both chambers. The electrolyte of anodic chamber contained 
$1.0 \mathrm{~mol} \mathrm{~L}^{-1}$ glucose and it was degassed with Ar, prior the yeast addition. The temperature of the BFC was kept at $40^{\circ} \mathrm{C}$.

Figure 5 - Schematic representation of MFC structure.

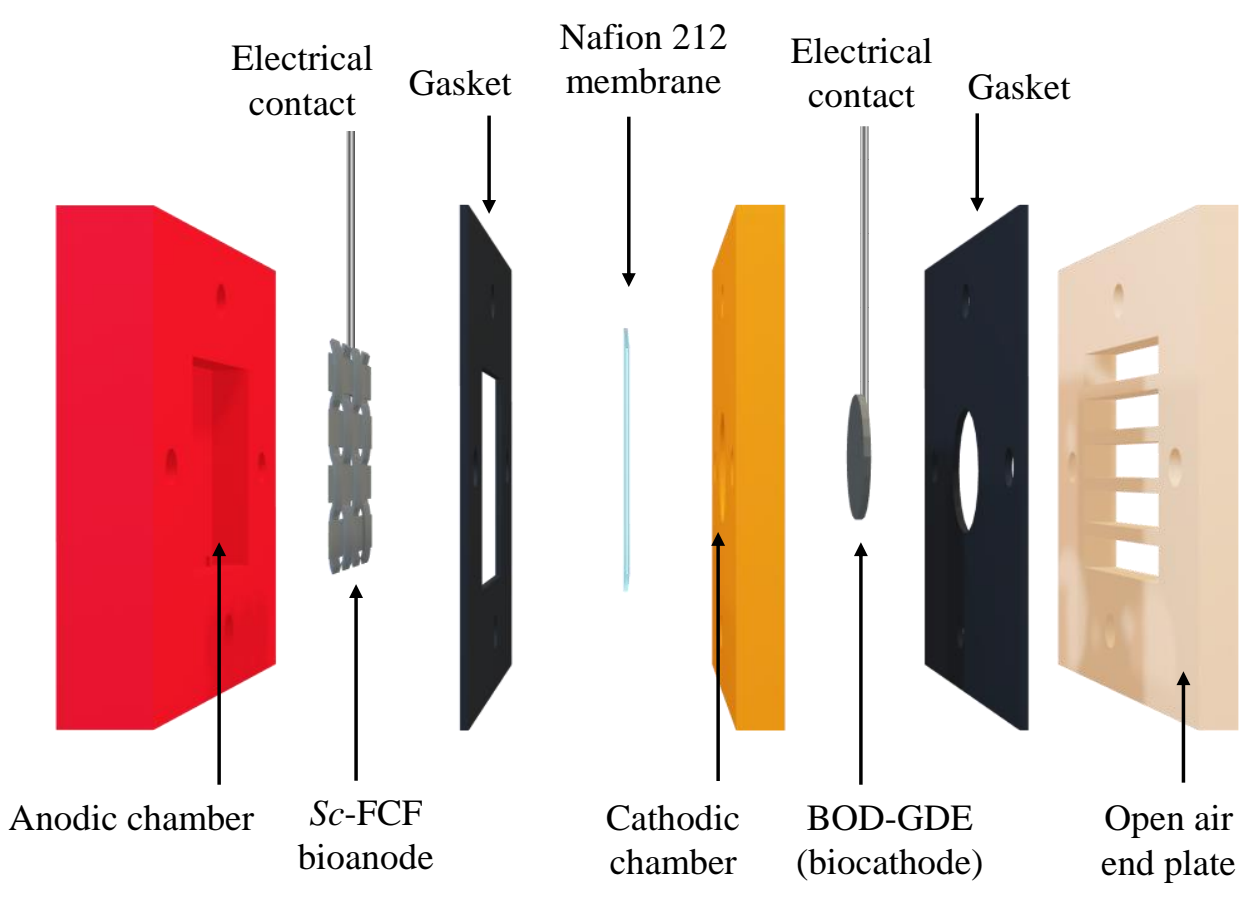

Source: own author.

Nafion 212 membrane was previously treated with $3 \%(\mathrm{v} / \mathrm{v}) \mathrm{H}_{2} \mathrm{O}_{2}$ at $85{ }^{\circ} \mathrm{C}$ for $1 \mathrm{~h}$, and then rinsed thrice in deionized water. Next, it was lightly boiled $\left(85^{\circ} \mathrm{C}\right)$ in $0.50 \mathrm{~mol} \mathrm{~L}^{-1} \mathrm{H}_{2} \mathrm{SO}_{4}$ for $30 \mathrm{~min}$, rinsed thrice in deionized water, and finally lightly boiled $\left(85^{\circ} \mathrm{C}\right)$ in deionized water. The treated membrane was stored in deionized water at room temperature until the use.

\section{RESULTS AND DISCUSSION}

\subsection{Electrochemical behavior of Saccharomyces cerevisiae on FCF electrode}

Saccharomyces cerevisiae is a facultative aerobic microorganism able to obtain energy (ATP) from carbohydrates aerobically and anaerobically. In the aerobic respiration, the pyruvate generated by the glycolysis (Equation 8 ) is completely oxidized in the citric acid cycle in the mitochondria, producing $\mathrm{CO}_{2}$ and $\mathrm{H}_{2} \mathrm{O}$. Whereas, in absence of $\mathrm{O}_{2}$, the pyruvate is metabolized via alcoholic fermentation in the cytosol, where is converted to ethanol and $\mathrm{CO}_{2}$ in a two-step process in the cytosol, according to the Equation $9 .{ }^{1}$ The glucose aerobic 
metabolism is more energetically efficient than the anaerobic one, as the citric acid cycle converts $\mathrm{NAD}(\mathrm{P})^{+}, \mathrm{FAD}, \mathrm{FMN}$ respectively into $\mathrm{NAD}(\mathrm{P}) \mathrm{H}, \mathrm{FADH}_{2}, \mathrm{FMNH}_{2}$ (universal electron carriers), which then transfer electrons to molecular oxygen through the respiratory chain, producing ATP. Differently, under anaerobic conditions, the glycolysis is the main pathway to energy obtention. ${ }^{1}$

Glucose $+2 \mathrm{NAD}^{+}+2 \mathrm{ADP}+2 \mathrm{P}_{\mathrm{i}} \rightarrow 2$ Pyruvate $+2 \mathrm{NADH}+2 \mathrm{H}^{+}+2 \mathrm{ATP}+2 \mathrm{H}_{2} \mathrm{O}$<smiles>CC(=O)CCCCC(C)=O</smiles>

Pyruvate<smiles>CC=O</smiles>

Acetaldehyde

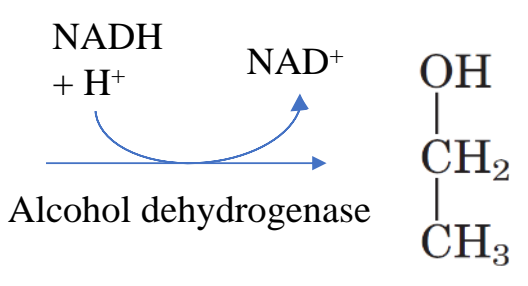

Ethanol

The electrons stored in the electron carriers produced in the glucose catabolism can be transferred to an electrode surface in a MFC through the EET mechanisms previously discussed in the Section 2.1. Although more electrons are produced in the complete glucose oxidation by the aerobic respiration than by the alcoholic fermentation, we evaluated the Saccharomyces cerevisiae EET to the FCF electrode in an anaerobic environment (fermentative conditions) to prevent the electrons are captured by the molecular oxygen before they can be transferred to the electrode surface. ${ }^{64}$

The electrochemical behavior of Saccharomyces cerevisiae was investigated by cyclic voltammetry with FCFs in phosphate buffer solution $(\mathrm{pH} 7.2)$ containing glucose at $40^{\circ} \mathrm{C}$, under inert atmosphere. Figure 6a shows representative CVs recorded after 1 h, 2 h, 3 h, 4 h, $5 \mathrm{~h}$ and $24 \mathrm{~h}$ of fermentation, and, for comparison, in the electrolyte containing glucose. No faradic current is observed in the absence of yeast (black curve), indicating that glucose is not oxidized in this potential range and under these conditions. After the yeast addition, it is observed a slight increase of the oxidation currents from $-0.20 \mathrm{~V}$, and over the time a redox couple arises, showing oxidation and reduction peak potentials ( $E_{\mathrm{pa}}$ and $E_{\mathrm{pc}}$, respectively) equal to $-0.08 \pm 0.04 \mathrm{~V}$ and $-0.27 \pm 0.03 \mathrm{~V}$, respectively, and oxidation onset potential of $-0.20 \pm 0.03$ $\mathrm{V}$ (Figure 6b) after $24 \mathrm{~h}$. Such behavior is in accordance with previous study of MFCs employing Saccharomyces cerevisiae. ${ }^{18}$ Also, it worth mentioning that the voltammetric profile 
and the current densities are stable from the second successive potential cycle, as shown in Figures $6 \mathrm{c}$ e $6 \mathrm{~d}$, and the measurements were repeated in different days and using fresh solutions, indicating the results are reproducible and were not affected by any external contamination. In addition, it is observed that the current densities significantly increase with the time, and in $24 \mathrm{~h}$ the anodic peak current density $\left(j_{\mathrm{p}, \mathrm{a}}\right)$ is $0.023 \pm 0.014 \mathrm{~mA} \mathrm{~cm}^{-2}$. Some factors can contribute to the current increase over the time: cell growth, adherence of cells on FCF surface, and production of the redox active species during the fermentation. Those contributions and how electrons are extracellularly transferred to the electrode surface will be further investigated and discussed in details in the next sections.

Figure 6 - (a) CVs (third cycles) at $5 \mathrm{mV} \mathrm{s}^{-1}$ of FCF in degassed $0.10 \mathrm{~mol} \mathrm{~L}^{-1}$ phosphate buffer solution ( $\mathrm{pH} 7.2)$ at $40{ }^{\circ} \mathrm{C}$, initially containing $1.00 \mathrm{~mol} \mathrm{~L}^{-1}$ glucose, before, right after the addition of

$0.05 \mathrm{~g} \mathrm{~mL}^{-1}$ yeast $(t=0 \mathrm{~h})$, and after $1 \mathrm{~h}, 2 \mathrm{~h}, 3 \mathrm{~h}, 4 \mathrm{~h}, 5 \mathrm{~h}$ of incubation in the fermentation suspension. (b) Zoomed-in view of the CVs. (c) Four successive CVs after $24 \mathrm{~h}$ of fermentation and (d) its zoomed-in view.
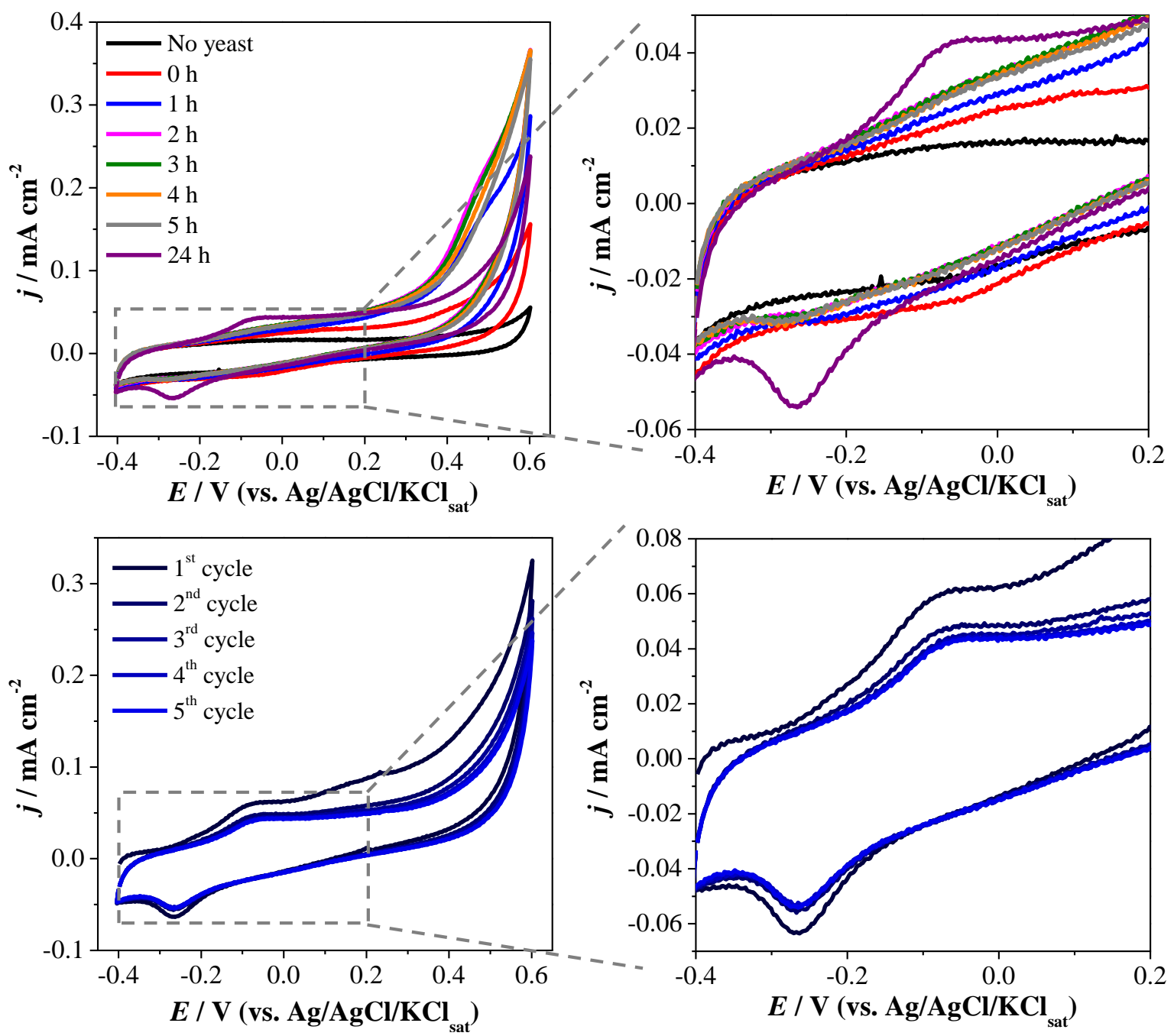

Source: own author. 


\subsection{Characterization of Saccharomyces cerevisiae fermentation}

To investigate the chemical composition changes of the yeast cells during the fermentation process, micro-FTIR measurements were performed in non-activated yeast cells (Figure 7) and compared those collected after different fermentation times (Figure 8). This technique was chosen because it is sensible to structural and chemical changes in organic and biological compounds, as those changes alter the vibrational modes of the molecules.

Figure 7 - (a) Optical microscopic image of non-activated Saccharomyces cerevisiae cells on $\mathrm{CaF}_{2}$ substrate, indicating the region where the spectra were recorded (blue dot). (b) FTIR spectra recorded on yeast aggregate. Zoomed-in view of the yeast spectrum at high (c) and low (d) wavenumbers.

a)



b)

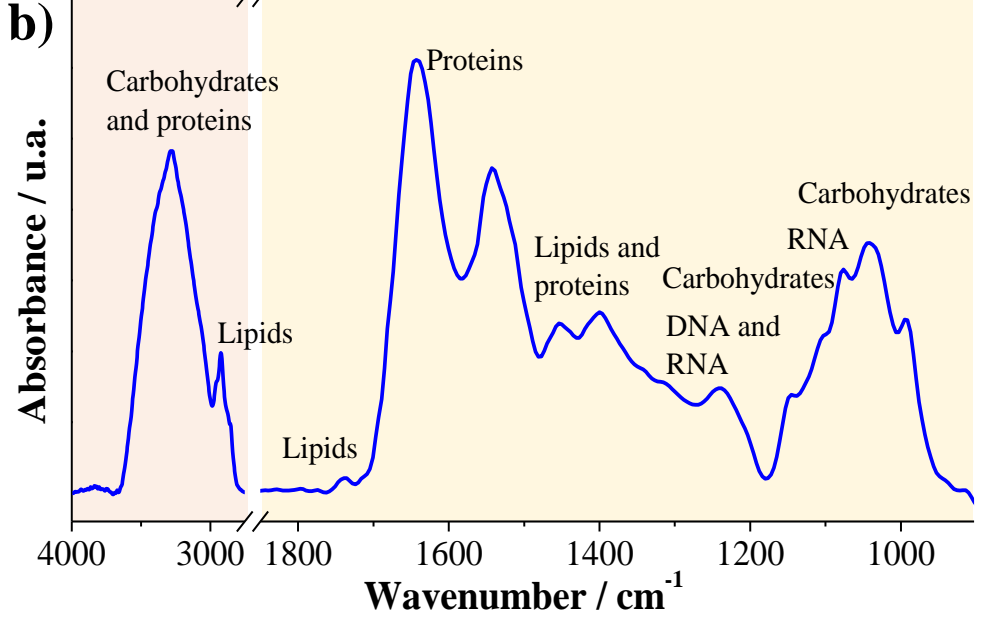

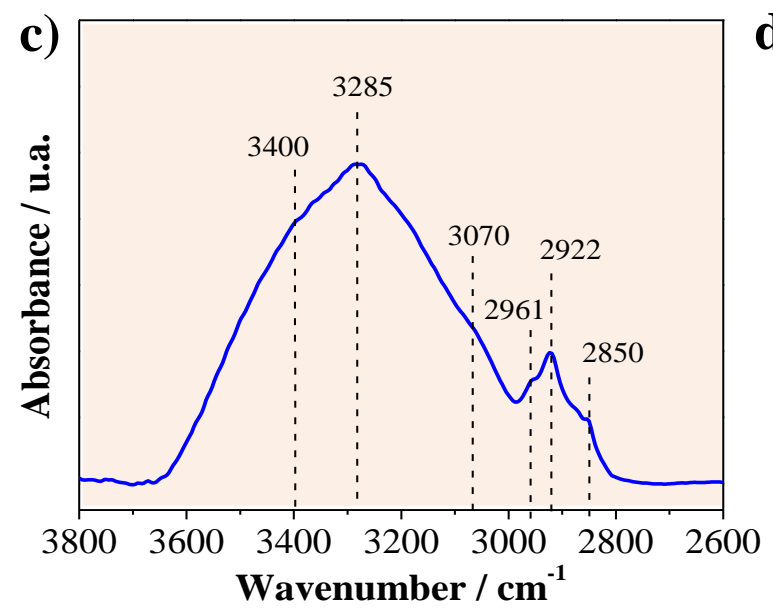

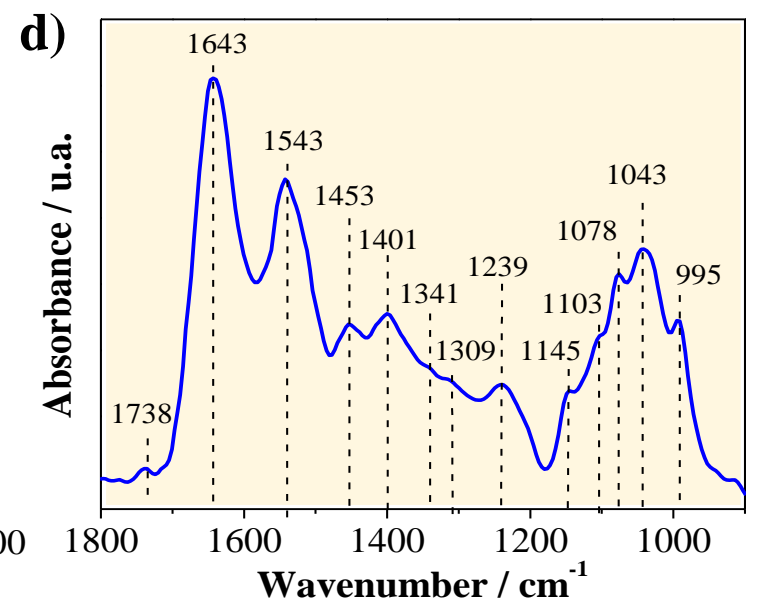

Source: own author.

Figure 7a displays an optical image of yeast cells on $\mathrm{CaF}_{2}$ substrate, which are previously suspended in deionized water, being called non-activated cells. Figure 7b shows the FTIR spectrum measured in a cell aggregate (region indicated by the blue dot). To facilitate the 
interpretation, the spectrum was divided into two regions: $4000-2600 \mathrm{~cm}^{-1}$ (Figure 7c) and $1800-900 \mathrm{~cm}^{-1}$ (Figure 7d). At higher wavenumbers, the wide band from 3400 to $3070 \mathrm{~cm}^{-1}$ arises from the overlayed absorption signals of carbohydrates and proteins; and the signals at 2961, 2922, and $2850 \mathrm{~cm}^{-1}$ are attributed to lipids (Figure 7c). ${ }^{65}$ Several bands can be visualized at lower wavenumbers (Figure 7d): the signal at $1783 \mathrm{~cm}^{-1}$ is assigned to lipids, and the bands at 1643,1543 , and 1311 are attributed to Amide-I, II and III vibrational modes, respectively. ${ }^{65}$ Other lipid and protein signals are also found at 1453, 1401, and $1341 \mathrm{~cm}^{-1}$, as well as, polysaccharide signals at 1239, 1145, 1103, 1043, and $995 \mathrm{~cm}^{-1} .{ }^{65}$ Finally, the bands at 1239 and $1078 \mathrm{~cm}^{-1}$ are assigned to DNA and RNA. Table 2 details all vibrational mode assignments.

Table 2 - Vibrational modes assignment of the non-activated Saccharomyces cerevisiae cells.

\begin{tabular}{|c|c|}
\hline Wavenumber $\left(\mathrm{cm}^{-1}\right)$ & Assignment \\
\hline 3400 & OH stretching in carbohydrates \\
\hline $3285-3070$ & $\mathrm{NH}$ stretching in proteins \\
\hline 2961 & $\mathrm{CH}_{3}$ asymmetric stretching in lipids \\
\hline 2922 & $\mathrm{CH}_{2}$ asymmetric stretching in lipids \\
\hline 2850 & $\mathrm{CH}_{2}$ symmetric stretching in lipids \\
\hline 1738 & $\mathrm{C}=\mathrm{O}$ stretching in ester of lipids \\
\hline 1643 & Amide-I (C=O stretching) \\
\hline 1543 & Amide-II (NH in plane bending and C-N stretching) \\
\hline 1453 & $\mathrm{CH}_{2}$ and $\mathrm{CH}_{3}$ bending in lipids and proteins \\
\hline 1401 & $\mathrm{C}\left(\mathrm{CH}_{3}\right)_{2}$ stretching mainly in proteins \\
\hline 1341 & $\mathrm{CH}_{2}$ bending in lipids \\
\hline 1311 & Amide-III ( $\mathrm{CN}$ and $\mathrm{CO}$ stretching, $\mathrm{NH}$ and $\mathrm{O}=\mathrm{C}-\mathrm{N}$ bending) \\
\hline 1239 & $\mathrm{PO}_{2}^{-}$asymmetric stretching in DNA, RNA in phospholipids \\
\hline 1145 & Mannans and glucans \\
\hline 1103 & $\beta 1,3$ glucans \\
\hline 1078 & $\mathrm{PO}_{2}^{-}$symmetric stretching mainly in RNA \\
\hline 1043 & Mannans \\
\hline 995 & $\beta 1,6$ glucans \\
\hline
\end{tabular}

Source: Burattini et al. (2008) ${ }^{65}$

Also, micro-FTIR measurements were recorded in yeast samples after 1, 5, and $24 \mathrm{~h}$ of fermentation. The optical microscopic images in Figure 8 show cells are quite homogeneous 
distributed on $\mathrm{CaF}_{2}$ substrate without presence of aggregates, unlike the non-activated cells (Figure 7a). This behavior indicates that the yeast cells interact with the hydrophobic substrate more effectively after the microbial metabolism is activated by the presence of glucose. That may be caused by the secretion of EPS by the yeast, forming a polymeric film around the cells that enables the cell-cell and cell-substrate interactions.

Figure 8 - Optical microscopic images of Saccharomyces cerevisiae cells on $\mathrm{CaF}_{2}$ substrate after $1 \mathrm{~h}$, $5 \mathrm{~h}$ and $24 \mathrm{~h}$ of fermentation.
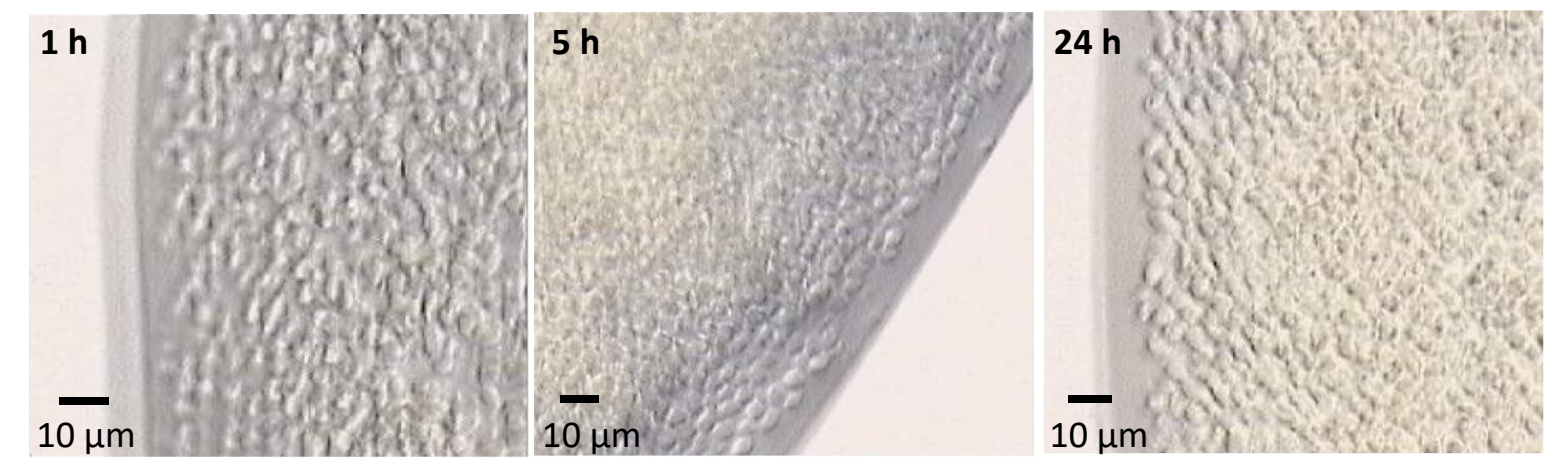

Source: own author.

The spectra collected on the post-fermentation yeast samples are shown in Figure 9. A wide absorption signal between 3750 and $2975 \mathrm{~cm}^{-1}$ can be observed in all spectra, as abovediscussed, this signal in the non-activated yeast spectra is relating to carbohydrates and proteins; in the post-fermentation yeast spectra, such band shows different profile, which can be attributed to the contribution of $\mathrm{OH}$ stretching from glucose and phosphate ions present in the medium, as well as solvating water molecules, ever after the sample drying. Amide-I and II bands (between 1720 and $1500 \mathrm{~cm}^{-1}$ ), as expected, are present in all samples, however no protein structural information from these bands can be extracted because the observed absorption signals have contributions of glucose and solvating water. 
Figure 9 - (a) FTIR spectra of non-activated Saccharomyces cerevisiae cells (black line) and after $1 \mathrm{~h}$ (blue line), $5 \mathrm{~h}$ (red line) and $24 \mathrm{~h}$ (green line) of fermentation. (b) Zoomed-in view of the spectra between 1500 and $900 \mathrm{~cm}^{-1}$.
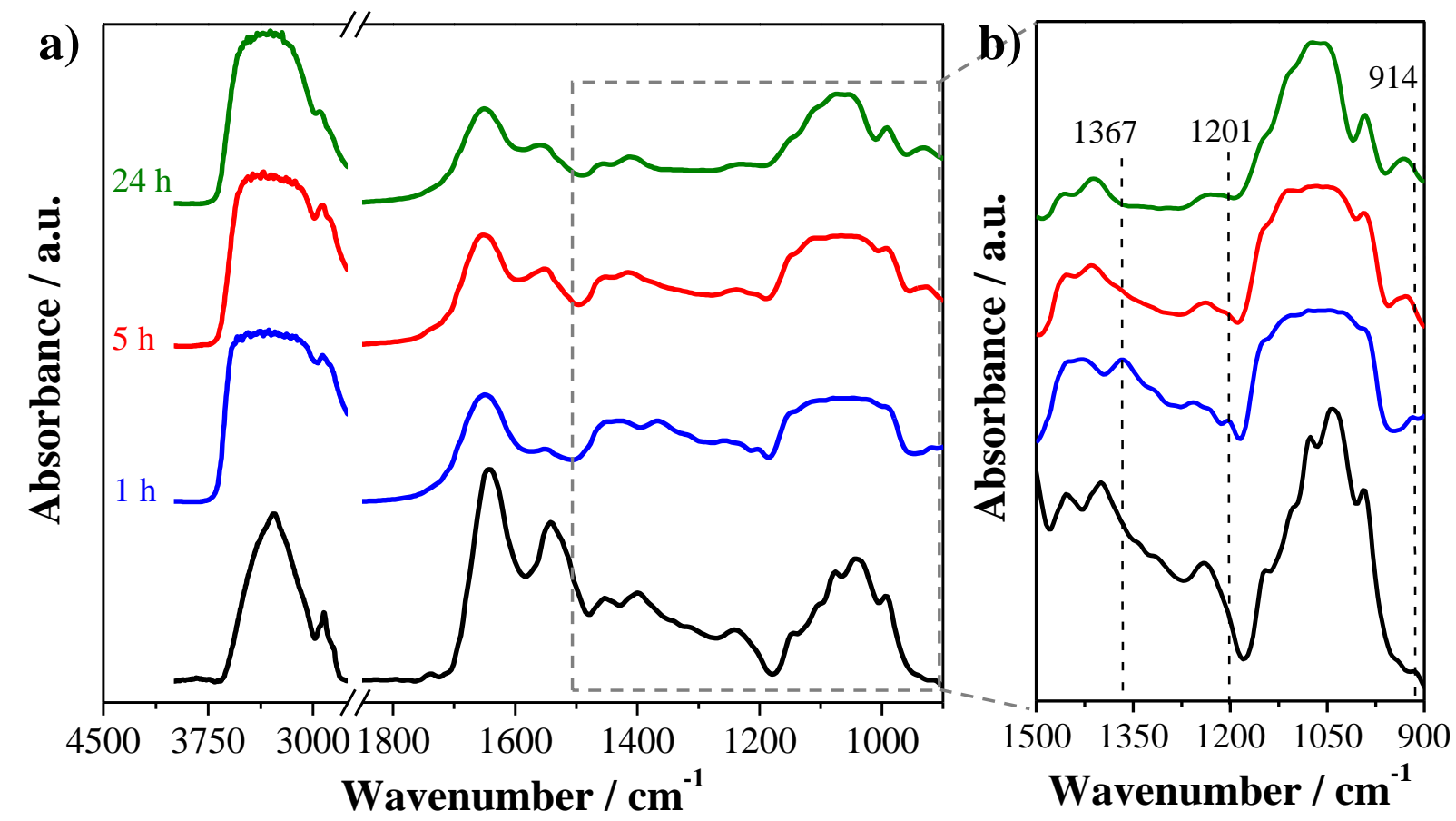

Source: own author.

The zoomed-in view of the spectra between 1400 and $900 \mathrm{~cm}^{-1}$ (Figure 9b) shows some absorption signals appears and/or disappears with the fermentation time. The vibrational mode at $1367 \mathrm{~cm}^{-1}$ emerges after $1 \mathrm{~h}$ of fermentation and disappear after $5 \mathrm{~h}$. This signal can be assigned to $\mathrm{CH}_{2}$ wagging in lipids and glucans. ${ }^{65}$ A very defined band at $1201 \mathrm{~cm}^{-1}$, attributed to $\mathrm{C}-\mathrm{O}-\mathrm{C}$ of ring carbohydrates, is observed in the samples after $1 \mathrm{~h}$ of fermentation, and becomes less-defined with the time, indicating the glucose consumption by the cellular metabolism. A band at $914 \mathrm{~cm}^{-1}$, which is absent in non-activated cells, arises after $1 \mathrm{~h}$ of fermentation and is shifted to $930 \mathrm{~cm}^{-1}$ after $5 \mathrm{~h}$ and $24 \mathrm{~h}$. This signal is assigned to asymmetric vibrations in pyranose ring, ${ }^{65}$ and indicates the metabolic synthesis of this kind of compound during the fermentation.

\subsection{Extracellular electron transfer of Saccharomyces cerevisiae to the FCF surface}

As previously presented in Section 2.1, the EET of Saccharomyces cerevisiae in bioanodes is still unclear and different studies show conflicting conclusions. In this context, detailed and systematic studies were performed to elucidate such mechanism, as follows. 
To evaluate if the redox couple observed in the CVs of Figure 6 is originated from the electrochemical reaction of a soluble excreted redox molecule or not, CVs were performed in the solution (ethanol + other excreted metabolites) from the fermentation. For that, the suspension resulting of $24 \mathrm{~h}$ of fermentation was centrifuged and the supernatant was filtered for complete cell removal. Then, a CV was recorded with a fresh FCF in the cell-free fermentation solution, as shown in Figure 10. For comparison, CVs of fresh FCF in phosphate buffer containing glucose (control) and of FCF incubated in the fermentation suspension (in presence of cells) for $24 \mathrm{~h}$ are also shown. $\mathrm{CV}$ of the fermentation solution after removal of the yeast cells shows tiny oxidation and reduction peaks at $0.00 \mathrm{~V}$ and $-0.12 \mathrm{~V}$, respectively, which is in the same potential region of the redox couple observed in the fermentation suspension. However, the peak current densities after the cell removal is approximately 10-fold lower than when the cells are present and the FCF was incubated in the fermentation suspension. Also, a $\mathrm{CV}$ of the FCF incubated in the fermentation suspension (in presence of cells) was transferred to a clean and fresh phosphate buffer solution and a CV was recorded (Figure 11). The voltammetric curve shows similar redox couple observed in Figure 10 , with $E_{\mathrm{pa}}$ and $E_{\mathrm{pc}}$ equal to -0.10 and $-0.25 \mathrm{~V}$ respectively. These results indicate yeast cells adsorb on FCF surface ( $S c$ FCF) when the electrode is incubated in the fermentation suspension, and support Saccharomyces cerevisiae EET mechanism takes place by a redox species mostly confined on the yeast cell surface.

Figure 10 - (a) CVs (third cycles) at $5 \mathrm{mV} \mathrm{s}^{-1}$ of fresh FCF in degassed $0.10 \mathrm{~mol} \mathrm{~L}^{-1}$ phosphate buffer solution ( $\mathrm{pH} 7.2$ ), at $40{ }^{\circ} \mathrm{C}$, containing $1.00 \mathrm{~mol} \mathrm{~L}^{-1}$ glucose (gray line), of $S c$-FCF after $24 \mathrm{~h}$ incubation in the fermentation suspension (black line), of fresh FCF recorded in $24 \mathrm{~h}$-fermentation solution without yeast cells (blue line). (b) The zoomed-in view.
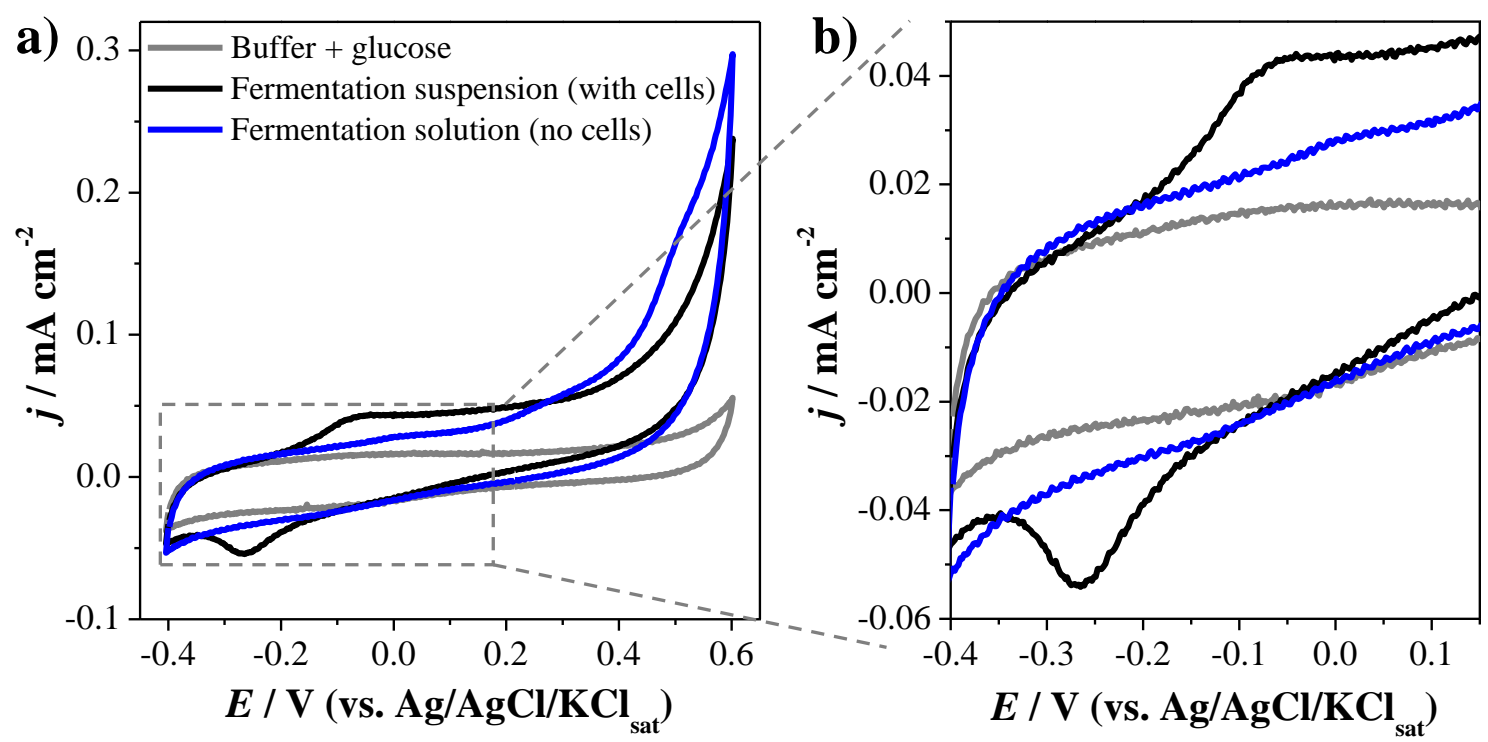

Source: own author. 
Figure 11 - CV (third cycle) at $5 \mathrm{mV} \mathrm{s}^{-1}$ of $S c$-FCF, resulting of $24 \mathrm{~h}$-incubation in fermentation suspension, recorded in degassed $0.10 \mathrm{~mol} \mathrm{~L}^{-1}$ phosphate buffer solution $\left(\mathrm{pH} \mathrm{7.2)}\right.$, at $40{ }^{\circ} \mathrm{C}$.

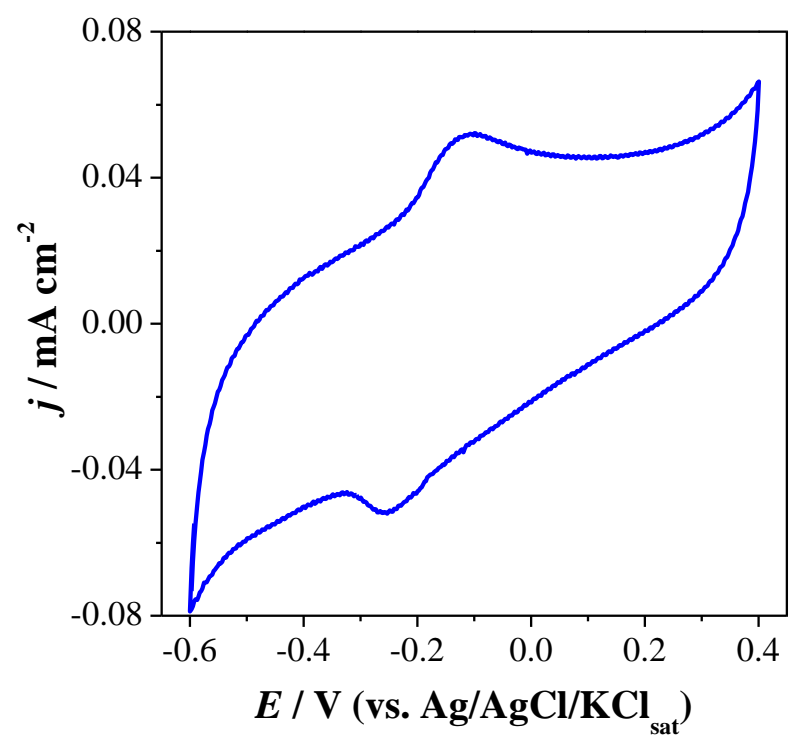

Source: own author.

It is very known yeasts spontaneous adhere to solid surfaces, as carbon materials. ${ }^{19,51}$ This corroborate the evidences EET occurs via excreted redox species confined on the cell surface, which is in contact with the electrode surface. As previously observed, Saccharomyces cerevisiae adsorbs on FCF under fermentation conditions. ${ }^{51}$ To evaluate the adsorption kinetics on FCF and correlate it with the above-discussed electrochemical response time, the morphology of electrodes incubated for different periods in the fermentation suspension were investigated by SEM. Figure 12 display SEM images of Saccharomyces cerevisiae-adsorbed FCF ( $S c$-FCF) after 1 h, 2 h, 3 h, 4 h, 5 h, and 24 h of fermentation. Figure 12a clearly shows a high number of adsorbed cells on the electrode surface since $1 \mathrm{~h}$ of incubation. The formation of cell aggregates makes the cell count impossible. The cells have ellipsoidal shape with major diameter equal to $5.0 \mu \mathrm{m} \pm 0.2 \mu \mathrm{m}$, and the FCF diameter is $6.9 \mu \mathrm{m} \pm 0.1 \mu \mathrm{m}$. EPS forming a film of $0.7 \mu \mathrm{m}$ in thickness is observed around the cells, between the different cells and between the cells and the fiber surface. Similar features are noted for FCFs incubated for $2 \mathrm{~h}$ (Figure $12 \mathrm{~b}$ 14), $3 \mathrm{~h}$ (Figure 12c), and $4 \mathrm{~h}$ (Figure 12d) in the fermentation suspension. 
Figure 12 - SEM images of FCFs at different magnifications after $1 \mathrm{~h}$ (a), $2 \mathrm{~h}$ (b), $3 \mathrm{~h} \mathrm{(c),} 4 \mathrm{~h}$ (d), $5 \mathrm{~h}$ (e), and $24 \mathrm{~h}$ (f) of incubation in Saccharomyces cerevisiae fermentation suspension.
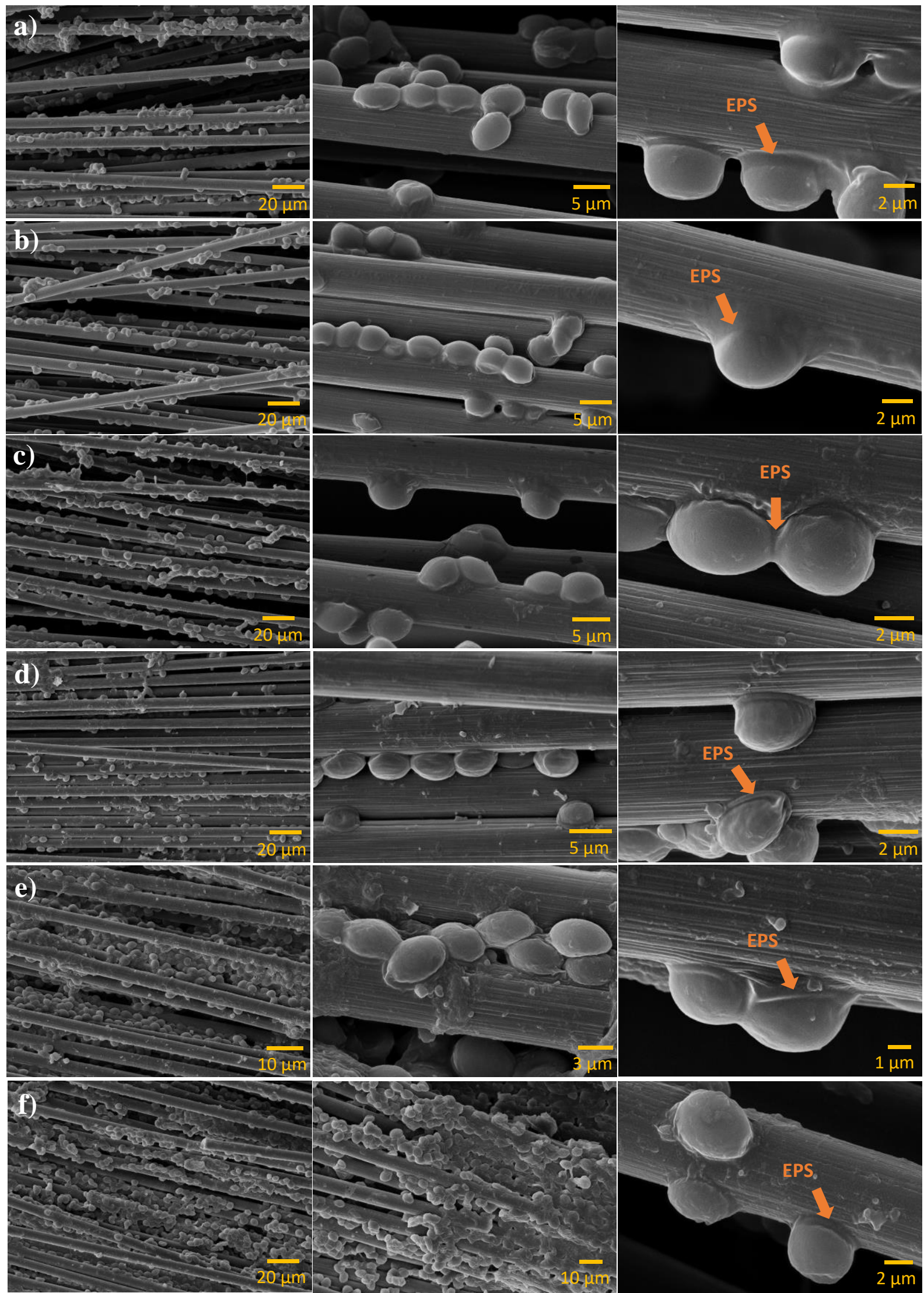

Source: own author. 
In contrast, after $5 \mathrm{~h}$ of incubation, the images in Figure 12e clearly show a higher number of adsorbed yeast cells on FCF surface and larger cell aggregates, when compared to 1-4 h. These features are more noticeable in $24 \mathrm{~h}$ (Figure 12f), when the presence of a biofilm can be verified. Therefore, SEM images evidence the quantity of adsorbed cells increases with the time, and it corroborates with the electrochemical signal increase with the fermentation time. Those results suggest that yeast cells can excrete a redox species and it may be store in the EPS film. Although it has been demonstrated EPS play important role in the EET of some bacteria and Pichia stipites,${ }^{59}$ it has not been studied in Saccharomyces cerevisiae yet. Therefore, a detailed investigation of EPS is needed.

\subsection{Saccharomyces cerevisiae EPS characterization}

Recently, it has been demonstrated EPS can store electrochemically active compounds, therefore acting as electron transient media between the cell some bacteria and in Pichia stipites yeast and extracellular electron acceptor. In bacteria, there are evidences those redox compounds are flavins and cytochromes. ${ }^{30}$ However, to the best of our knowledge, for Saccharomyces cerevisiae the role of EPS in the EET has not been investigated yet.

To prove the role of EPS in the EET of Saccharomyces cerevisiae this material was removed from the cells by a thermal treatment in $\mathrm{NaCl}$ solution, ${ }^{30,66}$ as described in Section 4.5, and some electrochemical and spectroscopic measurements were performed. Figure 13a shows the CVs of EPS solution recorded with fresh FCF, and for comparison, the CV of $S c$-FCF in cell suspension after $24 \mathrm{~h}$ of fermentation (same of purple curve in Figure 6a), and the background. CV of EPS displays small oxidation and reduction signals at $0.00 \mathrm{~V}$ and $-0.03 \mathrm{~V}$ respectively, which is close to the potentials observed in the fermentation suspension. To enhance the discrimination of the faradaic current and to better observe the anodic peak, a differential pulse voltammogram (DPV) of EPS solution was recorded (Figure 13b). It clearly shows an anodic peak at $-0.07 \pm 0.02 \mathrm{~V}$, which corroborates the potential values observed with $S c$-FCF in cell suspension after $24 \mathrm{~h}$ of fermentation (Figure 6a) and with Sc-FCF in clean electrolyte (Figure 11). Therefore, electrochemical results combined to microscopic data strongly suggest the EET mechanism of Saccharomyces cerevisiae involves a redox species that is excreted during the cellular metabolism and is mostly confined in EPS on the yeast cell surface. 
Figure 13 - (a) CVs at $5 \mathrm{mV} \mathrm{s}^{-1}$ and $40{ }^{\circ} \mathrm{C}$ of $\mathrm{FCF}$ recorded in degassed $0.10 \mathrm{~mol} \mathrm{~L}^{-1}$ phosphate buffer solution, $\mathrm{pH} 7.2$ (gray line), of $S c$-FCF incubated for $24 \mathrm{~h}$ in fermentation suspension (black line), of fresh FCF in EPS solution. (b) DPV at $5 \mathrm{mV} \mathrm{s}^{-1}$ and $40{ }^{\circ} \mathrm{C}$ of fresh FCF in EPS solution.
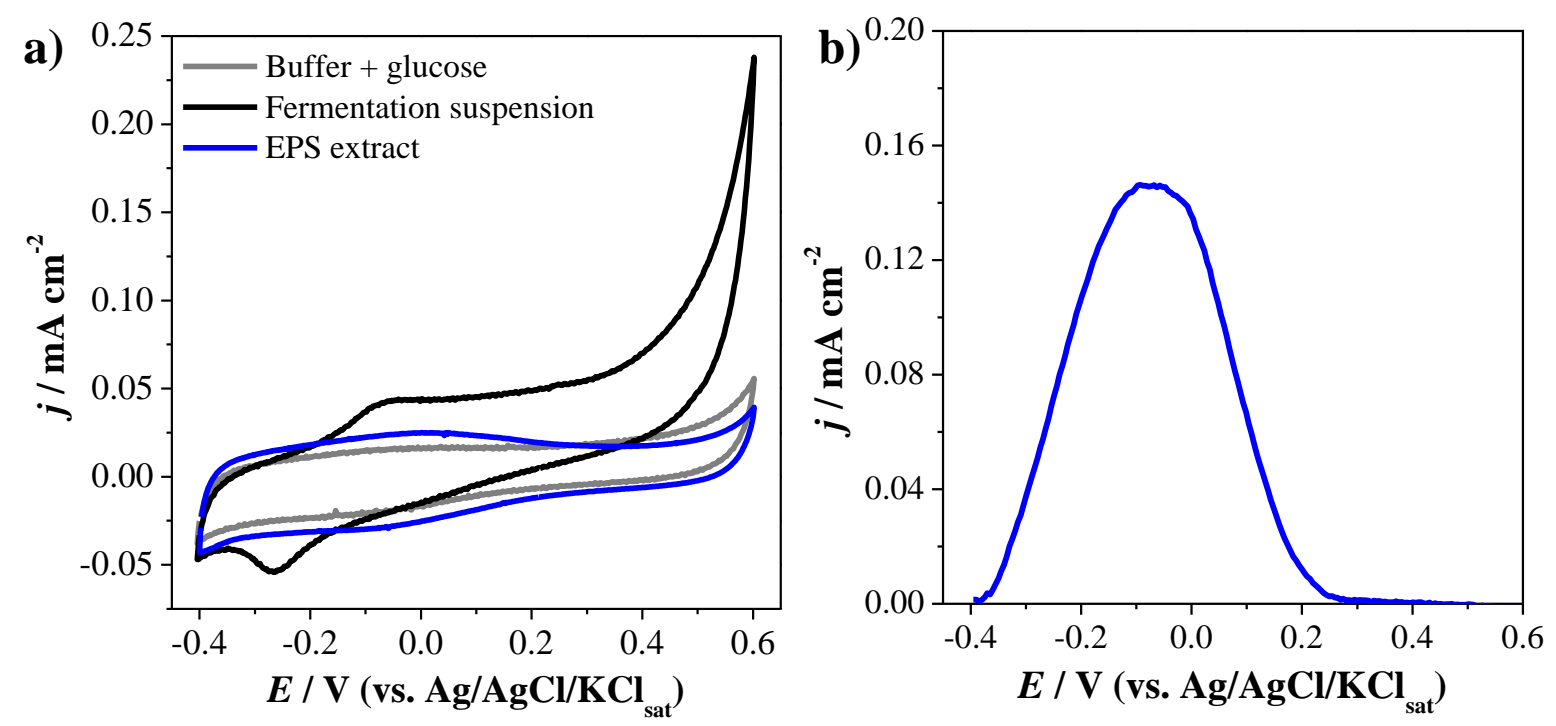

Source: own author.

It is very known EPS is mainly formed by polysaccharides and glycoproteins, and may contain nucleic acids and lipids as well. ${ }^{41-44}$ In some cases can store redox compounds, such as flavins and cytochromes, which transfer electrons to external electron acceptors. ${ }^{30}$ However, for Saccharomyces cerevisiae, the origin of the electrochemical response of EPS has not been elucidated yet. In this context, some spectroscopic measurements were performed to investigated the composition of EPS from this yeast, to possibly reveal the electrochemical active compound(s) present in this extracellular matrix, which is responsible for EET.

Figure 14a shows UV-vis spectra of EPS solution. Two major bands are observed at 217 and $258 \mathrm{~nm}$, the first can originate from, and from $\mathrm{n}-\sigma^{*}$ and/or $\pi-\pi^{*}$ transitions found in several functional groups, such as amine, carboxyl, carbonyl, and ester, ${ }^{67}$ also can have contribution of peptide bond absorption from proteins $;^{68}$ the latter can be attributed to the $\pi-\pi^{*}$ transitions of the pyrimidine and purine ring of nucleic acids, and may have contributions of aromatic side chains of amino acids residues, specially phenylalanine, absorption of disulfide bonds between cysteine residues. ${ }^{68}$ The zoomed-in view of the spectrum between 300-600 nm (Figure 14b) shows a small band centered at $450 \mathrm{~nm}$ and a shoulder at $368 \mathrm{~nm}$. Interestingly, those signals match the absorption signals of flavin molecules corresponding to $\pi-\pi^{*}$ transitions on the oxidized isoalloxazine ring, ${ }^{69-71}$ suggesting the presence of flavin in the EPS. The oxidized form of flavins, such as FAD, FMN and riboflavin, is the most stable one in solution or bound to a protein. 
Figure 14 - (a) UV-vis spectrum, (b) its zoomed-in view between 300 and $600 \mathrm{~nm}$, and (c) fluorescence emission spectrum of EPS solution with excitation at $450 \mathrm{~nm}$.
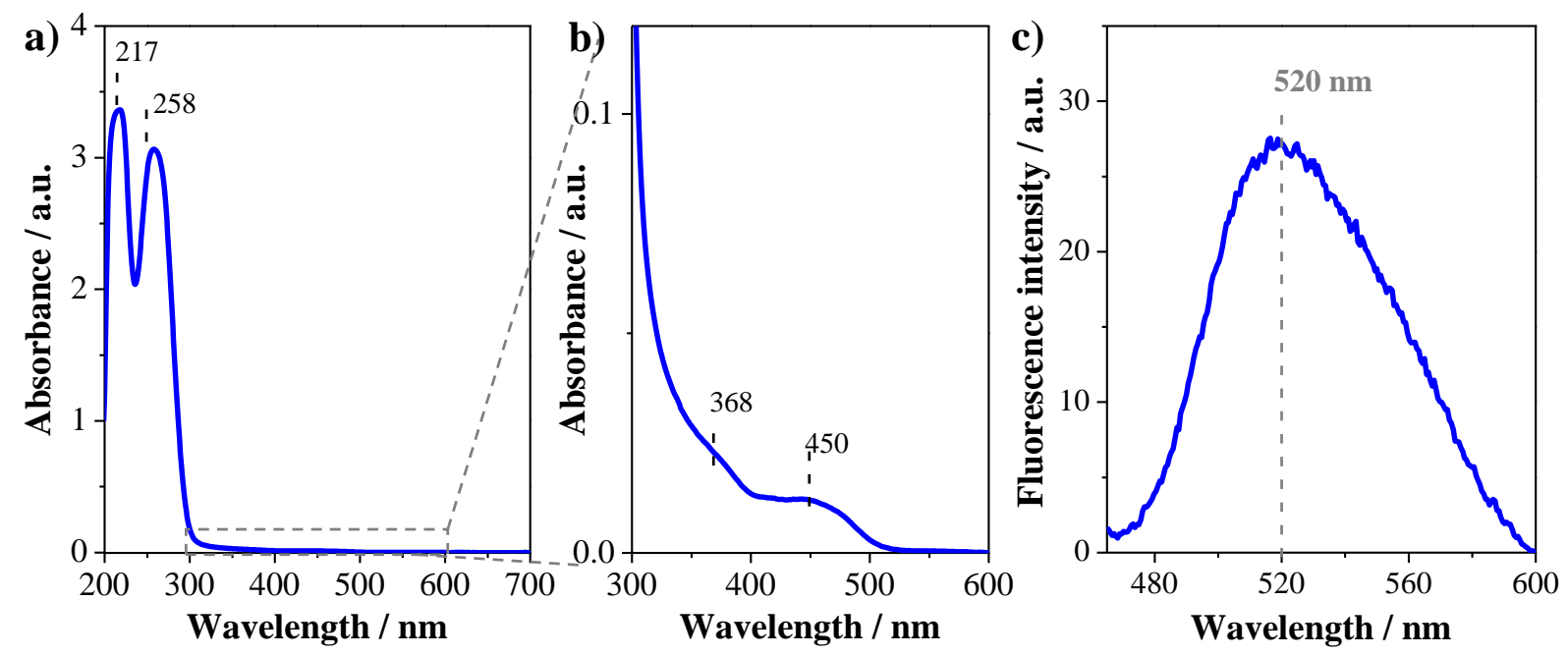

Source: own author.

To confirm the presence of flavin in the EPS, fluorescence spectroscopy was used. Flavins show relatively strong fluorescence with maximum emission typically at 500-530 nm when excited at $450 \mathrm{~nm}$, being the exact wavelength depending on the on the nature of the flavinbinding site in the protein and the redox state. ${ }^{70}$ The fluorescence emission spectrum of EPS solution in Figure 14c shows an emission band centered at $520 \mathrm{~nm}$, stating the presence of flavin-based compound in EPS from Saccharomyces cerevisiae.

According to electrochemical and electronic spectroscopic results, it is possible to infer that flavin(s), probably associated to a protein, is present in the EPS and is involved in the EET mechanism of Saccharomyces cerevisiae. Although, the observed formal potential is shifted to less negative values (see Figure 6) when compared to the expected value of free riboflavin, $\mathrm{FMN}$ or $\mathrm{FAD},-0.4 \mathrm{~V}$ (vs. $\mathrm{Ag} / \mathrm{AgCl} / \mathrm{KCl}_{\text {sat }}$ ), it is well-known that the redox potentials of those compounds are drastically affected by the microenvironment, for example, by the protein in which is associated. ${ }^{72}$ Therefore, it is proposed that the compound responsible to the electrochemical response of Saccharomyces cerevisiae is a flavoprotein in the EPS film, unlike from that observed for Pichia stipites yeast. ${ }^{30,45}$

The presence of proteins in the EPS was confirmed Bradford assay, which indicated the total protein concentration in EPS solution being $0.20 \pm 0.03 \mathrm{mg} \mathrm{mL}^{-1}$. The characterization of proteins in the EPS solution was investigated by electrophoresis in SDS-Page. The result of the SDS-page electrophoresis of EPS solution is shown in Figure 15. It is possible to observe the presence of 6 main proteins with approximately 50, 44, 32, 29, 20, and $15 \mathrm{kDa}$. 
Figure 15 - SDS-page electrophoresis of molecular weight standard (i) and EPS solution (ii) by staining with Coomassie blue dye. The orange arrows indicate the main separated proteins in the EPS solution.

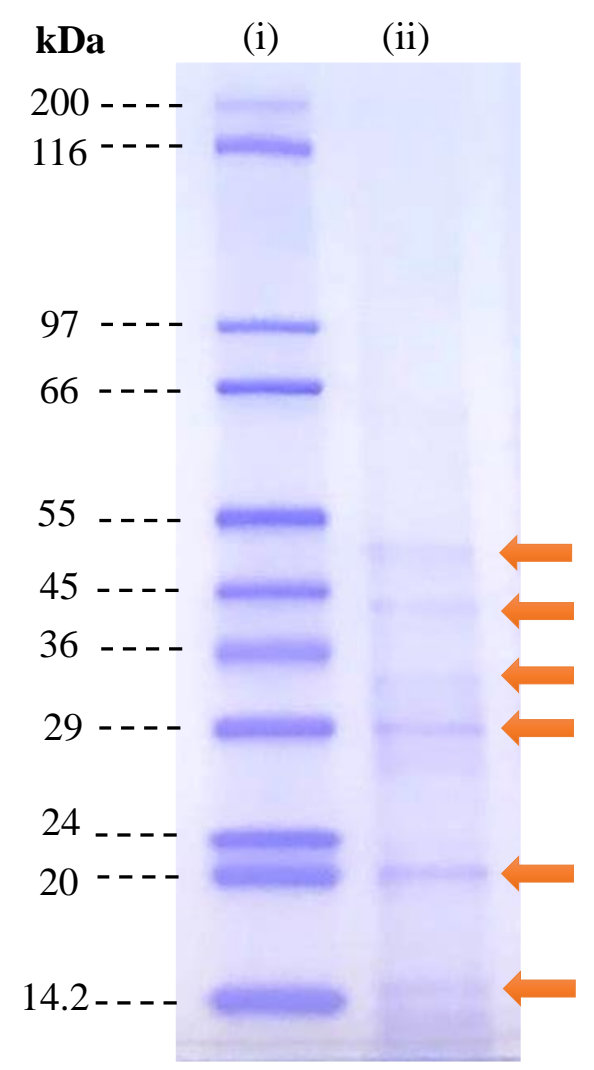

Source: own author.

Flavoproteins have been extensively studied in yeasts. The first recognized flavoprotein was called Old Yellow Enzyme (OYE1) and was purified from Saccharomyces carlsbergenesis (brewers' yeast) in 1933. Six decades later, two flavoproteins, called OYE2 ${ }^{73}$ and OYE3 ${ }^{74}$ were discovered in Saccharomyces cerevisiae. The OYEs are known to catalyze the oxidation of $\beta$ $\mathrm{NADH}, \beta-\mathrm{NADPH}$, and $\alpha-\mathrm{NADPH}$ and exist as dimers with one FMN per subunit. They show 400 amino acid residues and approximately $45 \mathrm{kDa}$. In total, 68 genes have been found to encode flavin-dependent proteins in Saccharomyces cerevisiae, which play central role in several aspects in this microorganism. ${ }^{75}$ The majority of flavoproteins operate in mitochondria and are involved in the electron transfer to the electron transport chain. However, the presence of flavoproteins in Saccharomyces cerevisiae EPS has never been reported. Interestingly, SDSpage shows a protein with approximately $45 \mathrm{kDa}$, possibly being an OYE. Therefore, for the first time, the combination of electrochemical, spectroscopic, microscopic and electrophoretic data shows strong evidences to support the proposal that Saccharomyces cerevisiae extracellularly transfers electrons by flavoprotein(s) stored in its EPS film. 


\subsection{Sc-FCF bioanode performance}

Evaluating the half-cell response for the bioanode and biocathode of a BFC is important to understand the bioelectrochemical behavior of individual electrodes, to identify possible electrode limitations and to predict the BFC performance. ${ }^{7}$ Therefore, some parameters of $S c$ FCF bioanode, such as OCP, oxidation current density, and performance over the time, were evaluated. The bioanode OCP was monitored over the course of the first hours of yeast fermentation (Figure 16a). It can be observed that the OCP value increases negatively up to $0.22 \mathrm{~V}$ in the first $3 \mathrm{~h}$, and then it keeps constant. This value agrees with the oxidation onset potential observed in Figure 6 and previous Saccharomyces cerevisiae-based bioanode report. ${ }^{51}$ This is an considerable negative potential value, which is crucial to furtherly obtain a BFC with significant voltage. Also, the faradaic oxidation current density generated by the yeast on the FCFs at several electrode potentials was evaluated in steady-state regime by measuring a polarization curve (Figure 16b) after $24 \mathrm{~h}$ of fermentation at the same conditions described before. The curve shows oxidation currents from $-0.20 \mathrm{~V}$, which is in accordance with the onset potential observed in the $\mathrm{CV}$ (Figure 6), and at $0.00 \mathrm{~V}$ the current density is $0.026 \mathrm{~mA} \mathrm{~cm}^{-2}$.

Figure 16 - (a) OCP monitoring and (b) steady-state polarization curve of Sc-FCF bioanode recorded after $24 \mathrm{~h}$ of fermentation. Measurements in degassed $0.10 \mathrm{~mol} \mathrm{~L}^{-1}$ phosphate buffer solution (pH 7.2) initially containing $1.00 \mathrm{~mol} \mathrm{~L}^{-1}$ glucose, at $40^{\circ} \mathrm{C}$.
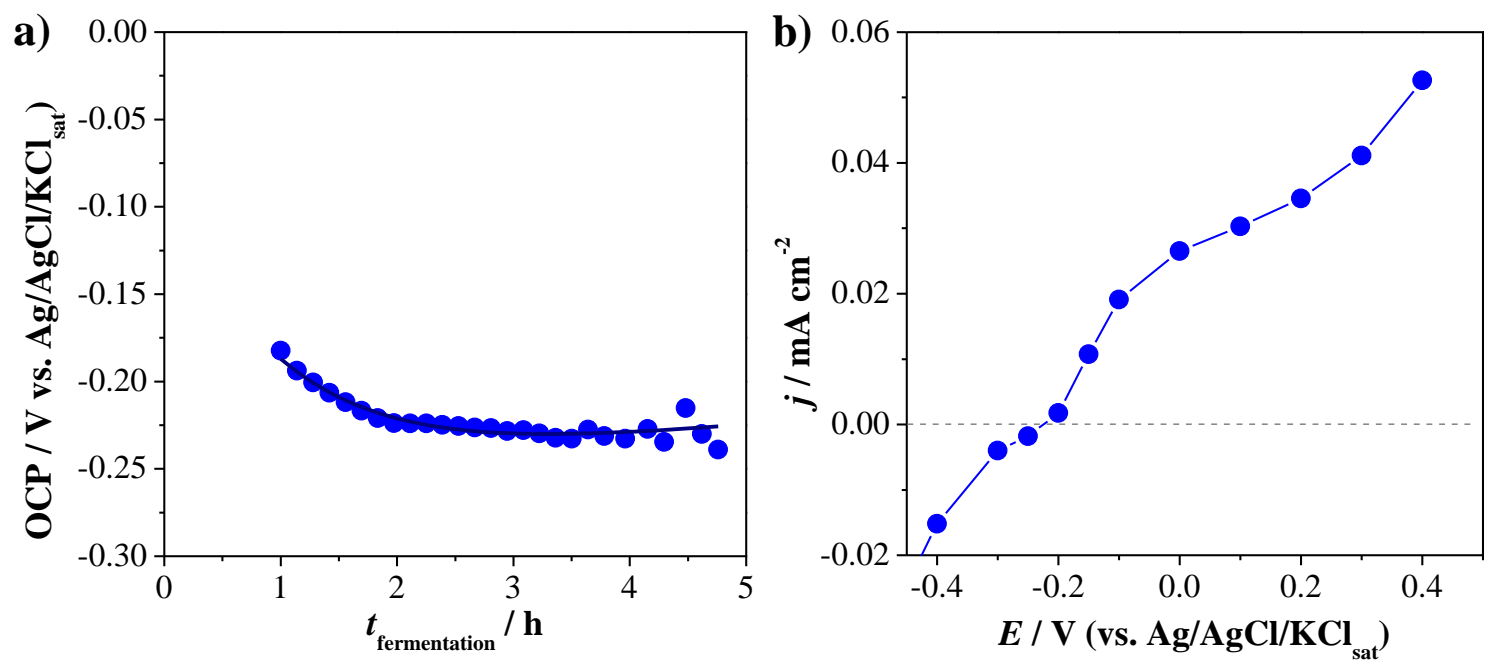

Source: own author.

As the operational stability and response time of bioelectrodes are also an important factor for the successful application in a BFC, this feature was evaluated. For that, the $S c$-FCF bioanode was polarized at $0.00 \mathrm{~V}$ and the current density was measured for $24 \mathrm{~h}$ from the yeast 
addition to the degassed electrolyte containing glucose (Figure 17). Right after the addition of yeast in the medium, a cathodic current is measured, however, in initial $5 \mathrm{~min}$, the first signals of cellular metabolism are observed, as $\mathrm{CO}_{2}$ evolution, the and then anodic currents are recorded. A sharp increase in the oxidation current density can be noted in the initial $6 \mathrm{~h}$. From 6 to $24 \mathrm{~h}$, the oxidation current density is quite stable, reaching $0.19 \mathrm{~mA} \mathrm{~cm}$.

Figure 17 - Current density-time curve of $S c$-FCF bioanode at $0.00 \mathrm{~V}$ in degassed $0.10 \mathrm{~mol} \mathrm{~L}^{-1}$ phosphate buffer solution ( $\mathrm{pH} 7.2$ ), at $40{ }^{\circ} \mathrm{C}$, initially containing $1.00 \mathrm{~mol} \mathrm{~L}^{-1}$ glucose.

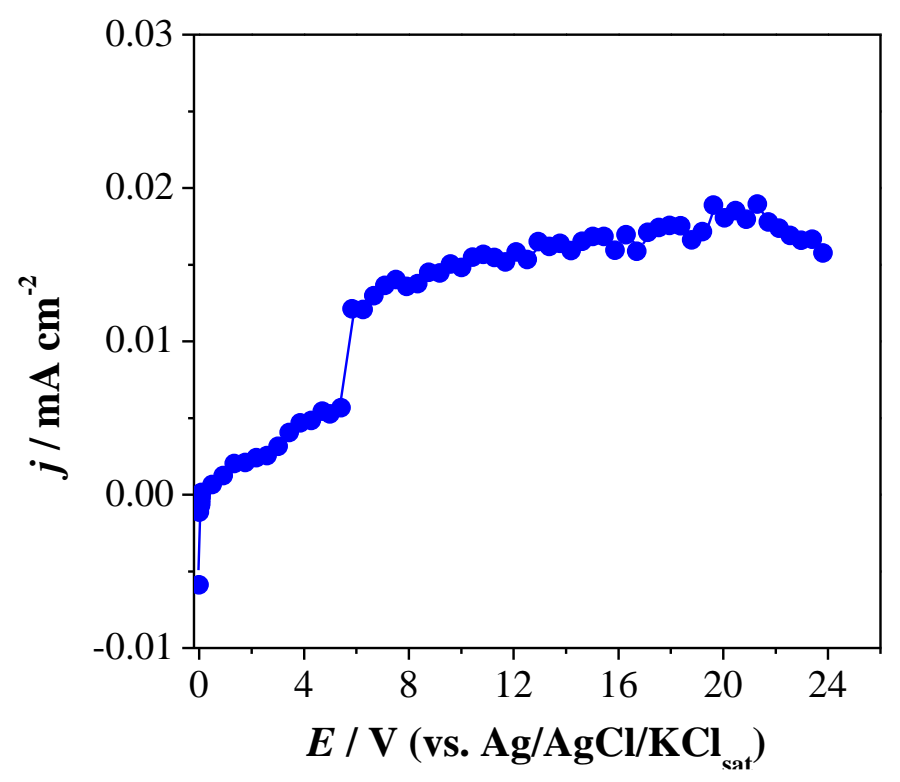

Source: own author.

Interestingly, the current-time curve profile is considerably similar to the growth curve of yeast (Figure 18). ${ }^{76,77}$ The fermentative catabolic pathway generates energy (ATP) for the cell maintenance and growth. The growth of microorganisms is related to the concentration of a limiting nutrient in the medium, glucose in this case, and can be modeled with four different phases: lag, exponential, stationary, and death phases (Figure 18). ${ }^{76,77}$ In the lag phase, the microorganisms are adapting themselves to growth conditions and they are not able to divide. During the exponential or log phase, the number of cells exponentially increases and the growth rate depends on the growth conditions, such as nutrient concentration, aeration, and cell density in the medium. If the growth is not limited for any reason, the cell division will continue at a constant rate. However, as in this case, the glucose was not supplied over the monitoring period, therefore the stationary phase is reached as soon as the nutrient concentration becomes limiting and inhibitory/toxic compounds are produced by the cellular metabolism. It is known that the higher intracellular concentrations of acetaldehyde inhibit the Saccharomyces cerevisiae growth. ${ }^{78}$ In the stationary phase, the growth and death rates are equal. At death phase, the count 
of viable cells decreases continuously because of inappropriate living conditions, such as depletion of nutrients, accumulation of toxic products, wrong temperature or $\mathrm{pH}$, etc. ${ }^{76,77}$

Figure 18 - Theoretical cell growth curve of a yeast colony.

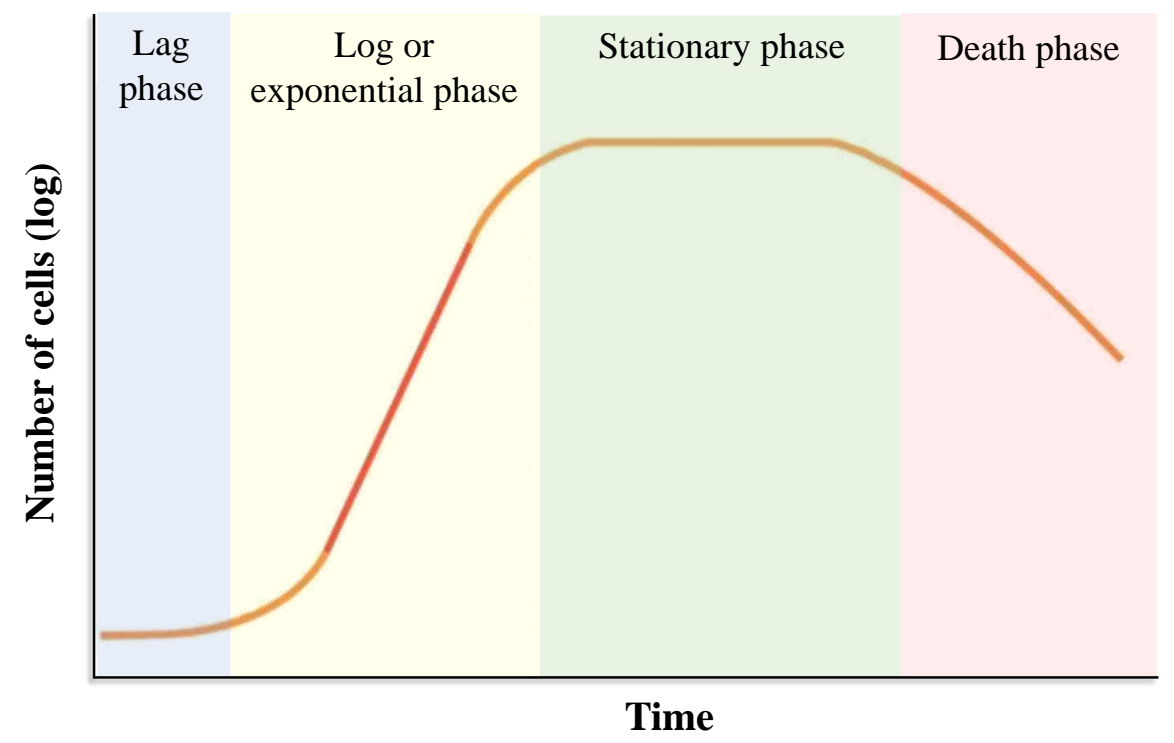

Source: Adapted from Barragán et al. (2006). ${ }^{77}$

Therefore, the similarity of the curve in Figure 17 and the cell growth curve suggest that the yeast growth is intrinsically related to the increase of the current density with the time. A similar correlation has been already reported between the ethanol concentration produced by the fermentation pathway and the growth curve.$^{51}$ As result, it can be inferred that, under present experimental conditions, the lag phase is very short and the stationary phase is reached in approximately $6 \mathrm{~h}$ of fermentation and extends at least up to $24 \mathrm{~h}$. During this period, the $S c$ FCF bioanode response is very stable, which is desirable for application in a BFC.

\subsection{Saccharomyces cerevisiae-based MFC}

Finally, after understanding the EET of Saccharomyces cerevisiae and evaluating the performance and limitations of $S c$-FCF bioanode, this bioanode was used in a MCF with BODGDE (shown in Chapter III) for atmospheric catalytic $\mathrm{O}_{2}$ reduction. Figure 19a shows the MFC, which comprise an anodic chamber with a FCF electrode and yeast suspension under anaerobic conditions (Figure 19b), and an open-air cathodic chamber with BOD-GDE (Figure 19c). Some minutes after yeast addition to the anodic chamber, it can be observed the metabolic activity of the microorganism evidenced by $\mathrm{CO}_{2}$ evolution, as shown in Figure $19 \mathrm{~b}$. 
Figure 19 - Photos of $S c-M F C$ MFC (a), the anodic (b) and cathodic (c) chambers.

(a)

(b)
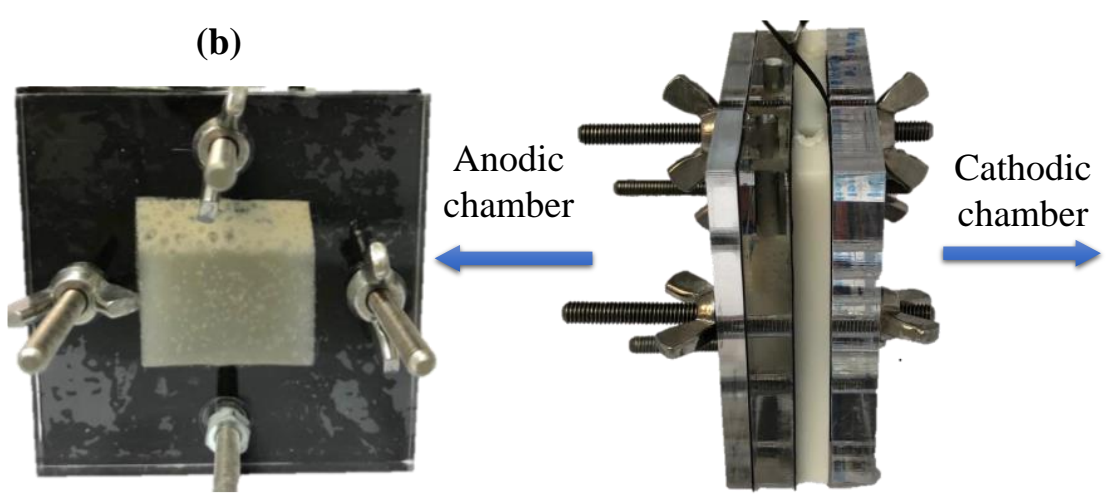

(c)

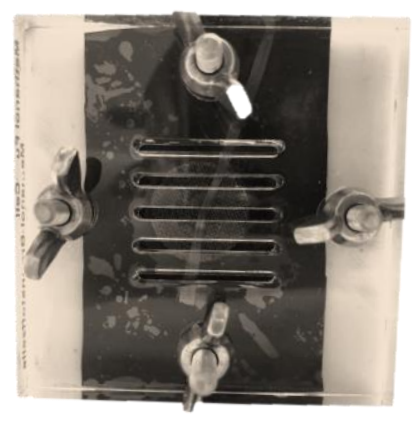

Source: own author.

The $O C V$ was monitored for $24 \mathrm{~h}$ from yeast addition on anodic chamber (Figure 20). In the first $4 \mathrm{~h}$ of fermentation, it is observed a drastic increase in the $O C V$ value from $0.27 \mathrm{~V}$ to $0.70 \mathrm{~V}$. This was expected according to the half-cell measurements (see Figure 16a) and indicates that a period of at least $4 \mathrm{~h}$ is necessary to reach the cellular metabolism stabilization and consequently the system stabilization. Then, during the next hours, the $O C V$ value slightly ranges around $0.69 \mathrm{~V}$. This value is little lower than $0.75 \mathrm{~V}$, which is the expected $O C V$ value based on the onset oxidation and reduction potentials of the $S c$-FCF bioanode $(-0.20 \mathrm{~V})$ and BOD-GDE $(0.55 \mathrm{~V})$, respectively, and this difference can be caused by ohmic losses in the MFC. However, this measured $O C V$ value is much higher than those previously reported for mediatorless Sc-MFC (see Table 1). ${ }^{14,16,18,19}$ This fact emphasizes the importance to choose suitable electrode materials and biocathode catalysts for minimizing the activation overpotentials of the reactions and consequently increasing the cell voltage. 
Figure 20 - OCP monitoring of the Saccharomyces cerevisiae-based MFC.



Source: own author.

As the maximum bioanode current is reached after approximately $24 \mathrm{~h}$ of fermentation, the performance of the MFC was evaluated after this period. The polarization curve in Figure 21a indicates an $O C V$ value equal to $0.70 \mathrm{~V}$, corroborating the previously measured value (Figure 20), and shows a maximum current density equal to $3.22 \mathrm{~A} \mathrm{~m}^{-2}$. The profile of the polarization curve indicates possible effects of kinetic and ohmic losses. The power curve in Figure $21 \mathrm{~b}$ shows the maximum power density of the MFC is $15.45 \mathrm{~mW} \mathrm{~m}^{2}$ at $0.25 \mathrm{~V}$. This value is higher than those previously reported for mediatorless Sc-MFC under non-flowing conditions (see Table 1).

Figure 21 - (a) Polarization and (b) power density curves of the MFC after $24 \mathrm{~h}$ of fermentation.
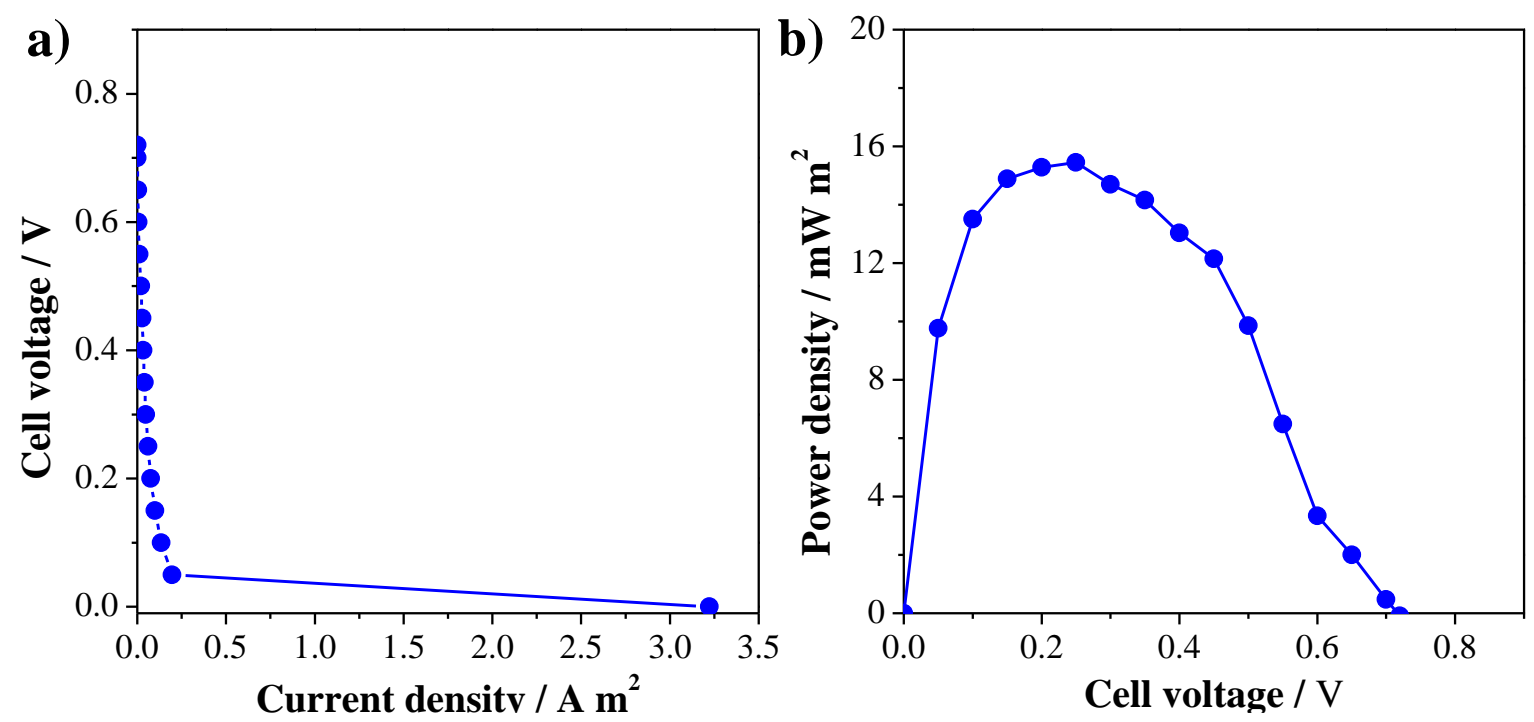

Source: own author. 


\section{CONCLUSIONS}

Electrochemical results showed that, under fermentative conditions, Saccharomyces cerevisiae is able to extracellularly transfer electrons to FCF electrode surface, exhibiting a redox couple with $E_{\mathrm{pa}}$ and $E_{\mathrm{pc}}$ equal to $-0.08 \pm 0.04 \mathrm{~V}$ and $-0.27 \pm 0.03 \mathrm{~V}$, respectively. The peak current densities increase with the fermentation, as result mainly of the cell growth, and adherence of cells on FCF surface over time. In addition, electrochemical measurements combined to microscopic images showed yeast cells adsorb and interact on hydrophobic surfaces, such as FCF, through the EPS film secreted by the cells, and Saccharomyces cerevisiae electrochemical response comes from a redox species mostly confined in the EPS film on the yeast cell surface. Spectroscopic and electrophoretic results strongly indicated the compound responsible for the Saccharomyces cerevisiae EET is a flavoprotein. Therefore, for the first time, it was possible to understand the EET mechanism of Saccharomyces cerevisiae, that is one of the first microorganisms proved to be able to convert chemical energy into electrical energy.

Also, Saccharomyces cerevisiae-based FCF electrode showed satisfactory performance and operational stability. Hence, this bioanode was successfully used in a MFC, where BODGDE, shown in Chapter III, was used as biocathode, for catalytic $\mathrm{O}_{2}$ reduction. This MFC showed a voltage equal to $0.69 \mathrm{~V}$ and maximum power density equal to $15.45 \mathrm{~mW} \mathrm{~m}^{2}$ at 0.25 V. These values are higher than those previously reported for mediatorless Saccharomyces cerevisiae-based MFC under non-flowing conditions. 


\section{REFERENCES}

1 NELSON, D. L.; COX, M. M. Lehninger principles of biochemistry. 4th ed. New York: W. H. Freeman \& Company, 2006. 1119 p.

2 HUSKINSON, B.; MARSHAK, M. P.; SUH, C.; ER, S.; GERHARDT, M. R.; GALVIN, C. J.; CHEN, X.; ASPURU-GUZIK, A.; GORDON, R. G.; AZIZ, M. J. A metal-free organicinorganic aqueous flow battery. Nature, London, v. 505, n. 7482, p. 195-198, 2014.

3 LIN, K.; CHEN, Q.; GERHARDT, M. R.; TONG, L.; KIM, S. B.; EISENACH, L.; VALLE, A. W.; HARDEE, D.; GORDON, R. G.; AZIZ, M. J.; MARSHAK, M. P. Alkaline quinone flow battery. Science, Washington, v. 349, n. 6255, p. 1529-1532, 2015.

4 YANG, Z.; TONG, L.; TABOR, D. P.; BEH, E. S.; GOULET, M. A.; DE PORCELLINIS, D.; ASPURU-GUZIK, A.; GORDON, R. G.; AZIZ, M. J. Alkaline benzoquinone aqueous flow battery for large-scale storage of electrical energy. Adv. Energy Mater., Weinheim, v. 8, n. 8, p. 1702056, 2018.

5 LIN, K.; GÓMEZ-BOMBARELLI, R.; BEH, E. S.; TONG, L.; CHEN, Q.; VALLE, A.; ASPURU-GUZIK, A.; AZIZ, M. J.; GORDON, R. G. A redox-flow battery with an alloxazine-based organic electrolyte. Nat. Energy, London, v. 1, n. 9, p. 16102, 2016.

6 ORITA, A.; VERDE, M. G.; SAKAI, M.; MENG, Y. S. A biomimetic redox flow battery based on flavin mononucleotide. Nat. Commun., London, v. 7, p. 13230, 2016.

7 LUZ, R. A. S.; PEREIRA, A. R.; DE SOUZA, J. C. P.; SALES, F. C. P. F.; CRESPILHO, F. N. Enzyme biofuel cells: thermodynamics, kinetics and challenges in applicability.

ChemElectroChem, Weinheim, v. 1, n. 11, p. 1751-1777, 2014.

8 SANTORO, C.; ARBIZZANI, C.; ERABLE, B.; IEROPOULOS, I. Microbial fuel cells: from fundamentals to applications. A review. J. Power Sources, Amsterdam, v. 356, p. 225 244, 2017.

9 ZHAO, X.; DENG, W.; TAN, Y.; XIE, Q. Promoting electricity generation of shewanella putrefaciens in a microbial fuel cell by modification of porous poly(3-aminophenylboronic acid) film on carbon anode. Electrochim. Acta, Amsterdam, v. 354, p. 136715, 2020.

10 KONDAVEETI, S.; LEE, S. H.; PARK, H. D.; MIN, B. Specific enrichment of different Geobacter sp. in anode biofilm by varying interspatial distance of electrodes in air-cathode microbialfuel cell (MFC). Electrochim. Acta, Amsterdam, v. 331, p. 135388, 2020.

11 ARIAS-THODE, Y. M.; HSU, L.; ANDERSON, G.; BABAUTA, J.; FRANSHAM, R.; OBRAZTSOVA, A.; TUKEMAN, G.; CHADWICK, D. B. Demonstration of the septistrand benthic microbial fuel cell powering a magnetometer for ship detection. J. Power Sources, Amsterdam, v. 356, p. 419-429, 2017.

12 SCHAETZLE, O. Bacteria and yeasts as catalysts in microbial fuel cells: electron transfer from micro-organisms to electrodes for green electricity. Energy Environ. Sci., London, v. 1, p. 607-620, 2008. 
13 GONG, Y.; RADACHOWSKY, S. E.; WOLF, M.; NIELSEN, M. E.; GIRGUIS, P. R.; REIMERS, C. E. Benthic microbial fuel cell as direct power source for an acoustic modem and seawater oxygen/temperature sensor system. Environ. Sci. Technol., Washington, v. 45, n. 11, p. 5047-5053, 2011.

14 SAYED, E. T.; TSUJIGUCHI, T.; NAKAGAWA, N. Catalytic activity of baker's yeast in a mediatorless microbial fuel cell. Bioelectrochemistry, Washington, v. 86, p. 97-101, 2012.

15 WILKINSON, S.; KLAR, J.; APPLEGARTH, S. Optimizing biofuel cell performance using a targeted mixed mediator combination. Electroanalysis, Weinheim, v. 18, n. 19-20, p. 2001-2007, 2006.

16 CHRISTWARDANA, M.; FRATTINI, D.; ACCARDO, G.; PIL, S. Early-stage performance evaluation of flowing microbial fuel cells using chemically treated carbon felt and yeast biocatalyst. Appl. Energy, Amsterdam, v. 222, p. 369-382, 2018.

17 CHRISTWARDANA, M.; FRATTINI, D.; ACCARDO, G.; PIL, S.; KWON, Y. Effects of methylene blue and methyl red mediators on performance of yeast based microbial fuel cells adopting polyethylenimine coated carbon felt as anode. J. Power Sources, Amsterdam, v. 396, p. 1-11, 2018.

18 RAGHAVULU, S. V.; GOUD, R. K.; SARMA, P. N.; MOHAN, S. V. Saccharomyces cerevisiae as anodic biocatalyst for power generation in biofuel cell: influence of redox condition and substrate load. Bioresour. Technol., Amsterdam, v. 102, n. 3, p. 2751-2757, 2011.

19 SAYED, E. T.; NAKAGAWA, N. Critical Issues in the performance of yeast based microbial fuel cell. J. Chem. Technol. Biotechnol., Weinheim, v. 93, n. 6, p. 1588-1594, 2018.

20 PRASAD, D.; ARUN, S.; MURUGESAN, M.; PADMANABAN, S.; SATYANARAYANAN, R. S.; BERCHMANS, S.; YEGNARAMAN, V. Direct electron transfer with yeast cells and construction of a mediatorless microbial fuel cell. Biosens. Bioelectron., Amsterdam, v. 22, n. 11, p. 2604-2610, 2007.

21 HASLETT, N. D.; RAWSON, F. J.; BARRIËRE, F.; KUNZE, G.; PASCO, N.; GOONERATNE, R.; BARONIAN, K. H. R. Characterisation of yeast microbial fuel cell with the yeast Arxula adeninivorans as the biocatalyst. Biosens. Bioelectron., Amsterdam, v. 26, n. 9, p. 3742-3747, 2011.

22 HUBENOVA, Y. V; RASHKOV, R. S.; BUCHVAROV, V. D.; ARNAUDOVA, M. H.; BABANOVA, S. M.; MITOV, M. Y. Improvement of yeast-biofuel cell output by electrode modifications. Ind. Eng. Chem. Res., Washington, v. 50, n. 2, p. 557-564, 2011.

23 HUBENOVA, Y.; MITOV, M. Potential application of Candida melibiosica in biofuel cells. Bioelectrochemistry, Amsterdam, v. 78, n. 1, p. 57-61, 2010. 
24 MOLENAAR, S. D.; MOL, A. R.; SLEUTELS, T. H. J. A.; TER HEIJNE, A.; BUISMAN, C. J. N. Microbial rechargeable battery: energy storage and recovery through acetate. Environ. Sci. Technol. Lett., Washington, v. 3, n. 4, p. 144-149, 2016.

25 XIE, X.; YE, M.; HSU, P.-C.; LIU, N.; CRIDDLE, C. S.; CUI, Y. Microbial battery for efficient energy recovery. Proc. Natl. Acad. Sci. U. S. A., Washington, v. 110, n. 40, p. 15925-15930, 2013.

26 POTTER, M. C. Electrical effects accompanying the decomposition of organic compounds. Proc. R. Soc. London, Ser. B, London, v. 84, n. 571, p. 260-276, 1911.

27 HE, L.; DU, P.; CHEN, Y.; LU, H.; CHENG, X.; CHANG, B.; Wang, Z. Advances in microbial fuel cells for wastewater treatment. Renewable Sustainable Energy Rev., Amsterdam, v. 71, p. 388-403, 2017.

28 CAO, X.; HUANG, X.; LIANG, P.; XIAO, K.; ZHOU, Y.; ZHANG, X.; LOGAN, B. E. A new method for water desalination using microbial desalination cells. Environ. Sci. Technol., Washington, v. 43, n. 18, p. 7148-7152, 2009.

29 STO, M.; TEUBNER, N. C.; HOLTMANN, D.; MANGOLD, K.; SAND, W. Extracellular polymeric substances from Geobacter sulfurreducens biofilms in microbial fuel cells. ACS Appl. Mater. Interfaces, Washington, v. 11, n. 9, p. 8961-8968, 2019.

30 XIAO, Y.; ZHANG, E.; ZHANG, J.; DAI, Y.; YANG, Z.; CHRISTENSEN, H. E. M.; ULSTRUP, J.; ZHAO, F. Extracellular polymeric substances are transient media for microbial extracellular electron transfer. Sci. Adv., Washington, v. 3, n. 7, e1700623, 2017.

31 HUBENOVA, Y.; MITOV, M. Extracellular electron transfer in yeast-based biofuel cells: a review. Bioelectrochemistry, Amsterdam, v. 106, p. 177-185, 2015.

32 HERNANDEZ, M. E.; NEWMAN, D. K. Extracellular electron transfer. Cell. Mol. Life Sci., New York, v. 58, n. 11, p. 1562-1571, 2001.

33 SJULSTOK, E.; OLSEN, J. M. H.; SOLOV, I. A. Quantifying electron transfer reactions in biological systems: what interactions play the major role? Sci. Rep., London, v. 5, p. 18446, 2015.

34 SAYED, E. T.; ABDELKAREEM, M. A. Yeast as a biocatalyst in microbial fuel cell. In: LUCAS, C., PAIS, C. (eds.) Old yeasts: new questions. London: IntechOpen, p. 41-65, 2017.

35 PALANISAMY, G.; JUNG, H.; SADHASIVAM, T.; KURKURI, M. D.; CHAI, S.; ROH, $\mathrm{S}$. A comprehensive review on microbial fuel cell technologies: processes, utilization, and advanced developments in electrodes and membranes. J. Cleaner Prod., Amsterdam, v. 221, p. 598-621, 2019.

36 CAO, Y.; MU, H.; LIU, W.; ZHANG, R.; GUO, J.; XIAN, M.; LIU, H. Electricigens in the anode of microbial fuel cells: pure cultures versus mixed communities. Microb. Cell Fact., London, v. 18, p. 39, 2019. 
37 GORBY, Y. A.; YANINA, S.; MCLEAN, J. S.; ROSSO, K. M.; MOYLES, D.; DOHNALKOVA, A.; BEVERIDGE, T. J.; CHANG, I. S.; KIM, B. H.; KIM, K. S.; CULLEY, D. E.; REED, S. B.; ROMINE, M. F.; SAFFARINI, D. A.; HILL, E. A.; SHI, L.; ELIAS, D. A.; KENNEDY, D. W.; PINCHUK, G.; WATANABE, K.; ISHII, S.; LOGAN, B.; NEALSON, K. H.; FREDRICKSON, J. K. Electrically conductive bacterial nanowires produced by Shewanella oneidensis strain MR-1 and other microorganisms. Proc. Natl. Acad. Sci. U. S. A., Washington, v. 103, n. 30, p. 11358-11363, 2006.

38 REGUERA, G.; MCCARTHY, K. D.; MEHTA, T.; NICOLL, J. S.; TUOMINEN, M. T.; LOVLEY, D. R. Extracellular electron transfer via microbial nanowires. Nature, London, v. 435, n. 7045, p. 1098-1101, 2005.

39 TAN, Y.; ADHIKARI, R. Y.; MALVANKAR, N. S.; WARD, J. E.; WOODARD, T. L.; NEVIN, K. P.; LOVLEY, R. Expressing the Geobacter metallireducens pila in geobacter sulfurreducens yields pili with exceptional conductivity. mBio, Washington, v. 8, n. 1, e02203-16, 2017.

40 LIU, T.; YU, Y.; DENG, X.; NG, C. K.; CAO, B.; WANG, J.; RICE, S. A.; KJELLEBERG, S.; SONG, H. Enhanced Shewanella biofilm promotes bioelectricity generation. Biotechnol. Bioeng., Hoboken, v. 112, p. 2051-2059, 2015.

41 COSTA, O. Y. A.; RAAIJMAKERS, J. M.; KURAMAE, E. E. Microbial extracellular polymeric substances: ecological function and impact on soil aggregation. Front. Terr. Microbiol., Lausanne, v. 9, p. 1636, 2018.

42 ANDERSEN, K. S.; BOJSEN, R.; SØRENSEN, L. G.; NIELSEN, M. W.; LISBY, M.; FOLKESSON, A.; REGENBERG, B. Genetic basis for Saccharomyces cerevisiae biofilm in liquid medium. G3-Genes, Genomes, Genet, Bethesda, v. 4, n. 9, p. 1671-1680, 2014.

43 SALAMA, Y.; CHENNAOUI, M.; SYLLA, A.; RIHANI, M.; ASSOBHEI, O.;

SALAMA, Y.; CHENNAOUI, M.; SYLLA, A. Characterization, structure, and function of extracellular polymeric substances (EPS) of microbial biofilm in biological wastewater treatment systems: a review. Desalin. Water Treat., London, v. 3994, p. 16220-16237, 2016.

44 REYNOLDS, T. B.; Fink, G. R. Bakers' yeast, a model for fungal biofilm formation. Science, Washington, v. 291, n. 5505, p. 878-882, 2001.

45 WU, S.; XIAO, Y.; WANG, L.; ZHENG, Y.; CHANG, K.; ZHENG, Z.; YANG, Z.; VARCOE, J. R.; ZHAO, F. Extracellular electron transfer mediated by flavins in grampositive Bacillus sp. WS-XY1 and yeast Pichia stipitis. Electrochim. Acta, Armsterdam, v. 146, p. 564-567, 2014.

46 RAWSON, F. J.; GROSS, A. J.; GARRETT, D. J.; DOWNARD, A. J.; BARONIAN, K. H. R. Mediated electrochemical detection of electron transfer from the outer surface of the cell wall of Saccharomyces cerevisiae. Electrochem. Commun., Amsterdam, v. 15, n. 1, p. 85-87, 2012.

47 IVNITSKI, D.; BRANCH, B.; ATANASSOV, P.; APBLETT, C. Glucose oxidase anode for biofuel cell based on direct electron transfer. Electrochem. Commun., Armsterdam, v. 8, n. 1, p. 1204-1210, 2006. 
48 KATZ, E.; WILLNER, I.; KOTLYAR, A. B. A non-compartmentalized glucose / $\mathrm{O}_{2}$ biofuel cell by bioengineered electrode surfaces. J. Electroanal. Chem., Armsterdam, v. 479, n. 1, p. 64-68, 1999.

49 RINCÓN, R. A.; LAU, C.; LUCKARIFT, H. R.; GARCIA, K. E.; ADKINS, E.; JOHNSON, G. R.; ATANASSOV, P. Enzymatic fuel cells: integrating flow-through anode and air-breathing cathode into a membrane-less biofuel cell design. Biosens. Bioelectron., Armsterdam, v. 27, n. 1, p. 132-136, 2011.

50 GAJDA, I.; GREENMAN, J.; MELHUISH, C.; IEROPOULOS, I. Self-sustainable electricity production from algae grown in a microbial fuel cell system. Biomass Bioenergy, Armsterdam, v. 82, p. 87-93, 2015.

51 PAGNONCELLI, K. C.; PEREIRA, A. R.; SEDENHO, G. C.; BERTAGLIA, T.; CRESPILHO, F. N. Ethanol generation, oxidation and energy production in a cooperative bioelectrochemical system. Bioelectrochemistry, Armsterdam, v. 122, p. 11-25, 2018.

52 HIGGINS, S. R.; LAU, C.; ATANASSOV, P.; MINTEER, S. D.; COONEY, M. J. Hybrid biofuel cell: microbial fuel cell with an enzymatic. ACS Catal., Washington, v. 1, n. 9, p. 994-997, 2011.

53 GUDE, V. G. Wastewater treatment in microbial fuel cells - an overview. J. Cleaner Prod., Washington, v. 122, p. 287-307, 2016.

54 PEREIRA, A. R.; DE SOUZA, J. C. P.; IOST, R. M.; SALES, F. C. P. F.; CRESPILHO, F. N. Application of carbon fibers to flexible enzyme electrodes. J. Electroanal. Chem., Washington, v. 780, p. 396-406, 2016.

55 FALK, M.; VILLARRUBIA, W. N.; BABANOVA, S.; ATANASSOV, P.; SHLEEV, S. Biofuel cells for biomedical applications: colonizing the animal kingdom. ChemPhysChem, Weinheim, v. 14, n. 10, p. 2045-2058, 2013.

56 RASMUSSEN, M.; ABDELLAOUI, S.; MINTEER, S. D. Enzymatic biofuel cells: 30 years of critical advancements. Biosens. Bioelectron., Amsterdam, v. 76, p. 91-102, 2016.

57 KATZ, E.; SHIPWAY, A. N.; WILLNER, I. Biochemical Fuel Cells. In: Vielstich, W.; Lamm, A.; Gasteiger, H. A.(eds). Handbook of fuel cells: fundamentals technology and applications,. New York: John Wiley \& Sons., 2003, p. 1-27.

58 GROUP, C. M.; SCIENCES, H.; GUALTAR, C. DE; RODRIGUES, F.; LUDOVICO, P.; LEÃO, C. Sugar metabolism in yeasts: an overview of aerobic and anaerobic glucose catabolism. In: PÉTER, R. C. G. Biodiversity and ecophysiology of yeasts. Berlin: Springer, 2006, p.101-122.

59 CONNORS, K. A. Electrical work. In: CONNORS, K. A. Thermodynamics of pharmaceutical systems: an introduction for students of pharmacy. Hoboken: John Wiley \& Sons, 2002, p. 206-236. 
60 KULIKOVSKY, A. A. Fuel cell basics. In: KULIKOVSKY, A. A. Analytical modelling of fuel cells. Amsterdam: Elsevier, 2010, p. 1-38.

61 SCOTT, K. An introduction to microbial fuel cells. In: SCOTT, K.; YU, E. H.(eds). Microbial electrochemical and fuel cells: fundamentals and applications. Amsterdam: Elsevier, 2016, p. 3-27.

62 MARTINS, M. V; PEREIRA, A. R.; LUZ, R. S.; IOST, R. M.; CRESPILHO, F. N. Evidence of short-range electron transfer of a redox enzyme on graphene oxide electrodes. Phys. Chem. Chem. Phys., London, v. 14, n. 33, p. 17426-17436, 2014.

63 PEREIRA, A. R.; SOUZA, J. C. P.; GONÇALVES, A. D.; PAGNONCELLI, K. C.; CRESPILHO, F. N. Bioelectrooxidation of ethanol using NAD-dependent alcohol dehydrogenase on oxidized flexible carbon fiber arrays. J. Braz. Chem. Soc., Campinas, v. 28, n. 9, p. 1698-1707, 2017.

64 MARIS, A. J. A. VAN; ABBOTT, D. A.; BELLISSIMI, E.; BRINK, J. V. D.; KUYPER, M.; LUTTIK, M. A. H.; WISSELINK, H. W.; SCHEFFERS, W. A.; DIJKEN, J. P. VAN; PRONK, J. T. Alcoholic fermentation of carbon sources in biomass hydrolysates by Saccharomyces cerevisiae: current status. Antonie van Leeuwenhoek, London, v. 90, n. 4, p. 391-418, 2006.

65 BURATTINI, E.; CAVAGNA, M.; ANNA, R. D.; CAMPEGGI, F. M.; MONTI, F.; ROSSI, F.; TORRIANI, S. A FTIR microspectroscopy study of autolysis in cells of the wine yeast Saccharomyces cerevisiae. Vib. Spectrosc., Amsterdam, v. 47, n. 2, p. 139-147, 2008.

66 MASAKI, S.; NAKANO, Y.; ICHIYOSHI, K.; KAWAMOTO, K.; TAKEDA, A.; OHNUK, T.; HOCHELLA Jr., M. F.; UTSUNOMIYA, S. Adsorption of extracellular polymeric substances derived from $S$. cerevisiae to ceria nanoparticles and the effects on their colloidal stability. Environments, Basel, v. 4, n. 3, p. 48, 2017.

67 TRABELSI, L.; M'SAKNI, N. H.; OUADA, H. B. ; BACHA, H.; ROUDESLI, S. Partial characterization of extracellular polysaccharides produced by cyanobacterium Arthrospira platensis. Biotechnol. Bioprocess Eng., London, v. 14, n. 1, p. 27-31, 2009.

68 SCHMID, F. X. Biological macromolecules: uv-visible spectrophotometry. In: ENCYCLOPEDIA of Life Science. Hoboken: John Wiley \& Sons, 2001, p. 1-4.

69 GHISLA, S.; MASSEY, V.; LHOSTE, J.; MAYHEW, S. G. Fluorescence and optical characteristics of reduced flavines and flavoproteins. Biochemistry, Washington, v. 13, n. 3, p. 589-597, 1974.

70 WANG, X. M.; CHEN, H. Y. A spectroelectrochemical study of the interaction of riboflavin with $\beta$-cyclodextrin. Spectrochim. Spectrochim. Acta A Mol. Biomol. Spectrosc., Amsterdam, v. 51, n. 5, p. 599-605, 1996.

71 SCHWINN, K.; FERRE, N.; HUIX-ROTLLANT, M. UV-visible absorption spectrum of fad and its reduced forms embedded in a cryptochrome protein. Phys. Chem. Chem. Phys., London, v. 22, n. 22, p. 12447-12455, 2020. 
72 BUCKEL, W.; THAUER, R. K. Energy conservation via electron bifurcating ferredoxin reduction and proton/ $\mathrm{Na}^{+}$translocating ferredoxin oxidation. Biochim. Biophys. Acta, Bioenerg., Amsterdam v. 1827, n. 2, p. 94-113, 2013.

73 STOTTS, K.; SAITOJ, K.; THIELE, J. D.; MASSEY, V. Old yellow enzyme. J. Biol. Chem., Rockville, v. 268, n. 9, p. 6097-6106, 1993.

74 NIINO, Y. S ; CHAKRABORTY, S.; BROWN, B. J.; MASSEY, V. A new old yellow enzyme of Saccharomyces cerevisiae. J. Biol. Chem., Rockville, v. 270, n. 5, p. 1983-1991, 1995.

75 GUDIPATI, V.; KOCH, K.; LIENHART, W.; MACHEROUX, P. The flavoproteome of the yeast Saccharomyces cerevisiae. Biochim. Biophys. Acta, Amsterdam, v. 1844, n. 3, p. 535-544, 2014.

76 BARBER, E. D.; LANDS, W. E. M. Quantitative measurement of the effectiveness of unsaturated fatty acids required for the growth of Saccharomyces cerevisiae. J. Bacteriol., Washington; v. 115, n. 2, p. 543-551, 1973.

77 BARRAGÁN, L. A. P.; FIGUEROA, J. J. B.; DURÁN, L. V. R.; GONZÁLEZ, C. N. A.; HENNIGS, C. Fermentative production methods. In: POLTRONIERI, P.; D’URSO, O. F. (eds.). Biotransformation of agricultural waste and by-products. Amsterdam: Elsevier, 2016, p. 189-217.

78 STANLEY, G. A.; DOUGLAS, N. G.; EVERY, E. J.; TZANATOS, T.; PAMMEN, N. B. Inhibition and stimulation of yeast growth by acetaldehyde. Biotechnol. Lett., London, v. 15, n. 12, p. 1199-1204, 1993. 


\section{APPENDIX}

List of publications during the doctorate period:

1. SOUZA, J. C. P.; MACEDO, L. J. A.; HASSAN, A.; SEDENHO, G. C.; MODENEZ, I. A.; CRESPILHO, F. N. In situ and operando techniques for investigating electron transfer in biological systems. ChemElectroChem, v. 8, n. 3, p. 431-446, 2021.

2. Sedenho, G. C.; Hassan, A.; Macedo, L. J. A.; Crespilho, F. N. Stabilization of bilirubin oxidase in a biogel matrix for high-performance gas diffusion electrodes. J. Power Sources, v. 482, 229035, 2021.

3. SEDENHO, G. C.; DE PORCELLINIS, D.; JING, Y.; KERR, E.; MEJIA-MENDOZA, L. M.; VÁZQUEZ-MAYAGOITIA, A.; ASPURU-GUZIK, A.; GORDON, R. G.; CRESPILHO, F. N.; AZIZ, M. J. Effect of molecular structure of quinones and carbon electrode surfaces on the interfacial electron transfer process. ACS Appl. Energy Mat., v. 3, n. 2, p. 1933-1943, 2020

4. MACEDO, L. J. A.; HASSAN, A.; SEDENHO, G. C.; CRESPILHO, F. N. Assessing electron transfer reactions and catalysis in multicopper oxidases with operando X-ray absorption spectroscopy. Nat. Commun., v. 11, p. 316, 2020

5. ALI, M. A.; HASSAN, AYAZ; SEDENHO, G. C.; GONÇALVES, R. V.; CARDOSO, D. R.; CRESPILHO, F. N. Operando electron paramagnetic resonance for elucidating the electron transfer mechanism of coenzymes. J. Phys. Chem. C., v. 123, n. 26, p. 1605816064, 2019.

6. MELO, A. F. A. A.; SEDENHO, G. C.; OSICA, I.; ARIGA, K.; CRESPILHO, F. N. Electrochemical behaviour of cytochrome $\mathrm{c}$ immobilized in magnetically induced mesoporous framework. ChemElectroChem, v. 6, n. 23, p. 5802-5809, 2019.

7. CRESPILHO, F. N.; SEDENHO, G. C.; DE PORCELlINIS, D.; KERR, E.; GRANADOS-FOCIL, S.; GORDON, R. G.; AZIZ, M. J. Non-corrosive, low-toxicity gelbased microbattery from organic and organometallic molecules. J. Mat. Chem. A,, v. 7 , n. 43, p. 24784-24787, 2019.

8. PAGNONCELli, K. C.; PEREIRA, A. R.; SEDENHO, G. C.; BERTAGLIA, T.; CRESPILHO, F. N. Ethanol generation, oxidation and energy production in a cooperative bioelectrochemical system. Bioelectrochemistry, v. 122, p. 11-25, 2018.

9. SEDENHO, G. C.; PEREIRA, A.R.; PAGNONCELLI, K. C.; DE SOUZA, J. C. P.; CRESPILHO, F. N. Implantable enzyme-based biofuel cells, In: Reference Module in Chemistry, Molecular Sciences and Chemical Engineering, Encyclopedia of Interfacial Chemistry: Surface Science and Electrochemistry. Amsterdam: Elsevier, 2018, p., 248-260. 


\section{ANNEX}

Permissions from the publishers to reproduce the articles in this thesis:

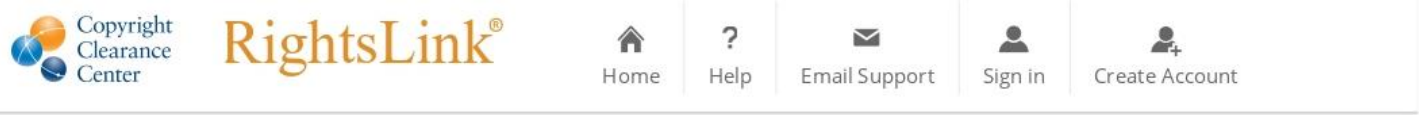

Effect of Molecular Structure of Quinones and Carbon Electrode
Surfaces on the Interfacial Electron Transfer Process
Author: Graziela C. Sedenho, Diana De Porcellinis, Yan Jing, et al
ACSPublications
Publication: ACS Applied Energy Materials
Publisher: American Chemical Society
Date: Feb 1, 2020
Copyright 0 2020, American Chemical Society
PERMISSION/LICENSE IS GRANTED FOR YOUR ORDER AT NO CHARGE
This type of permission/license, instead of the standard Terms \& Conditions, is sent to you because no fee is being
charged for your order. Please note the following:
- Permission is granted for your request in both print and electronic formats, and translations.
- If figures and/or tables were requested, they may be adapted or used in part.
- Please print this page for your records and send a copy of it to your publisher/graduate school.
- Appropriate credit for the requested material should be given as follows: "Reprinted (adapted) with permission
from (COMPLETE REFERECE CITATION). Copyright (YEAR) American Chemical Society." Insert appropriate
information in place of the capitalized words.
- One-time permission is granted only for the use specified in your request. No additional uses are granted (such as
derivative works or other editions). For any other uses, please submit a new request.
BACK

(C) 2020 Copyright - All Rights Reserved I Copyright Clearance Center, Inc. I Privacy statement | Terms and Conditions Comments? We would like to hear from you. E-mail us at customercare@copyright.com 


\section{Non-corrosive, low-toxicity gel-based microbattery from organic and organometallic molecules}

F. N. Crespilho, G. C. Sedenho, D. De Porcellinis, E. Kerr, S. Granados-Focil, R. G. Gordon and M. J. Aziz, J. Mater. Chem. A, 2019, 7, 24784

DOI: $10.1039 / C 9 T A 08685 D$

If you are not the author of this article and you wish to reproduce material from it in a third party nonRSC publication you must formally request permission using Copyright Clearance Center. Go to our Instructions for using Copyright Clearance Center page for details.

Authors contributing to RSC publications (journal articles, books or book chapters) do not need to formally request permission to reproduce material contained in this article provided that the correct acknowledgement is given with the reproduced material.

Reproduced material should be attributed as follows:

- For reproduction of material from NJC:

Reproduced from Ref. XX with permission from the Centre National de la Recherche

Scientifique (CNRS) and The Royal Society of Chemistry.

- For reproduction of material from PCCP:

Reproduced from Ref. XX with permission from the PCCP Owner Societies.

- For reproduction of material from PPS:

Reproduced from Ref. XX with permission from the European Society for Photobiology, the European Photochemistry Association, and The Royal Society of Chemistry.

- For reproduction of material from all other RSC journals and books:

Reproduced from Ref. XX with permission from The Royal Society of Chemistry.

If the material has been adapted instead of reproduced from the original RSC publication "Reproduced from" can be substituted with "Adapted from".

In all cases the Ref. $X X$ is the $X X$ th reference in the list of references.

If you are the author of this article you do not need to formally request permission to reproduce figures, diagrams etc. contained in this article in third party publications or in a thesis or dissertation provided that the correct acknowledgement is given with the reproduced material.

Reproduced material should be attributed as follows:

- For reproduction of material from NJC:

[Original citation] - Reproduced by permission of The Royal Society of Chemistry (RSC) on behalf of the Centre National de la Recherche Scientifique (CNRS) and the RSC

- For reproduction of material from PCCP:

[Original citation] - Reproduced by permission of the PCCP Owner Societies

- For reproduction of material from PPS:

[Original citation] - Reproduced by permission of The Royal Society of Chemistry (RSC) on behalf of the European Society for Photobiology, the European Photochemistry Association, and RSC

- For reproduction of material from all other RSC journals:

[Original citation] - Reproduced by permission of The Royal Society of Chemistry

If you are the author of this article you still need to obtain permission to reproduce the whole article in a third party publication with the exception of reproduction of the whole article in a thesis or dissertation. 
12/17/2020 Non-corrosive, low-toxicity gel-based microbattery from organic and organometallic molecules - Journal of Materials Chemistry A (RSC Information about reproducing material from RSC articles with different licences is available on our Permission Requests page. 


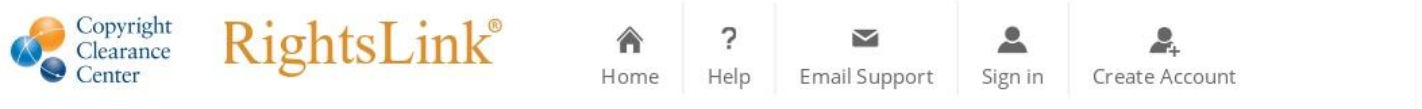

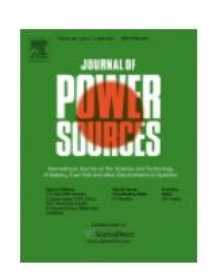

Stabilization of bilirubin oxidase in a biogel matrix for highperformance gas diffusion electrodes

Author: Graziela C. Sedenho,Ayaz Hassan,Lucyano J.A. Macedo,Frank N. Crespilho

Publication: Journal of Power Sources

Publisher: Elsevier

Date: 15 January 2021

(c) 2020 Elsevier B.V. All rights reserved.

Please note that, as the author of this Elsevier article, you retain the right to include it in a thesis or dissertation, provided it is not published commercially. Permission is not required, but please ensure that you reference the journal as the original source. For more information on this and on your other retained rights, please visit: https://www.elsevier.com/about/our-business/policies/copyright\#Author-rights

BACK

(c) 2020 Copyright - All Rights Reserved | Copyright Clearance Center, Inc. I Privacy statement | Terms and Conditions Comments? We would like to hear from you. E-mail us at customercare@copyright.com 